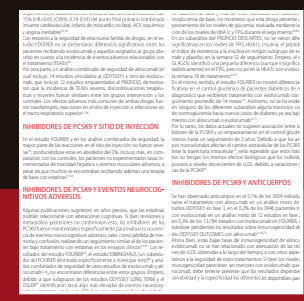

REVISIÓN POR EXPERTOS

Inhibidores de las PCSK9: nuevos tratamientos hipolipemiantes

Augusto M. Lavalle Cobo, Sebastián García Zamora, Luciano N. Fallabrino, Ricardo M. Iglesias,

Juan J. Badimon

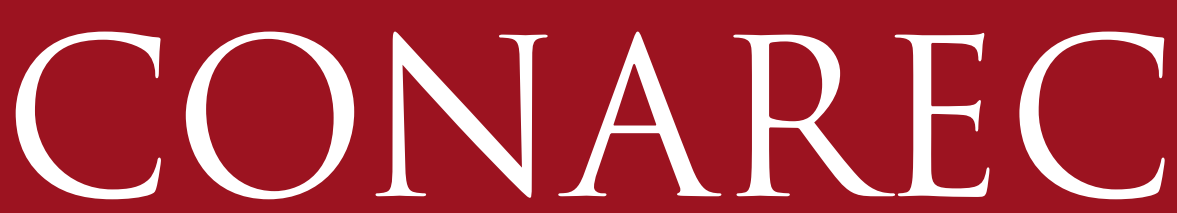

Julio - Agosto de 2018 - Año 33 - № 145

\section{MONOGRAFÍA SELECCIONADA}

Inhibición de los receptores de la angiotensina

y de la neprilisina: una nueva esperanza en el tratamiento de la insuficiencia cardíaca

Naso CG

\section{ARTÍCULOS ORIGINALES}

Prevalencia del bloqueo interauricular avanzado en pacientes revertidos de fibrilación auricular

Foressi Fy cols.

Métodos ecocardiográficos para evaluar la aurícula derecha utilizando los valores de corte publicados por sociedades internacionales

Acosta M del Py cols.

\section{Intubación y manejo ventilatorio del paciente con cardiopatía aguda}

\author{
Hernán E. Núñez, Laura Buira
}

Isquemia cerebral silente perioperatoria en pacientes con fibrilación auricular

Contreras AEy cols.

\section{CASOS CLÍNICOS}

Ablación exitosa de vía anómala en paciente con anomalía de Ebstein Firpo MFy cols.

Denervación simpática como tratamiento alternativo en adolescente con taquicardia ventricular catecolaminérgica polimórfica

Soto Arévalo Fy cols.

\section{IMÁGENES EN CARDIOLOGÍA}

Trombo en la aorta aparentemente sana, el poder de la anticoagulación Lin YSy cols.. 

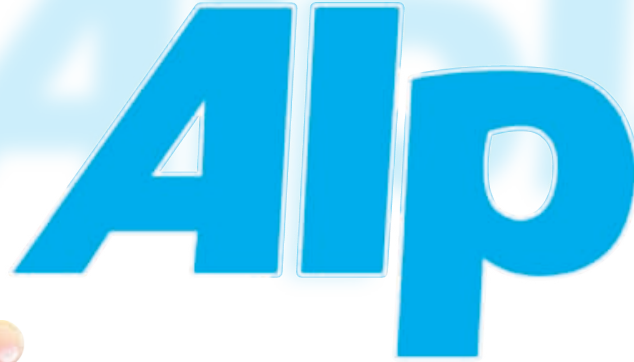

\section{ALPRAZOLAM}
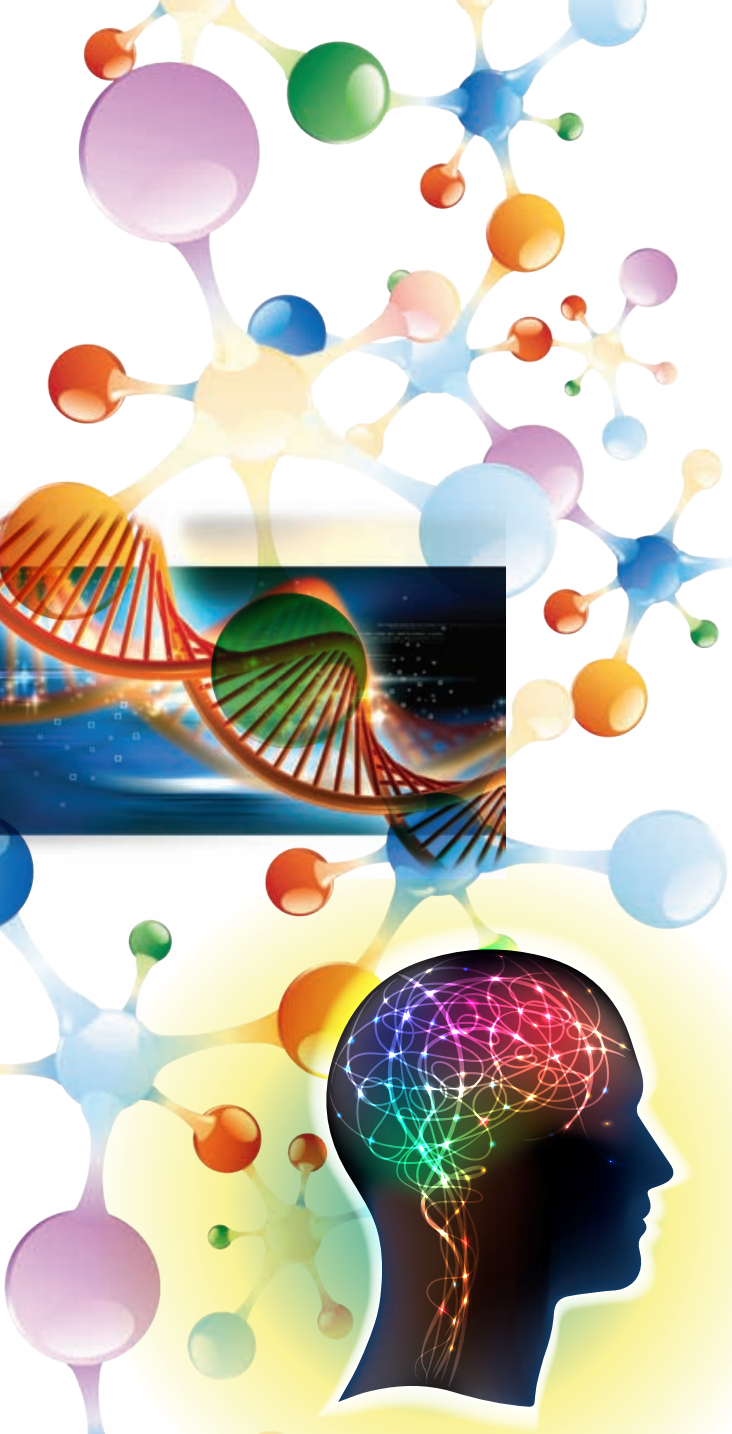

\section{Disminuye la vulnerabilidad frente al estrés ${ }^{3}$}

\section{Favorece la resiliencia ${ }^{4}$}

\section{Garantía de calidad farmacéutica}

La más alta tecnología de fabricación, bajo normas internacionales

\section{Confiabilidad y seguridad ansiolítica}

Más de 100 controles garantizan la calidad Gador Insumos y procesos que son claves del cumplimiento de la prescripción

\section{PRESENTACIONES:}

\section{ALPLAX $^{\circ} 0,25,0,5$ y $1 \mathrm{mg}$ :}

Envases con 30 y 60 comprimidos ranurados.

ALPLAX 2 mg:

Envases con 30 y 60 comprimidos multirranurados.

ALPLAX XR 0,5, 1 y $2 \mathrm{mg}$ :

Envases con 20 comprimidos de liberación controlada.

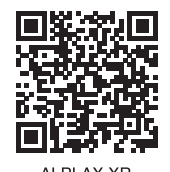

\section{IOMs}

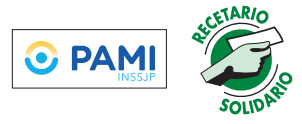

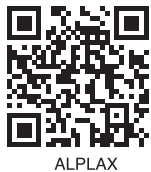
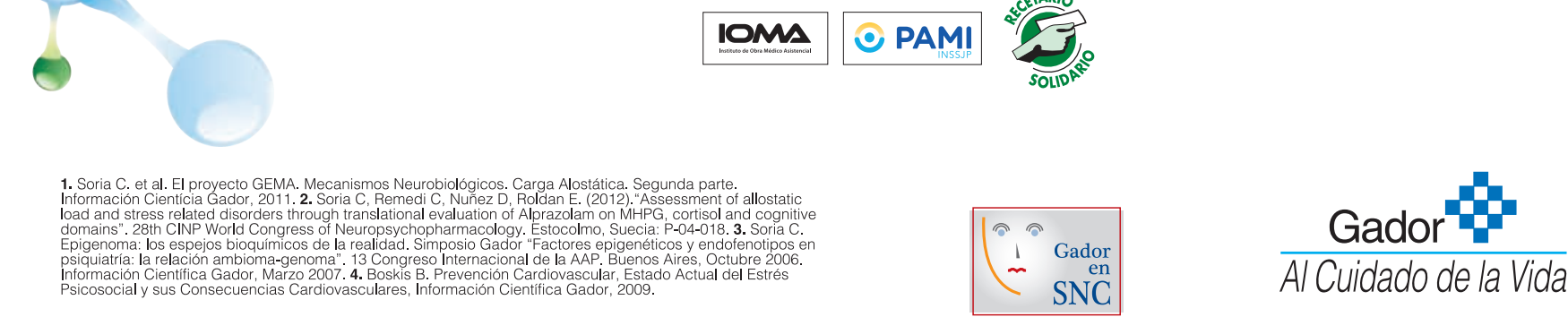


\section{Gadocor}

Nebivolol 5 - $10 \mathrm{mg}$

SELECTIVO Y VASODILATADOR ${ }^{1}$

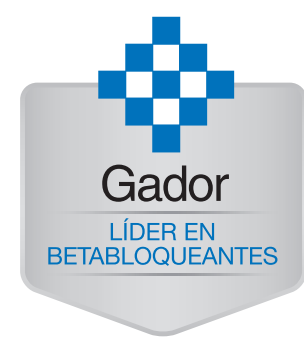

- Brinda un eficaz control de la presión arterial en el paciente hipertenso ${ }^{2}$

- Permite ser utilizado con seguridad en pacientes diabéticos o con síndrome metabólico ${ }^{3}$

- Preserva la función eréctil ${ }^{4}$

- Está indicado en pacientes con EPOC ${ }^{5}$

- No interfiere en el desarrollo de la actividad física del paciente ${ }^{6}$

Gadocor ${ }^{\star}$ permite que cada parte contenga la dosis correspondiente debido al diseño de sus comprimidos birranurados de $5 \mathrm{mg}$
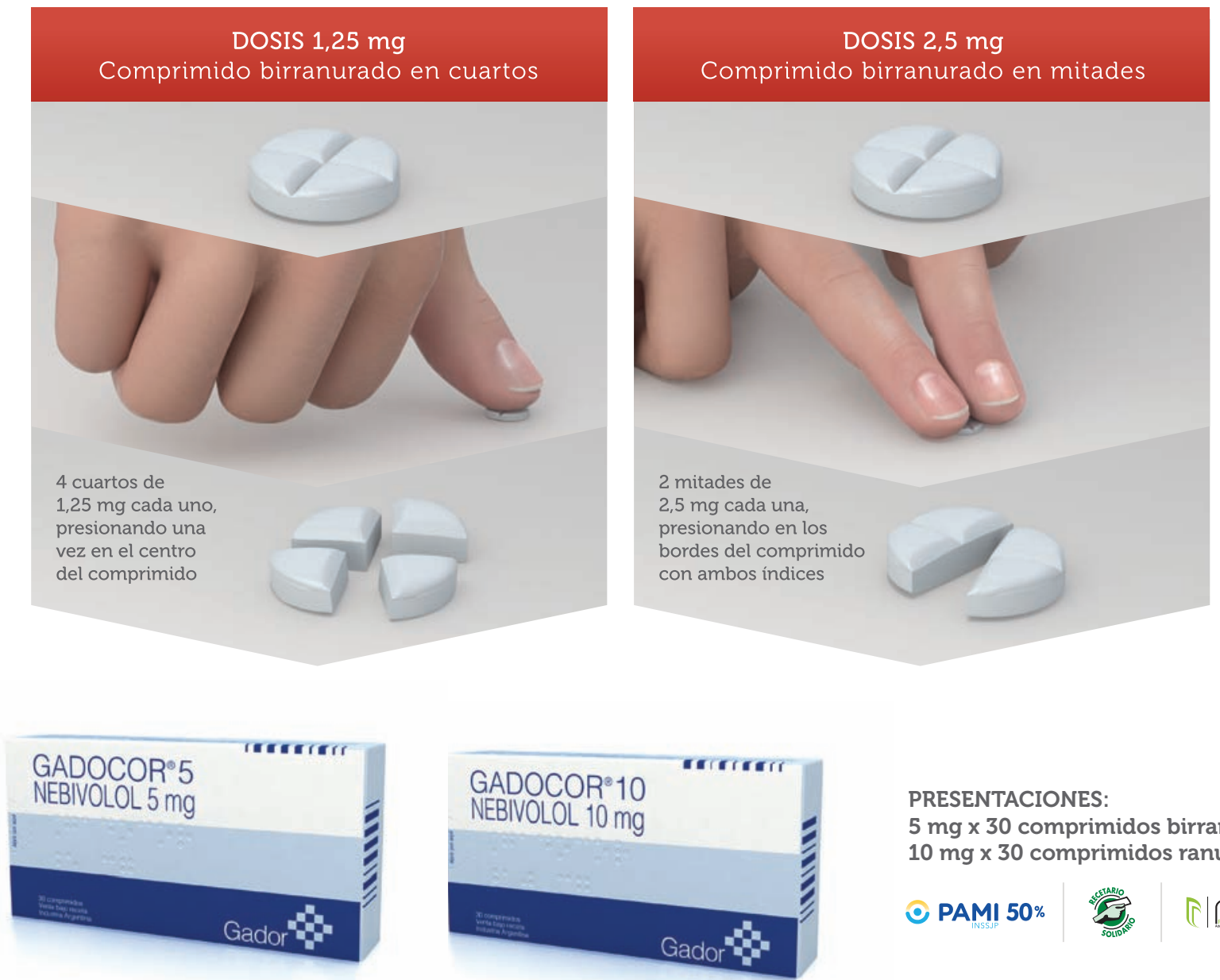

PRESENTACIONES:

$5 \mathrm{mg} \times 30$ comprimidos birranurados $10 \mathrm{mg} \times 30$ comprimidos ranurados

○ PAMI 50\% 


\section{Artome $\mathbf{y}^{\circ}$}

\section{Máxima prevención en la enfermedad}

cardiovascular.

$\triangleright 44 \%$ de reducción de eventos cardiovasculares en prevención primaria. ${ }^{1}$

$\checkmark$ Control lipídico en alto riesgo cardiovascular. ${ }^{2}$

$\checkmark$ Estabiliza placas coronarias ricas en lípidos. ${ }^{3}$

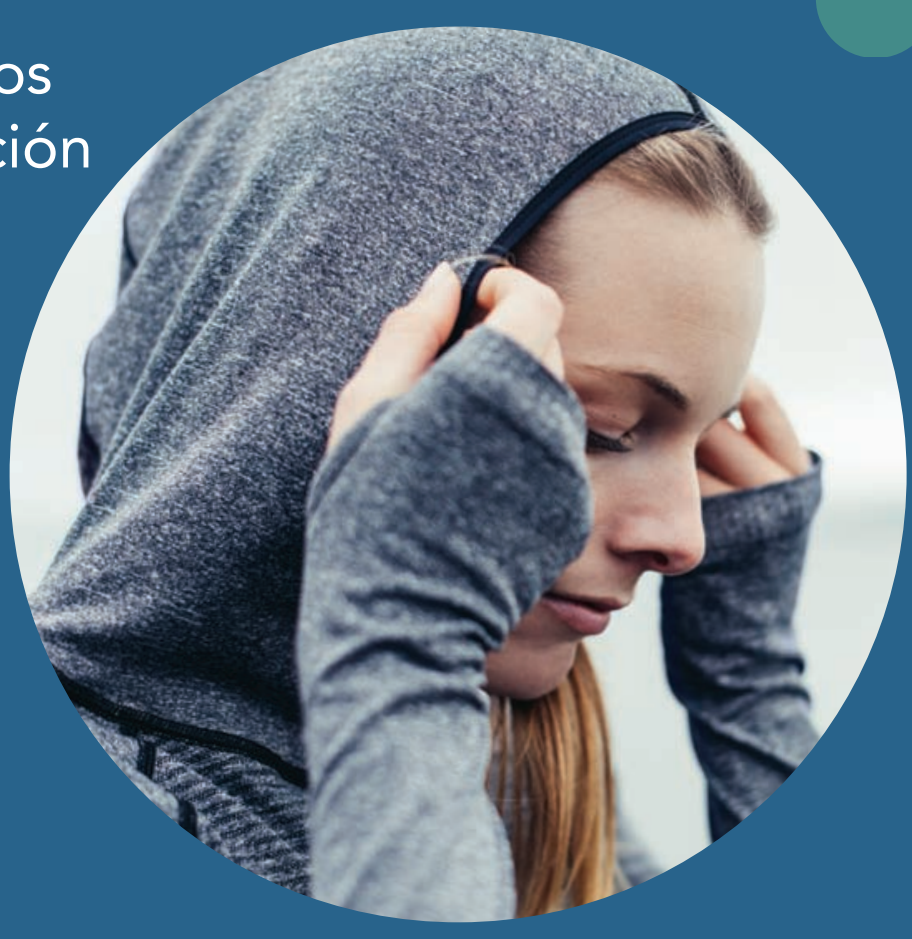

$\checkmark$ Reduce la progresión del volumen de placa de ateroma. ${ }^{4}$

$\checkmark$ Mayor eficacia para alcanzar las metas del NCEP ATP III. ${ }^{5}$

\section{REFERENCIAS BIBLIOGRÁFICAS}

1- Ridker P et al. Jupiter Trial N Eng J Med 2008; 359: 195-207 2- Shepherd J. Am J Cardiol" 2003; 91 (Suppl): 11c-19c

3- Soeda T et al. Circ J 2011; 75: 2621-7

4- Nissen S et al. Estudio Asteroid. JAMA 2006; 295: 1556-65

5- Shepherd J. Am J Cardiol: 2003; 91 (Suppl): 11c-19c
Presentaciones

Artomey ${ }^{\circledR} 5$ mg - 10 mg - 20 mg y 40 mg envases conteniendo 30 comp. recub. Artomey $^{\circledR} 10 \mathrm{mg}$ envases conteniendo 60 comp. recubiertos 


\section{DIRECTORA}

Lucrecia María Burgos

Instituto Cardiovascular de Buenos Aires | CABA

SUBDIRECTORES

Franco Facciuto

Instituto Cardiovascular de Rosario | Santa Fe

Sebastián Srur

Sanatorio Mitre |CABA

JEFE DE REDACCIÓN

Andreína Gil Ramírez

Instituto Cardiovascular de Buenos Aires|CABA

COORDINADORES

Elián Facundo Giordanino

Fundación Favaloro |CABA

Sebastián García Zamora

Hospital de Alta Complejidad "El Cruce"

Buenos Aires

COMITÉ DE REDACCIÓN

Bruno Nicolás Acosta

Hospital Escuela de Corrientes |Corrientes

Belén Aguilar

Sanatorio Güemes | CABA

Cecilina Arnaudo

Sanatorio Mitre|CABA

Ivana Bolzán

Sanatorio Adventista del Plata | Entre Ríos

Maximiliano Echevarría

Hospital JM Cullen | Santa Fe

Fanny Fritz

Hospital Durand |CABA

Carolina Gálvez Gil

Hospital Fernández|CABA

Andrea Gil Plozzer

Hospital Naval |CABA

Florencia Giménez

Hospital JM Cullen |Santa Fe

Juan Pablo Guzmán

Hospital Británico |CABA

Martina Labaqui

Hospital Naval ICABA

Belén Leguizamón

Hospital JM Cullen |Santa Fe

Benjamín Litre

Sanatorio Mitre |CABA

Nahuel Litwak

Fundación Favaloro |CABA

Nadia Martínez

Sanatorio Güemes |CABA

Fernanda Petrucci

Hospital Fernández | CABA

Lucia Rossi

Hospital JM Cullen | Santa Fe

Federico Swedzky

Instituto Modelo de Cardiología | Córdobo

Carolina Yanzon

Sanatorio Adventista del Plata| Entre Ríos

TRADUCCIONES AL INGLÉS

María Isabel Ayala

Traductora Literaria y Técnico-Científica

COMITÉ ASESOR

Antonio Bayés de Luna

Profesor en Medicina. Investigador Senior - ICCC. Fundación de In vestigación Cardiovascular. Hospital Sta. Creu y St. Pau, Barcelona, España.
Juan José Badimon, Ph.D. FACC, FAHA

Profesor en Medicina. Director, Atherothrombosis Research Unit, Cardiovascular Institute New York. Icahn School of Medicine at Mount Sinai.

Adrián Baranchuk MD FACC FRCPC FCCS

Profesor en Medicina. Queen's University. Presidente, International Society of Electrocardiology. Editor-in-Chief, Journal of Electrocardiology.

Lina Badimon

Profesora en Medicina. Director Cardiovascular Research Center (CSIC-ICCC). Hospital de la Santa Creu i Sant Pau. Vicepresidente de la European Society of Cardiology.

Julio A. Panza

Jefe de Cardiologíay Profesor de Medicina, Westchester Medical Center/New YorkMedical College.

Andrés Pérez-Riera

Médico, Universidad Nacional de Córdoba (1973). Revalidación médico, Federal University of Goiás (1979). Residencia en Medicina Interna, Hospital de Clínicas, Córdoba (1974-1975). Residencia en Cardiología, Dante Pazzanese Institute, São Paulo, Brazil (1976-1977). Título Cardiólogo "Instituto do Coração" Brazil (InCor) (1978). Título Métodos Gráficos en Cardiología, "Instituto do Coração" (InCor) (1979). Master Degree, São Paulo School of Medicine - São Paulo Hospital - Graphic Methods Area in the Cardiology Chair (1980-1981). Degree of Specialist by proficiency test in Cardiology-Brazilian Society of Cardiology (1980). Medalla de oro y Diploma, Universidad de Córdoba.

Julián Segura

Jefe de la Unidad de Hipertensión Arterial. Servicio de Nefrología Hospital Universitario 12 de Octubre. Presidente de la Sociedad Española de Hipertensión-Liga Española para la Lucha contra la Hipertensión Arterial.

David Prieto-Merino

Associate Professor, London School of Hygiene \& Tropical Medicine. Director de la Cátedra de Análisis Estadístico y Big Data de la Universidad Católica de Murcia España.

Manlio F. Márquez

Departamento de Electrofisiología, Instituto Nacional de Cardiología "Ignacio Chávez," México D.F. Exvicepresidente de la Sociedad Latinoamericana de Estimulación Cardiacay Electrofisiología.

Fernando Peñafort

Cardiólogo universitario SAC UBA. Especialista en Electrofisiología. Universidad de la Plata SADEC. Jefe de Electrofisiología: Hospital Español de Mendoza. Clínica de Cuyo. Hospital Santa Isabel de Hungría. Médico de planta, Servicio de Cardiología. Hospital Lagomaggiore, Mendoza. Miembro titular de la Federación Argentina de Cardiología y Sociedad Argentina de Cardiología.

Daniel Piskorz

Presidente Federación Argentina de Cardiología 2017. Presidente Sociedad Argentina de Hipertensión Arterial 2011-2013. Director Centro de Investigaciones Cardiovasculares del Sanatorio Británico SA de Rosario

Eduardo R. Perna

Jefe División de Insuficiencia Cardiaca e Hipertensión Pulmonar. Unidad de Cuidados Intensivos Coronarios Instituto de Cardiología "J. F. Cabral", Corrientes. Argentina.

Mario Bendersky

Profesor titular Farmacología Aplicada UNC

Director maestría HTA, Univ Católica Córdoba. Jefe unidad HTA, Inst. Modelo Cardiología, Cba.

Néstor A. Vita

Jefe de Cardiologia del Hospital Italiano de Rosario. Ex presidente de Federación Argentina de Cardiología.

Jorge Thierer

Jefe Unidad Insuficiencia Cardíaca CEMIC. Director Asociado

Revista Argentina de Cardiología
Ricardo Iglesias

Ex Presidente CONAREC. Expresidente Sociedad Argentina de Cardiología. Expresidente Fundación Cardiológica Argentina Fellow American College of Cardiology.

Hernán C. Doval

Médico de Cardiología del Htal. Italiano de Bs. As. Director de la Revista Argentina de Cardiología.

Carlos Taje

Jefe de Cardiología Hospital El Cruce. Expresidente Sociedad Argentina de Cardiología.

Hugo Grancelli

Jefe del Servicio de Cardiología del Sanatorio Finochietto Director Carrera de Especialista en Cardiología. Universidad de Buenos Aires. Expresidente de la Sociedad Argentina de Cardiología.

José Horacio Casabé FACC, PhD

Jefe de Cardiología ICYCC. Hospital Universitario Fundación Favaloro. Miembro titular Sociedad Argentina de Cardiología. Laura Schreier

Doctora en Bioquímica, Profesora Titular Facultad de Farmacia y Bioquímica-UBA Jefe del Laboratorio de Lípidos y Aterosclerosis Directora del Departamento de Bioquímica Clínica, Hospital de Clínicas, UBA. Secretaria Asuntos Internacionales de Sociedad Argentina de Lípidos, Miembro Comité Asesor del Consejo de Aterosclerosis y Trombosis, Sociedad Argentina de Cardiología.

Martín Donato

Profesor en Medicina. Instituto de Fisiopatología Cardiovascular. Facultad de Medicina, Universidad de Buenos Aires. Investigador CONICET

Alejandro Macchia

Fundación GESICA.

Roberto Héctor lermoli

Profesor en Medicina. Director de Docencia e Investigación, Hospital de Clínicas, UBA. Director del Dpto. de Medicina, Facultad de Medicina, UBA

Raul Borracci

Profesor de Bioestadística, Facultad de Ciencias Biomédicas, Universidad Austral. Servicio de Cirugía Cardiovascular, Facultad de Medicina, UBA. Director Adjunto de la Revista Argentina de Cardiología. Coordinador del Comité de Bioética de la Sociedad Argentina de Cardiología.

Hernán Cohen Araz

Cardiólogo CEMIC y centro médico Pilares. Magister en Efectividad Clínica y Sanitaria. Miembro titular, integrante del área de investigación y exdirector del Consejo de Emergencias Cardiovasculares. Sociedad Argentina de Cardiología. Exjefe de Cardiología FLENI.

COORDINADOR REVISIÓN ANUAL

Guillermo R. Chiappero

Hospital Fernández |CABA

MIEMBROS HONORARIOS

Dr. René Favaloro +

Dr. Carlos Bertolasi +

Dr. Arnaldo Angelino

SECRETARIA CONAREC

Mariela Tolcachier

Tel: (011) 1536772989

secretariaconarec@yahoo.com.ar

CORRESPONDENCIA

www revistaconarec.com.ar

conarecrevista@gmail.com

SEDE SOCIAL

Azcuénaga 980 - CABA 


\section{AUTORIDADES - CONAREC 2018}

\section{PRESIDENTE}

Sebastián García Zamora

Hospital de Alta Complejidad en Red "El

cruce"

VICEPRESIDENTE

Hernán Pulenta

Hospital Lagomaggiore| Mendoza

TESORERA

Eliane Sasovsky

Trinidad Mitre | CABA

PROTESORERO

Pablo Schmidt

Sanatorio Güemes | Chaco

SECRETARIO

Emmanuel Scatularo

Fundación Favaloro|CABA

PROSECRETARIO

Mariano Visconti

Instituto de Cardiología de Corrientes

VOCALES

\section{CABA y Gran Buenos Aires}

Macarena Cousirat Liendro Clinica Bazterrica | CABA

Matías Anuati

UAI|CABA

María Esperanza Raimundo

Malvinas Argentinas | Gran Buenos Aires

\section{Chaco}

Matías Villacorta

Sanatorio Güemes

\section{SEDES DE JORNADAS}

$\begin{array}{ll}\text { 1980: I } & \text { Buenos Aires } \\ \text { 1981: II } & \text { Buenos Aires } \\ \text { 1982: III } & \text { Buenos Aires } \\ \text { 1983: IV } & \text { Buenos Aires } \\ \text { 1984:V } & \text { Buenos Aires } \\ \text { 1985: VI } & \text { Buenos Aires } \\ \text { 1986: VII } & \text { Rosario } \\ \text { 1988: IX } & \text { San Juan } \\ \text { 1990: X } & \text { Buenos Aires } \\ \text { 1991: XI } & \text { Buenos Aires } \\ \text { 1992: XII } & \text { Córdoba } \\ \text { 1994: XIV } & \text { Rosario }\end{array}$

\begin{tabular}{|c|c|c|}
\hline Chubut & Neuquén & COMITÉ CIENTíFICO \\
\hline $\begin{array}{l}\text { Víctor Ramírez } \\
\text { Clínica del Valle }\end{array}$ & $\begin{array}{l}\text { Soledad Orazi } \\
\text { Hospital Provincial Neuquén }\end{array}$ & $\begin{array}{l}\text { Ana Lía Gamarra } \\
\text { Hospital Italiano de Buenos Aires |CABA }\end{array}$ \\
\hline Córdoba & Rosario & Paula Berlien \\
\hline Cintia Sánchez & María del Carmen Salvia & Hospital "J. M. Cullen" | Santa Fe \\
\hline Sanatorio Allende & Hospital Provincial & Alan Sigal \\
\hline Corrientes & Salta & Instituto Cardiovascular de Buenos Aires | \\
\hline $\begin{array}{l}\text { Mariana Andrea Candia } \\
\text { Instituto de Cardiología de Corrientes }\end{array}$ & $\begin{array}{l}\text { Valentina Botelli } \\
\text { Hospital San Bernardo }\end{array}$ & $\begin{array}{l}\text { ÓRGANO DE FISCALIZACIÓN } \\
\text { Y PERMANENCIA }\end{array}$ \\
\hline Entre Ríos & San Juan & Ignacio Cigalini \\
\hline $\begin{array}{l}\text { Iván Vilar Evequoz } \\
\text { Hospital San Martin de Paraná }\end{array}$ & $\begin{array}{l}\text { Carolina Robles } \\
\text { ICVO (Instituto Cardiovascular del Oeste) }\end{array}$ & $\begin{array}{l}\text { Instituto Cardiovascular de Buenos Aires } \\
\text { CABA }\end{array}$ \\
\hline Formosa & Santa Fe & $\begin{array}{l}\text { Darío Igolnikof } \\
\text { Hospital Austral| Buenos Aires }\end{array}$ \\
\hline $\begin{array}{l}\text { Norali Miranda } \\
\text { Hospital de Alta Complejidad "Juan } \\
\text { Domingo Perón" }\end{array}$ & $\begin{array}{l}\text { Sanatorio Cullen } \\
\text { DIRECTORA REVISTA }\end{array}$ & $\begin{array}{l}\text { STAFF } \\
\text { Mariela Tolcachier } \\
\text { Secretaria Presidencia }\end{array}$ \\
\hline $\begin{array}{l}\text { Jujuy } \\
\text { Carolina Galarza } \\
\text { Sanatorio Nuestra Señora del Rosario }\end{array}$ & $\begin{array}{l}\text { Lucrecia Burgos } \\
\text { Instituto Cardiovascular de Buenos Aires | } \\
\text { CABA }\end{array}$ & \\
\hline La Rioja & SUBDIRECTORES & \\
\hline $\begin{array}{l}\text { Juan Santillán } \\
\text { INCOR }\end{array}$ & $\begin{array}{l}\text { Franco Facciuto } \\
\text { Instituto Cardiovascular de Rosario | Santa Fe }\end{array}$ & \\
\hline Mendoza & $\begin{array}{l}\text { Sebastián Srur } \\
\text { Sanatorio Mitre|CABA }\end{array}$ & \\
\hline Romano Trionfi & PÁGINA WEB & \\
\hline $\begin{array}{l}\text { Mospltal Espanol } \\
\text { Misiones }\end{array}$ & $\begin{array}{l}\text { Director: Lin YuShan } \\
\text { Hospital Durand } \mid C A B A\end{array}$ & \\
\hline $\begin{array}{l}\text { Angelo Zubrzycki } \\
\text { Hospital SAMIC El Dorado }\end{array}$ & $\begin{array}{l}\text { Subdirector (CABA): Juan Pablo Cattáneo } \\
\text { Sagrado Corazon |CABA }\end{array}$ & \\
\hline
\end{tabular}

$\begin{array}{llll}\text { 1995: XV } & \text { Mendoza y San Juan } & \text { 2007: XXVII } & \text { Buenos Aires } \\ \text { 1996: XVI } & \text { Tucumán } & \text { 2008: XXVIII } & \text { La Rioja } \\ \text { 1997: XVII } & \text { Corrientes } & \text { 2009: XXIX } & \text { Mendoza } \\ \text { 1998: XVIII } & \text { San Juan } & \text { 2010: XXX } & \text { Jujuy } \\ \text { 1999: XIX } & \text { Buenos Aires } & \text { 2011: XXXI } & \text { Córdoba } \\ \text { 2000: XX } & \text { Córdoba } & \text { 2012: XXXII } & \text { Santa Fe } \\ \text { 2001: XXI } & \text { Rosario } & \text { 2013: XXXIII } & \text { Rosario } \\ \text { 2002: XXII } & \text { Entre Ríos } & \text { 2014: XXXIV } & \text { Mar del Plata } \\ \text { 2003: XXIII } & \text { Tucumán } & \text { 2015: XXXV } & \text { Mendoza } \\ \text { 2004: XXIV } & \text { Corrientes } & \text { 2016: XXXVI } & \text { Rosario } \\ \text { 2005: XXV } & \text { Córdoba } & \text { 2017: XXXVII } & \text { Santa Fe } \\ \text { 2006: XXVI } & \text { San Juan } & & \end{array}$

\section{f. CONAREC}

\section{Fundada en 1985 por el Dr. Arnaldo Adrián Angelino}

\section{Publicación bimestral. @ CONAREC}

Registro de la Propiedad Intelectual № 572790. Reservados todos los derechos. Ninguna parte de esta publicación puede ser reproducida en forma o medio alguno, electrónico o mecánico, incluyendo fotocopias, grabaciones y otros sistemas de información sin la autorización por escrito del titular del Copyright.

ISSN: 0329-0433 | ISSN: 1853-2357 (en línea). Propietario: Consejo Nacional de Residentes de Cardiología (CONAREC). Se distribuye exclusivamente entre los profesionales de la medicina. Es una publicación del CONAREC, Azcuénaga 980 C1122AAJ | Ciudad Autónoma de Buenos Aires.

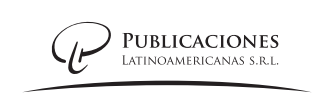

PRODUCCIÓN EDITORIAL, COMERCIAL Y GRÁFICA

PUBLICACIONES LATINOAMERICANAS S.R.L.

Piedras $13332^{\circ} \mathrm{C}$ C1240ABC Ciudad Autónoma de Buenos Aires | Argentina tel/fax (5411) 5217-0292 | e-mail info@publat.com.ar | http://www.publat.com.ar 


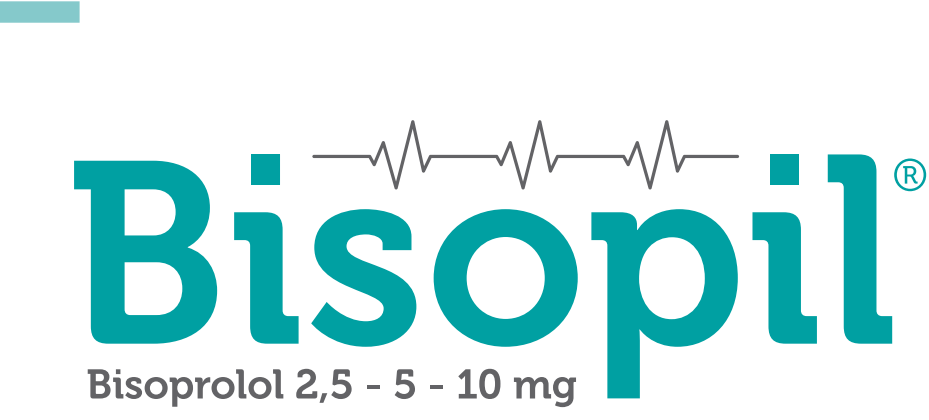

CARDIOSELECTIVO DE AMPLIA COBERTURA ${ }^{\top}$

\section{NUEVO}

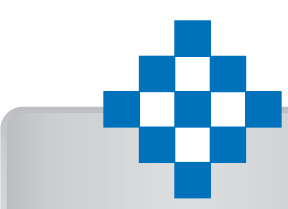

Gador

LÍDER EN

BETABLOQUEANTES

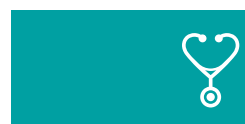

Posee alta selectividad por los receptores

$\beta 1^{2}$

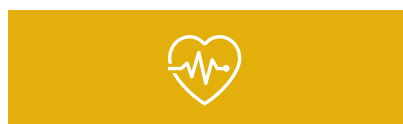

Disminuye la presión arterial de manera rápida $y$ eficaz ${ }^{3}$

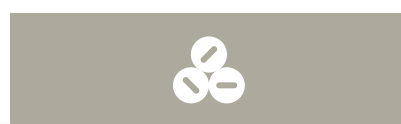

Está indicado en pacientes diabéticos compensados y/o con dislipemias $4,5,6$

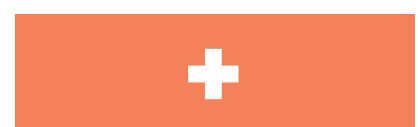

\section{Reduce las} hospitalizaciones

por

agravamiento de IC ${ }^{1}$

\section{TTMA} DIARIA

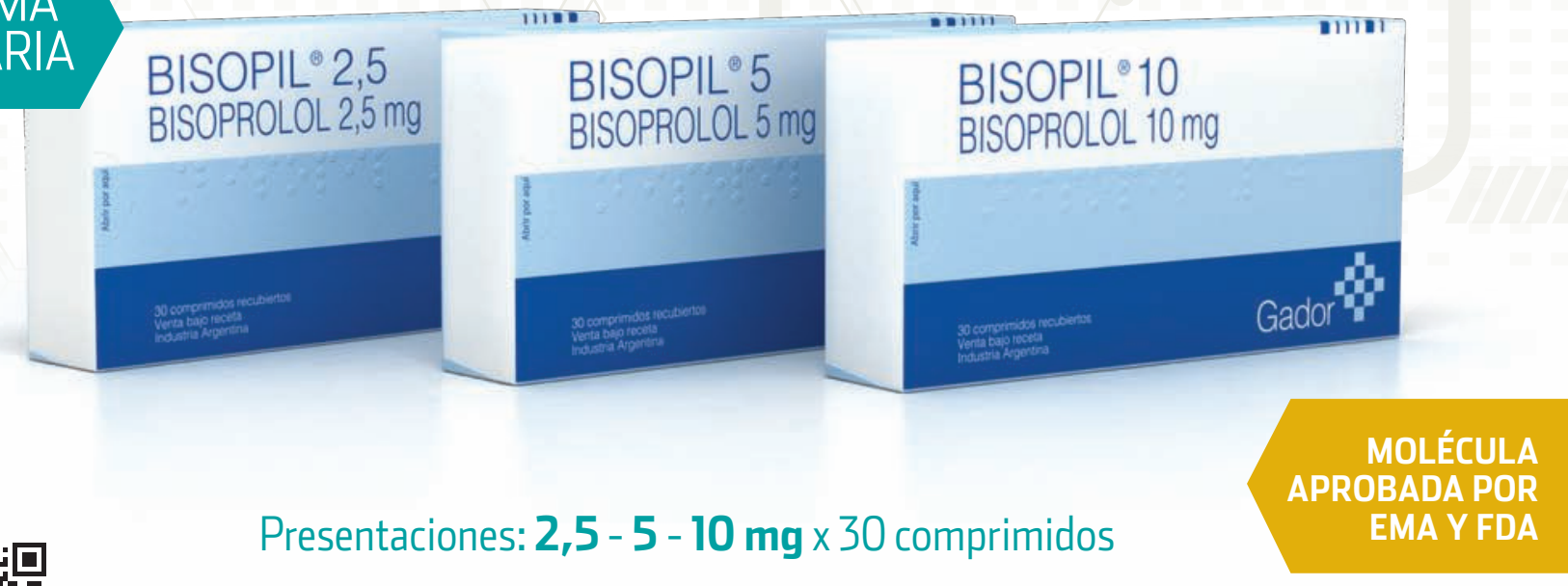

\section{PAMI 60\% IOMA 选}


CIUDAD AUTÓNOMA DE BUENOS AIRES Hospital General de Agudos Ramos Mejía Complejo Médico Policial "Churruca-Visca" Hospital Británico de Buenos Aires Sanatorio "Sagrado Corazón" Hospital Universitario Fundación Favaloro Hospital Español (Univ. Abierta Interamericana)

Hospital General de Agudos Durand Hospital General de Agudos Rivadavia Hospital Alemán

Hospital Naval Buenos Aires P. Mallo

Sanatorio de la Trinidad Mitre

Sanatorio Municipal "Dr. Julio Méndez"

Sanatorio Otamendi y Miroli

Sanatorio Colegiales

Hospital General de Agudos Santojanni Hospital de Clínicas "José de San Martín"

Sanatorio Güemes

Hospital Militar Central

Instituto Denton Cooley

Sanatorio Centro Gallego

Hospital General de Agudos Argerich

Policlínico Bancario

Hospital César Milstein

Clinica Bazterrica

Clinica Santa Isabe

Hospital Italiano de Buenos Aires Instituto Cardiovasc. de Buenos Aires "ICBA"

Hospital General De Agudos Fernández

Hospital Aeronáutico Central

GRAN BUENOS AIRES

Hospital Central de San Isidro

Sanatorio Modelo Quilmes

Hptal. Gral. de Agudos "Eva Perón" (Ex Castex)

Hospital Interzonal de Agudos Gandulfo

Hospital "Juan D. Perón"- Malvinas Argentinas

Hospital Universitario Austral

Clínica IMA - Adrogue

Hospital Municipal "Dr. Larcade"- San Miguel

Sanatorio San Miguel

Hospital Nacional Posadas

Hospital Interzonal Pte. Perón (Ex Finochietto)

Hospital Interzonal Gral de Agudos Evita - Lanús Clínica del Vall

Hospital El Cruce - Florencio Varela

CATAMARCA

$\mathrm{CHACO}$

de Urgencias

CÓRDOBA

Clínica Chutro

Clínica Sucre

CHUBUT
PROVINCIA DE BUENOS AIRES

CORRIENTES Htal Gral de Agudos "R. Rossi" - La Plata

Htal Gral de Agudos "O Alende"- Mar del Plata Htal Privado de la Comunidad - Mar Del Plata

Htal Gral de Agudos "J. Penna"- Bahía Blanca

Clinica Privada Fumeba - Hospital Privado del

Sur - Bahía Blanca

Hospital San Nicolás de los Arroyos

Htal Gral Agudos Dr. Paroissien - I. Casanova

Instituto de Cardiología Intervencionista

Instituto del Corazón "CORDIS"

Gran Hospital Dr Julio C. Perrando

Sanatorio Güemes

Centro Cardiovascular del Nordeste - Clínica

Clínica Privada Vélez Sarfield

Clínica Universitaria Reina Fabiola

Hospital Italiano de Córdob

Instituto Modelo de Cardiología

Sanatorio Allende

Sanatorio Mayo

Hospital Córdoba

Instituto Modelo de Cardiología Privado

Hospital Aeronáutico Córdoba

Hospital Privado Centro Médico de Córdoba

Hospital "San Roque"

Clínica Romagosa

Sanatorio del Salvador

Sanatorio Parque

Clínica Fusavim Privada

Clínica Privada de Especialidades - Villa María Instituto Médico Río Cuarto

Centro Materno
Hospital Españo
Sanatorio Britán

ENTRE RÍOS

Hospital Centra

Hospital Españo

Hospital Italiano

MISIONES

NEUQUÉN

RÍO NEGRO

ROSARIO

Sanatorio Plaza
CORRIENTES Sanatorio Delta

nstituto De Cardiologia Juana Francisca Cabral Hospital de Emergencias "Dr. C. Álvarez" Hospital Escuela "José Francisco de San Martín" Sanatorio Rosendo García

Sanatorio Regional

Hospital de Alta Complejidad "Juan D. Perón" C Clínica de Nefrología, Urología y Enfermeda-

des Cardiovasculares

Sanatorio Privado San Gerónimo

Sanatorio Médico de Diagnóstico y Tratamiento

Hospital Proviencial "J.M. Cullen"

Instituto Privado de Cardiología"Sagrada

Familia"

Sanatorio Mayo

Sanatorio Santa Fe

Sanatorio San Martín

Sanatorio Nosti

Sociedad Española De Socorros Mutuos

Hospital Luis Carlos Lagomaggiore

Hospital Del Carmen

SALTA

Hospital "San Bernardo"

SAN JUAN

Hospital Dr. Guillermo Rawson

Hospital "Dr. Marcial V. Quiroga

Hospital Escuela de Agudos Ramón Madariaga Centro Integral de Medicina de Alta Compleji-

Hospital Provincial Neuquén Castro Rendón

Instituto Cardiovascular Del Sur

Sanatorio Juan XXII

Hospital Provincial De Rosario

Hospital Provincial Del Centenario

Sanatorio Los Arroyos

Instituto Cardiovascular De Rosario dad (Clinica El Castaño)

\section{SANTIAGO DEL ESTERO}

Centro Cardiovascular Clinica Yunes

Sanatorio Instituto de Cardiología

TUCUMÁN

Inst. Tucumán de Enfermedades del Corazón Instituto de Cardiología de Tucumán

Hospital Centro De Salud Zenon J Santillan

Cardiología del Parque

Sanatorio 9 de Julio

Centro Modelo de Cardiología

Centro Privado de Cardiología

\section{MIEMBROS HONORARIOS}

Dr. Atdemar Álvarez +

Dr. Carlos Benjamín Álvarez

Dr. Roberto Basile

Dr. César Belziti

Dr. Carlos Bertolasi

Dr. Daniel Boccardo

Dr. Arturo Cagide

Dr. Ramiro Castellanos

Dr. Carlos Crespo

Dr. Miguel Del Río

Dr. Hernán Doval

Dr. René Favaloro +
Dr. Francisco Gadaleta

Dr. Joaquín García

Dr. Hugo Grancelli

Dr. Pablo Heredia

Dr. Juan Humphreys

Dr. Ricardo Iglesias

Dr. Juan Krauss

Dr. Jorge Lerman

Dr. José Martínez Martínez +

Dr. Osvaldo Masoli

Dr. José Milei

Dr. Raúl Oliveri
Dr. Igor Palacios

Dr. Néstor Pérez Baliño

Dr. Horacio Pomes I parraguirre

Dr. Rubén Posse +

Dr. Luis Pozzer

Dr. Osvaldo Robiolo

Dr. César Serra

Dr. Carlos Tajer

Dr. Jorge Trongé

Dr. Alejandro De Cerccio

Dr. Jorge Thierer

\section{COMITÉ ASESOR}

Dr. Andrés Ahuad Guerrero

Dr. Raúl J. Bevacqua

Dr. Rafael Cecchi

Dr. Jorge González Zuelgaray

Dr. Hugo Grancelli

Dr. Delfor Hernández

Dr. José Hidalgo

Dr. Gabriel Martino

Dra. Margarita Morley

Dra. Viviana Perugini

\section{EXPRESIDENTES}

1982: Dr. Francisco Gadaleta 1983: Dr. Enrique Retyk

1984: Dr. Ricardo Iglesias 1985: Dr. Juan José Nasif 1986: Dr. Arnaldo Angelino 1987: Dr. Raúl J. Bevacqua 1988: Dr. Andrés Ahuad Guerrero 1989: Dr. Rafael Cecchi 1990: Dra. Viviana Perugini
1991: Dr. Rodolfo Sansalone 1992: Dra. Gladys Aranda

1993: Dr. Gerardo Bozovich 1994: Dr. Alejandro Cherro 1996: Dr. Sergio Baratta 1997: Dr. Félix Paredes 1998: Dr. Marcelo E. Halac 1999: Dr. Pablo Perel 2000: Dr. Esteban Ludueña Clos
2001: Dr. Juan Arellano 2002: Dra. Mariana Pizzella 2003: Dr. Marcelo M. Casas 2004: Dr. Humberto Bassani Molinas 2005: Dr. Martín Descalzo 2006: Dr. Bruno Linetzky 2007: Dr. Juan Cruz López Diez 2008: Dr. Fernando Guardiani 2009: Dr. Diego Lowenstein
2010: Dr. Pablo Pieroni

2011: Dr. Gonzalo Pérez

2012: Dr. Nicolás González

2013: Dr. Ezequiel Zaide

2014: Dr. Matías Galli

2015: Dr. Luciano Fallabrino

2016: Dr. Darío lgolnikof 


\section{SUMMARY}

REVISTA CONAREC JULIO - AGOSTO DE 2018 | AÑO 33 | NÚMERO 145

EDITORIAL | EDITORIAL

RELACIÓN DEL BLOQUEO INTERAURICULAR AVANZADO

Y LA FIBRILACIÓN AURICULAR

ADVANCED INTERATRIAL BLOCK AND ATRIAL FIBRILLATION

Soledad Orazi

REVISIÓN POR EXPERTOS | EXPERT REVIEW

INHIBIDORES DE LAS PCSK9: NUEVOS TRATAMIENTOS HIPOLIPEMIANTES

INHIBITORS OF PCSK9: NEW LIPID-LOWERING TREATMENTS

Augusto M. Lavalle Cobo, Sebastián García Zamora, Luciano N. Fallabrino,

Ricardo M. Iglesias, Juan J. Badimon

REVISIÓN ANUAL | ANNUAL REVIEW

INTUBACIÓN Y MANEJO VENTILATORIO DEL PACIENTE CON CARDIOPATÍA AGUDA

INTUBATION AND VENTILATORY MANAGEMENT OF PATIENTS WITH ACUTE HEART FAILURE

Hernán E. Núñez, Laura Buira

MONOGRAFÍA SELECCIONADA | SELECTED MONOGRAPH

165

INHIBICIÓN DE LOS RECEPTORES DE LA ANGIOTENSINA

Y DE LA NEPRILISINA: UNA NUEVA ESPERANZA

EN EL TRATAMIENTO DE LA INSUFICIENCIA CARDÍACA

ANGIOTENSIN RECEPTOR BLOCKER AND NEPRILYSIN INHIBITORS:

A NEW HOPE IN THE TREATMENT OF HEART FAILURE

Carolina G. Naso

ARTÍCULOS ORIGINALES | ORIGINAL ARTICLES

PREVALENCIA DEL BLOQUEO INTERAURICULAR AVANZADO

EN PACIENTES REVERTIDOS DE FIBRILACIÓN AURICULAR

INTERATRIAL BLOCK PREVALENCE IN PATIENTS WITH REVERTED

ATRIAL FIBRILLATION

Florencia Foressi, Victoria Hoyle, Florencia Traficante, Romina Deganutto,

M. Belén Cigalini, J. Martín Galiano, Carlos Dumont, Jorge Garguichevich

ISQUEMIA CEREBRAL SILENTE PERIOPERATORIA EN PACIENTES CON FIBRILACIÓN AURICULAR

PERIOPERATIVE SILENT CEREBRAL ISCHEMIA IN PATIENTS WITH ATRIAL FIBRILLATION

Alejandro E. Contreras, Federico Roca, Jose I. Revigliono, Florencia Becerra, Teresita Cornavaca, Ricardo A. Albertini, Aldo H. Tabares

CASOS CLÍNICOS | CLINICAL CASES

ABLACIÓN EXITOSA DE VÍA ANÓMALA EN PACIENTE CON ANOMALÍA DE EBSTEIN

SUCCESSFUL ABLATION OF ANOMALY PATHWAY IN PATIENT WITH EBSTEIN ANOMALY

María F. Firpo, María Fernanda Godoy, Daniela Fernanda Chilabert, Juan M. Domínguez, Camila Antonietta, Marcelo Lanzotti, Silvano Diangelo

159 DENERVACIÓN SIMPÁTICA COMO TRATAMIENTO ALTERNATIVO EN ADOLESCENTE CON TAQUICARDIA VENTRICULAR CATECOLAMINÉRGICA POLIMÓRFICA

SYMPATHETIC DENERVATION AS AN ALTERNATIVE TREATMENT IN ADOLESCENTS WITH CATECHOLAMINERGIC POLYMORPHIC VENTRICULARTACHYCARDIA

Fiorella Soto Arévalo, Juan Guzmán, Juan Colaiacovo, Miranda Spinelli, Gustavo Costa, Claudio De Zuluaga, Gustavo Romera

IMÁGENES EN CARDIOLOGÍA | IMAGES IN CARDIOLOGY

TROMBO EN LA AORTA APARENTEMENTE SANA,

\section{EL PODER DE LA ANTICOAGULACIÓN}

THROMBUS IN APPARENTLY HEALTHY AORTA:THE POWER

OF ANTICOAGULATION

Yu Shan Lin, Diana Gutiérrez, Ezequiel Lerech, Luciano Ocampos,

Julieta Soricetti, Daniel Orquera

REGLAMENTO DE PUBLICACIONES |

RULES OF PUBLICATIONS

MÉTODOS ECOCARDIOGRÁFICOS PARA EVALUAR

LA AURÍCULA DERECHA UTILIZANDO LOS VALORES DE CORTE PUBLICADOS POR SOCIEDADES INTERNACIONALES

ECHOCARDIOGRAPHIC METHODS TO EVALUATE THE RIGHT ATRIUM USING

THE VALUES PUBLISHED BY INTERNATIONAL SOCIETIES

María del Pilar Acosta, Marcelo Storino, Guillermo Godoy, Vanesa Marasa,

Victor Arregui, Juan Erriest, Jorge Camilletti, Alejandro Vilchez,

Diego Martínez Demaría, María Laura Plastino 


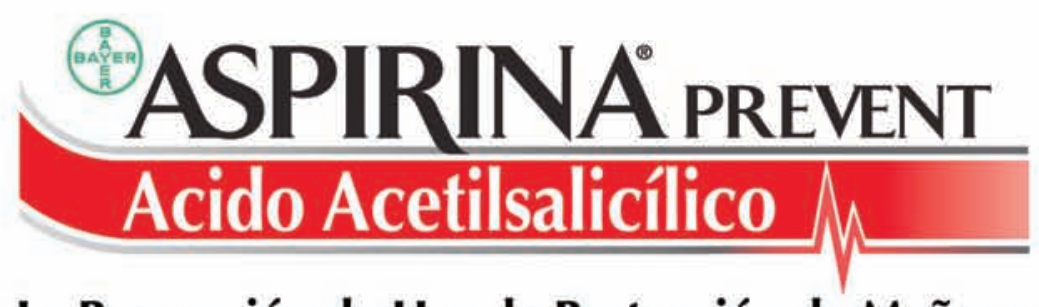

\section{La Prevención de Hoy, la Protección de Mañana}

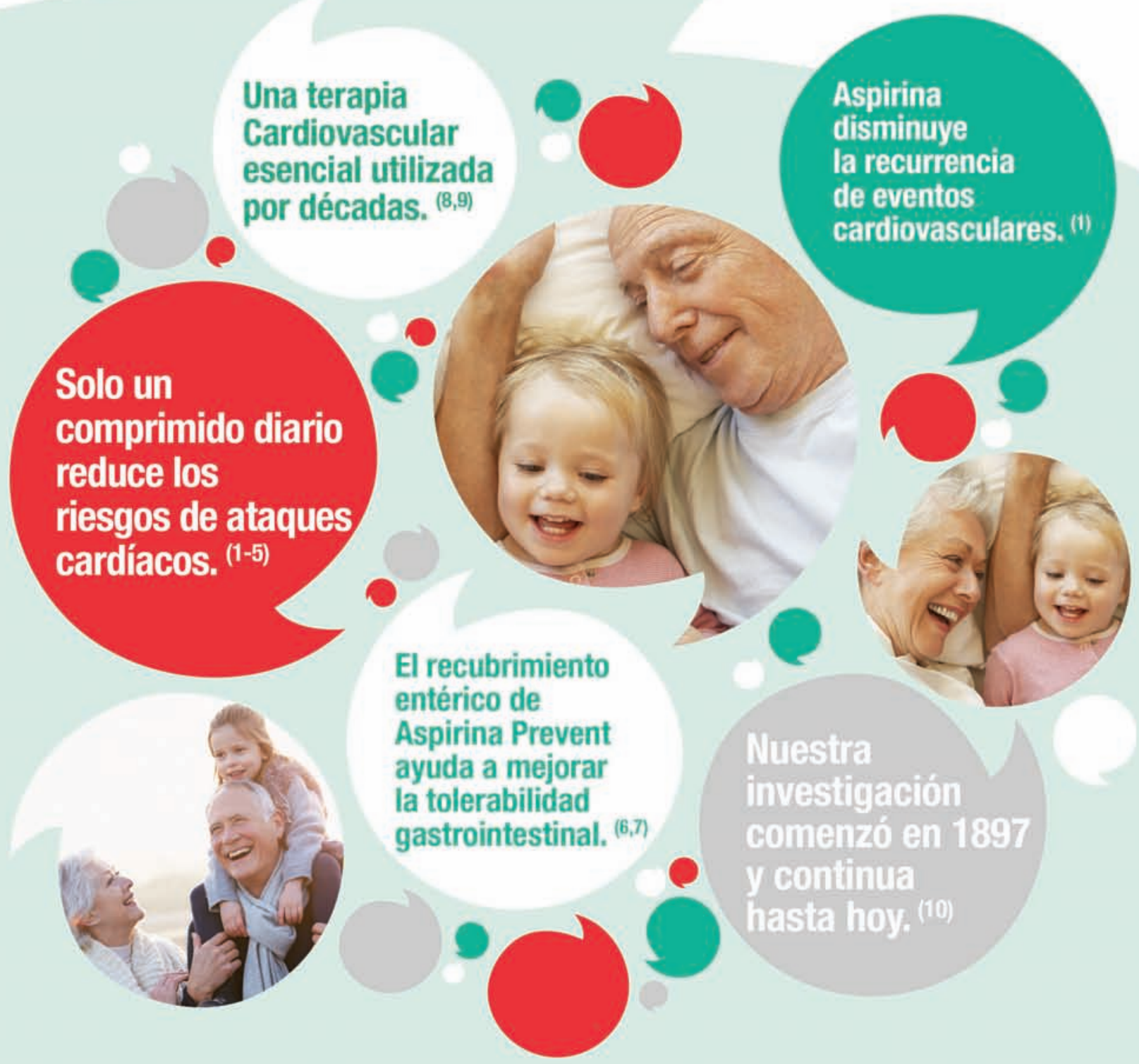

REFERENCLAS: 1. Antithrombotic Trialists' (ATT) Collaboration. Aspirin in the primary and secondary prevention of vascular disease: collaborative meta- analysis of individual participant data from randomised trial. Lancet 2009;373:1849-60. 2. Antithrombotic Trialist' (ATT) Collaboration. Collaborative meta- analysis of randomised trials of antiplatelet therapy for prevention of death, myocardia Infarction, and stroke in high risk patents. BMJ 2002;324 (7329):71-86, 3. BartolucciAA Tendera M and Howard G. Meta- analysys of multiple primary prevention trials of cardiovascular events using aspirin. Am J Cardiol 2011; 107: 1796-801. 4. Ryden L, Frant PJ, Anker SD et al. ESC Guidelines on diabetes, pre-diabetes, and cardiovascular diseases developed in collaboration with the EASD: the Task Force on diabetes, pre- diabetes, and cardiovascular diseases of the European Society of Cardiology (ESC) and developed in collaboration with the European Association for the Study of Diabetes (EASD). Eur Heart 2013. J34: 3035-87. 5. Bayer Aspirin Cardio SmPC. Bayer Healthcare 6. Banoob DW, McCloskey WW, Webster W. Risk of Gastric Iniury with Enteric-Versus Nonnenteric-Coated Aspirin Arn Phat streptokis 1988,2:349-60. 9. Baigent C, Collins R, Apple by P, et al. ISIS-2: 10 year survival among patents with suspected acute myocardial Infarction in randomised comparison of Intervenous streptokinase,

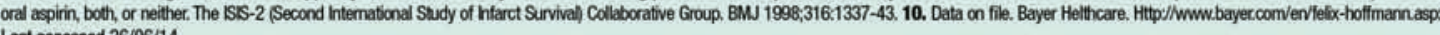
Last accessed 26/06/14.

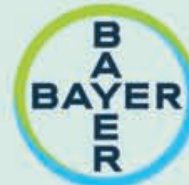




\section{(1)ASPIRINÅ PREVENT Acido Acetilsalicílico L}

ASPIRINA PREVENT. COMPOSICIÓN Cada comprimido con cubierta entérica contiene: Ácido acetilsalicilico: 100 mg / 350mg. INDICACIONES 100mg: Reducción del riesgo de mortalidad en pacientes con sospecha de infarto agudo de miocardio. Reducción del riesgo de morbilidad y mortalidad en pacientes con antecedentes de infarto de miocardio. Reducción del riesgo de un primer episodio de infarto de miocardio en pacientes con factores de riesgo cardiovascular, p.ej. diabetes mellitus, hiperlipidemia, hipertensión, obesidad, fumadores, tercera edad. Prevención secundaria de accidentes cerebrovasculares. Reducción de riesgo de ataques isquémicos transitorios (TIA) y accidentes cerebrovasculares en pacientes con TIA. Reducción de riesgo de morbilidad y muerte en pacientes con angina de pecho estable o inestable. Prevención de tromboembolias luego de una cirugía vascular o intervenciones, p.ej. PTCA, endarterectomía carotidea, shunts arteriovenosos. Profilaxis de trombosis venosas profundas y embolias pulmonares luego de inmovilizaciones prolongadas, p.ej. Iuego de cirugias mayores. INDICACIONES $350 \mathrm{mg}$ : Reducción del riesgo de mortalidad en pacientes con sospecha de infarto agudo de miocardio. Reducción del riesgo de morbilidad y mortalidad en pacientes con antecedentes de infarto de miocardio. Reducción del riesgo de un primer episodio de infarto de miocardio en pacientes con factores de riesgo cardiovascular, p.ej. diabetes mellitus, hiperlipidemia, hipertensión, obesidad, fumadores, tercera edad. Prevención secundaria de accidentes cerebrovasculares. Reducción de riesgo de ataques isquémicos transitorios (TIA) y accidentes cerebrovasculares en pacientes con TIA. Reducción de riesgo de morbilidad y muerte en pacientes con angina de pecho estable o inestable. Prevención de tromboembolias luego de una cirugla vascular 0 intervenciones, p.ej.PTCA, endarterectomla carotidea, derivaciones arteriovenosas. Profilaxis de trombosis venosas profundas y embolias pulmonares luego de inmovilizaciones prolongadas, p ej. luego de cirugías mayores. POSOLOGIA Y FORMA DE ADMINISTRACIÓN $100 \mathrm{mg}$ : Salvo otra indicación médica, se recomienda en adultos la siguiente dosificación. Para reducir el riesgo de mortalidad en pacientes con sospecha de infarto agudo de miocardio: dosis inicial es de 200 a $300 \mathrm{mg}$ administrada tan pronto como se sospeche el IM. En caso de utilizarse en esta indicación, la aspirina con recubrimiento gastrorresistente deberá triturarse o masticarse para lograr una absorción más rápida. Para reducir el riesgo de morbilidad y mortalidad en pacientes con antecedentes de infarto de miocardio; para prevención secundaria de accidentes cerebrovasculares; para reducir el riesgo de ataques isquémicos transitorios (TIA); para reducir el riesgo de morbilidad y muerte en pacientes con angina de pecho estable o inestable; para prevención de tromboembolias luego de una cirugia vascular o intervenciones: 100 a $300 \mathrm{mg}$ por dia. Para reducir el riesgo de un primer episodio de infarto de miocardio en pacientes con factores de riesgo cardiovascular y para profilaxis de trombosis venosas profundas y embolias pulmonares luego de inmovilizaciones prolongadas: 100 a $200 \mathrm{mg}$ por día o $300 \mathrm{mg}$ día por medio. POSOLOGIA Y FORMA DE ADMINISTRACIÓN $350 \mathrm{mg}$ : Salvo otra indicación médica, se recomienda en adultos la siguiente dosificación. Para reducir el riesgo de mortalidad en pacientes con sospecha de infarto agudo de miocardio: 325 mg por día. La dosis de mantenimiento es de $325 \mathrm{mg}$ todos los dias hasta 30 dias posterior al infarto. Luego de los 30 dias deberá tenerse en cuenta la terapia adicional suministrada para evitar un nuevo infarto de miocardio. Para reducir el riesgo de morbilidad y mortalidad en pacientes con antecedentes de infarto de miocardio, para prevención secundaria de accidentes cerebrovasculares; para reducir el riesgo de ataques isquémicos transitorios (TIA); para reducir el riesgo de morbilidad y muerte en pacientes con angina de pecho estable o inestable; para prevención de tromboembolias luego de una cirugia vascular o intervenciones: $325 \mathrm{mg}$ por dia. Para reducir el riesgo de un primer episodio de infarto de miocardio en pacientes con factores de riesgo cardiovascular y para profilaxis de trombosis venosas profundas y embolias pulmonares luego de inmovilizaciones prolongadas: 325 mg día por medio. CONTRAINDICACIONES. Úlcera gastrointestinal aguda. Diátesis hemorrágica. Hipersensibilidad al ácido acetilsalicilico, a salicilatos, 0 a algún otro componente de este producto. Antecedentes de asma inducido por la administración de salicilatos o sustancias con una acción similar, en especial drogas antiinflamatorias no esteroideas. Combinación con metotrexate en dosis de 15 mg por semana o más. Último trimestre de embarazo. Falla renal severa. Falla hepática severa. Falla cardiaca severa. ADVERTENCIAS Y PRECAUCIONES. Hipersensibilidad a los analgésicos y a agentes antiinflamatorios/antirreumáticos y en presencia de otras alergias: en pacientes con fiebre de heno, múltiples pólipos nasales, asma bronquial o enfermedades respiratorias crónicas, el ácido acetilsalicilico puede precipitar un broncoespasmo e inducir ataques de asma u otras reacciones de hipersensibilidad. Debido al efecto inhibitorio sobre la agregación plaquetaria que persiste por varios dias luego de su administración, el ácido acetilsalicilico tiende a aumentar las hemorragias durante y luego de intervenciones quirúrgicas (incluyendo cirugias menores, p.ej. extracciones dentales). EI paciente debe consultar con su médico acerca del uso de ácido acetilsalicilico. Tratamiento conjunto con anticoagulantes. Algunos AINES, como el ibuprofeno y el naproxeno pueden atenuar el efecto inhibitorio del ácido acetilsalicilico sobre la agregación plaquetaria. El paciente deberá advertir al médico cuando esté bajo terapia con ácido acetilsalicilico y deba tomar ibuprofeno. En pacientes que sufren de graves deficiencias de la glucosa-S-fosfato deshidrogenasa (G6PD), el ácido acetilsalicilico puede inducir hemólisis o anemia hemolitica. Los factores que pueden aumentar el riesgo de hemólisis son, por ejemplo dosis altas, fiebre o infecciones agudas. A dosis bajas, el ácido acetilsalicilico reduce la excreción del ácido úrico. Esto puede favorecer la aparición de gota en pacientes predispuestos. Antecedentes de úlcera gastrointestinal incluyendo úlceras crónicas o recurrentes o antecedentes de hemorragias gastrointestinales. Daño de función renal y hepática. Los pacientes con insuficiencia renal o en pacientes con trastornos en la circulación cardiovascular el ácido acetilsalicilico pueden aumentar el riesgo de insuficiencia renal y falla renal aguda. Alteración de la función hepática. Los productos medicinales que contengan ácido acetilsalicilico/aspirina no deben ser utilizados en niños y adolescentes menores de 16 años que tengan enfermedades virales, con o sin fiebre sin consultar al médico. Existe el riesgo de que ciertas enfermedades virales, como ser influenza A, B y varicela provocar el sindrome de Reyé, una patologia rara pero severa que requiere una intervención médica inmediata. REACCIONES ADVERSAS. Las reacciones adversas a medicamentos (RAM) enumeradas a continuación se basan en informes espontáneos postcomercialización con todas las formulaciones de aspirina de administración oral, incluyendo tratamientos a corto y largo plazo, por lo que una clasificación de acuerdo con las categorias CIOMS III de frecuencia no es pertinente: trastornos del sistema inmunitario: reacciones de hipersensibilidad con las respectivas manifestaciones clinicas y de laboratorio: sindrome de asma, reacciones leves a moderadas que puedan afectar a la piel, vias respiratorias, tracto gastrointestinal y sistema cardiovascular, incluyendo sintomas como ser sarpullido, urticaria, edema, prurito, rinitis, congestión nasal, insuficiencia cardiorrespiratoria y muy raramente reacciones severas, incluyendo shock anafiláctico; trastornos gastrointestinales: trastornos frecuentes del tracto gastrointestinal bajo y alto, asi como signos y sintomas de dispepsia, dolor abdominal y gastrointestinal, raramente trastornos como ser: inflamación gastrointestinal, úlcera gastrointestinal que puede evolucionar muy raramente a una úlcera gastrointestinal sangrante y perforación con los correspondientes valores de laboratorio y los caracteristicos signos clinicos y sintomas. Trastornos hepatobiliares: se han reportado casos aislados y transitorios de alteraciones de la función hepática. Trastornos de la sangre y del sistema linfático: debido al efecto inhibitorio sobre la agregación plaquetaria, el ácido acetilsalicilico puede ser asociado con un riesgo aumentado de sangrados. Se han observado sangrados, como ser hemorragias perioperatorias, hematomas, epistaxis, sangrados urogenitales y gingivales. Se han informado episodios raros a muy raros de sangrados severos, como ser hemorragia del tracto gastrointestinal, hemorragia cerebral (especialmente en pacientes con hipertensión no controlada y/o con administraciỏn concomitante de agentes anticoagulantes) que pueden ser, en casos aislados, fatales. Las hemorragias pueden provocar anemias agudas y crónicas secundarias a hemorragias/anemia ferropénica con los correspondientes valores de laboratorio los caracteristicos signos clinicos y sintomas, tales como astenia, palidez, hipoperfusión. Se ha reportado hemólisis y anemia hemolitica en pacientes con formas graves de deficiencia de glucosa-6-fosfato (G6PD). Trastornos del sistema nervioso: mareos y tinnitus son signos indicativos de sobredosis. Trastornos renales y urinarios: se han reportado casos de alteración de la función renal e insuficiencia renal aguda. PRESENTACıón Envases con 4,10,20,30,50 y 100 comprimidos.

Bayer S.A., Ricardo Gutiérrez 3652, (B1605EHD), Munro, Bs. As., Argentina.

Director Técnico: José Luis Role, Farmacéutico.

Especialidad medicinal autorizada por el Ministerio de Salud. Certificado № 33575 Versión: CCDS v6 revisión: 09.2017 


\title{
SUMARIO ANALÍTICO
}

\author{
ANALYTICAL SUMMARY
}

REVISTA CONAREC JULIO - AGOSTO DE 2018 | AÑO 33 | NÚMERO 145

\section{REVISIÓN POR EXPERTOS | EXPERT REVIEW}

\section{INHIBIDORES DE LAS PCSK9: NUEVOS TRATAMIENTOS HIPOLIPEMIANTES}

AUGUSTO M. LAVALLE COBO, SEBASTIÁN GARCÍA ZAMORA, LUCIANO N. FALLABRINO, RICARDO M. IGLESIAS, JUAN J. BADIMON

Actualmente las estatinas son la piedra angular para el tratamiento de la hipercolesterolemia, logrando no solo descensos en los niveles de colesterol sino también reducir eventos cardiovasculares. En la búsqueda de alcanzar metas terapéuticas más bajas del colesterol asociado a lipoproteínas de baja densidad y de abarcar a la mayor cantidad de poblaciones de pacientes, los anticuerpos monoclonales demostraron ser una buena alternativa. En este escenario, los inhibidores de la PCSK9 se presentan como nuevas opciones terapéuticas a los fármacos utilizados para el tratamiento de las dislipidemias. La presente revisión tiene como objetivo resumir la historia, indicaciones, eficacia y seguridad de las dos nuevas moléculas de esta familia de fármacos: alirocumab y evolocumab.

REVISIÓN ANUAL | ANNUAL REVIEW

\section{INTUBACIÓN Y MANEJO VENTILATORIO DEL PACIENTE CON CARDIOPATÍA AGUDA \\ HERNÁN E. NÚÑEZ, LAURA BUIRA}

Una de las formas de presentación más frecuentes de la insuficiencia cardíaca corres ponde a la disnea, generalmente con hipoxemia. Resulta de capital importancia realizar un tratamiento rápido de sostén vital a fin de corregirla. Esto se puede lograr con oxigenoterapia, aunque es muy frecuente que además de ésta los pacientes requieran asistencia ventilatoria mecánica, ya sea de forma invasiva como no invasiva.

El manejo apropiado de la vía aérea, la elección de la estrategia ventilatoria, asi como las drogas a utilizar para sedoanalgesia en pacientes con falla cardíaca conducirán a obtener mejores resultados.

La siguiente revisión se enfocará en la asistencia ventilatoria mecánica invasiva en pacientes con enfermedad cardíaca aguda.

\section{MONOGRAFÍA SELECCIONADA | SELECTED MONOGRAPH}

\section{INHIBICIÓN DE LOS RECEPTORES DE LA ANGIOTENSINA \\ Y DE LA NEPRILISINA: UNA NUEVA ESPERANZA EN EL TRATAMIENTO DE LA INSUFICIENCIA CARDÍACA \\ CAROLINA G. NASO}

La insuficiencia cardíaca (IC) es un trastorno progresivo frente al cual se activan sistemas reguladores, como el sistema renina-angiotensina-aldosterona (SRAA) y mecanismos contrarreguladores, como los péptidos natriuréticos. Es ya reconocido el tratamiento neurohormonal de la IC, que ha demostrado disminuir la mortalidad en dicha patología, como lo son los inhibidores del SRAA, los betabloqueantes y los antagonistas de los mineralocorticoides. Actualmente, toma importancia un nuevo grupo de fármacos que recientemente también demostró disminuir mortalidad, los inhibidores de la recaptación de neprilisina y de la angiotensina. Los péptidos natriuréticos son hormonas secretadas por el corazón que poseen propiedades pleiotrópicas protectoras del sistema cardiovascular, secretadas frente al estiramiento parietal cardíaco, y que son degradados por la neprilisina. Sobre esta base fisiopatológica, se originó un nuevo fármaco compuesto por el sacubitril (inhibidor de la degradación de la neprilisina), con el valsartán (inhibidor de los receptores de angiotensina II) que demostró disminuir la mortalidad en IC contra el enalapril. El objetivo de esta monografía es realizar una revisión exhaustiva de la fisiopatología de la IC, del SRAA y de los péptidos natriuréticos, para posteriormente presentar al fármaco sacubitril/valsartán, su mecanismo de acción y evidencia actual.

\section{ARTÍCULOS ORIGINALES | ORIGINAL ARTICLES}

\section{6}

\section{PREVALENCIA DEL BLOQUEO INTERAURICULAR AVANZADO EN PACIENTES REVERTIDOS DE FIBRILACIÓN AURICULAR}

FLORENCIA FORESSI, VICTORIA HOYLE, FLORENCIA TRAFICANTE, ROMINA DEGANUTTO, M. BELÉN CIGALINI, J. MARTÍN GALIANO, CARLOS DUMONT, JORGE GARGUICHEVICH

Introducción. El bloqueo interauricular (BIA) representa un sustrato anatomoe léctrico para el desarrollo de arritmias supraventriculares. Su prevalencia en pacientes con fibrilación auricular (FA) no ha sido claramente estudiada. El objetivo de este trabajo es determinar la prevalencia de BIA en pacientes internados por FA y revertidos a ritmo sinusal.

Métodos. Estudio observacional, analítico, prospectivo, unicéntrico. Se incluyeron pacientes internados por fibrilación auricular (FA) y que hubieran presentado en cualquier momento de su evolución reversión a ritmo sinusal. Post reversión inmediata se realizó un electrocardiograma. A todos los pacientes se les realizó un ecocardiograma transtorácico para evaluar el tamaño de la aurícula izquierda (Al).

Resultados. Se incluyeron 48 pacientes, con una edad promedio de 67,7 años $56,2 \%$ de sexo masculino. Veintiún pacientes $(43,7 \%)$ presentaron historia previa de FA. El 72,9\% de los pacientes fueron revertidos por cardioversión eléctrica, $12,5 \%$ farmacológica y $14,6 \%$ espontánea. El tamaño de la Al por ecocardiografía $12,5 \%$ farmacológica y $14,6 \%$ espontánea. El tamaño de la Al por ecocardiografía
fue normal en el $6,2 \%$ de los pacientes, levemente dilatada en el $62,5 \%$, moderada en el $27,1 \%$ y severa en el $4,2 \%$. La duración promedio de la onda P fue de $128,1 \mathrm{~ms}$. La presencia de componente negativo en las 3 derivaciones de la cara inferior solo se observó en el 4,2\% de los pacientes.

Conclusiones. En nuestra población, la incidencia de BIA en pacientes revertidos de FA fue baja.

\section{MÉTODOS ECOCARDIOGRÁFICOS PARA EVALUAR}

\section{LA AURÍCULA DERECHA UTILIZANDO LOS VALORES DE CORTE} PUBLICADOS POR SOCIEDADES INTERNACIONALES

MARÍA DEL PILAR ACOSTA, MARCELO STORINO, GUILLERMO GODOY, VANESA MARASA, VÍCTOR ARREGUI, JUAN ERRIEST, JORGE CAMILLETTI, ALEJANDRO VILCHEZ, DIEGO MARTÍNEZ DEMARÍA, MARÍA LAURA PLASTINO

Introducción. El tamaño de la aurícula derecha (AD) medido por ecocardiografía ha mostrado ser un marcador de riesgo cardiovascular en diferentes condiciones cardíacas. La cuantificación del tamaño de la AD se realiza más comúnmente en la vista apical de 4 cámaras, donde se realiza planimetría para estimar el área. Hasta el momento, no se conocen estudios que correlacionen el área de la AD (Área AD) con los nuevos valores de corte propuestos para el volumen de la AD. Las guías de la Sociedad Americana de Ecocardiografía (ASE)/Sociedad Europea de Cardiología (ESC) establecen que el parámetro recomendado para evaluar el tamaño de la $A D$ es el volumen $A D(V o l A D)$ calculado a través del método área-longitud o de sumatoria de discos en un solo plano apical de 4 cámaras. Objetivos. Correlacionar el volumen de la $\mathrm{AD}(\mathrm{Vol} \mathrm{AD})$ con el área de la $\mathrm{AD}$ según los parámetros de las recomendaciones ASE/ESC

Materiales y métodos. Estudio observacional y descriptivo, retrospectivo, donde se analizaron 109 pacientes que concurrieron al laboratorio de Ecocardiografía del Hospital Italiano de La Plata para control cardiovascular entre los meses de septiembre y octubre del año 2015; la edad media fue de 56,41 \pm 17 años, 53,21\% de sexo masculino.

Resultados. Del total de participantes, 24 (22,01\%) fueron clasificados con AD anormal por Área AD y $15(13,76 \%)$ con AD anormal por Vol AD $(p<0,02)$. De lo 85 pacientes que tuvieron AD normal según Área AD, el 2,75\% (3 pacientes) tuvieron $V_{v o l} A D$ anormal; contrariamente, de los 24 que tuvieron $A D$ anormal por área, 12 tuvieron también AD anormal por Vvol AD (concordancia moderada, kappa 0,53). El análisis estadístico según género evidenció una concordancia mejor para el sexo femenino (kappa 0,73 vs. 0,43). La variabilidad interobservado para evaluar las dimensiones de la AD según Área AD fue de $2,4 \pm 0,2 \mathrm{~mm}$ y según Volvolumen $A D$ de $4 \pm 0,36 \mathrm{ml} / \mathrm{m} 2$; valores que concuerdan con reportes previos. Se observó una correlación positiva lineal moderada entre el Área AD y el Vol AD $(r=0,799)$. 
Conclusión. Los valores de corte para tamaño AD según el área y el volumen han demostrado una buena concordancia, mejor aún para el sexo femenino. Es importante seguir las recomendaciones de las guías de la ASE/ESC, evaluar a los pacientes según los valores de corte recomendados y definir dilatación AD por Vol AD y Área AD.

\section{ISQUEMIA CEREBRAL SILENTE PERIOPERATORIA \\ EN PACIENTES CON FIBRILACIÓN AURICULAR}

ALEJANDRO E. CONTRERAS, FEDERICO ROCA, JOSE I. REVIGLIONO,

FLORENCIA BECERRA, TERESITA CORNAVACA, RICARDO A. ALBERTINI, ALDO H. TABARES

Introducción. Frecuentemente en la práctica clínica se plantea la necesidad de revertir la anticoagulación con antagonistas de la vitamina K en pacientes con fibrilación auricular (FA) previo a la realización de procedimientos invasivos. Trabajos científicos recientemente publicados sugieren que es segura la suspensión del tratamiento anticoagulante sin necesidad de terapia sustitutiva con heparina. Objetivos. Determinar si los pacientes con FA decon bajo riesgo tromboembólico presentaron eventos cerebrales isquémicos silentes durante intervenciones invasivas luego de la suspensión de la anticoagulación.

Métodos. Estudio observacional, prospectivo, que se realizó mediante el seguimiento clínico de pacientes internados para procedimiento invasivos desde el año 2010 a la actualidad en el Hospital Privado Universitario de Córdoba.

Resultados. Fueron evaluados 7 pacientes con FA de bajo riesgo tromboembólico, a quienes se los estudió mediante resonancia nuclear magnética cerebra pre- y posquirúrgicas (en secuencias de difusión, T2 y FLAIR). La totalidad de la muestra tenía $F A$, encontrándose bajo tratamiento anticoagulante con antagonistas de la vitamina $K_{1}$ y tenía una mediana de $\mathrm{CHA}_{2} \mathrm{DS}_{2}$-VASc de 2 puntos (0-2 puntos, riesgo tromboembólico bajo). El día de la intervención quirúrgica el grupo de estudio presentó un RIN promedio de $1,36(1,02-1,86)$ y necesitaron para alcanzar el rango terapéutico de anticoagulación 4,86 días (4-5 días). Ninguno recibió heparinas en dosis anticoagulantes y un solo paciente recibió profilaxis. No se evidenciaron eventos neurológicos clínicamente evidentes, sin embargo en un paciente $(14,2 \%)$ se observó una imagen isquémica cerebral en el posoperatorio, sin repercusión clínica.

Conclusión. A pesar del pequeño número casos, nuestra experiencia genera la hipótesis de que algunos pacientes con FA con bajo riesgo de tromboembolis mo perioperatorio podrían tener isquemia silente sin terapia anticoagulante. Un estudio futuro con mayores dimensiones teniendo en cuenta el momento de realización de las imágenes y el seguimiento a largo plazo podría dilucidar la frecuencia de la isquemia silente y sus consecuencias.

\section{CASOS CLÍNICOS | CLINICAL CASES}

\section{ABLACIÓN EXITOSA DE VÍA ANÓMALA EN PACIENTE CON ANOMALÍA DE EBSTEIN}

MARÍA F. FIRPO, MARÍA FERNANDA GODOY, DANIELA FERNANDA CHILABERT, JUAN M. DOMÍNGUEZ, CAMILA ANTONIETTA, MARCELO LANZOTTI, SILVANO DIANGELO

La anomalía de Ebstein (AE) consiste en el desplazamiento congénito de las valvas septal y posterior de la tricúspide hacia el ventrículo derecho. Gracias a esto existe dilatación auricular por "atrialización" ventricular, insuficiencia tricuspídea y falla ventricular derecha. Un 30\% se asocia con arritmias supraventriculares y síndrome de Wolff-Parkinson-White (WPW). Se presenta el caso de un paciente con ablación exitosa de vía anómala con coexistencia de AE y síndrome de WPW.
DENERVACIÓN SIMPÁTICA COMO TRATAMIENTO ALTERNATIVO EN ADOLESCENTE CON TAQUICARDIA

\section{VENTRICULAR CATECOLAMINÉRGICA POLIMÓRFICA}

FIORELLA SOTO ARÉVALO, JUAN GUZMÁN, JUAN COLAIACOVO, MIRANDA SPINELLI, GUSTAVO COSTA, CLAUDIO DE ZULUAGA, GUSTAVO ROMERA

La taquicardia ventricular catecolaminérgica polimórfica es una entidad caracterizada por el desarrollo de taquiarritmias potencialmente fatales en circunstancias que incrementan el tono simpático debido a una alteración en los canales iónicos del músculo cardíaco. Los betabloqueantes constituyen el tratamiento de elección. En pacientes con arritmia refractaria o cuando existen contraindicaciones formales para el uso de fármacos, está indicado el implante de cardiodesfibrilador implantable con riesgo de múltiples descargas. Se ha propuesto como nueva herramienta la denervación simpática cardíaca izquierda.

IMÁGENES EN CARDIOLOGÍA | IMAGES IN CARDIOLOGY

TROMBO EN LA AORTA APARENTEMENTE SANA,

\section{EL PODER DE LA ANTICOAGULACIÓN}

YU SHAN LIN, DIANA GUTIÉRREZ, EZEQUIEL LERECH, LUCIANO OCAMPOS, JULIETA SORICETTI, DANIEL ORQUERA

Los trombos móviles en la aorta sana en ausencia de enfermedad constituyen una entidad poco frecuente, cuya sospecha clínica suele aparecer luego de eventos embólicos. La ecocardiografía cardíaca transesofágica constituye una herramienta de gran utilidad para el diagnóstico. La forma más frecuente de presentación es la embolización arterial a predominio del miembro superior izquierdo. A continuación, se presenta un caso de una paciente con trombo móvil en la aorta ascendente sintomática por impotencia funcional y frialdad en el miembro superior izquierdo al esfuerzo y ausencia del pulso, la cual requirió anticoagulación con posterior resolución. 


\section{PRESIMAX Losartán}

EXPERIENCIA, SEGURIDAD Y EFICACIA EN HIPERTENSIÓN ARTERIAL

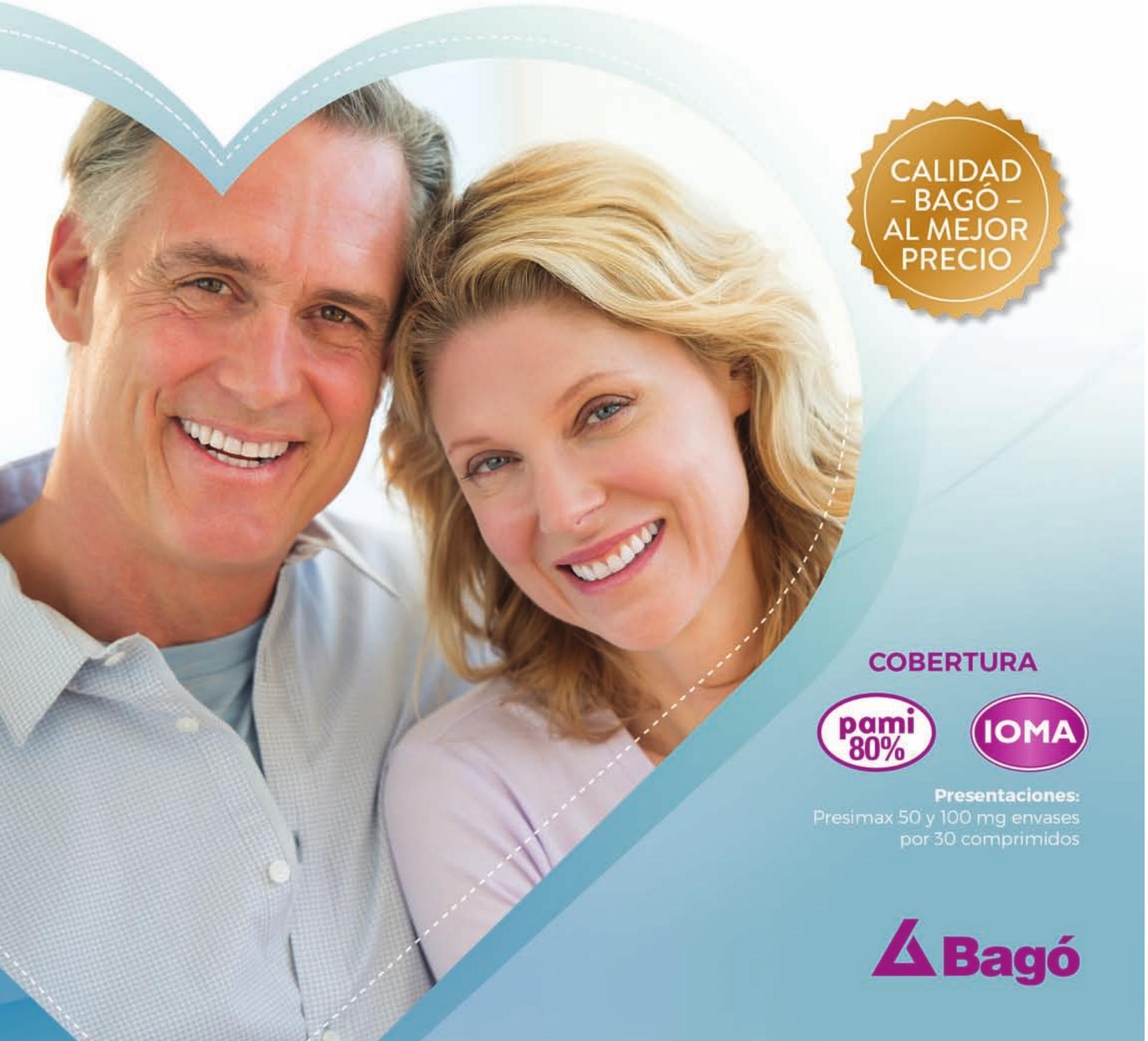




\title{
RELACIÓN DEL BLOQUEO INTERAURICULAR AVANZADO Y LA FIBRILACIÓN AURICULAR
}

\author{
ADVANCED INTERATRIAL BLOCK AND ATRIAL FIBRILLATION
}

REVISTA CONAREC 2018;33(145):149-150| DOI:10.32407/RCON/2018145/0149-0150

En el año 1979 Bayés de Luna describió los bloqueos de la conducción auricular y los clasificó como inter- e intraauriculares. Los bloqueos interauriculares (BIA) se refieren a las alteraciones de la conducción entre ambas aurículas, mientras que los bloqueos intraauriculares ocurren en la misma aurícula'. En el electrocardiograma (ECG) de superficie se observa una onda P $\geq 120 \mathrm{~ms}$, a lo cual se denominó BIA parcial; y si se agrega a la prolongación de la onda P la morfología +/- (positiva/negativa) en las derivaciones inferiores, se lo denominó BIA avanzado. También puede clasificarse como de primer grado (parcial), de segundo grado (bloqueo transitorio interauricular o aberrancia de la conducción auricular), o de tercer grado (avanzado).

Este enlentecimiento en el impulso y contracción auricular izquierda, en comparación con la derecha, genera alteraciones hemodinámicas y eléctricas. Goyal y Spodick analizaron los ecocardiogramas y ECG de pacientes con agrandamiento auricular izquierdo. Veinticuatro pacientes tenían BIA, y 16 pacientes no lo presentaban, los cuales conformaron el grupo control. Se calcularon los volúmenes de la Al (aurícula izquierda), los tiempos de aceleración de la onda A, el volumen sistólico de la Al, la fracción de eyección y la energía cinética. El resultado fue que los pacientes con BIA tuvieron iguales volúmenes de Al, significativamente más prolongados los tiempos de aceleración de la onda A y volumen sistólico, fracción de eyección y energía cinética. Se concluyó que los pacientes con BIA tienen alteración en la función contráctil de la Al, y la extensión de la disfunción está relacionada con el grado de retardo eléctrico del BIA. A su vez, sugieren que el BIA debe ser considerado como un marcador de disfunción primariamente eléctrico y con repercusión mecánica en la Al, y por lo tanto un factor de riesgo para el desarrollo de fibrilación auricular (FA) e insuficiencia cardíaca congestiva².

Esta relación entre FA y otras arritmias supraventriculares, como el aleteo auricular atípico y extrasístoles auriculares, con el BIA avanzado se evidenció en el año 1988 cuando Bayés de Luna et al. publicaron el primer trabajo³. En este estudio se compararon 16 pacientes con BIA avanzado con diferentes cardiopatías con un grupo control de iguales características clínico-ecocardiográficas, donde a todos los pacientes se les realizó registros de monitorización con Holter. El 93,7\% de los pacientes con BIA presentaron en un seguimiento a 30 meses taquicardias paroxísticas supraventriculares, mientras que solo las padecieron el 27,7\% de los pacientes del grupo control $(p<0,01)$. Al mismo tiempo, el grupo con BlA avanzado presentó mayor prevalencia de extrasístoles supraventriculares (75\%) en comparación al grupo control (16,6\%), siendo esta diferencia estadísticamente significativa $(p<0,01)^{3}$.

En el presente número de la revista, se presenta un estudio realizado entre los años 2016 y 2017 en el Hospital Privado de Rosario (Santa Fe), observacional y prospectivo, donde se incluyó a 48 pacientes internados por FA que presentaron en algún momento de su evolución reversión a ritmo sinusal, teniendo como objetivo determinar la prevalencia de BIA avanzado. Se observó que la misma fue baja (4,2\%), encontrando como limitante principal el bajo número de pacientes.

A pesar de que la prevalencia de BIA aumenta con la edad, la patogénesis exacta se desconoce. Se han propuesto diversas patologías, como la enfermedad arterial coronaria, la hipertensión arterial y la diabetes mellitus; sin embargo, ninguno de ellas mostró una correlación estadísticamente significativa con la progresión del BIA4.

Podemos concluir que el BIA representa un sustrato anátomo-eléctrico para el desarrollo de arritmias supraventriculares, como bien lo describió a fines de la década de los setenta el Dr. Bayés de Luna, lo cual se ha confirmado en numerosos estudios posteriores. Por tal motivo, esta entidad se denomina "Síndrome de Bayés"5,6. 


\section{BIBLIOGRAFÍA}

1. Conde D, Seoane L, Gysel M, Mitrione S, Bayés de Luna A, Baranchuk A. Bayés'syndrome: the association between interatrial block and supraventricular arrhythmias. Expert Rev Cardiovasc Ther 2015;13(5):541-50.

2. Goyal SB, Spodick DH. Electromechanical dysfunction of the left atrium associated with interatrial block. Am Heart J 2001;142(5):823-7.

3. Bayés de Luna A, Cladellas M, Oter R, Torner P, Guindo J, Martí V, et al. Interatrial conduction block and retrograde activation of the left atrium and paroxysmal supraventricular tachyarrhythmia. Eur Heart J 1988:9(10):1112-8.

4. Chhabra L, Devadoss R, Chaubey VK, Spodick DH. Interatrial block in the modern era. Curr Cardiol Rev 2014;10(3):181-9.

5. Conde D, Baranchuk A. Síndrome de Bayés: lo que un cardiólogo no debe dejar de saber. Rev Argent Cardiol 2014;82(3):237-9.

6. Conde D, Baranchuk A. Bloqueo interauricular como sustrato anatómico-eléctrico de arritmias supraventriculares: síndrome de Bayés. Arch Cardiol Mex 2014;84(1):32-40 


\title{
INHIBIDORES DE LAS PCSK9: NUEVOS TRATAMIENTOS HIPOLIPEMIANTES
}

\author{
INHIBITORS OF PCSK9: NEW LIPID-LOWERING TREATMENTS
}

AUGUSTO M. LAVALLE COBO', SEBASTIÁN GARCÍA ZAMORA², LUCIANO N. FALLABRINO³, RICARDO M. IGLESIAS4, JUAN J. BADIMON ${ }^{5}$

\section{RESUMEN}

Actualmente las estatinas son la piedra angular para el tratamiento de la hipercolesterolemia, logrando no solo descensos en los niveles de colesterol sino también reducir eventos cardiovasculares. En la búsqueda de alcanzar metas terapéuticas más bajas del colesterol asociado a lipoproteínas de baja densidad y de abarcar a la mayor cantidad de poblaciones de pacientes, los anticuerpos monoclonales demostraron ser una buena alternativa. En este escenario, los inhibidores de la PCSK9 se presentan como nuevas opciones terapéuticas a los fármacos utilizados para el tratamiento de las dislipidemias. La presente revisión tiene como objetivo resumir la historia, indicaciones, eficacia y seguridad de las dos nuevas moléculas de esta familia de fármacos: alirocumab y evolocumab.

Palabras clave: proproteína convertasa 9; hiperlipoproteinemia tipo II; LDL-colesterol; receptores de LDL; alirocumab; evolocumab.

\section{ABSTRACT}

Currently, statins are the cornerstone for the treatment of hypercholesterolemia, achieving not only decreases in cholesterol levels, but also reducing cardiovascular events. In the search to achieve lower therapeutic targets of cholesterol associated with low density lipoproteins (LDL), and to cover the largest number of patient populations, monoclonal antibodies proved to be a good alternative. In this scenario, the inhibitors of PCSK9 are presented as new therapeutic options to the drugs used for the treatment of dyslipidemias. The objective of this review is to summarize the history, indications, efficacy and safety of the two new molecules in this family of drugs: Alirocumab and Evolocumab.

Keywords: proprotein convertase 9; hyperlipoproteinemia type II; LDL-cholesterol; LDL receptors; alirocumab; evolocumab.

\section{REVISTA CONAREC 2018;33(145):151-157 | DOI:10.32407/RCON/2018145/0151-0157}

\section{INTRODUCCIÓN}

Según la Organización Mundial de la Salud (OMS), las enfermedades cardiovasculares son la principal causa de mortalidad a nivel global, responsables de aproximadamente un 30\% de las causas de fallecimiento'. La etiología de las mismas es multicausal, por lo que se debe contemplar el tratamiento de todos los factores involucrados, en tanto que el tratamiento de las dislipidemias resulta fundamental para lograr esto. Focalizarse en un factor de riesgo cardiovascular (hipertensión arterial, sobrepeso u obesidad, tabaquismo

1. Coordinador del Servicio de Cardiología. Sanatorio Finochietto. Secretario Técnico del Consejo de Epidemiología y Prevención cardiovascular de la Sociedad Argentina de Cardiología. Vocal de la Sociedad Argentina de Lípidos.

2. Instructor de Residentes. Servicio de Cardiología, Hospital de Alta Complejidad en Red S.A.M.I.C. "El Cruce". Presidente del CONAREC 2018.

3. Instructor de Residentes. Servicio de Cardiología del Sanatorio Trinidad Mitre. Vocal Titular del Consejo de Ateroesclerosis y Trombosis de la Sociedad Argentina de Cardiología. Presidente del CONAREC 2015.

4. Miembro Titular de la Sociedad Argentina de Cardiología. Fellow del American College of Cardiology. Presidente de la Sociedad Argentina de Cardiología 2009. Presidente de la Fundación Cardiológica Argentina 2010-2011. Presidente del CONAREC 1983.

5. Profesor de Medicina. Director del Departamento de Investigación Cardiovascular y Aterotrombosis de Mount Sinai School of Medicine, New York. Comité Revisor de la Revista CONAREC.

$\triangle$ Correspondencia: Dr. Augusto M. Lavalle Cobo. Av Córdoba 2678. CP 1187. Capital Federal, Argentina. augustolavallecobo@hotmail.com

Los autores declaran no poseer conflictos de intereses.

Recibido: 01/06/2018| Aceptado: 15/06/2018 o diabetes, entre otros) implica un reduccionismo, que difícilmente provea a nuestros pacientes el beneficio perseguido.

En la actualidad, se ha demostrado que además del control de los factores enumerados previamente, la reducción de los valores de colesterol asociado a lipoproteínas de baja densidad (cLDL) resulta un pilar fundamental para disminuir la aparición de eventos cardiovasculares. La evidencia es contundente para afirmar que a menores niveles de colesterol, y en particular del CLDL, menor incidencia de enfermedades cardiovasculares y mortalidad por esta causa.

Hoy se pueden identificar varias estrategias exitosas para lograr descensos en los niveles de cLDL. El tratamiento con estatinas, ezetimibe o la combinación de ambas drogas ha permitido controlar farmacológicamente los valores de colesterol en gran parte de la población con cifras anormalmente alta de estas variables biológicas. Sin embargo, ante la existencia del denominado "riesgo residual"en algunos pacientes, se ha promovido el desarrollo y utilización de nuevos fármacos para intentar disminuir este "riesgo", entre los que se encuentran los inhibidores de la proproteína convertasa subtilisina kexina tipo 9 (PCSK9).

Por lo expuesto anteriormente, el objetivo de la presente revisión es el análisis del camino recorrido y el porvenir de estas nuevas opciones terapéuticas.

\section{DESARROLLO}

\section{METAS TERAPÉUTICAS}

Existe una relación directamente proporcional entre los niveles de CLDL y la enfermedad aterosclerótica. Es decir, a mayor concentración sérica de $\mathrm{CLDL}$, mayor es la probabilidad de desarrollar enfermedad cardiovascular ${ }^{2}$. 
En la práctica clínica, estas observaciones han impulsado la selección de objetivos terapéuticos de valores CLDL más bajos ${ }^{2-5}$. Empero, el objetivo de $C L D L$ dependerá en última instancia del riesgo individual de cada paciente.

Las guías del Colegio Americano de Cardiólogos (ACC, por sus siglas en inglés, American College of Cardiology) y de la Asociación Americana del Corazón (AHA, por sus siglas en inglés American Heart Association) publicadas en el año 2013 recomiendan que, mediante el uso intensivo de tratamiento con estatinas se reduzca el colesterol de pacientes con alto riesgo cardiovascular en por lo menos un 50\%2. Es de destacar que, por su parte, las guías europeas y la Asociación Nacional de Lípidos (NLA) de los Estados Unidos especifican que, en prevención primaria, los objetivos de los niveles $\mathrm{CLDL}$ deben ser menores a $70 \mathrm{mg} / \mathrm{dl}$ en pacientes con alto riesgo cardiovascular y menores a $100 \mathrm{mg} / \mathrm{dl}$ en individuos con elevado riesgo ${ }^{3,4}$.

Asimismo, las guías americanas de endocrinología (American College of Endocrinology y American Association of Clinical Endocrinologists) incluyen una categoría novedosa de "riesgo cardiovascular extremo" recomendando como meta de CLDL lograr valores de menos de 55 $\mathrm{mg} / \mathrm{dl}^{5}$.

La selección de dichos valores de CLDL como objetivo terapéutico se sustenta esencialmente en los niveles alcanzados por los individuos asignados a las ramas de intervención de ensayos clínicos aleatorizados en esta temática. Sin embargo, utilizamos el verbo en potencial, ya que se trata de un tema en constante discusión y revisión. En la práctica, los valores también se ven influenciados por la congruencia entre los estudios y la relación costo-efectividad de los tratamientos. Asimismo, existe una importante variación interindividual en la respuesta a la dieta y la medicación hipolipemiante, lo que justifica además, la selección y el ajuste de una dosis de medicación adecuada para cada paciente acorde a los objetivos terapéuticos seleccionados. En los últimos años se ha generado un importante debate al sugerirse el uso de dosis fijas de estatinas para determinados grupos de riesgo independientemente del valor de CLDL alcanzado. Empero, haber podido reducir el CLDL a valores más bajos que los hasta el momento "perseguidos", y hacerlo con fármacos que tienen mecanismos de acción diferentes a las estatinas, desplazó esta discusión, centrándonos nuevamente en las "metas" a intentar alcanzar ${ }^{6}$.

Por último, pero no menos importante, merece ser destacado el reciente metanálisis de Silverman y colaboradores, quienes incluyeron ensayos clínicos aleatorizados que compararon diferentes esquemas hipolipemiantes. Se observó que por cada milimol ( $\mathrm{mmol}$ ) de reducción de $\mathrm{CLDL}(1 \mathrm{mmol}=38,7 \mathrm{mg} / \mathrm{dl}$ ), el riesgo relativo para la reducción de eventos cardiovasculares fue de 0,77 (IC95\%: 0,71-0,84; $p<0,001$ ) para las estatinas, y de 0,75 (IC95\%: $0,66-0,86 ; p=0,002$ ) para otros tratamientos hipolipemiantes (ezetimibe, secuestradores de ácidos biliares, bypass ileal y dieta). No se detectaron diferencias estadísticamente significativas entre las estatinas y las demás estrategias hipolipemiantes sobre el efecto de reducción de riesgo cardiovascular global $(p=0,74)$. Asimismo, este metaanálisis demostró la estrecha relación entre los valores de CLDL alcanzado y el riesgo de eventos cardiovasculares, tanto en prevención primaria (1,5\% menor incidencia de eventos por cada $1 \mathrm{mmol} / \mathrm{l}$ menor concentración de $\mathrm{LLL}$ alcanzado; $\mathrm{p}<0,001$ ) como en prevención secundaria (4,6\% menor incidencia de eventos por cada $1 \mathrm{mmol} / /$ menor concentración de CLDL alcanzado; $\mathrm{p}<0,001)$

Estos resultados en conjunto sustentan las diferentes estrategias para reducir el CLDL y la selección de objetivos terapéuticos como elementos útiles en la toma de decisión para mejorar la atención de nuestros pacientes. Así, independientemente del fármaco utilizado, los niveles de CLDL alcanzados están íntimamente relacionados al riesgo de desarrollar enfermedad cardiovascular.

Ahora bien, ha quedado claro que la reducción del cLDL mediante el uso de estatinas tiene una relación directa con la baja en la mortalidad por enfermedad cardiovascular, y la disminución de la ocurrencia de eventos cardiovasculares en general ${ }^{7}$. Sin embargo, algunos pacientes no logran alcanzar niveles adecuados de reducción del cLDL utilizando estatinas, o son intolerantes a las mismas, y por ende reciben dosis insuficientes o directamente no las reciben, por lo que se encuentran expuestos a un elevado riesgo de sufrir eventos cardiovasculares ${ }^{3,6}$.

Para este grupo de pacientes, se debe considerar dos posibilidades: un tratamiento combinado entre estatinas y otro fármaco, y/o un tratamiento alternativo a las estatinas. Entre las terapias no estatínicas, actualmente disponemos de ezetimibe, secuestrantes de ácido biliar el ácido nicotínico (niacina) y los fibratos ${ }^{3,4,6-11}$

El estudio IMPROVE-IT demostró que la terapia combinada de estatinas con ezetimibe redujo el cLDL en mayor medida a que el alcanzado con estatinas como monoterapia, lo cual implicó también una reducción de eventos cardiovasculares ${ }^{12}$. Sin embargo, estudios clínicos que evaluaron el rol de la niacina (AIM-HIGH y HPS2-THRIVE) y los fibratos (ACCORD y FIELD) en pacientes de alto riesgo cardiovascular no pudieron demostrar beneficios consistentes en la reducción de eventos cardiovasculares, posiblemente debido a una menor reducción del CLDL comparado con otros fármacos ${ }^{13-17}$. Respecto al estudio ACCORD, debe tenerse presente que en base a sus resultados sería razonable el empleo de fibratos en ciertos subgrupos de pacientes, como aquellos con niveles muy bajos de colesterol asociado a lipoproteínas de alta densidad (CHDL), y/o muy altos niveles de triglicéridos.

Recientemente, se comenzó a prestar especial atención a los anticuerpos monoclonales que inhiben la producción de PCSK9, al presentarse como opciones terapéuticas para el manejo de los desórdenes lipídicos.

\section{HISTORIA DEL USO TERAPÉUTICO DE LOS ANTICUERPOS MONOCLONALES}

La utilización terapéutica de anticuerpos ha ido evolucionando a través del tiempo. Hace más de 100 años, Hoechst fue el primero en introducir un tratamiento inmunobiológico para la difteria. Posteriormente, con el descubrimiento de la tecnología de hibridoma por Milstein y Kohler, se observaron los mayores avances en el desarrollo de los anticuerpos monoclonales terapéuticos (mAb) disponibles en la actualidad ${ }^{18}$

Algunos años más tarde, Genentech y Eli Lilly elaboraron el primer mAb terapéutico recombinante (insulina humana: Humulin) aprobada en 1982, la cual fue seguida rápidamente por una amplia 
gama de mAbs para uso en diferentes áreas terapéuticas, incluyendo oncología, hematología, reumatología y cardiología ${ }^{18}$.

A raíz del desarrollo en la ingeniería de anticuerpos en biología molecular a principios de la década del 90, los mAbs fueron evolucionando desde los primeros quiméricos a los humanizados, para llegar finalmente a los completamente humanos, que son los disponibles en la actualidad ${ }^{19}$.

Desde la comercialización del primer mAb terapéutico, esta clase de productos biofarmacéuticos ha crecido significativamente y, con la tasa de aprobación actual (alrededor de 4 nuevos productos por año), se estima que aproximadamente 70 mAbs terapéuticos estarán disponibles para tratar diversas enfermedades en el año $2020^{18}$.

\section{MECANISMO DE ACCIÓN DE LOS INHIBIDORES DE LAS PCSK9}

La molécula de PCSK9 opera en el organismo como un regulador de los niveles circulantes de CLDL. A partir de estudios genéticos, se pudo identificar que ante determinadas mutaciones por ganancia de función en el gen de la PCSK9, los niveles de CLDL eran más elevados y prevalecía la enfermedad coronaria prematura ${ }^{17,20-21}$. Inversamente, en las mutaciones por pérdida de función de la molécula (como en el caso de ciertas poblaciones africanas), se identificaron niveles más bajos de CLDL y una reducción del riesgo de sufrir enfermedad coronaria ${ }^{22-24}$. Es más: se evidenció en pacientes sanos con una pérdida severa de la función de la PCSK9 concentraciones de CLDL tan bajas como $14 \mathrm{mg} / \mathrm{dl}^{23-25}$.

La evidencia indica que la molécula de PCSK9 regula los niveles de CLDL a través de un receptor de LDL (rLDL). Este receptor se encuentra en la superficie de las células hepáticas que se entrelazan con las partículas de LDL. Este complejo LDL-rLDL se internaliza, y luego el rLDL se recicla retornando a la superficie celular. Las moléculas secretadas de PCSK9 se unen al rLDL en la superficie del hepatocito, resultando en la internalización y subsecuente degradación del receptor por parte de lisosomas, lo que implica una disminución en el número de rLDL en la superficie celular. La inhibición de la secreción de PCSK9 implica el aumento de rLDL en la superficie celular y, por ende, se eleva el consumo de CLDL hacia el interior de la célula.

En resumidas cuentas: la inhibición de la acción de las PCSK9 ofrece una nueva opción terapéutica para disminuir los niveles de $\mathrm{CLDL}^{26}$. Las estatinas, al igual que los inhibidores de la PCSK9, aumentan el número disponible de receptores de LDL para el consumo del CLDL por parte del hígado, disminuyendo su porcentaje. Esto se debe a la inhibición inducida por estatinas de la 3-hidroxi-3-metil-glutaril CoA reductasa (HMGCR), así como a la reducción de la síntesis del colesterol, activando la proteína 2 de unión a elementos reguladores de esteroles (SREBP-2) 27 .

También se ha demostrado que la SREBP-2 desinhibe la transcripción de la PCSK928, lo que podría atenuar hasta cierto punto la disminución del CLDL por parte de las estatinas.

En definitiva, es esperable que los inhibidores de la PCSK9 aumenten la eficacia de las estatinas al utilizarlos en forma combinada.

\section{INHIBIDORES DE LA PCSK9 EN LA PRÁCTICA COTIDIANA}

A partir del año 2015, alirocumab y evolocumab han sido aprobados para su uso en humanos en Estados Unidos y Europa por sus respectivas agencias regulatorias (FDA y EMA). Se trata de dos mAb totalmente humanizados, cuya administración es en forma subcutánea, y su periodicidad de aplicación es quincenal o mensual. Su indicación terapéutica es conjunta a la dieta y al tratamiento con estatinas en máximas dosis toleradas en pacientes con hipercolesterolemia familiar heterocigota, o en enfermedad aterosclerótica que requiere una mayor reducción del cLDL 29,30 .

Evolocumab también se indica conjuntamente a la dieta y otros tratamientos hipolipemiantes (estatinas, ezetimibe, aféresis del LDL) en pacientes con hipercolesterolemia familiar homocigota que necesitan de una mayor reducción de $\mathrm{CLDL}^{30}$.

En Argentina, al momento de la publicación de la presente revisión, solo se encuentra aprobado alirocumab por la Administración Nacional de Medicamentos, Alimentos y Tecnología Médica (ANMAT) desde junio de 2017 (disposición N6924). Está disponible tanto en dosis de 75 mg y 150 mg para administración vía subcutánea y con aplicación quincenal ${ }^{31}$. Su indicación se basa en adultos con hipercolesterolemia primaria (familiar heterocigota y no familiar) o dislipidemia mixta, como tratamiento complementario a la dieta, en los siguientes escenarios clínicos:

Como combinación con una estatina, o una estatina sumada a otros tratamientos hipolipemiantes, en pacientes que con dosis máximas toleradas de estos fármacos no consiguen alcanzar sus objetivos de colesterol LDL, 0

Como monoterapia, o en combinación con otros tratamientos hipolipemiantes en pacientes con intolerancia a las estatinas, o en los que presenten contraindicaciones para el uso de estas drogas.

La aprobación de alirocumab se basó en datos del programa de estudios clínicos de fase III denominado ODYSSEY, que mostró resultados consistentes y positivos en comparación con el tratamiento estándar actual con estatinas. Por otra parte, se estima que evolocumab podría ser aprobado por ANMAT en el transcurso del presente año.

\section{EFICACIA Y SEGURIDAD DE LAS MOLÉCULAS}

Las aptitudes clínicas de alirocumab y evolocumab así como su perfil de seguridad han sido exhaustivamente medidos en sus respectivos estudios clínicos (ODYSSEY y PROFICIO, respectivamente). Sus poblaciones target fueron individuos con hipercolesterolemia (incluyendo aquellos con eventos vasculares previos), hipercolesterolemia familiar e intolerantes a estatinas ${ }^{32,33}$.

En cuanto a la eficacia de los tratamientos, debemos destacar que los comparadores fueron placebos y/o ezetimibe. En general, se requirió que los pacientes se encontraran transitando una terapia estable con estatinas, a excepción de aquellos estudios sobre los intolerantes a las mismas. Algunos análisis también permitieron el uso de terapias hipolipemiantes alternativas de base.

En casi todos los estudios vinculados al ODYSSEY se administró alirocumab de la siguiente manera: dosis de $150 \mathrm{mg}$ quincenalmente du- 
rante toda la duración del estudio, dosis inicial de 75 mg quincenalmente, con la potencialidad de subir a $150 \mathrm{mg}$ en la semana 12 en aquellos pacientes que no alcanzaron sus niveles óptimos de CLDL (en función de su riesgo cardiovascular) para la semana 8. En menor proporción, también se administró 300 mg o 150 mg de alirocumab cada 4 semanas.

En cuanto al estudio PROFICIO, la mayoría de los pacientes recibieron dosis de $140 \mathrm{mg}$ de evolocumab suministradas quincenalmente, o 420 mg una vez al mes.

\section{EFICACIA Y REDUCCIÓN DE LDL}

Tanto los estudios ODYSSEY como PROFICIO demostraron que alirocumab y evolocumab -ya sea como monoterapia o en combinación con estatinas y/u otros tratamientos hipolipemiantes- redujeron los niveles de $C L D L$ hasta un 60\%. Ambas moléculas evidenciaron ser efectivas en la reducción del $\mathrm{CLDL}$ en pacientes con hipercolesterolemia familiar heterocigota ${ }^{34-37}$, intolerantes a las estatinas ${ }^{38,39}$ e individuos con alto riesgo cardiovascular, incluyendo a quienes padecen diabetes ${ }^{40-46}$.

También se alcanzaron importantes reducciones de CLDL en pacientes con hipercolesterolemia familiar homocigota que fueron tratados con evolocumab. Se debe tener presente que la efectividad de la molécula en pacientes con hipercolesterolemia familiar homocigota se evaluó únicamente en el subgrupo de individuos que poseían suficiente actividad residual de los receptores de LDL (es decir, 2 al 25\% del consumo normal, e identificado como un defecto, no como la negatividad de la expresión de los receptores de LDL ${ }^{47}$. Se espera que en abril de 2019 se complete un estudio de fase 3 en individuos de esta población tratados con alirocumab ${ }^{48}$.

Ciertas investigaciones de alirocumab encontraron reducciones significativas de $C L D L$ en pacientes con hipercolesterolemia y diabetes tipo 1 o tipo 2 con alto riesgo cardiovascular y tratados en forma concomitante con insulina (ODYSSEY DM-INSULIN) ${ }^{49}$, como también en sujetos con diabetes tipo 2 y dislipidemia mixta con alto riesgo cardiovascular (ODYSSEY DM-DYSLIPIDEMIA) ${ }^{50}$.

Próximamente se conocerán los resultados de 2 estudios de fase 3 con evolocumab, que analizan pacientes con diabetes tipo 2 e hipercolesterolemia o dislipidemia mixta ${ }^{51}$.

\section{EFICACIA Y REDUCCIÓN DE EVENTOS CARDIOVASCULARES}

Análisis post-hoc de los estudios de fase 3 recientemente publicados, tanto con alirocumab como con evolocumab, demostraron una reducción de eventos cardiovasculares con el uso combinado de inhibidores de las PCSK9 y estatinas en pacientes con alto riesgo cardiovascular.

Uno de los análisis posteriores al ODYSSEY LONG TERM (con un seguimiento de 18 meses) encontró un 48\% de reducción de los principales eventos cardiovasculares mediante el uso alirocumab versus placebo ${ }^{42}$, lo que se asoció con una disminución del $\mathrm{CLDL}$ de un promedio de $123 \mathrm{mg} / \mathrm{dl}$ a aproximadamente de $58 \mathrm{mg} / \mathrm{dl}$. Otro análisis posteriores a los estudios OSLER-1 y OSLER-2 (con un seguimiento promedio de 11,1 meses) comunicaron una reducción del 53\% de even- tos cardiovasculares (incluyendo muerte, infarto de miocardio, angina inestable que requirió hospitalización o revascularización coronaria, accidente cerebrovascular $[\mathrm{ACV}]$, ataque isquémico transitorio o insuficiencia cardíaca con requerimiento de hospitalización) mediante el uso de evolocumab versus tratamiento estándar, concordante con una reducción del cLDL de $120 \mathrm{mg} / \mathrm{dl}$ a $48 \mathrm{mg} / \mathrm{dl}^{52}$. Ninguno de estos análisis fue predefinido, debido a lo cual la interpretación de estos resultados debe hacerse con cautela.

Hallazgos recientes del estudio GLAGOV sugieren que el uso de evolocumab en combinación con estatinas en pacientes con enfermedad coronaria produciría una reducción en las placas ateroscleróticas de los sujetos asignados a la rama intervención después de 76 semanas de tratamiento ${ }^{53}$

Por su parte, el estudio FOURIER fue el primer estudio clínico publicado que evaluó la efectividad de un inhibidor de los PCSK9 (evolocumab). Incluyó 27.564 pacientes con enfermedad cardiovascular aterosclerótica clínicamente evidente, que se encontraban en tratamiento con dosis moderadas a altas de estatinas, realizando un seguimiento promedio de 2,2 años. FOURIER demostró un 15\% de reducción en la ocurrencia del punto final primario compuesto, el cual incluía muerte cardiovascular, infarto de miocardio, ACV, hospitalización por angina inestable o revascularización coronaria (9,8\% vs. 11,3\%; hazard ratio $[H R]=0.85 ;$ IC95\%: 0,79-0,92; $\mathrm{p}<0,001)^{54}$.

Si bien la reducción de eventos cardiovasculares fue menor en comparación con los análisis post-hoc de los estudios LONG TERM y OSLER, se objetivaron diferencias significativas entre los valores de $\mathrm{CLDL}$ de base y los finales. El promedio absoluto de la reducción de CLDL en FOURIER fue de $56 \mathrm{mg} / \mathrm{dl}$ en 48 semanas $^{54}$ versus $74 \mathrm{mg} / \mathrm{dl}$ a las 24 semanas en el análisis post-hoc del LONG TERM ${ }^{42}$ y $73 \mathrm{mg} / \mathrm{dl}$ a las 12 semanas en OSLER ${ }^{52}$

Teniendo en cuenta los diferentes puntos finales respecto de los cuales estas reducciones en los niveles de CLDL fueron evaluadas, y considerando que las reducciones de CLDL en ensayos clínicos de inhibidores de la PCSK9 típicamente se evidencian a partir de la semana 4 y se mantienen durante todo el estudio, esta brecha en la reducción del CLDL absoluto de casi $20 \mathrm{mg} / \mathrm{dl}$ entre FOURIER y los estudios posthoc son interesantes, sobre todo dada la reducción del riesgo cardiovascular en FOURIER.

Los metaanálisis de tratamiento del colesterol con estatinas reportaron una reducción del 22\% del riesgo relativo luego de 5 años de seguimiento por cada $1 \mathrm{mmol} / \mathrm{l}$ (39 mg/dl) de reducción del $\mathrm{CLDL}^{6}$. Teniendo en cuenta esto, que la magnitud del beneficio de evolocumab en el estudio FOURIER (con una reducción media de CLDL desde 92 a $30 \mathrm{mg} / \mathrm{dl}$ ) se posicionó en un rango esperado para la reducción de colesterol lograda. Conjuntamente con los hallazgos del estudio GLAGOV, estos resultados demuestran que los pacientes con enfermedad aterosclerótica se benefician con la reducción de CLDL por debajo de las metas actuales ${ }^{54}$

El estudio ODYSSEY OUTCOMES representó el seguimiento a largo plazo (promedio 2,8 años) de pacientes tratados con alirocumab. E mismo enroló 18.924 pacientes durante el primer año luego de sufrir un síndrome coronario agudo, los cuales se encontraban tratados con dosis altas de estatinas de alta intensidad (atorvastatina o rosuvastatina). Los resultados preliminares comunicados fueron que, al cabo de 
seguimiento, el tratamiento con evolucumab tuvo una reducción del 15\% (HR=0.85, IC95\%: 0.78-0.93) del punto final primario combinado (muerte cardiovascular, infarto de miocardio no fatal, ACV isquémico y angina inestable) $)^{55,56}$.

Con respecto a la seguridad de esta nueva familia de drogas, en el estudio FOURIER no se presentaron diferencias significativas entre los pacientes recibiendo evolocumab y aquellos asignados al grupo placebo en cuanto a la incidencia de eventos adversos relacionados con el tratamiento $(\text { TEAEs) })^{54}$.

Por otra parte, un análisis combinado de seguridad de alirocumab (el cual incluyó 14 estudios vinculados al ODYSSEY) y otro de evolocumab, que incluyó 12 estudios emparentados al PROFICIO, demostraron que la incidencia de TEAEs severos, discontinuaciones terapéuticas y muertes fueron similares entre los grupos intervención y los controles. Los efectos adversos más comunes de ambas drogas fueron nasofaringitis, reacciones en el sitio de inyección e infecciones en el tracto respiratorio superior ${ }^{57,58}$.

\section{INHIBIDORES DE PCSK9 Y SITIO DE INYECCIÓN}

En el estudio FOURIER y en los análisis combinados de seguridad, la mayor parte de las reacciones en el sitio de inyección no fueron severas $^{54}$, produciéndose estas en alrededor del 2\%. Incluso más, en comparación con los controles, los pacientes no experimentaron tasas incrementadas de toxicidad hepática o eventos musculares adversos, a pesar de que muchos se encontraban recibiendo además una terapia de base con estatinas ${ }^{57,58}$.

\section{INHIBIDORES DE PCSK9 Y EVENTOS NEUROCOGNITIVOS ADVERSOS}

Algunas publicaciones sugirieron, en años previos, que las estatinas podrían relacionarse con alteraciones cognitivas. Si bien revisiones y metaanálisis posteriores no confirmaron esto, los inhibidores de las PCSK9 fueron monitoreados específicamente para evaluar la ocurrencia de eventos neurocognitivos adversos, tales como pérdida de memoria y confusión, realizando un seguimiento similar al de los pacientes bajo tratamiento con estatinas en los ensayos clínicos ${ }^{59-65}$. Los resultados del estudio FOURIER ${ }^{54}$, el estudio EBBINGHAUS (un subestudio del FOURIER destinado específicamente a investigar esto ${ }^{66}$ y análisis combinados de seguridad de otros estudios de evolocumab y alirocumab ${ }^{57,58}$, no encontraron diferencias entre estos grupos. Empero, debido a que subgrupos de los estudios ODYSSEY LONG TERM y el OSLER ${ }^{67}$ identificaron tasas algo más elevadas de eventos neurocognitivos menores, en la actualidad se encuentra en fase de reclutamiento un estudio específicamente diseñado para evaluar el efecto del alirocumab en la función cognitiva, estimándose que sus resultados se conocerán en el año $2020^{68}$.

\section{INHIBIDORES DE PCSK9 Y DIABETES}

La terapia con estatinas se ha vinculado con un aumento del riesgo de desarrollar diabetes tipo $2^{3}$; asimismo, un reciente estudio epidemiológico sugirió que ciertas variaciones genéticas del gen de la
HMGCR, que derivan en una disminución del $C L D L$, se vincularían también con un mayor riesgo de diabetes. Este último estudio también relacionó las reducciones de CLDL a partir de las variaciones genéticas de la PCSK9 por pérdida de función, a un pequeño aumento del riesgo en desarrollar diabetes en individuos con resultados negativos de la glucosa en plasma (FPG) ${ }^{69}$.

Un estudio secundario comunicó la relación entre la pérdida de función de la PCSK9 y un riesgo incrementado de desarrollar diabetes, mayores concentraciones de glucosa en plasma, pero no de hemoglobina glicosilada $(\mathrm{HbA} 1 \mathrm{c})^{70}$. Por otra parte, datos del ODYSSEY COMBO II, el estudio combinado que reunió más de 2400 pacientes sin diabetes de base y más de 3300 individuos con diabetes o normoglucemia de base, no mostraron que esta droga presente un empeoramiento de los niveles de glucemia, evaluada mediante la medición de los niveles de HbA1c y FPG durante el seguimiento44,46,71.

En un subanálisis del PROFICIO DESCARTES, no se vieron diferencias significativas en los niveles de FPG, HbA1c, insulina, el péptido " $C$ " ni el índice de resistencia a la insulina en ningún subgrupo de evolocumab y placebo, en la semana 52 de seguimiento. Empero, el estudio GLAGOV identificó una pequeña diferencia (aunque insignificante estadísticamente) en el FPG, pero no así en la HbA1c con evolocumab a la semana 78 de tratamiento ${ }^{43,53}$.

En el mismo sentido, el estudio FOURIER no mostró diferencias significativas en el control glucémico de pacientes diabéticos de reciente diagnóstico que recibieron tratamiento con evolocumab con un seguimiento promedio de 14 meses $^{54}$. Asimismo, no se ha evidenciado en ninguno de los diferentes subanálisis alguna transición creciente de normoglucemia hacia nuevos casos de diabetes ya sea bajo tratamiento con alirocumab o evolocumab ${ }^{43,71}$.

Por lo tanto, los datos actuales no sugieren asociación entre los inhibidores de la PCSK9 y un empeoramiento en el control glucémico, al menos hasta un seguimiento de 2 años. Debido a que los anticuerpos monoclonales afectan el camino extracelular de las PCSK9 sin alterar la trayectoria intracelular ${ }^{72}$, sería esperable que estos tratamientos no tengan los mismos efectos biológicos que los individuos expuestos a niveles decrecientes de CLDL debido a variaciones genéticas de la PCSK9 ${ }^{69}$.

\section{INHIBIDORES DE PCSK9Y ANTICUERPOS}

Se han observado anticuerpos en el 5,1\% de los 3039 individuos durante el tratamiento con alirocumab en un análisis mixto de 10 estudios ODYSSEY en fase 3, en el 0,2\% de los 3946 pacientes tratados con evolocumab en un análisis mixto de 12 estudios en fase 2 y 3, y en $0,3 \%$ de los 13.784 tratados con evolocumab en FOURIER, encontrándose pendientes los resultados sobre inmunogenicidad del estudio ODYSSEY OUTCOMES con alirocumab $\mathrm{b}^{54,58,73}$.

Ahora bien, estas bajas tasas de inmunogenicidad de alirocumab y evolocumab no se han relacionado con atenuación de las reducciones de CLDL obtenidas a lo largo del tiempo, o con otros aspectos relativos a la seguridad de estos tratamientos. Si bien los niveles de inmunogenicidad parecieran ser menores con evolocumab que en alirocumab, debe tenerse presente que los resultados dependen de la sensibilidad y la especificidad los diferentes kit disponibles para su 
detección, factores relacionados con la manipulación y frecuencia de la recolección de las muestras, y el uso concomitante de otros fármacos, entre otros. Por tanto, no hay hasta el momento datos certeros respecto a las implicancias pronósticas o terapéuticas de esto, su detección no se recomienda en la práctica cotidiana ${ }^{74}$.

\section{CONCLUSIONES}

Los anticuerpos monoclonales inhibidores de las PCSK9 son actualmente opciones válidas para el tratamiento hipolipemiante de ciertas poblaciones especiales de pacientes. Tanto evolocumab y alirocumab han demostrado reducciones del CLDL en forma segura y sostenida, impactando esto en una disminución de eventos cardiovasculares. El uso de esta nueva familia de fármacos debería considerarse en pacientes que presenten características similares a aquellos enrolados en los estudios publicados, es decir, hipercolesterolemia familiar tanto homocigota como heterocigota, y pacientes de muy alto riesgo cardiovascular que hayan sufrido un evento reciente.

Es esperable que en años venideros debamos discutir su efectividad y eficacia en nuevas poblaciones.

\section{BIBLIOGRAFÍA}

1. Organización Mundial de la Salud (OMS). "Enfermedades Cardiovasculares", Enero de 2015. Disponible en: http://www.who.int/mediacentre/factsheets/fs317/es/

2. Stone NJ, Robinson JG, Lichtenstein AH, Bairey Merz CN, Blum CB, Eckel RH, et al. 2013 ACC/AHA guideline on the treatment of blood cholesterol to reduce atherosclerotic cardiovascular risk in adults: a report of the American College of Cardiology/American Heart Association Task Force on Practice Guidelines. J Am Coll Cardiol 2014:63(25):2889-2934.

3. Bays HE, Jones PH, Orringer CE, Brown WV, Jacobson TA. National Lipid Associa tion Annual Summary of Clinical Lipidology 2016. J Clin Lipidol 2016;10(1):S1-43.

4. Catapano AL, Graham I, De Backer G, Wiklund O, Chapman MJ, Drexel H, et al 2016 ESC/EAS Guidelines for the Management of Dyslipidaemias. Eur Heart $J$ 2016:37(39):2999-3058.

5. Jellinger PS, Handelsman $Y$, Rosenblit PD, Bloomgarden ZT, Fonseca VA, Garber AJ, et al. American Association of Clinical Endocrinologists and American College of Endocrinology Guidelines for Management of Dyslipidemia and Prevention of Cardiovascular Disease. Endocr Pract 2017:23(2):1-87.

6. Lloyd-Jones DM, Morris PB, Ballantyne CM, Birtcher KK, Daly DD Jr, DePalma SMe al. 2016 ACC Expert Consensus Decision Pathway on the Role of Non-Statin Therapies for LDL-Cholesterol Lowering in the Management of Atherosclerotic Cardiovascular Disease Risk: A Report of the American College of Cardiology Task Force on Clinical Expert Consensus Documents. J Am Coll Cardiol 2016;68(1):92-125.

7. Cholesterol Treatment Trialists Collaboration, Baigent C, Blackwell L, Emberson $J$, Holland LE, Reith C, et al. Efficacy and safety of more intensive lowering of $L D L$ cholesterol: a meta-analysis of data from 170,000 participants in 26 randomised trials. Lancet 2010;376(9753):1670-1681.

8. Gidding SS, Champagne MA, de Ferranti SD, Defesche J, Ito MK, Knowles JW, et al. The Agenda for Familial Hypercholesterolemia: A Scientific Statement From the American Heart Association. Circulation 2015;132(22):2167-2192.

9. Jacobson TA, Maki KC, Orringer CE, Jones PH, Kris-Etherton P, Sikand G, et al. Na tional Lipid Association Recommendations for Patient-Centered Management of Dyslipidemia: Part 2. J Clin Lipidol 2015;9(6):S1-122.

10. Orringer CE, Jacobson TA, Saseen JJ, Brown AS, Gotto AM, Ross JL, et al. Update on the use of PCSK9 inhibitors in adults: Recommendations from an Expert Panel of the National Lipid Association. J Clin Lipidol 2017;11(4):880-890.

11. Landmesser U, John Chapman M, Farnier M, Gencer B, Gielen S, Hovingh GK, et al. European Society of Cardiology/European Atherosclerosis Society Task Force consensus statement on proprotein convertase subtilisin/kexin type 9 inhibitors: practical guidance for use in patients at very high cardiovascular risk. Eur Heart $\rfloor$ 2017;38(29):2245-2255.

12. Cannon CP, Blazing MA, Giugliano RP, McCagg A, White JA, Theroux P, et al. Ezetimibe Added to Statin Therapy after Acute Coronary Syndromes. N Engl J Med 2015;372(25):2387-2397.

13. AIM-HIGH Investigators, Boden WE, Probstfield $J L$, Anderson T, Chaitman BR, Desvignes-Nickens $P$, et al. Niacin in patients with low HDL cholesterol levels receiving intensive statin therapy. N Engl J Med 2011;365(24):2255-2267.

14. ACCORD Study Group, Ginsberg HN, Elam MB, Lovato LC, Crouse JR 3rd, Leiter LA, et al. Effects of combination lipid therapy in type 2 diabetes mellitus. N Engl J Med 2010;362(17):1563-1574.

15. HPS2-THRIVE Collaborative Group, Landray MJ, Haynes R, Hopewell JC, Parish S, Aung $T$, et al. Effects of extended-release niacin with laropiprant in high-risk patients. N Engl J Med 2014;371(3):203-212

16. Keech A, Simes RJ, Barter P, Best J, Scott R, Taskinen MR, et al. Effects of longterm fenofibrate therapy on cardiovascular events in 9795 people with type 2 diabetes mellitus (the FIELD study): randomised controlled trial. Lancet 2005;366(9500):1849-1861.
17. Abifadel M, Elbitar S, El Khoury P, Ghaleb Y, Chémaly M, Moussalli ML, et al. Living the PCSK9 adventure: from the identification of a new gene in familial hypercholesterolemia towards a potential new class of anticholesterol drugs. Curr Atheroscler Rep 2014;16(9):439.

18. Zhiqiang A. Therapeutic monoclonal antibodies. From Bench to clinic. Primera edición. Hoboken: Editorial Whiley. 2010.

19. Foltz IN, Karow M, Wasserman SM, et al. Evolution and emergence of therapeutic monoclonal antibodies: what cardiologists need to know. Circulation 2013;127(22):2222-2230.

20. Abifadel M, Varret M, Rabès JP, Allard D, Ouquerram K, Devillers M, et al. Mutations in PCSK9 cause autosomal dominant hypercholesterolemia. Nat Genet 2003;34(2):154-156.

21. Kotowski IK, Pertsemlidis A, Luke A, Cooper RS, Vega GL, Cohen JC, et al. A spectrum of PCSK9 alleles contributes to plasma levels of low-density lipoprotein cholesterol. Am J Hum Genet 2006;78(3):410-422.

22. Cohen J, Pertsemlidis A, Kotowski IK, Graham R, Garcia CK, Hobbs HH. Low LDL cholesterol in individuals of African descent resulting from frequent nonsense mutations in PCSK9. Nat Genet 2005;37(2):161-165.

23. Zhao Z, Tuakli-Wosornu Y, Lagace TA, Kinch L, Grishin NV, Horton JD, et al. Molec ular characterization of loss-of-function mutations in PCSK9 and identification of a compound heterozygote. Am J Hum Genet 2006;79(3):514-523.

24. Langsted A, Nordestgaard BG, Benn M, Tybjærg-Hansen A, Kamstrup PR. PCSKO R46L Loss-of-Function Mutation Reduces Lipoprotein (a), LDL Cholesterol, and Risk of Aortic Valve Stenosis. J Clin Endocrinol Metab 2016;101(9):3281-3287.

25. Hooper AJ, Marais AD, Tanyanyiwa DM, Burnett JR. The C679X mutation in PCSKS is present and lowers blood cholesterol in a Southern African population. Atherosclerosis 2007;193(2):445-448.

26. Seidah NG, Awan Z, Chretien M, Mbikay M. PCSK9: a key modulator of cardiovas cular health. Circ Res 2014;114(6):1022-1036.

27. Goldstein JL, Brown MS. The LDL receptor. Arterioscler Thromb Vasc Biol 2009;29(4):431-438.

28. Jeong HJ, Lee HS, Kim KS, Kim YK, Yoon D, Park SW. Sterol-dependent regulation of proprotein convertase subtilisin/kexin type 9 expression by sterol-regulatory element binding protein-2. J Lipid Res 2008;49(2):399-409

29. Sanofi-aventis U.S. LLC. Highlights of PRALUENT prescribing information [Consuttado el 1/1/2018]. Disponible en: http://products.sanofi.us/praluent/praluent.pdf.

30. Amgen Inc. Highlights of Repatha prescribing information [Consultado el 1/12/2017]. Disponible en: https://pi.amgen.com/ /media/amgen/repositorysites/pi-amgen-com/repatha/repatha_pi_hcp_english.pdf

31. A.N.M.A.T., Disposición no 6924. Disponible en: http://www.anmat.gov.ar/boletin anmat/junio 2017/Dispo 6924-17pdf

32. Raal FJ, Hovingh GK, Blom D, Santos RD, Harada-Shiba M, Bruckert E, et al. Long-term treatment with evolocumab added to conventional drug therapy, with or without apheresis, in patients with homozygous familial hypercholesterolaemia: an interim subset analysis of the open-label TAUSSIG study. Lancet Diabetes Endocrinol 2017;5(4):280-290.

33. Moriarty PM, Parhofer KG, Babirak SP, Cornier MA, Duell PB, Hohenstein B, et al. Alirocumab in patients with heterozygous familial hypercholesterolaemia undergoing lipoprotein apheresis: the ODYSSEY ESCAPE trial. Eur Heart $J$ 2016;37(48):3588-3595.

34. Kastelein JJ, Ginsberg HN Langslet G, Hovingh GK Ceska R, Dufour R et al ODYS SEY FH I and FH II: 78 week results with alirocumab treatment in 735 patients with heterozygous familial hypercholesterolaemia. Eur Heart J 2015;36(43):2996-3003.

35. Ginsberg HN, Rader DJ, Raal FJ, et al. Efficacy and Safety of Alirocumab in Patients with Heterozygous Familial Hypercholesterolemia and LDL-C of $160 \mathrm{mg} / \mathrm{dl}$ or Higher. Cardiovasc Drugs Ther 2016;30:473-483. 
36. Raal FJ, Stein EA, Dufour R, Turner T, Civeira F, Burgess L, et al. PCSK9 inhibition with evolocumab (AMG 145) in heterozygous familial hypercholesterolaemia (RUTHERFORD-2): a randomised, double-blind, placebo-controlled trial. Lancet 2015:385(9965):331-340.

37. Kastelein JJ, Hovingh GK, Langslet G, Baccara-Dinet MT, Gipe DA, Chaudhari U, et al. Efficacy and safety of the proprotein convertase subtilisin/kexin type 9 monoclonal antibody alirocumab vs placebo in patients with heterozygous familial hypercholesterolemia. J Clin Lipidol 2017;11(1):195-203.

38. Stroes E, Colquhoun D, Sullivan D, Civeira F, Rosenson RS, Watts GF, et al. Anti-PCSK9 antibody effectively lowers cholesterol in patients with statin intolerance: the GAUSS-2 randomized, placebo-controlled phase 3 clinical trial of evolocumab. $J$ Am Coll Cardiol. 2014;63(23):2541-2548.

39. Moriarty PM, Thompson PD, Cannon CP, Guyton JR, Bergeron J, Zieve FJ, et al. Efficacy and safety of alirocumab vs ezetimibe in statin-intolerant patients, with a statin rechallenge arm: The ODYSSEY ALTERNATIVE randomized trial. J Clin Lipidol 2015:9(6):758-769.

40. Cannon CP, Cariou B, Blom D, McKenney JM, Lorenzato C, Pordy R, et al. Efficacy and safety of alirocumab in high cardiovascular risk patients with inadequately controlled hypercholesterolaemia on maximally tolerated doses of statins: the ODYSSEY COMBO II randomized controlled trial. Eur Heart J 2015;36(19):1186-1194.

41. Kereiakes DJ, Robinson JG, Cannon CP, Lorenzato C, Pordy R, Chaudhari U, et al. Efficacy and safety of the proprotein convertase subtilisin/kexin type 9 inhibitor alirocumab among high cardiovascular risk patients on maximally tolerated statin therapy: The ODYSSEY COMBO I study. Am Heart J 2015;169(6):906-915.

42. Robinson JG, Farnier M, KrempfM, Bergeron J, LuC G, Averna M, et al. Efficacy and safety of alirocumab in reducing lipids and cardiovascular events. N Engl J Med 2015;372(16):1489-1499.

43. Blom DJ, Koren MJ, Roth E, Monsalvo ML, Djedjos CS, Nelson P, et al. Evaluation of the efficacy, safety and glycaemic effects of evolocumab (AMG 145) in hypercholesterolaemic patients stratified by glycaemic status and metabolic syndrome. Diabetes Obes Metab 2017:19(1):98-107.

44. Leiter LA, Müller-Wieland D, Baccara-Dinet MT, Letierce A, Samuel R, Cariou B. Efficacy and safety of alirocumab in people with prediabetes vs those with normoglycaemia at baseline: a pooled analysis of 10 phase III ODYSSEY clinical trials. Diabet Med 2018:35(1):121-130.

45. Sattar N, Preiss D, Robinson JG, Djedjos CS, Elliott M, Somaratne R, et al. Lipid-lowering efficacy of the PCSK9 inhibitor evolocumab (AMG 145) in patients with type 2 diabetes: a meta-analysis of individual patient data. Lancet Diabetes Endocrinol 2016;4(5):403-410.

46. Leiter LA, Zamorano JL, Bujas-Bobanovic M, Louie MJ, Lecorps G, Cannon CP, et al. Lipid-lowering efficacy and safety of alirocumab in patients with or without diabe tes: A sub-analysis of ODYSSEY COMBO II. Diabetes Obes Metab 2017;19(7):989-996.

47. Raal FJ, Honarpour N, Blom DJ, Hovingh GK, XU F, Scott R, et al. Inhibition of PCSKS with evolocumab in homozygous familial hypercholesterolaemia (TESLA Part B): a randomised, double-blind, placebo-controlled trial. Lancet 2015;385(9965):341-350.

48. U.S. National Library of Medicine: "Study in Participants $\geq 12$ Years of Age With Homozygous Familial Hypercholesterolemia (hoFH)." Disponible en: https://clinicaltrials.gov/ct2/show/NCT03156621

49. Leiter LA, Cariou B, Müller-Wieland D, Colhoun HM, Del Prato S, Tinahones FJ, et al. Efficacy and safety of alirocumab in insulin-treated individuals with type 1 or type 2 diabetes and high cardiovascular risk: The ODYSSEY DM-INSULIN randomized trial. Diabetes Obes Metab 2017;19(12):1781-1792.

50. Müller-Wieland D, Leiter LA, Cariou B, Letierce A, Colhoun HM, Del Prato S, et al. Design and rationale of the ODYSSEY DM-DYSLIPIDEMIA trial: lipid-lowering efficacy and safety of alirocumab in individuals with type 2 diabetes and mixed dyslipidaemia at high cardiovascular risk. Cardiovasc Diabetol 2017;16(1):70.

51. U.S. National Library of Medicine: "A Study in Subjects With Type 2 Diabetes Mellitus With Hypercholesterolemia/Mixed Dyslipidemia" y "A Double-blind, Randomized Study in Diabetic Subjects With Hyperlipidemia or Mixed Dyslipidemia" Disponibles en: https://clinicaltrials.gov/ct2/show/NCT02739984 yhttps://clinicaltrials.gov/ct2/show/NCT02662569

52. Sabatine MS, Giugliano RP, Wiviott SD, Raal FJ, Blom DJ, Robinson J, et al. Efficacy and safety of evolocumab in reducing lipids and cardiovascular events. N Engl J Med 2015;372(16):1500-1509.

53. Nicholls SJ, Puri R, Anderson T, Ballantyne CM, Cho L, Kastelein JJ, et al. Effect of Evolocumab on Progression of Coronary Disease in Statin-Treated Patients: The GLAGOV Randomized Clinical Trial. JAMA 2016;316(22):2373-2384.
54. Sabatine MS, Giugliano RP, Keech AC, Honarpour N, Wiviott SD, Murphy SA, et al. Evolocumab and Clinical Outcomes in Patients with Cardiovascular Disease. N Engl J Med 2017;376(18):1713-1722.

55. Schwartz GG, Bessac L, Berdan LG, Bhatt DL, Bittner V, Diaz R, et al. Effect of alirocumab, a monoclonal antibody to PCSK9, on long-term cardiovascular outcomes following acute coronary syndromes: rationale and design of the ODYSSEY outcomes trial. Am Heart J 2014;168(5):682-689.

56. U.S. National Library of Medicine, "ODYSSEY Outcomes: Evaluation of Cardiovascular Outcomes After an Acute Coronary Syndrome During Treatment With Alirocumab", Disponible en: https://clinicaltrials.gov/ct2/show/ NCT01663402

57. Jones PH, Bays HE, Chaudhari U, Pordy R, Lorenzato C, Miller K, et al. Safety of Alirocumab (A PCSK9 Monoclonal Antibody) from 14 Randomized Trials. Am J Cardiol 2016;118(12):1805-1811.

58. Toth PP, Descamps O, Genest J, Sattar N, Preiss D, Dent R, et al. Pooled Safety Analysis of Evolocumab in Over 6000 Patients From Double-Blind and Open-Label Extension Studies. Circulation 2017;135(19):1819-1831.

59. US Food and Drug Administration. FDA Drug Safety Communication: Import ant safety label changes to cholesterol-lowering statin drugs 2012 [Consultado el 18/7/2017]. Disponible en: http://www.fda.gov/Drugs/DrugSafety/ ucm293101.htm.

60. Collins R, Reith C, Emberson J, Armitage J, Baigent C, Blackwell L et al. Interpretation of the evidence for the efficacy and safety of statin therapy. Lancet 2016;388(10059):2532-2561.

61. Everett BM, Mora S, Glynn RJ, MacFadyen J, Ridker PM, et al. Safety profile of subjects treated to very low low-density lipoprotein cholesterol levels $(<30 \mathrm{mg} / \mathrm{dl})$ with rosuvastatin $20 \mathrm{mg}$ daily (from JUPITER). Am J Cardiol 2014;114(11):16821689.

62. Ott BR, Daiello LA, Dahabreh IJ, Springate BA, Bixby K, Murali M, et al. Do statins impair cognition? A systematic review and meta-analysis of randomized controlled trials. J Gen Intern Med 2015;30(3):348-358.

63. Richardson K, Schoen M, French B, Umscheid CA, Mitchell MD, Arnold SE, et al. Statins and cognitive function: a systematic review. Ann Intern Med 2013;159(10):688-697.

64. Shepherd J, Blauw GJ, Murphy MB, Bollen EL, Buckley BM, Cobbe SM, et al. Pravastatin in elderly individuals at risk of vascular disease (PROSPER): a randomised controlled trial. The Lancet 2002;360(9346):1623-1630.

65. Swiger KJ, Manalac RJ, Blumenthal RS, Blaha MJ, Martin SS, et al. Statins and cognition: a systematic review and meta-analysis of short-and long-term cognitive effects. Mayo Clin Pro. 2013;88(11):1213-1221.

66. Giugliano RP, Mach F, Zavitz K, Kurtz C, Im K, Kanevsky E, et al. Cognitive Function in a Randomized Trial of Evolocumab.N Engl J Med 2017;377(7):633-643.

67. Khan AR, Bavishi C, Riaz H, Farid TA, Khan S, Atlas M, et al. Increased Risk of Adverse Neurocognitive Outcomes With Proprotein Convertase Subtilisin-Kexin Type 9 Inhibitors. Circ Cardiovasc Qual Outcomes 2017;10(1):e003153.

68. U.S. National Library of Medicine, "Evaluating Effect of the Study Drug Praluent (Alirocumab) on Neurocognitive Function When Compared to Placebo". Disponible en: https://clinicaltrials.gov/ct2/show/NCT02957682

69. Ference BA, Robinson JG, Brook RD, Catapano AL, Chapman MJ, Neff DR, et al. Variation in PCSK9 and HMGCR and Risk of Cardiovascular Disease and Diabetes. N Engl J Med 2016;375(22):2144-2153

70. Schmidt AF, Swerdlow DI, Holmes MV, Patel RS, Fairhurst-Hunter Z, Lyall DM, et al. PCSK9 genetic variants and risk of type 2 diabetes: a mendelian randomisation study. Lancet Diabetes Endocrinol 2017;5(2):97-105.

71. Colhoun HM, Ginsberg HN, Robinson JG, Leiter LA, Müller-Wieland D, Henry RR, et al. No effect of PCSK9 inhibitor alirocumab on the incidence of diabetes in a pooled analysis from 10 ODYSSEY Phase 3 studies. Eur Heart $J$ 2016;37(39):2981-2989

72. Cariou B, Si-Tayeb K, Le May C. Role of PCSK9 beyond liver involvement. Curr Opin Lipidol 2015;26(3):155-161.

73. Roth EM, Goldberg AC, Catapano AL, Torri A, Yancopoulos GD, Stahl N, et al. Antidrug Antibodies in Patients Treated with Alirocumab. N Engl J Med 2017;376(16):1589-1590.

74. US Food and Drug Administration. Assay Development and Validation for Immunogenicity Testing of Therapeutic Protein Products. Guidance for Industry 2016. [Consultado el 17/11/2017]. Disponible en: http://www.fda.gov/downloads/ Drugs/.../Guidances/UCM192750.pdf. 


\section{Magnefen}

El fenofibrato más ventajoso en dislipemia aterogénica

- El fenofibrato de colina se disocia a su forma activa, ácido fenofíbrico, en el tubo digestivo

- El ácido fenofíbrico no requiere metabolismo de primer paso hepático para su activación

- El ácido fenofíbrico tiene mayor biodisponibilidad plasmática que el fenofibrato

- Tratamiento de elección en dislipemia mixta e hipertrigliceridemia severa

- Efectivo co-administrado con estatinas

- Óptima tolerabilidad en monoterapia como en combinación

- Puede administrarse con o sin alimentos

\section{INDICACIONES}
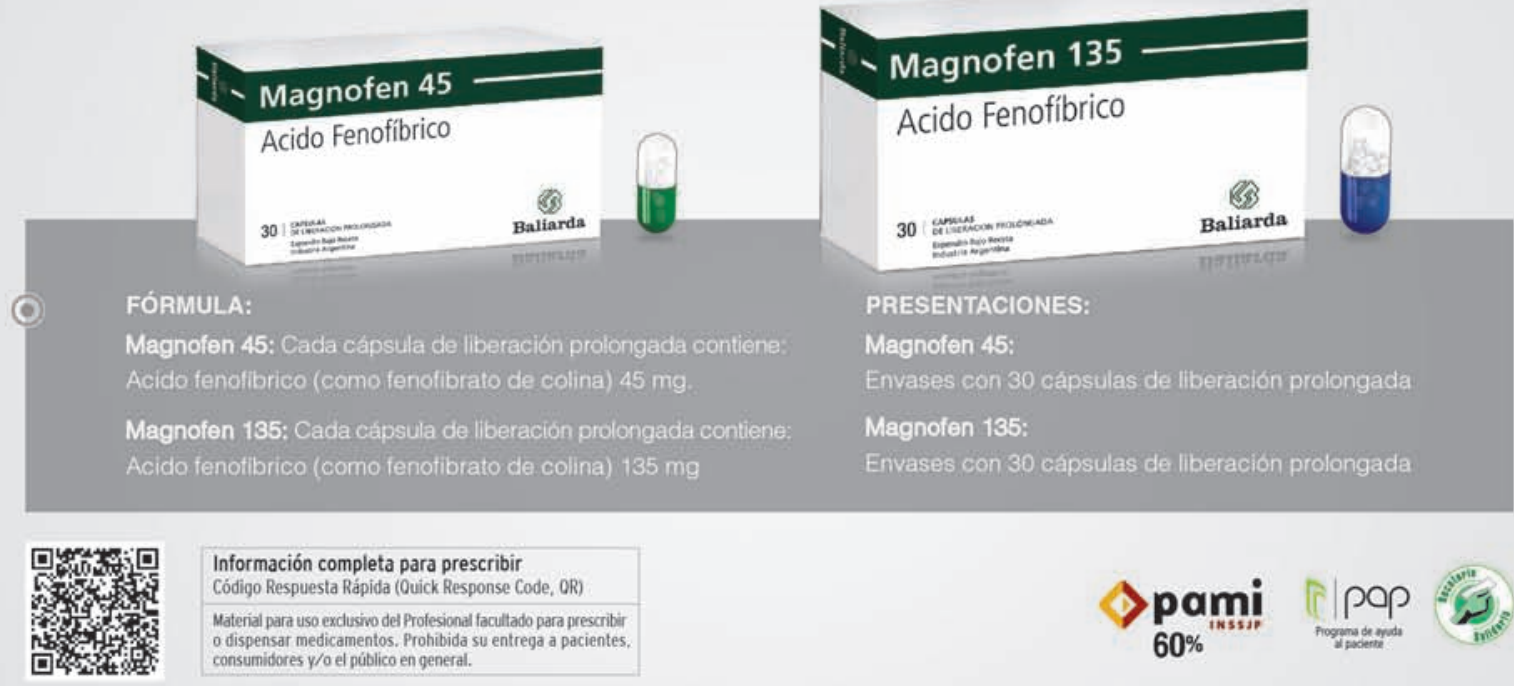
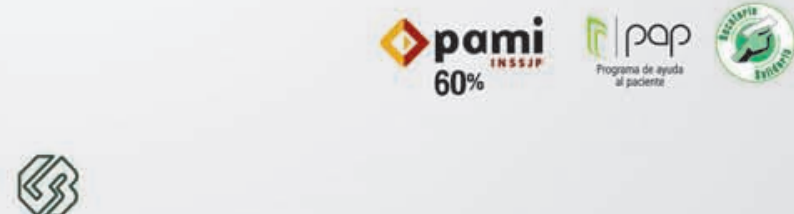

Baliarda

Vida con salud

www.baliarda.com.ar 


\title{
INTUBACIÓN Y MANEJO VENTILATORIO DEL PACIENTE CON CARDIOPATÍA AGUDA
}

\author{
INTUBATION AND VENTILATORY MANAGEMENT OF PATIENTS \\ WITH ACUTE HEART FAILURE
}

\author{
HERNÁN E. NÚÑEZ', LAURA BUIRA²
}

\section{RESUMEN}

Una de las formas de presentación más frecuentes de la insuficiencia cardíaca corresponde a la disnea, generalmente con hipoxemia. Resulta de capital importancia realizar un tratamiento rápido de sostén vital a fin de corregirla. Esto se puede lograr con oxigenoterapia, aunque es muy frecuente que además de esta los pacientes requieran asistencia ventilatoria mecánica, ya sea de forma invasiva como no invasiva.

El manejo apropiado de la vía aérea, la elección de la estrategia ventilatoria, así como las drogas a utilizar para sedoanalgesia en pacientes con falla cardíaca conducirán a obtener mejores resultados.

La siguiente revisión se enfocará en la asistencia ventilatoria mecánica invasiva en pacientes con enfermedad cardíaca aguda.

Palabras clave: edema pulmonar; insuficiencia cardíaca; respiración artificial; intubación.

\section{ABSTRACT}

One of the most frequent forms of presentation of heart failure corresponds to dyspnea, usually with hypoxemia. Itis of paramount importance to perform a rapid life support treatment in order to correct it. This can be achieved with oxygen therapy, although it is very common that in addition, these patients may require mechanical ventilation, either invasive or non-invasive. The appropriate management of the airway, the ventilation strategy, as well as the drugs for sedoanalgesia in patients with heart failure lead to the better results.

The following review will focus on invasive mechanical ventilatory assistance in patients with acute heart disease.

Keywords: pulmonary edema; heart failure; artificial respiration; intubation.

REVISTA CONAREC 2018;33(145):159-164 | DOI:10.32407/RCON/2018145/0159-0164

\section{INTRODUCCIÓN}

La falla cardiaca aguda se considera una patología que cursa con descompensación rápida del estado general del paciente y que se pone de manifiesto a través de la aparición de síntomas graves que requieren hospitalización. En esta circunstancia puede verse comprometido seriamente el aporte de oxígeno. En respuesta a esta hipoxemia se deben tomar medidas de sostén vital en forma rápida, como el uso de oxigenoterapia, drogas inotrópicas o vasopresoras y diuréticos. A pesar de estas intervenciones terapéuticas, la utilización del soporte ventilatorio mecánico es casi inevitable en la mayoría de las situaciones.

La disfunción ventricular aguda es una de las causas de indicación de asistencia ventilatoria mecánica (AVM) en pacientes hospitalizados. Las patologías cardiológicas más frecuentes asociadas

1. Médico Especialista en Terapia Intensiva. Médico interno de la UTI Hospital Juan A. Fernández CABA. Coordinador de Terapia Intensiva Sanatorio San Lucas, San Isidro, Buenos Aires. Coordinador UTI respiratoria Clínica Altergarten CABA. Instructor FCCS - SATl (Sociedad Argentina de Terapia Intensiva).

2. Médica Especialista en Terapia Intensiva. Médica de planta Sanatorio Suizo Argentino. Médica UTI Hospital Juan A. Fernández CABA. Jefa de trabajos prácticos del Departamento de docencia la SATI.

$\triangle$ Correspondencia:Dr. Hernán E.Núñez.Cerviño 3356, C1425.CABA. henunez@ gmail.com,

Los autores declaran no poseer conflictos de intereses.

Recibido: 02/04/2018 | Aceptado: 01/06/2018 a AVM son: edema agudo pulmonar (EAP), cardiopatía isquémico/ necrótica y posoperatorio de cirugía cardíaca central.

Los efectos cardiovasculares de la AVM en pacientes graves requieren un adecuado conocimiento para que las variables de la ventilación mecánica puedan ajustarse acorde a cada padecimiento y finalmente la desvinculación de la AVM se lleve a cabo cuando la causa que motivó la intubación esté resuelta.

Hay varios registros hospitalarios de falla cardíaca aguda en el mundo, como ADHERE (Acute Decompensated Heart Failure National Registry) y el Euro Heart Failure Surveys I y II, los cuales muestran un elevado porcentaje de pacientes con hospitalización prolongada asociada al uso de ventilación mecánica, y con datos que evidencian una importante tasa de mortalidad ${ }^{1,2}$.

El shock cardiogénico es una emergencia médica; el manejo clínico inicial se fundamenta en la rápida implementación de medidas de sostén vital, debiéndose asegurar la vía aérea con conexión del paciente a la ventilación mecánica, y además lograr un adecuado acceso vascular, con el objetivo de mejorar la hipoxia y reducir el consumo

Tabla 1. Factores de riesgo para ventilación mecánica invasiva en paciente con edema agudo pulmonar.

Edema alveolar difuso en la radiografía de tórax Infarto agudo de miocardio

Hipercapnia severa $\mathrm{pH}<7,25$

Presión arterial sistólica $<140$ mmHg al ingreso Fracción de eyección ventricular izquierda $<30 \%$ APACHE score elevado

APACHE score: Acute Physiology And Chronic Health Evaluation 
de oxígeno de los músculos respiratorios. Asimismo se debe reducir la pre- y la poscarga ventricular para optimizar la perfusión tisular³. El adecuado manejo de la vía aérea, la estrategia ventilatoria a seguir, así como la elección de las drogas a utilizar para sedoanalgesia en pacientes con shock cardiogénico merecen particular atención.

\section{DESARROLLO}

\section{MANEJO DE VÍA AÉREA Y DROGAS PARA INTUBACIÓN OROTRAQUEAL}

Una vez tomada la decisión de proceder a la intubación, siempre se debe contar con un plan alternativo en el caso de que fracase en la intubación u ocurra alguna complicación hemodinámica. El algoritmo de vía aérea difícil debe ser conocido y seguido, y el plan alternativo debe incluir la opción de despertar al paciente.

Es fundamental la adecuada preparación del paciente ${ }^{4}$.

De ser necesario, colocar sonda nasogástrica para evitar la aspiración del contenido gástrico, considerar eventualmente la utilización antiácidos, sean inhibidores de la bomba de protones o bloqueantes del receptor de histamina 2 .

Preoxigenar al paciente al menos 3 minutos con un flujo de oxígeno no menor a $10 \mathrm{l} / \mathrm{min}$. En pacientes obesos se recomienda realizar la preoxigenación en posición semisentado (cabecera a $25^{\circ}$ ) y se puede considerar la utilización de presión positiva no invasiva (CPAP: continuous positive airway pressure $)^{5}$.

No existe una droga o combinación ideal, ya que todas producen efectos secundarios asociados a su uso. Para reducir el riesgo de inestabilidad hemodinámica y complicaciones relacionadas con la vía aérea durante la intubación, se recomienda la combinación de un hipnótico y un opiáceo. También se puede utilizar un bloqueante neuromuscular.

En general, en situaciones de emergencia las drogas más utilizadas en nuestro medio son: propofol, midazolam, fentanilo, morfina, remifentanilo. Los bloqueantes neuromusculares pueden ser despolarizantes de la placa neuromuscular (succinilcolina) o no despolarizantes (atracurio, rocuronio).

El propofol produce descenso de la presión arterial y un aumento compensatorio del gasto cardíaco y del llenado ventricular, pero no así en la frecuencia cardíaca (efecto simpaticolítico y vagotónico).

Los efectos hemodinámicos del propofol son mucho más acentuados en los pacientes deshidratados (hipovolémicos) y en ancianos, así como en pacientes con compromiso ventricular izquierdo ${ }^{6}$.

Los efectos hemodinámicos del midazolam incluyen un moderado descenso de la presión arterial media (15 al 20\% con grandes dosis), del gasto cardiaco y del volumen sistólico.

A dosis terapéuticas usadas en la clínica, los opiáceos no producen depresión miocárdica importante y no predisponen a arritmias, pero pueden producir vasodilatación periférica, disminución de las resistencias sistémicas, e inhibir los reflejos barorreceptores, dando lugar a la aparición de hipotensión ortostática. En los enfermos coronarios, 8 a 15 mg de morfina administrado por vía intravenosa, producen una disminución en el consumo de oxígeno, de la presión de fin de diástole del ventrículo izquierdo y del trabajo cardíaco, pero el efecto sobre el índice cardíaco es poco significativo.
La succinilcolina, si bien suele ser segura dado su corta vida media, puede producir arritmias severas, dolor muscular, hiperkalemia y aumento de las presiones intraoculares e intragástrica. Se ha asociado a uso de esta droga la hipertermia maligna, poco frecuente, pero potencialmente fatal, con una incidencia de 1 en 50000 adultos.

Las drogas no despolarizantes tienen la capacidad de producir efectos sobre los receptores muscarínicos y los nicotínicos situados fuera de la unión neuromuscular. El atracurio y el vecuronio no poseen efectos cardiovasculares directos aunque el rocuronio tiene efecto vagolítico. La liberación de histamina puede llevar a vasodilatación, hipotensión y taquicardia compensadora, la mayoría de estos efectos ocurren con los compuestos bencilisoquinolínicos, en especial el atracurio.

El propofol a 2,5 mg/kg proporciona buenas condiciones para la intubación. Si se lo elige, debe utilizarse un opiáceo. La dosis de remifentanilo debe ser $4 \mathrm{mg} / \mathrm{kg}$ o superior, mientras que la dosis de fentanilo debe ser 3 a 5 ug/kg; esto produce un ligero efecto hipotensor, pero no inhibe completamente la respuesta al estímulo de la laringoscopia y la intubación; en este caso se recomienda asociar un bloqueante neuromuscular, como por ejemplo succinilcolina $1,5 \mathrm{mg} / \mathrm{kg}^{7}$ o rocuronio $0,6 \mathrm{mg} / \mathrm{kg}$. El midazolam puede utilizarse $(0,2-0,4 \mathrm{mg} / \mathrm{kg})$, teniendo en cuenta su efecto hipotensor, así como el aumento de las resistencias vasculares a los 3 minutos de su inyección?

\section{EVENTOS FISIOPATOLÓGICOS COMO CONSECUENCIA DE LA VENTILACIÓN MECÁNICA}

\section{EFECTOS CARDIOVASCULARES}

Los efectos cardiovasculares de la ventilación mecánica dependen de diversas variables incluyendo función miocárdica, volumen intravascular, presión intratorácica y tono autonómico intrínseco.

La circulación sanguínea está representada por dos compartimientos, uno dentro del tórax afectado por la presión intratorácica (PIT) y otro fuera del tórax afectado por la presión atmosférica, siendo así, los cambios generados por la ventilación mecánica o el esfuerzo respiratorio espontáneo son los que influyen en el compartimiento vascular intratorácico. El retorno venoso varía con la inspiración y espiración espontánea, y la presión del retorno venoso es influenciada por el volumen intravascular efectivo y su tono muscular, resultando así una presión venosa sistémica media, que tiene gradiente dinámico con la presión venosa central debido al movimiento diafragmático y los cambios de presión pleural. Durante la inspiración espontánea se reduce la PIT, permitiendo que la sangre fluya desde la periferia hacia las grandes venas intratorácicas y el corazón (la presión transmural de la aurícula derecha disminuye, aumentando el gradiente de presiones entre las venas cavas y la propia aurícula, facilitando el flujo sanguíneo o retorno venoso). El aumento inspiratorio del retorno sanguíneo venoso incrementa el volumen de fin de diástole del ventrículo derecho (o precarga) y secundariamente su volumen sistólico. Por el contrario, durante la ventilación mecánica con presión positiva, el aumento de la presión alveolar se transmite al espacio intrapleural y a todas las estructuras intratorácicas, induciendo un efecto de compresión de los grandes vasos que da lugar a un ascenso de la presión venosa central. Esta elevación de la presión auricular derecha reduce el gradiente de presión 
Tabla 2. Factores de riesgo asociados a la necesidad de ventilación mecánica.

- Edad >60 años.

- Sexo femenino

- Mayor estadía en la UTI.

- Localización anterior del IAM en mayor proporción.

- Grado Killip IV.

- Valor pico máximo de CPK > 2000.

- Reinfarto.

- Asociación de diabetes y HTA

UTI: unidad de terapia intensiva. HTA: hipertensión arterial. IAM: infarto agudo de miocardio CPK: creatinfosfoquinasa.

existente entre las venas sistémicas y el lado derecho del corazón, y se produce una reducción del retorno venoso y un descenso de la precarga ventricular derecha. Por otra parte, los cambios en el volumen pulmonar van a generar cambios sobre los vasos pulmonares, principalmente los alveolares, haciendo que durante la inspiración, al aumentar el volumen alveolar, la sangre contenida en los capilares se vea obligada a fluir hacia delante y hacia el final de la inspiración con presión positiva; si esta presión es alta, la compresión sobre los capilares aumenta la resistencia al flujo sanguíneo con las siguientes consecuencias: 1) disminución del vaciamiento ventricular derecho y aumento de la presión auricular derecha, y 2) la mayor resistencia al flujo sanguíneo disminuye el Ilenado auricular izquierdo y, por lo tanto, el volumen de fin de diástole ventricular izquierdo. Dependiendo de la volemia, el mayor volumen ventricular derecho puede desplazar el septum hacia la izquierda restringiendo aún más el llenado ventricular izquierdo y condicionando así un efecto de menor gasto cardíaco (GC), denominado interdependencia ventricular. Todo esto se traduce en disminución del gasto cardíaco e hipotensión arterial.

Asimismo, cuando se programan valores elevados de presión positiva de fin de espiración (PEEP) para evitar el colapso alveolar y optimizar la capacidad residual pulmonar, se incrementa la PIT y se reduce la precarga. La función ventricular derecha radica principalmente en mantener un adecuado volumen diastólico final, el cual está influenciado por la distensibilidad diastólica ventricular y la presión de distensión. La distensibilidad está disminuida en un ventrículo derecho dilatado, en isquemia aguda o sobredistensión del ventrículo izquierdo. Acorde a esto la estrategia ventilatoria que logra una reducción de las presiones para optimizar el retorno venoso son: disminuir el tiempo inspiratorio (Ti), incrementar el flujo inspiratorio (F) e incrementar la presión venosa sistémica media mediante la infusión de volumen isotónicos.

La poscarga ventricular derecha se define como el estrés de la pared durante la sístole, es decir que si aumenta la presión transmural se dilata el VD y disminuye su volumen-latido, debiendo incrementarse el volumen de fin de diástole para que esto no suceda. Por otro lado, el ventrículo izquierdo (VI) está fuertemente influenciado por la PIT, alterando el Ilenado ventricular y cambiando la poscarga del VI.

En pacientes isquémicos donde las presiones de llenado ventricular están adecuadas pero reducida su función miocárdica, la utilización de PEEP al disminuir la poscarga del VI mejora la función miocárdica. Cuando los pacientes son destetados de la ventilación mecánica, la pérdida súbita de la presión intratorácica, incrementa la poscarga nuevamente, disminuye el volumen de eyección del ventrículo izquierdo y con el incremento de las demandas metabólicas, en individuos susceptibles, puede causar isquemia, precipitar el desarrollo de edema pulmonar agudo e insuficiencia respiratoria aguda.
Además de la reducción del retorno venoso y el aumento de la resistencia vascular pulmonar, la ventilación mecánica puede conducir a disfunción ventricular isquémica. El flujo arterial coronario depende de la presión de perfusión coronaria (diferencia entre la presión diastólica aórtica y la presión telediastólica ventricular izquierda). La reducción de este gradiente de presión (disminución del gasto cardiaco, hipotensión arterial, aumento de la precarga) o la compresión de los vasos coronarios, como consecuencia del aumento de la presión intratorácica, pueden causar isquemia miocárdica.

\section{EFECTOS A NIVEL RENAL Y ENDOCRINO}

En un paciente con cardiopatía aguda, la ventilación mecánica con presión positiva reduce el gasto cardíaco, el cual se compensa por aumento de la frecuencia cardíaca y por aumento en las resistencias vasculares periféricas. A nivel renal, las células yuxtaglomerulares, altamente sensibles a la caída de presión, liberan renina, que actúa a nivel hepático formando angiotensina I y esta a su vez se transforma en angiotensina II, un vasoconstrictor potente. Estos fenómenos incrementan la presión arterial aun teniendo un menor gasto cardíaco.

Asimismo, el efecto de la presión positiva intratorácica sobre la presión arterial incrementa la liberación de hormona antidiurética (HAD), inhibiendo la libre excreción de agua y disminuyendo así la diuresis. Por otro lado, existen barorreceptores en las arterias carótidas y el arco aórtico que sensan la disminución de la presión inducida por la ventilación mecánica, resultando de un descenso de los niveles de HAD.

\section{BASES DE LA VENTILACIÓN MECÁNICA}

La AVM tiene como objetivo cumplir con dos funciones básicas: soporte ventilatorio en la falla cardiaca aguda y soporte en su oxigenación.

El soporte ventilatorio reemplaza total o parcialmente la función de los músculos respiratorios, disminuyendo el trabajo respiratorio inducido por el estado hipoxémico en el paciente cardiópata. Se logra mediante la implementación de presión positiva en la vía aérea, lo que permite entregar un volumen corriente apropiado y una frecuencia respiratoria similar a lo normal. Por otro lado, el soporte de la oxigenación se alcanza con suplemento en la fracción inspirada $\left(\mathrm{FiO}_{2}\right)$ y optimizando la relación ventilación perfusión con el fin de mejorar el intercambio del oxígeno a nivel alvéolo-capilar.

A través de la ventilación con presión positiva se busca restablecer la capacidad residual funcional, perdida por colapso alveolar y evitar la fatiga muscular de pacientes hipoxémicos con cardiopatía aguda. La disnea, en los pacientes con falla cardíaca aguda, incrementa el trabajo respiratorio de los músculos inspiratorios prolongando el tiempo inspiratorio y ocasionando fatiga muscular.

Existen dos factores que pueden ocasionar efectos hemodinámicos deletéreos: la magnitud de la presión inspiratoria y la duración de la misma. Ambos factores se combinan en un parámetro denominado presión media de la vía aérea; así, mientras menor sea el valor de este parámetro, menores serán los efectos hemodinámicos. 


\section{PROGRAMACIÓN DEL VENTILADOR}

Al programar un respirador, todas las variables deben ser ajustadas de acuerdo al monitoreo de la mecánica respiratoria, los gases arteriales y el estado hemodinámico del paciente.

Modo ventilatorio: se debe elegir aquella modalidad ventilatoria que mejor se adecue a las demandas metabólicas del paciente. Esto significa que en un paciente que esté cursando una cardiopatía aguda e insuficiencia respiratoria, ya sea por un proceso isquémico coronario con descompensación hemodinámica, arritmia descompensada (por ejemplo: fibrilación auricular de alta respuesta ventricular con hipotensión arterial) o insuficiencia cardíaca que no responde a tratamiento médico no invasivo, deberá optarse por un modo ventilatorio controlado ya sea por presión o por volumen. Esto dependerá del modo que logre la mejor sincronización del paciente y el respirador artificial.

Los parámetros que deben ser establecidos en el equipo de ventilación mecánica son:

Volumen corriente (VC) o volumen tidal: en cardiópatas sin afección pulmonar se calcula de 6 a $8 \mathrm{ml} / \mathrm{kg}$ de peso ideal del paciente, pudiendo modificarse en base a la estrategia ventilatoria planteada siempre controlando que la presión meseta o plateau de la vía aérea generada por el VC no supere los $30 \mathrm{CmH}_{2} \mathrm{O}$.

Frecuencia respiratoria (FR): los pacientes con cardiopatía avanzada tienen un trabajo respiratorio incrementado, por lo tanto su programación debe ser mayor a lo habitual, es decir 18-20 respiraciones minuto. No obstante debe adecuarse la programación de este parámetro a la $\mathrm{PaCO}_{2}$ deseada, y además verificar que no haya atrapamiento aéreo mediante la curva de flujo/tiempo o la cuantificación de auto-PEEP (presión espiratoria al final de la espiración positiva). Si es necesario, debe ajustarse la dosis de sedoanalgesia con opiáceos y benzodiazepinas para lograr la mejor la adaptación del paciente a ventilador.

Flujo inspiratorio: es la velocidad a la que ingresa el volumen programado en un tiempo determinado. La utilización de un flujo inspiratorio rápido permite el suministro del volumen circulante en un tiempo más corto (menor tiempo inspiratorio), lo cual produce una reducción de la presión media de la vía aérea en los pacientes con resistencias normales. Además, un flujo alto genera un aumento de la presión pico inspiratoria, y puesto que gran parte de esta presión se dispersa en las vías aéreas de conducción y no se transmite a los espacios alveolar e intrapleural, puede dar lugar a una ventilación desigual. En contraste, el uso de un flujo inspiratorio lento disminuye la presión pico, pero provoca un aumento de la presión media al generar atrapamiento aéreo (auto-PEEP). El objetivo debe ser la utilización de un flujo inspiratorio apropiado, ni demasiado rápido ni excesivamente lento, y lo establecido en estos pacientes es de 50-60 l/min, cuidando que la relación inspiración/espiración (I:E) sea la adecuada de 1:2 a 1:4. Valores superiores a 1:1 aumentarán de forma significativa la presión media de la vía aérea, generarán atrapamiento aéreo y acentúan la afectación hemodinámica.

Fracción inspirada de oxígeno: es aquella que permita alcanzar una adecuada saturación de oxígeno ( $\mathrm{SpO}_{2}$ entre 91 a 94\%), y debe evitarse el uso de fracciones mayores al 60\%, relacionadas con efectos tóxicos y daño alveolar (estrés oxidativo a nivel celular).
Presión positiva al final de la espiración (PEEP): habitualmente se ajus ta a $5 \mathrm{CmH}_{2} \mathrm{O}$ para compensar la pérdida de volumen de las regiones pulmonares posteriores colapsadas por el decúbito. En casos como el edema agudo pulmonar, se requieren mayores niveles de PEEP. Sensibilidad inspiratoria: en pacientes con cardiopatía severa, la sensibilidad óptima es aquella que permite al paciente disparar el respirador con el menor esfuerzo posible sin que exista autodisparo y se utiliza de -0.5 a $-2 \mathrm{CmH}_{2} \mathrm{O}$ en el disparo por presión y de 1-2 I/min en el disparo por flujo.

Las alarmas también son un elemento básico en la programación del ventilador y hay que vigilar su correcta programación y funcionamiento para disminuir la posibilidad de complicaciones graves

\section{AVM EN EDEMA AGUDO DE PULMÓN}

La claudicación aguda del ventrículo izquierdo en su función de bomba produce acúmulo de líquido en el espacio intersticial y los alvéolos pulmonares, lo cual incrementa el trabajo respiratorio, compromete el adecuado intercambio de gases, resultando en fatiga respiratoria e hipoxemia. Existen alteraciones sistémicas como hipotensión arterial, oliguria, incluso anuria, acidosis metabólica, signos de hipoperfusión periférica y trastornos neurológicos (agitación o deterioro del sensorio).

En el edema agudo pulmonar la ventilación mecánica no invasiva (VNI) proporciona soporte ventilatorio parcial que no necesita de una vía aérea artificial y que mejora el intercambio gaseoso y alivia la disnea. Además la VNI disminuye el trabajo respiratorio al disminuir la carga de los músculos inspiratorios y evita su fatiga. Tanto el CPAP como el BIPAP (bilevel positive airway pressure) disminuyen el trabajo respiratorio y previenen en un gran porcentaje las intubaciones en pacientes con edema agudo. En un estudio de 100 pacientes asignados aleatoriamente a recibir oxígeno suplementario vs. CPAP (3-12 $\mathrm{cmH}_{2} \mathrm{O}$ ), con todos los pacientes sometidos a cateterización pulmonar, se encontró que el grupo de pacientes con CPAP tuvo una mejoría en la $\mathrm{PaO}_{2}$ (presión arterial de oxígeno) asociado con una disminución significativa de shunt intrapulmonar, además de un mejor índice de GC y con menor incidencia de intubación traqueal (16\% en el grupo de (PAP vs. 36\% en el grupo de oxígeno suplementario) $)^{9,10}$.

El CPAP consiste en un sistema de entrega constante de presión en la vía aérea durante la inspiración y la espiración, evitando el colapso o cierre completo de las unidades alveolares y, al incrementar la presión alveolar, esta se hace mayor que la presión de los capilares pulmonares, trayendo como consecuencia disminución en la poscarga y mejoría del gasto cardíaco.

Los ventiladores no invasivos que disponen de la modalidad BiPAP emplean ciclos de alto flujo. En respiración espontánea los pacientes inician la inspiración mediante un esfuerzo voluntario; esta inspiración es detectada por el ventilador que le aporta un flujo determinado en un tiempo dado para lograr la presión inspiratoria en la vía aérea programada (IPAP); la espiración comienza cuando la velocidad de flujo inspiratorio disminuye a un 25\% del pico flujo máximo y durante la misma se mantiene una presión positiva espiratoria (EPAP) que logra una presión alveolar suficiente para impedir la formación de atelectasias, manteniendo como resultado una capacidad residual funcional normal. El modo BIPAP es un análogo cualitativo de ventilación con presión 
soporte (PSV) más PEEP, siendo la presión de soporte el resultante de la diferencia entre IPAP y EPAP, es decir, EPAP=PEEP. Esto provoca que toda modificación del EPAP sin cambio proporcional del IPAP Ileve a un aumento o disminución de la PSV.

La PSV en el edema agudo de pulmón se considera como una ventilación parcial, iniciada por el paciente, limitada por presión y ciclado por flujo. Se inicia con el esfuerzo inspiratorio espontáneo del paciente, el respirador presuriza el circuito y suministra un flujo inspiratorio alto. La velocidad de presurización y el flujo ajustan el tiempo que tarda en alcanzar una presión meseta. Durante el resto de la inspiración se administra un flujo desacelerado, establecido por el nivel de soporte, las propiedades mecánicas del sistema respiratorio y del esfuerzo inspiratorio. Para determinar el nivel adecuado de presión inspiratoria durante la PSV se han descrito diferentes métodos. MacIntyre utilizó el máximo nivel de PSV que resultara en una condición de patrón respiratorio estable, sin fases de hiper- o hipopnea. Brochard ha recomendado observar el nivel de reclutamiento de los músculos accesorios de la inspiración, principalmente el esternocleidomastoideo, a través de la inspección y palpación ${ }^{11}$. Diversos autores concuerdan, por otro lado, en que la frecuencia respiratoria es un modo sencillo y práctico para verificar el nivel adecuado de PSV, siendo valores entre 15-25 respiraciones/min los recomendados.

El éxito de la VNI no es fácil, sobre todo en los pacientes con disnea continua, debido al edema agudo pulmonar; la colocación de la interfase debe conseguir comodidad, tolerancia y eficacia, y puede ser mascarilla nasal, oronasal, facial total y sistema Helmet. Lo más recomendado en este tipo de pacientes son las mascarillas oronasales o la facial total, ya que reciben el flujo de gas por ambos orificios naturales y el efecto presión positiva del ventilador no se pierde. Los pacientes con edema pulmonar que no respondan adecuadamente con la VNI debido a una mala interacción paciente-ventilador tendrán que ser intubados para una ventilación mecánica invasiva bajo sedación. Estos pacientes están expuestos a un mayor riesgo de neumonía y tienen una mayor mortalidad (Tabla 1).

\section{AVM EN INFARTO AGUDO DE MIOCARDIO COMPLICADO}

La cardiopatía isquémica ocasiona el mayor número de muertes cardiovasculares y, dentro de ella, el infarto agudo de miocardio (IAM) es la más frecuente.

Aunque la mayoría de los pacientes responden al tratamiento médico, otros llegan a necesitar intubación y ventilación mecánica. Los factores de riesgo asociados a la necesidad de ventilación mecánica según el estudio ARIAM se encuentran detallados en la Tabla $\mathbf{2}^{12,13}$. Otras causas de intubación fueron shock cardiogénico, edema agudo pulmonar y arritmias de difícil control.

Aquellos pacientes con IAM complicado que requieren ventilación mecánica pueden sufrir daño pulmonar e inducir o perpetuar la lesión pulmonar aguda (LPA) si no son manejados adecuadamente. Este fenómeno (lesión pulmonar asociada o inducida por el respirador o VILI) se produce tanto en pulmones sanos, como en aquellos previamente dañados. Ello quedó demostrado en los estudios publicados por el Acute Respiratory Distress Syndrome Network (ARDSnet), que evidenciaron una reducción relativa del riesgo de muerte del $22 \%$ en aquellos pacientes ventilados con una estrategia respiratoria protectora del pulmón.

Los mecanismos de producción de lesión alveolar en pacientes isquémicos bajo ventilación mecánica son ${ }^{14,15}$ :

Daño pulmonar inducido por fracciones inspiradas de oxígeno elevadas: Clásicamente se describe un efecto tóxico sobre el pulmón por el empleo de unaFiO2 elevada durante periodos prolongados de tiempo, aunque las únicas lesiones que se han podido demostrar son los fenómenos de atelectasia, con el consiguiente efecto shunt y una bronquitis hiperóxica.

Daño pulmonar inducido por presión excesiva en la vía aérea (barotrauma) y sobredistensión pulmonar (volutrauma): Ios pacientes que son ventilados con elevadas presiones alveolares (presión plateau o meseta mayor de $30 \mathrm{cmH}_{2} \mathrm{O}$ ) presentaron lesiones consistentes en un importante edema tanto perivascular como alveolar, incrementando el deterioro hemodinámico secundario al edema agudo no cardiogénico ${ }^{16}$. Por otro lado, los volúmenes pulmonares elevados incrementan la permeabilidad alveolar, por lo que se recomienda programar 8 $\mathrm{ml} / \mathrm{kg} /$ peso ideal en pacientes sin daño pulmonar y $5-7 \mathrm{ml} / \mathrm{kg} /$ peso ideal en pacientes con daño pulmonar.

Daño pulmonar inducido por bajo volumen total (atelectrauma): el repetido colapso y apertura cíclica del alvéolo genera daño pulmonar por lo que el empleo de la PEEP por encima del punto de colapso alveolar mejora la distensibilidad y evita el cizallamiento alveolar. Se recomienda utilizar niveles adecuados de PEEP para no modificar el estado hemodinámico del paciente y siempre en lo posible optimizar la precarga. Daño pulmonar inducido por factores inflamatorios (biotrauma): existen mecanismos celulares y humorales que ocasionan reacciones bioquímicas e inflamatorias que finalizan en lesión pulmonar. Esta elevada producción local de citocinas favorece una respuesta inflamatoria local y sistémica, translocación bacteriana, edema pulmonar y falla orgánica múltiple en estadios avanzados. Existe evidencia de que la ventilación protectora (bajos volúmenes y PEEP elevado) se asocia a una importante reducción en la mortalidad.

Existen otros parámetros ventilatorios que también juegan un papel importante en el desarrollo de daño pulmonar, como el flujo constante, variable que se relaciona con el incremento de sobredistensión pulmonar en las zonas no dependientes, razón que justifica el uso del flujo desacelerado. También el ciclado frecuente (>25 por min) se relaciona con mayor daño pulmonar.

La tasa de mortalidad en pacientes con IAM complicado y AVM sigue siendo alta y varía de 13,5\% al 28\% para pacientes hospitalizados en la unidad de cuidados intensivos, siendo la fracción de eyección ventricular izquierda $<40 \%$ y el shock cardiogénico predictores independientes de mortalidad después de un infarto ${ }^{17}$

\section{CONCLUSIÓN}

La falla cardíaca aguda cursa con síntomas que ponen en riesgo de vida a los pacientes, con trastornos graves en la oxigenación, que requieren un soporte vital avanzado para lograr la compensación cardiorespiratoria. La intubación orotraqueal en general es un procedimiento de urgencia en estas situaciones, sin embargo deben tomarse 
los recaudos necesarios, con una preparación adecuada del paciente y además contar con un plan alternativo ante el fallo en la intubación. La elección de los fármacos (relajantes musculares y sedoanalgesia) en dicho procedimiento y durante la ventilación mecánica requiere del conocimiento de sus efectos hemodinámicos a fin de evi- tar mayor compromiso cardiovascular del paciente. Asimismo, es de vital importancia evaluar las respuestas fisiopatológicas que ejerce la presión positiva en el paciente cardiópata, por lo que la programación del ventilador debe ajustarse acorde al monitoreo de la mecánica respiratoria, los gases arteriales y el estado hemodinámico.

\section{BIBLIOGRAFÍA}

1. Adams KF, Fonarow GC, Emerman CL, Lelemtel TH, Costanzo MR Abraham WT et al. Characteristics and outcome of patients hospitalized for heart failure in the United States: Rationale, design, and preliminary observations from the first 100 000 cases in the Acute Decompensated Heart Failure National Registry (ADHERE). Am Heart J 2005;149(2):209-16

2. Nieminen MS, Brutsaert D, Dickstein K, Drexler H, Follath F, Harjola VP, et Al. Euro HeartFailureSurvey II (EHFS II): A survey on hospitalized acute heart failure patients: Description of population. Eur Heart J 2006;27(22):2725-36.

3. Castillo Costa Y, Mauro V. Shock cardiogénico. En Sociedad Argentina de Terapia Intensiva, Terapia Intensiva (2008, cuarta edición, 574-583). Argentina: Editorial Panamericana.

4. Jensen AG, Callensen T, Hagemo JS, Hreinsson K, Lund V, Nordmark J, et al. Scandinavian clinical practice guidelines on general anaesthesia for emergency situations. Acta Anaesthesiol Scand 2010;54(8):922-50.

5. Altermatt FR, Munoz HR, Delfino AE, Cortinez LI. Preoxygenation in the obese patient: effects of position on tolerance to apnoea. Br J Anaesth 2005:95(5):706-9.

6. Stoelting RK, Hillier S. Pharmacology and Physiology in Anesthetic Practice (2005, Cuarta edición, 144). Estados Unidos: Editorial Lippincott Williams and Wilkins.

7. Cork RC, Weiss JL, Hameroff SR, Bentley J. Fentanyl preloading for rapid-sequence induction of anesthesia. Anesth Analg 1984;63(1):60-4

8. Boralessa H, Senior DF, Whitwam JG. Cardiovascular response to intubation. A comparative study of thiopentone and midazolam. Anaesthesia 1983;38(7):623-7. Levitt MA. A prospective, randomized trial of BiPAP in severe acute congestive heart failure. J Emerg Med 2001;21(4):363-9.
9. Mehta S, Jay GD, Woolard RH, Hipona RA, Connolly EM, Drinkwine JH, et al. Randomized, prospective trial of bilevel versus continuous positive airway pressure in acute pulmonary edema. Crit Care Med 1997;25(4):620-8.

10. Masip J, Betbesé AJ, Páez J, Vecilla F, Cañizares R, Padró J, et Al. Non invasive pressure support ventilation versus conventional oxygentherapy in acute cardiogenic pulmonary oedema: a randomized trial. Lancet 2000;356(9248): 2126-32.

11. Pinsky MR. The effects of mechanical ventilation on the cardiovascular system Crit Care Clin 1990;6(3):663-78

12. Marini JJ, Gattinoni L. Ventilatory management of acute respiratory distress syndrome: a consensus of two. Crit Care Med 2004;32(1):250-5.

13. Esteban A, Anzueto A, Frutos F, Alia I, Brochard L, Stewart T et al. Characteristics and outcomes in adult patients receiving mechanical ventilation. A 28-day international study. JAMA 2002:287(3):345-55.

14. Brower RG, Matthay MA, Morris A, Schoenfeld D, Thompson BT, Wheeler A, et al. The Acute Respiratory Distress Syndrome Network. Ventilation with lower tidal volumes as compared with traditional tidal volumes for acute lung injury and the acute respiratory distress syndrome. N Engl J Med 2000;342(18):1301-8.

15. Dreyfuss D, Soler P, Basset G, Saumom G. High inflation pressure pulmonary edema. Respective effects of high airway pressure, high tidal volume, and positive end-expiratory pressure. Am J Respir Crit Care Med 1988:137(5):1159-64.

16. Villalobos SJA, Montes OMA, Camacho MLA. Ventilación mecánica en pacientes con cardiopatía aguda. Rev Mex Cardiol 2011;22(2):96-107. 


\title{
INHIBICIÓN DE LOS RECEPTORES DE LA ANGIOTENSINA Y DE LA NEPRILISINA: UNA NUEVA ESPERANZA EN EL TRATAMIENTO DE LA INSUFICIENCIA CARDÍACA
}

\author{
ANGIOTENSIN RECEPTOR BLOCKER AND NEPRILYSIN INHIBITORS: \\ A NEW HOPE IN THE TREATMENT OF HEART FAILURE
}

\section{CAROLINA G. NASO'}

\section{RESUMEN}

La insuficiencia cardíaca (IC) es un trastorno progresivo frente al cual se activan sistemas reguladores, como el sistema renina-angiotensina-aldosterona (SRAA) y mecanismos contrarreguladores, como los péptidos natriuréticos. Es ya reconocido el tratamiento neurohormonal de la IC, que ha demostrado disminuir la mortalidad en dicha patología, como lo son los inhibidores del SRAA, los betabloqueantes y los antagonistas de los mineralocorticoides. Actualmente, toma importancia un nuevo grupo de fármacos que recientemente también demostró disminuir mortalidad, los inhibidores de la recaptación de neprilisina y de la angiotensina. Los péptidos natriuréticos son hormonas secretadas por el corazón que poseen propiedades pleiotrópicas protectoras del sistema cardiovascular, secretadas frente al estiramiento parietal cardíaco, y que son degradados por la neprilisina. Sobre esta base fisiopatológica, se originó un nuevo fármaco compuesto por el sacubitril (inhibidor de la degradación de la neprilisina), con el valsartán (inhibidor de los receptores de angiotensina II) que demostró disminuir la mortalidad en IC contra el enalapril. El objetivo de esta monografía es realizar una revisión exhaustiva de la fisiopatología de la IC, del SRAA y de los péptidos natriuréticos, para posteriormente presentar al fármaco sacubitril/valsartán su mecanismo de acción y evidencia actual.

Palabras clave: insuficiencia cardíaca; péptidos natriuréticos; neprilisina; valsartán.

\section{ABSTRACT}

Heart failure (HF) is a progressive disorder against which regulatory systems are activated, such as the Renin-Angiotensin-Aldosterone system (RAAS) and counterregulatory mechanisms, such as natriuretic peptides. The neurohormonal treatment of $\mathrm{HF}$ is already well-known, which has been shown to reduce mortality in this pathology, as are the RAAS inhibitors, beta-blockers and mineralocorticoid antagonists. Currently, a new group of drugs that recently also showed a decrease in mortality, the inhibitors of the reuptake of neprilysin and angiotensin, is becoming important. $\mathrm{Na}$ triuretic peptides are hormones secreted by the heart that have protective pleiotropic properties of the cardiovascular system, secreted against cardiac parietal stretch, and that are degraded by neprilysin. On this pathophysiological basis, a new drug composed of sacubitril (inhibitor of neprilysin degradation) was originated, with valsartan (inhibitor of angiotensin II receptors) that showed to decrease the mortality in $\mathrm{HF}$ against enalapril. The objective of this monograph is to carry out an exhaustive review of the pathophysiology of HF, RAAS and natriuretic peptides, to subsequently present the drug sacubitril / valsartan, its mechanism of action and current evidence.

Keywords: heart failure, natriuretic peptides, valsartan, neprilysin.

REVISTA CONAREC 2018;33(145):165-175 | DOI:10.32407/RCON/2018145/0165-0175

\section{INTRODUCCIÓN}

La insuficiencia cardíaca (IC) es un trastorno progresivo que se inicia después de un acontecimiento índice capaz de reducir el inotropismo cardíaco. En la mayoría de los casos los pacientes inicialmente se mantienen asintomáticos u oligosintomáticos gracias a la puesta en juego de mecanismos compensadores como el sistema neurohormonal (sistema nervioso autónomo, sistema renina-angiotensina-aldosterona -SRAA-, vasopresina), sosteniendo en límites fisiológicos las funciones del corazón, de manera de preservar la homeostasis cardiovascular del paciente en las primeras etapas de esta patología'.

En etapas avanzadas, la activación sostenida de los sistemas neurohormonales lleva al remodelado del ventrículo izquierdo, generando el cuadro clínico florido de IC. A partir de esta pérdida de compensación, la progresión de la enfermedad sigue un curso independiente y defini-

1. Residente de Cardiología, Hospital Ramos Mejía.

$\triangle$ Correspondencia:Dra. Carolina Giselle Naso. Avenida Chivilcoy 4406 CP 1419 CABA, Rep. Argentina.Email:docnasocarolina@gmail.com

Los autores declaran no poseer conflictos de intereses.

Recibido: 15/10/2017 | Aceptado: 03/03/2018 tivo, acelerando su progresión natural y disminuyendo la supervivencia del paciente. Frente a esta situación existen mecanismos contrarreguladores que se contraponen a estos efectos perjudiciales, como los péptidos natriuréticos que son hormonas producidas por el corazón que poseen propiedades pleiotrópicas protectoras del sistema cardiovascular. Estos péptidos son degradados por una enzima, la neprilisina.

En base a este sustrato fisiopatológico es que surgió el sacubitril, un nuevo fármaco que se basa en el bloqueo de la neprilisina que, combinado con el de los receptores de la angiotensina II (valsartán), tiene como objetivo el aumento de los péptidos natriuréticos más el bloqueo del SRAA para ejercer su efecto favorable en IC con fracción de eyección deteriorada. Este nuevo fármaco demostró disminuir la mortalidad en un ensayo clínico randomizado cuando fue comparado con enalapril ${ }^{2,3}$

Teniendo en cuenta esta información, el tema de esta monografía fue elegido en base a la gran incidencia de esta patología y al daño que ella produce a nivel individual, poblacional y sanitario, y por el interés preventivo mediante su tratamiento específico, previo al arribo a un curso irreversible. A su vez, plantear un posible cambio de paradigma en el tratamiento de la insuficiencia cardíaca, siendo que por primera vez un fármaco nuevo demuestra superioridad frente al enalapril, la piedra angular de su tratamiento desde hace 30 años. Por lo tanto, el objetivo principal de esta monografía es realizar una revisión exhaustiva de la fisiopatología de la IC, del SRAA y de los péptidos natriuréticos, para posteriormente presentar al nuevo fármaco, sacubitril/valsartán, su mecanismo de acción y evidencia actual. 


\section{DESARROLLO}

\section{CONCEPTOS BÁSICOS DE INSUFICIENCIA CARDÍACA}

La IC es un síndrome caracterizado por la presencia de signos y síntomas típicos causados por anomalías cardíacas estructurales o funcionales, que producen reducción del gasto cardíaco y elevación de las presiones intracardíacas ${ }^{1,2}$

Es una entidad de importancia, con prevalencia e incidencia aumentada en nuestros tiempos, debido en gran parte al auge de las enfermedades crónicas que le dan origen (enfermedad coronaria, diabetes e hipertensión arterial, principalmente), el aumento de la expectativa de vida y la mayor supervivencia de los pacientes. Esto genera al sistema de salud un aumento en el número de hospitalizaciones, en la mortalidad y en los costos asociados a su tratamiento, sumado al gran deterioro de la calidad de vida del paciente ${ }^{3}$.

En cuanto al tratamiento neurohormonal de la IC, contamos con tres grupos de fármacos que han demostrado disminuir la mortalidad: los inhibidores del SRAA ${ }^{4-7}$, los betabloqueantes ${ }^{8-12}$ y los antagonistas de los mineralocorticoides ${ }^{13-15}$. Respecto a los bloqueantes de los receptores de la angiotensina, no demostraron disminución significativa de la mortalidad ${ }^{16,17}$ ni que sean mejores respecto de los inhibidores de la enzima convertidora de angiotensina (IECA $)^{18,19}$; por lo tanto, su indicación se reserva para aquellos pacientes que no toleren los IECA.

\section{FISIOPATOLOGÍA}

El desarrollo de la insuficiencia cardíaca comienza con un daño miocárdico primario que produce disfunción ventricular, lo cual lleva a una disminución de la descarga sistólica con la consecuente caída en el volumen minuto y disminución en la oferta tisular de oxígeno. Para contrarrestar estas manifestaciones y preservar la homeostasis cardiocirculatoria en las primeras etapas de esta enfermedad, se ponen en marcha dos mecanismos adaptativos: la activación neurohormonal (con el sistema renina-angiotensina-aldosterona -SRAA- y el sistema nervioso simpático -SNS-) y el remodelado ventricular ${ }^{20}$. Por disminución de la presión arterial, se activa el SRAA, el cual retiene agua y sodio, aumentando de esta forma la precarga del ventrículo izquierdo (VI), lo cual, por la ley de Frank Starling, genera inicialmente un aumento de la fuerza de contracción incrementando la descarga sistólica y de esta manera el volumen minuto. Por estimulación del SNS, se produce mayor descarga adrenérgica, que por estímulo beta aumenta la frecuencia cardíaca y la contractilidad del ventrículo izquierdo, y por estímulo alfa genera vasoconstricción.

Estos mecanismos compensan transitoriamente la caída en el volumen minuto, pero sostenidos en el tiempo, terminan siendo deletéreos para el músculo cardíaco. La sobrecarga crónica de volumen y de presión y el aumento del estrés parietal provocan dilatación e hipertrofia ventricular, aumentando el consumo miocárdico de oxígeno que, junto con la isquemia debida a la disminución de la perfusión miocárdica por el aumento de la frecuencia cardíaca y el acortamiento del tiempo de fin de diástole, generan un "círculo vicioso" que contribuye al remodelado ventricular.
Para contrarrestar estos efectos perjudiciales, nuestro organismo pone en funcionamiento mecanismos contrarreguladores: sistemas vasodilatadores como el óxido nítrico y el sistema de péptidos natriuréticos, que intentan compensar el daño que se auto perpetúa en la IC, con acción vasodilatadora, diurética, natriurética y lucitrópica, y con efecto beneficioso sobre el remodelado ventricular y la fibrosis.

\section{SISTEMA RENINA ANGIOTENSINA ALDOSTERONA}

El sistema renina-angiotensina-aldosterona (SRAA) es uno de los mecanismos compensadores que se activan en la insuficiencia cardía$\mathrm{ca}^{21}$. La renina es una aspartil proteasa secretada por las células yuxtaglomerulares de las paredes de las arteriolas eferentes del riñón, escinde el angiotensinógeno circulante (sintetizado en el hígado) para formar angiotensina I, proteasa desprovista de acción biológica. Su secreción es estimulada por tres vías: (a) vía mácula densa (células de la rama ascendente gruesa cortical renal): al detectar disminución de la concentración de cloruro de sodio que llega a este punto, se estimula la secreción de renina; (b) vía del barorreceptor renal: en cuanto detecta disminución de la presión en la arteriola aferente (por hipotensión arterial sistémica), se estimula la secreción de renina; (c) vía del receptor beta adrenérgico: la liberación de noradrenalina de terminales nerviosas simpáticas produce liberación de renina por la estimulación del receptor $\beta 1$.

En este contexto, la enzima convertidora de angiotensina, secretada principalmente por las células endoteliales de los pulmones, cataliza la conversión de angiotensina I en angiotensina II. Este proceso no se realiza solamente en el riñón, sino también a nivel local en otros tejidos (pared vascular, pulmones, gónadas, sistema nervioso central y el corazón). El SRAA local está activado en los pacientes con disfunción ventricular izquierda asintomática, y ello tiene que ver con la progresión hacia una etapa clínica de la enfermedad. Ello explica por que el tratamiento con inhibidores del SRAA en etapa asintomática, pero con disfunción del ventrículo izquierdo, demostró reducir la tasa de progresión a insuficiencia cardíaca clínica.

Los efectos deletéreos de la activación del SRAA se basan principalmente en la activación de los receptores del tipo 1 de la angiotensina II (AT II). Su estimulación produce varios efectos, entre ellos, una potente respuesta vasoconstrictora arteriovenosa, ya sea por acción directa, activando los receptores para AT II, como por acción indirecta, a través de la activación del tono simpático central y periférico, estimulando la liberación de vasopresina, endotelina y aldosterona. También produce efectos tróficos a largo plazo (como hipertrofia, fibrosis y remodelado cardíaco y vascular), lo que contribuye a reducir la distensibilidad vascular, aumentar la rigidez ventricular y promover estímulos arrítmicos. A su vez, genera disfunción de los barorreceptores, que origina una activación mantenida del sistema nervioso simpático y del SRAA, de manera que aun cuando haya retención hidrosalina interpretarán depleción de volumen y estimularán la respuesta hipertensora. También aumenta la actividad de la nicotinamida adenina dinucleótido 2' fosfato oxidasa, incrementando la producción de radicales libres y el estrés oxidativo, lo cual resulta en mayor inflamación. En el riñón, aumenta la reab- 
sorción de sodio y agua, tanto por una acción directa a nivel del túbulo proximal, como indirectamente, a través de la liberación de aldosterona que, como veremos a continuación, actúa a nivel del túbulo distal y colector.

La aldosterona genera efectos extracardiovasculares y cardiovasculares, similares a los de la AT II. Entre los primeros, a nivel renal reabsorbe sodio a cambio de potasio en los segmentos distales de las nefronas que, análogamente a la AT II, generando el ascenso de la tensión arterial y mayor retención de sodio; todo ello promueve la aparición de edema, hipokalemia e hipomagnesemia, y con ello, las arritmias ventriculares. A nivel del sistema nervioso central, genera aumento de la sed y apetito por la sal. A nivel cardiovascular, la aldosterona produce aumento del tono vascular por distintos mecanismos: aumento de la respuesta a catecolaminas, disminución de la sensibilidad de los barorreceptores carotídeos, y libera de esta manera al tono simpático, lo que generaría también la aparición de arritmias cardíacas. Es por ello que los pacientes con insuficiencia cardíaca presentan una frecuencia cardíaca persistentemente elevada y vasoconstricción sistémica. A su vez, promueve la inflamación sistémica a nivel perivascular e intersticial, generando lisis del colágeno y fibrosis, favoreciendo el remodelado cardíaco y vascular. Estos dos sucesos sumados tienen que ver con la disminución de la capacidad de vasodilatación periférica y con la disfunción diastólica, generada por el aumento del tejido de contenido fibroso a nivel del intersticio miocárdico.

El "escape de aldosterona" es un fenómeno producido en pacientes tratados crónicamente con IECA, en quienes aumenta la producción de aldosterona por varios mecanismos: la reducción de la producción de AT II lleva a un aumento reflejo de la producción de renina, efecto que sobrepasa al efecto inhibidor de la enzima convertidora, generando, por lo tanto, aumento tanto de la AT II como de la aldosterona; el aumento del potasio plasmático atribuible al tratamiento, más la disfunción renal frecuente en los pacientes con IC; y el aumento de los niveles de ACTH, que activan el eje córtico-suprarrenal. Este hecho parece ser la base del tratamiento con antialdosterónicos ${ }^{22}$.

Podemos resumir que, en base a todos estos efectos, se generarán los siguientes efectos hemodinámicos: aumento de la precarga (por expansión de volumen gracias a la retención de sodio), aumento de la poscarga (por producir hipertensión arterial), aumento de la frecuencia cardiaca (por respuesta simpática), y con ello, aumento de las demandas miocárdicas de oxígeno.

En este contexto, en el cual la activación de sistemas compensadores en un principio, que se tornan en perjudiciales a largo plazo, existen otros sistemas neurohormonales contrarreguladores que se activan con el fin de tratar de compensar los efectos perjudiciales. Entre ellos, la prostaglandina E2 (vasodilatadora y potenciadora de la excreción renal de sodio), la prostaciclina, el óxido nítrico y el sistema de los péptidos natriuréticos, de los cuales trataremos a continuación ${ }^{23}$.

\section{PÉPTIDOS NATRIURÉTICOS}

Debemos el descubrimiento de los péptidos natriuréticos al bioquímico argentino Adolfo J. De Bold, quien en 1981 en la
Universidad de Toronto, Canadá, llevó a cabo un protocolo científico que se basó en la comparación de la acción de extractos homogeneizados de miocardio auricular, ventricular, y de ambos, de corazón de ratas, recalcando la presencia de gránulos parecidos morfológica e histológicamente a las hormonas únicamente en los miocardiocitos auriculares. Con ello, generó respectivamente tres extractos que fueron inyectados en otras ratas y observó en el grupo perteneciente al extracto atrial el aumento de la natriuresis y de la kaliuresis, el descenso de la presión arterial, sin caída del filtrado glomerular. Por medio del presente experimento, se describió por primera vez un potente inhibidor de la reabsorción renal de sodio a nivel cardíaco, el factor natriurético atrial, y se sentaron las bases para el estudio de las propiedades endocrinológicas del corazón ${ }^{24}$.

\section{A. TIPOS Y FUNCIONES DE LOS PÉPTIDOS NATRIURÉTICOS}

Los péptidos natriuréticos están comprendidos en un grupo de diferentes hormonas cardíacas con propiedades pleiotrópicas protectoras del sistema cardiovascular ${ }^{25}$ :

Péptido natriurético atrial (ANP). Es un péptido producido únicamente en las aurículas. Es un contrarregulador natural del sistema renina-angiotensina-aldosterona y del sistema nervioso simpático, por sus propiedades antifibróticas, natriuréticas, kaliuréticas, vasodilatadoras y diuréticas. Se almacena en gránulos en los miocardiocitos de las aurículas y se libera como hormona activa estimulada por el aumento de tensión transmural en las mismas, secundario al aumento de volumen. Su tiempo de vida media es de tres minutos.

Péptido natriurético cerebral (BNP). Debe su nombre por su unión observada a receptores en el cerebro ${ }^{26}$, lo cual a la vez demostró su acción contrarreguladora del sistema nervioso simpático. Es un péptido secretado preferencialmente por el ventrículo, que posee las mismas acciones que el ANP, pero que presenta mayor vida media (21 minutos). Su secreción es estimulada por el aumento de la tensión parietal a nivel ventricular ${ }^{27}$. El BNP se secreta como prohormona glicosilada. En circulación, es sucesivamente deglicosilado y clivado por la corina en su forma activa, y en su forma inactiva (más conocida como NT-proBNP) ${ }^{28}$.

Péptido natriurético tipo C (CNP). Es un péptido liberado por células endoteliales y renales como prohormona, clivado en circulación a sus formas activas, que posee propiedades vasodilatadoras y antifibróticas. Su secreción es estimulada por citoquinas y agonistas endoteliales como la acetilcolina.

\section{B. MECANISMO DE ACCIÓN Y DEGRADACIÓN DE LOS PÉPTIDOS NATRIURÉTICOS}

Respecto a su mecanismo de acción, ANP y BNP se ligan a receptores de membrana tipo guanil ciclasa tipo A (GC-A), mientras que CNP se liga a los receptores tipo B (GC-B), distribuidos principalmente en riñón y corazón, y ejercen sus funciones intracelulares mediante segundo mensajero vía GMP cíclico a nivel intracelular (Figura 1).

La neprilisina, también conocida como endopeptidasa neutra, es la principal enzima responsable de la degradación de los péptidos natriuréticos en fragmentos inactivos. Se encuentra ampliamente expresada en nuestro organismo: se encontró en riñón, pulmones, cé- 


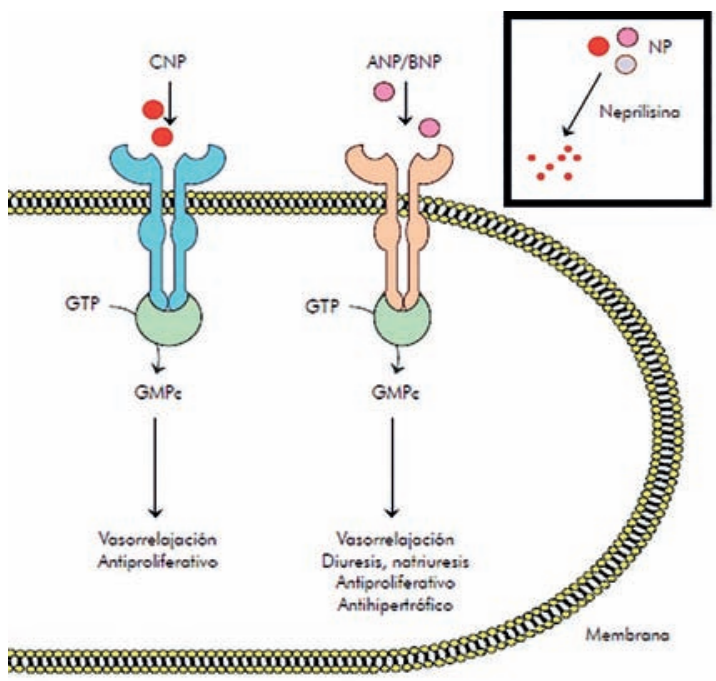

Figura 1. Señalización intracelular de los péptidos natriuréticos. Tanto el ANP (péptido natriurético auricular) como el BNP (péptido natriurético cerebral) se ligan al mismo receptor. La neprilisina es la principal enzima encargada de la degradación de estos. ANP: péptido natriurético auricular. BNP: péptido natriurético cerebral. CNP: péptido natriurético tipo C. NP: péptidos natriuréticos. GTP: guanosín trifosfato. GMPC: guanosín monofosfato cíclico. Modificado de Manzur F, Villarreal T, Moneriz C. Inhibición dual de la neprilisina y el receptor de angiotensina II: nueva estrategia prometedora en el tratamiento de la enfermedad cardiovascular. Rev Colomb Cardiol 2013;20(6):388

lulas endoteliales, células de músculo liso, cardiomiocitos, adipocitos y en cerebro, con mayor concentración en las células de túbulo renal proximal. A su vez, es la responsable de la degradación de otros péptidos, involucrados en funciones cardiovasculares, como angiotensina I y II, bradiquininas y endotelina-1, y no involucrados en ellas, como sustancia P, proteína beta amiloidea y gastrina. La neprilisina no degrada al NT-proBNP, por lo cual se utiliza como biomarcador para diagnóstico y pronóstico en IC ${ }^{29}$.

\section{C. ACCIONES Y UTILIDADES}

Uno de sus principales efectos es la vasodilatación, de hecho se ha reportado la disminución de la presión de aurícula derecha, de la arteria pulmonar, de la presión de enclavamiento pulmonar y de las resistencias vasculares en falla cardíaca congestiva tras la infusión de BNP. Los péptidos natriuréticos promueven la excreción de sodio y agua mediante la inhibición de la reabsorción de sodio en la porción proximal y distal de la nefrona, sin alterar el filtrado glomerular mediante la regulación del feedback túbulo-glomerular, lo cual mejora la función hemodinámica y renal en pacientes con falla cardíaca. Los efectos diuréticos, natriuréticos y hemodinámicos, a su vez, resultan de una inhibición de los sistemas renina-angiotensina-aldosterona y del sistema nervioso simpático. También se han hallado otras funciones mediadas por estos péptidos, como la estimulación de la lipólisis activada por el ANP en los receptores NPR-A de los adipocitos, generando ácidos grasos libres que se cree que contribuirían como sustrato para el trabajo cardíaco ${ }^{30}$. Otras de las funciones de los péptidos natriuréticos es la antifibrótica, demostrada por la inhibición de la hipertrofia cardíaca que generan la angiotensina II y la endotelina 1, ya que en los fibroblastos cardíacos, el ANP y el BNP inhiben los efectos del factor de crecimiento beta ${ }^{31}$. A su vez, la medición de péptidos natriuréticos en plasma se utiliza como método diagnóstico y pronóstico en $\mathrm{IC}^{31-34}$. De todas formas, nunca debe reemplazar al criterio clínico, y siempre debe ser contextuado en el caso de cada paciente, ya que el BNP puede estar elevado en otras patologías tanto cardíacas (valvulopatías, cardiopatía isquémica, arritmias auriculares, hipertensión pulmonar) como extracardíacas (edad, insuficiencia renal, sepsis, tromboembolismo pulmonar) ${ }^{35}$. Más recientemente, se descubrió que existen determinadas situaciones en las cuales sus valores pueden encontrarse normales a pesar de presentar falla cardíaca, conocidos como estados de deficiencia de péptidos natriuréticos, como en la obesidad. La reducción de BNP en esta población podría explicar su mayor susceptibilidad a las enfermedades cardiovasculares. Este efecto se cree debido a que, a pesar de la mayor producción de ANP y BNP por la retención de sodio y el consiguiente aumento del volumen que se da en la obesidad, el tejido adiposo reúne gran cantidad de receptores para la degradación de péptidos natriuréticos ${ }^{36}$.

En estadíos avanzados de insuficiencia cardíaca, debido al procesamiento alterado del BNP de causa aún no aclarada, existe menor cantidad de hormona activa, a pesar de los elevados niveles de BNP inmunorreactivo. Esto es debido al clivaje de precursores inactivos o de menor actividad biológica' hecho que explicaría la falta de actividad fisiológica contrarrestadora de los sistemas compensadores en la IC avanzada, a pesar de los altos niveles registrados de BNP, de los que no se distingue por laboratorio entre formas activas e inactivas del mismo ${ }^{37}$.

A su vez, otra explicación de la elevación del BNP en IC avanzada es la gran activación del SRAA, de manera que reflejan mayor activación de los sistemas vasoconstrictores. Otra es que, a medida que avanza la enfermedad, sus efectos biológicos se pierden por disminución de número de receptores y un fenómeno de desacople de los mismos ${ }^{38}$

\section{D. PÉPTIDOS NATRIURÉTICOS EN EL TRATAMIENTO DE LA INSUFICIENCIA CARDÍACA}

Por su naturaleza contrarreguladora de la insuficiencia cardíaca, han sido varios los intentos en la historia por plasmar su beneficio fisiológico en un fármaco para tratar dicha enfermedad.

Uno de los primeros intentos fue con el candoxatril en 1991, un inhibidor de la neprilisina utilizado como monodroga por vía ora ${ }^{39}$. A principio, se vio un beneficio al aumentar la natriuresis y aumentar los valores plasmáticos de ANP, pero posteriormente se encontró un aumento de los valores de angiotensina II, con los efectos deletéreos que ella produce, por lo cual se discontinuó ${ }^{40}$

Visto que la inhibición de la neprilisina por sí sola no bastaba para batallar la activación neurohormonal en la insuficiencia cardíaca, se decidió combinarla junto con una droga que inhiba el SRAA. Es as como surgió el omapaprilat, un inhibidor dual de la neprilisina y de la enzima convertidora de angiotensina. Se realizaron numerosos ensayos comparando esta droga con los IECA, siendo notable que en uno de ellos se la comparó con enalapril, en el cual no demostró inferioridad respecto al punto primario combinado de muerte $u$ hospitalizaciones ${ }^{41,42}$. Incluso se realizó un estudio randomizado con una población de más de 25 mil participantes para comparar omapaprilat en contra del enalapril en pacientes hipertensos ${ }^{43}$. A pesar de obtener buenos resultados en cuanto al control de la presión arterial a favor del omapaprilat, se observó un aumento del angioedema severo. Se piensa que este efecto se produce porque ambos fármacos generan 
altos niveles de bradiquininas. Dado este efecto adverso tan importante, la Food and Drug Administration (FDA) no aprobó su utilización.

\section{INHIBICIÓN DEL RECEPTOR DE ANGIOTENSINA Y DE LA NEPRILISINA}

En los últimos años se originó una nueva y prometedora combinación de dos fármacos para el tratamiento de la insuficiencia cardíaca: el sacubitril (inhibidor de la neprilisina), con el valsartán (un inhibidor de los receptores de angiotensina II), que se denominó LCZ696. Es el primero de una nueva clase de fármacos para el tratamiento de la insuficiencia cardíaca: inhibidores de los receptores de la angiotensina y de la neprilisina (IRAN). Este doble bloqueo permite actuar en contra del mecanismo neurohormonal, al bloquear al SRAA y aumentar la concentración de péptidos natriuréticos ${ }^{44}$.

Dado que la inhibición de neprilisina es insuficiente para bloquear por sí sola al sistema renina-angiotensina-aldosterona, ya que entre sus sustratos no solo se encuentra la enzima catalizadora de péptidos natriuréticos sino que también degrada péptidos vasoconstrictores como la angiotensina I y |l y la endotelina, entre otros, es que debe ser acompañada simultáneamente con un fármaco que permita bloquear al SRAA. La neprilisina asociada con inhibidores de la enzima convertidora de la angiotensina, como ya hemos visto, demostró aumento del angioedema, de modo que esa combinación no se utilizó. En su lugar, se combinó con un inhibidor de la angiotensina II, el valsartán.

La forma farmacéutica del sacubitril/valsartán son comprimidos recubiertos, disponibles en distintas concentraciones: 50 mg, $100 \mathrm{mg}$ y 200 mg (24 mg sacubitril / 26 mg valsartan, 49 mg sacubitril / 51 mg valsartan, y 97 mg sacubitril / 103 mg valsartan, respectivamente). Si bien la dosis prevista es de $200 \mathrm{mg}$ dos veces al día, se recomienda una dosis inicial de $50 \mathrm{mg}$ dos veces al día en los pacientes que no estén tomando un IECA ni un ARA II, y debe considerarse en el caso de los pacientes que hayan tomado anteriormente dosis bajas de estos fármacos. Se duplicará la dosis cada 2-4 semanas según tolerabilidad del paciente, hasta llegar a la dosis objetivo. Debemos recordar el riesgo aumentado de angioedema con la administración concomitante con un IECA, por lo cual el mismo debe suspenderse 36 horas antes del inicio del tratamiento con sacubitril/valsartán. Si los pacientes presentan problemas de tolerabilidad (hipotensión arterial sintomática, hiperpotasemia, disfunción renal), se debe estudiar la posibilidad de reajustar la dosis. Está contraindicado en embarazadas, en insuficiencia renal crónica con clearance menor a $30 \mathrm{mg} / \mathrm{ml} /$ por 1.73 de metros cuadrados corporales, en pacientes con enfermedad hepática severa y antecedente de angioedema.

Tras la administración oral, el LCZ696 se disocia en: sacubitril, que es metabolizado a AHU377, el cual luego se metaboliza a su vez en LBQ657, su componente activo, inhibidor directo de la neprilisina; y valsartán (Figura 2). Alcanzan concentraciones plasmáticas máximas al cabo de una media de 0,5 horas, 3 horas y 1,5 horas, respectivamente. Se estima que la biodisponibilidad absoluta por vía oral es del 60\% como mínimo en el caso del sacubitril y del 23\% en el caso del valsartán. Las vidas medias del LBQ657 y el valsartán son 12 y 14 horas, respectivamente, permitiendo la administración del fármaco dos veces al día. Con ello, se alcanzan concentraciones de estado estacio-

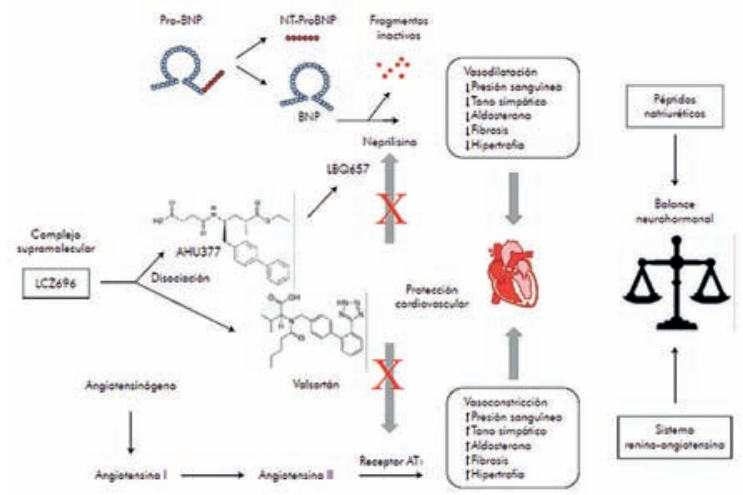

Figura 2. Acción dual de inhibición de la neprilisina y bloqueo del receptor de angiotensina II mediante el LCZ696. La prodroga del sacubitril es el AHU377, que luego se metaboliza a LBQ657, un inhibidor específico de la neprilisina. Se inhiben principalmente las acciones perjudiciales de la angiotensina II, y se potencian los efectos beneficiosos del péptido natriurétiCo, al inhibir la enzima que lo degrada. AT 1: angiotensina I. Pro-BNP: pro péptido natriurético cerebral. BNP: péptido natriurético cerebral. NT-pro-BNP: fragmento aminoterminal de dicha molécula. Modificado de Manzur F, Villarreal T, Moneriz C. Inhibición dual de la neprilisina y el receptor de angiotensina II: nueva estrategia prometedora en el tratamiento de la enfermedad cardiovascular. Rev Colomb Cardiol 2013;20(6):389.

nario de sacubitril, LBQ657 y valsartán al cabo de 3 días. Puede administrarse con o sin alimentos. En cuanto a su distribución, muestra un alto grado de unión a proteínas plasmáticas (94-97\%). Según la comparación entre las concentraciones plasmáticas y las del LCR, el LBQ657 atraviesa la barrera hematoencefálica en grado limitado $(0,28 \%)$. Respecto al metabolismo, el sacubitril se biotransforma rápidamente en LBQ657 por la acción de esterasas, que no se metaboliza en grado significativo. El valsartán se metaboliza en grado mínimo, ya que apenas el 20\% de la dosis, aproximadamente, se recupera en forma de metabolitos. En cuanto a su eliminación, tras la administración oral, entre el $52 \%$ y el $68 \%$ del sacubitril (principalmente en forma de LBQ657), y aproximadamente el 13\% del valsartán y sus metabolitos se excretan en la orina; entre el $37 \%$ y el $48 \%$ del sacubitril (principalmente en forma de LBQ657) y el 86\% del valsartán y sus metabolitos se excretan en las heces. El sacubitril, el LBQ657 y el valsartán se eliminan del plasma con una vida media de eliminación que ronda en las 1,43 horas, 11,48 horas y 9,90 horas, respectivamente ${ }^{45}$.

\section{EVIDENCIA ACTUAL}

Recientemente se publicó el estudio PARADIGM-HF ${ }^{46}$, ensayo clínico prospectivo que demostró que este nuevo fármaco disminuye la mortalidad significativamente, comparado con un inhibidor de la enzima convertidora de angiotensina, el enalapril. En este ensayo clínico randomizado se seleccionaron 8442 pacientes (Tabla 1) con insuficiencia cardíaca con fracción de eyección disminuida (FEy menor a 40\%), y luego por una enmienda, menor a 35\%, en clase funcional según la escala de New York Heart Association (NYHA) II a IV (la mayoría de los participantes se encontraban en clase funcional II), con valor de BNP igual o mayor a 150 picogramos por mililitro (pg/ml), o NTproBNP igual o mayor a $600 \mathrm{pg} / \mathrm{ml}$, o si estuvieron hospitalizados por insuficiencia cardíaca los doce meses previos, igual o mayor a 100 pg/ $\mathrm{ml}$, o igual o mayor a $400 \mathrm{pg} / \mathrm{ml}$, respectivamente. Los criterios de exclusión fueron: pacientes hipotensos (TAS $<90 \mathrm{mmHg}$ ), con deterioro de la función renal (clearance de creatinina menor a $30 \mathrm{ml} /$ minuto/ 
Tabla 1. Características basales de los pacientes incluidos en el PARADIGM-HF.

\begin{tabular}{|c|c|c|}
\hline Características & $\begin{array}{c}\text { LCZ696 } \\
(\mathrm{N}=4187)\end{array}$ & $\begin{array}{l}\text { Enalapril } \\
(\mathrm{N}=4212)\end{array}$ \\
\hline Edad & $63,8 \pm 11,5$ & $63,8 \pm 11,3$ \\
\hline Sexo femenino & $879(21,0)$ & $953(22,6)$ \\
\hline \multicolumn{3}{|l|}{ Raza o grupo étnico } \\
\hline $\begin{array}{l}\text { Blanco } \\
\text { Negro } \\
\text { Asiático } \\
\text { Otro }\end{array}$ & $\begin{array}{l}2763(66,0) \\
213(5,1) \\
759(18,1) \\
452(10,8)\end{array}$ & $\begin{array}{l}2781(66,0) \\
215(5,1) \\
750(17,8) \\
466(11,1)\end{array}$ \\
\hline \multicolumn{3}{|l|}{ Región - N (\%) } \\
\hline $\begin{array}{l}\text { Norteamérica } \\
\text { América latina } \\
\text { Europa del Este } \\
\text { Europa Central } \\
\text { Asiáticos y del Pacífico }\end{array}$ & $\begin{array}{c}310(7,4) \\
713(17,0) \\
1026(24,5) \\
1393(33,3) \\
745(17,8)\end{array}$ & $\begin{array}{c}292(6,9) \\
720(17,1) \\
1025(24,3) \\
1433(34,0) \\
742(17,6)\end{array}$ \\
\hline Presión arterial sistólica (mmHg) & $122 \pm 15$ & $121 \pm 15$ \\
\hline Frecuencia cardíaca (latidos/minuto) & $72 \pm 12$ & $73 \pm 12$ \\
\hline Índice de masa corporal & $28 \pm 5,5$ & $28,2 \pm 5,5$ \\
\hline Creatinina sérica (mg/ml) & $1,13 \pm 0,3$ & $1,12 \pm 0,3$ \\
\hline \multicolumn{3}{|c|}{ Características técnicas de la insuficiencia cardíaca } \\
\hline $\begin{array}{l}\text { Cardiopatía isquémica - N (\%) } \\
\text { Fracción de eyección del VI (\%) } \\
\text { Media de BNP (pg/ml) } \\
\text { Media de NT-proBNP (pg/ml) }\end{array}$ & $\begin{array}{c}2506(59,9) \\
29,6 \pm 6.1 \\
255(155-474) \\
1631(885-3154)\end{array}$ & $\begin{array}{c}2530(60,1) \\
29,4 \pm 6,3 \\
251(153-465) \\
1594(886-3305)\end{array}$ \\
\hline \multicolumn{3}{|l|}{ Clase funcional de la NYHA - N (\%) } \\
\hline $\begin{array}{l}\text { I } \\
\text { II } \\
\text { III } \\
\text { IV }\end{array}$ & $\begin{array}{c}180(4,3) \\
2998(71,6) \\
969(23,1) \\
33(0,8)\end{array}$ & $\begin{array}{c}209(5,0) \\
2921(69,3) \\
1049(24,9) \\
27(0,6)\end{array}$ \\
\hline Datos perdidos & $7(0,2)$ & $6(0,1)$ \\
\hline \multicolumn{3}{|l|}{ Antecedentes (ํo y \%) } \\
\hline $\begin{array}{l}\text { Hipertensión arterial } \\
\text { Diabetes } \\
\text { Fibrilación auricular } \\
\text { Hospitalización por falla cardíaca } \\
\text { Infarto de miocardio } \\
\text { Accidente cerebrovascular } \\
\text { Uso previo de IECA } \\
\text { Uso previo de ARA II } \\
\text { Diuréticos } \\
\text { Digitálicos } \\
\text { Betabloqueantes } \\
\text { Antagonistas de los mineralocorticoides } \\
\text { Cardiodesfibrilador implantable } \\
\text { Terapia de resincronización cardíaca }\end{array}$ & $\begin{array}{l}2969(70,9) \\
1451(34,7) \\
1517(36,2) \\
2607(62,3) \\
1818(43,4) \\
355(8,5) \\
3266(78,0) \\
929(22,2) \\
3363(80,3) \\
1223(29,2) \\
3899(93,1) \\
2271(54,2) \\
623(14,9) \\
292(7,0)\end{array}$ & $\begin{array}{l}2971(70,5) \\
1456(34,6) \\
1574(37,4) \\
2667(63,3) \\
1816(43,1) \\
370(8,8) \\
3266(77,5) \\
963(22,9) \\
3375(80,1) \\
1316(31,2) \\
3912(92,9) \\
2400(57,0) \\
620(14,7) \\
282(6,7)\end{array}$ \\
\hline
\end{tabular}

VI: ventrículo izquierdo. BNP: péptido natriurético cerebral. NYHA: escala de disnea de la New York Heart Association. IECA: inhibidores de la enzima convertidora de angiotensina. ARA II: inhibidores de receptores de angiotensina II. Modificado de McMurray JJ, Packer M, Desai AS, Gong J, Lefkowitz MP, Rizkala AR, et al. Angiotensin-neprilysin inhibition versus enalapril in heart failure. N Engl J Med 2014;371(11):993-1004.

por 1,73 de metros cuadrados corporales), con hiperkalemia (potasio sérico $>5,4 \mathrm{mEq} / \mathrm{ll}$ ). Y los de inclusión: pacientes que estén recibiendo $10 \mathrm{mg} /$ día de enalapril bien tolerados. El promedio de edad fue de 64 años, con mayoría de hombres, y mayoría de pacientes en CF II y III, alta prevalencia de pacientes con diabetes y fibrilación auricular, correctamente medicados con el tratamiento estándar para IC.

El punto final primario fue un compuesto de muerte por causa cardiovascular o primera hospitalización por insuficiencia cardíaca. Los puntos finales secundarios fueron muerte por cualquier causa, un cambio en la clínica desde el basal hasta los 8 meses de seguimiento medido por un score norteamericano (the Kansas City Cardiomyopathy
Questionnaire -KCCQ-), aparición de fibrilación auricular y falla renal (que fue definido como estadio final de la enfermedad renal, o como una caída del filtrado glomerular de más de $30 \mathrm{ml} /$ minuto/por 1,73 de metros cuadrados corporales). Respecto del análisis estadístico, estimaron que el promedio anual del punto final primario sería del $14,5 \%$, y el promedio de muerte por causas cardiovasculares sería del 7,0\% en el grupo del enalapril, con lo cual el cálculo de la muestra les arrojó que necesitaban seguir a 8000 pacientes durante 34 meses, con 1229 muertes por causa cardiovascular, para que el estudio posea un poder del $80 \%$ y detectar un reducción relativa del 15\% de riesgo de muerte por causa cardiovascular en el grupo con LCZ696, con un valor de alfa de 0,05.

Constó de dos fases, la primera fue la de run in en 9419 pacientes, en la que se probó el enalapril a dosis de 10 mg dos veces al día durante dos semanas, seguido de un día sin fármaco, para luego probar el LCZ696 durante dos semanas más (primero 100 mg cada 12 horas, luego 200 mg cada 12 horas), para así excluir del estudio a los pacientes que presentaban efectos adversos (hipotensión, hiperkalemia, faIla renal). Finalizados los tamizajes, los pacientes fueron randomizados en dos grupos para recibir el compuesto LCZ696 (200 mg, dos veces al día) o enalapril (10 mg, dos veces al día), respectivamente, más el tratamiento estándar de insuficiencia cardíaca, con betabloqueantes y antagonistas de la aldosterona.

El estudio fue detenido a los 27 meses por el comité de ética debido a la reducción significativa de la mortalidad a favor del LCZ696. Como resultados, este estudio mostró significancia estadística a favor del grupo con LCZ696 por disminuir el punto final primario combinado de muerte por causa cardiovascular o primera hospitalización por insuficiencia cardíaca descompensada, y a su vez, en el subanálisis posterior de cada punto por separado, y de los puntos finales secundarios, la reducción de la mortalidad por cualquier causa (Tabla 2

y Figura 3). Como conclusiones de este estudio, se pudo desprender que el tratamiento con inhibición dual de la neprilisina y del receptor de angiotensina II, con sacubitril/valsartán, redujo significativamente la mortalidad total y de causa cardiovascular, y menor hospitalización, comparado con enalapril. Respecto a los efectos adversos, la hipotensión, tanto sintomática como asintomática, fue significativamente más frecuente en el grupo tratado con LCZ696, y la tos, en el de enalapril. Otros eventos adversos, como la elevación de los niveles de creatinina, angioedema, hiperkalemia, no mostraron diferencias estadísticamente significativas entre ambos grupos.

Un análisis posterior sobre el riesgo de progresión clínica de la IC en pacientes tratados con enalapril o LCZ696 concluyó que el LCZ696 también muestra beneficio frente al enalapril, mostrando significancia estadística en la disminución de las internaciones por insuficiencia cardíaca descompensada, y en la disminución del valor del NTproBNP a favor del LCZ696 (Figura 4) ${ }^{47}$

Posteriormente, se llevó a cabo un estudio doble ciego y randomizado diseñado para la titulación de dosis de LCZ696 en 498 pacientes con FEy menor al 35\% durante un período designado de seguimiento de 12 semanas. Para su análisis, los pacientes fueron estratificados según tolerancia a dichos fármacos, en el estrato alto, a aquellos que toleraban más de $10 \mathrm{mg} /$ día de enalapril, o más de 160 mg/día de valsartán, o su dosis equivalente de otro IECA/ARAll 
Tabla 2. Resultados de los puntos finales primarios y secundarios del PARADIGM-HF.

\begin{tabular}{|c|c|c|c|c|}
\hline Resultado & $\begin{array}{c}\text { LCZ696 } \\
(\mathrm{N}=4187)\end{array}$ & $\begin{array}{l}\text { Enalapril } \\
(\mathrm{N}=4212)\end{array}$ & $\begin{array}{l}\text { Hazard ratio } \\
\text { (IC95\%) }\end{array}$ & Valor de $p$ \\
\hline \multicolumn{5}{|l|}{ Resultado primario compuesto - N (\%) } \\
\hline $\begin{array}{l}\text { Muerte por causa cardiovascular o primera hospitalización por empeoramiento de la IC } \\
\text { Muerte por causa cardiovascular } \\
\text { Primera hospitalización por empeoramiento de la IC }\end{array}$ & $\begin{array}{l}914(21,8) \\
558(13,3) \\
537(12,8)\end{array}$ & $\begin{array}{l}1117(26,5) \\
693(16,5) \\
658(15,6)\end{array}$ & $\begin{array}{l}0,80(0,73-0,87) \\
0,80(0,71-0,89) \\
0,79(0,71-0,89)\end{array}$ & $\begin{array}{l}<0,001 \\
<0,001 \\
<0,001\end{array}$ \\
\hline \multicolumn{5}{|l|}{ Resultados secundarios - N (\%) } \\
\hline $\begin{array}{l}\text { Muerte por cualquier causa } \\
\text { Cambio en el cuestionario KCCQ } \\
\text { Aparición de fibrilación auricular } \\
\text { Empeoramiento de la función renal }\end{array}$ & $\begin{array}{c}711(17,0) \\
-2,99 \pm 0,36 \\
84(3,1) \\
94(2,2)\end{array}$ & $\begin{array}{c}835(19,8) \\
-4,62 \pm 0,36 \\
83(3,1) \\
108(2,6)\end{array}$ & $\begin{array}{l}0,84(0,76-0,93) \\
1,64(0,63-2,65) \\
0,97(0,72-1,31) \\
0,86(0,65-1,13)\end{array}$ & $\begin{array}{c}<0,001 \\
0,001 \\
0,83 \\
0,28\end{array}$ \\
\hline
\end{tabular}

IC: insuficiencia cardíaca. KCCQ: Kansas city cardiomyopathy questionnaire. Modificado de MCMurray JJ, Packer M, Desai AS, Gong J, Lefkowitz MP, Rizkala AR, et al. Angiotensin-neprilysin inhibition versus enalapril in heart failure. N Engl J Med 2014;371(11):993-1004.
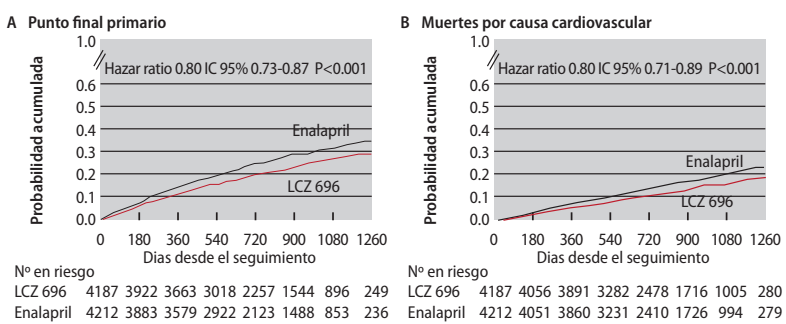

LCZ $696418739223663301822571544896249 \quad$ LCZ $696 \quad 4187405638913282247817161005280$ C Hospitalizaciones por insuficiencia cardíaca

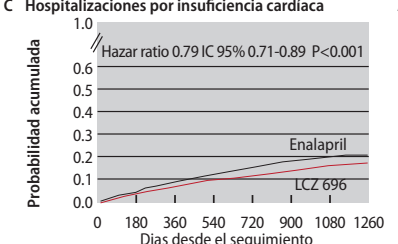

$\begin{array}{llllllll}0 & 180 & 360 & 540 & 720 & 900 & 1080 & 1260\end{array}$

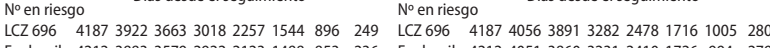
Enalapril $421238833579292221231488 \quad 853 \quad 236 \quad$ Enalapril 421240513860323124101726994279

Figura 3. Curvas de Kaplan y Meier para los puntos finales del estudio PARADIGM-HF.IC: intervalo de confianza. Modificado McMurray JJ, Packer M, Desai AS, Gong J, Lefkowitz MP, Rizkala AR, et al. Angiotensin-neprilysin inhibition versus enalapril in heartfailure. N Engl J Med 2014;371 (11):993-1004.

y en el estrato bajo, a aquellos que toleraban menos de eso, con una relación 1:1 en dicho estudio (Tabla 3). Después de un período de run in de 5 días en el cual todos los pacientes recibieron 50 mg cada 12 horas de LCZ696 (habiendo suspendido IECA/ARAll 36 horas antes), se los dividió en dos grupos, un grupo para titulación conservadora ( $n=251$ ), que siguieron con 50 mg dos veces por día por dos semanas, 100 dos veces por día por seis semanas, y luego 200 mg dos veces por día, y otro para titulación rápida ( $n=247$ ), que pasaron de $50 \mathrm{mg}$ dos veces por día a $200 \mathrm{mg}$ dos veces por día cada tres semanas, durante un período total de seguimiento de 11 semanas. Como puntos finales primarios, el estudio se propuso testear la ocurrencia de efectos adversos: hipotensión sintomática, hiperkalemia, insuficiencia renal y angioedema entre ambos grupos, obteniendo como resultado diferencias sin significancia estadística, con mayor ocurrencia de los mismos en el grupo de titulación rápida. Los puntos finales secundarios fueron: 1) éxito del tratamiento, definido como la proporción de pacientes en los dos grupos de tratamiento que lograran alcanzar y mantener una dosis de sacubitril/valsartán de 200 mg dos veces por día sin bajar o suspender el fármaco durante doce semanas; 2) éxito de tolerabilidad, definido como la proporción de pacientes, excluyendo a los pacientes que discontinuaron el tratamiento por razones diferentes a efectos adversos o muerte, que toleraran una dosis de sacubitril/valsar-
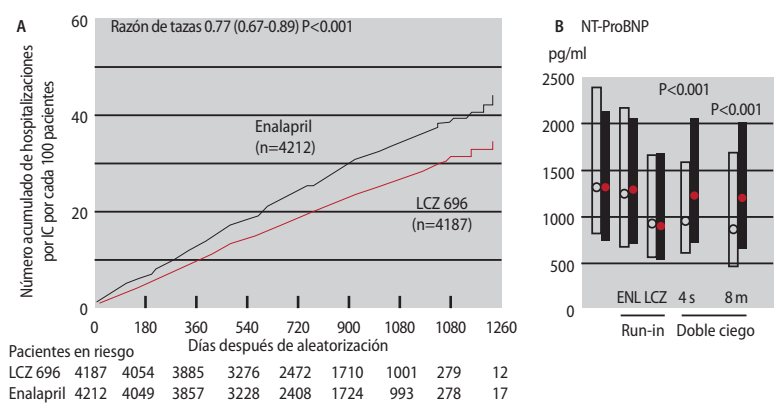

Figura 4. A. Número acumulado de hospitalizaciones por insuficiencia cardíaca en los pacientes tratados con enalapril comparado con los tratados por LCZ696. B. La mediana obtenida de los valores de N-terminal pro-BNP al ingreso y durante el estudio. Los pacientes en el grupo de LCZ696 se encuentran representados por barras blancas, y los pacientes en el grupo de enalapril por las barras grises. NT-pro-BNP: Fragmento aminoterminal de la molécula del pro-péptido natriurético cerebral. Modificado de Packer M, McMurray J, Desai AS, Gong J, Lefkowitz MP, Rizkala AR, et al. Angiotensin receptor neprilysin inhibition compared with enalapril on the risk of clinical progression in surviving patients with heart failure. Circulation 2015;131(1):54-61

tán de 200 mg dos veces por día por al menos las dos últimas semanas permitiendo completar el estudio, a pesar de previa disminución o interrupción del tratamiento. Como resultado, un 75,9\% de los pacientes alcanzaron el éxito terapéutico, y un 79,7\% alcanzó la tolerabilidad. Cuando examinaron estos dos resultados acorde a los estratos alto y bajo según tolerancia a IECA/ARA II, se encontró que alcanzaron el éxito terapéutico en mayor medida los del estrato bajo ${ }^{48}$

Posteriormente se realizó un estudio en base al PARADIGM-HF para saber el verdadero riesgo de los pacientes enrolados en dicho estudio utilizando el score MAGGIC como marcador pronóstico, y el efecto del LCZ696 para reducirlo, analizando en base a los puntos finales de dicho estudio. Respecto al puntaje de cada paciente y su categorización en el estudio, la mediana fue de 20, con un rango intercuartilo de 16-24, y puntajes desde 4 a 40 (Figura 5). Como resultados, cada 1 punto de aumento en el score se asoció a un aumento del $6 \%$ del riesgo para producir el punto final primario, con una diferencia estadísticamente significativa. En cuanto al efecto del LC696 respecto a ese riesgo, se observó que el efecto del tratamiento fue mayor en los pacientes con puntuaciones más altas de riesgo. Por ejemplo, aplicando la reducción del riesgo proporcional con LCZ696 (en comparación con enalapril) a los pacientes del quintilo 5 (con puntuaciones de riesgo de 26-40 puntos), representaría que 8 pacientes menos presenten los eventos del punto final primario, recibiendo el trata- 
Tabla 3. Características basales de los pacientes incluidos en el estudio TITRATION.

\begin{tabular}{|c|c|c|c|c|c|}
\hline \multirow[b]{2}{*}{ Demografía } & \multicolumn{2}{|c|}{ Titulación } & \multicolumn{2}{|c|}{ Estrato IECA/ARA II } & \multirow{2}{*}{$\begin{array}{c}\text { Total } \\
(\mathrm{n}=498)\end{array}$} \\
\hline & Rápida (n=247) & Conservadora $(n=251)$ & Alto $(n=247)$ & Bajo $(n=251)$ & \\
\hline Edad media (DS) & $64,2(11,86)$ & $63,8(10,94)$ & $63,1(12,10)$ & $64,9(10,60)$ & $64,0(11,39)$ \\
\hline Género masculino & $191(77,3)$ & $201(80,1)$ & $196(79,4)$ & $196(78,1)$ & $392(78,7)$ \\
\hline \multicolumn{6}{|l|}{ Raza predominante (\%) } \\
\hline $\begin{array}{l}\text { Caucásicos } \\
\text { Negros } \\
\text { Otra }\end{array}$ & $\begin{array}{c}228(92,3) \\
12(4,9) \\
7(2,8)\end{array}$ & $\begin{array}{c}234(93,2) \\
11(4,4) \\
6(2,4)\end{array}$ & $\begin{array}{c}224(90,7) \\
12(4,9) \\
11(4,5)\end{array}$ & $\begin{array}{c}238(94,8) \\
11(4,4) \\
2(0,8)\end{array}$ & $\begin{array}{c}462(92,8) \\
23(4,6) \\
13(2,6)\end{array}$ \\
\hline \multicolumn{6}{|l|}{ Composición de los pacientes. N (\%) } \\
\hline $\begin{array}{l}\text { Hospitalizados } \\
\text { Ambulatorios } \\
\text { Altas dosis IECA/ARAll } \\
\text { Bajas dosis IECA/ARAll } \\
\text { Dosis inocente/sin IECA/ARAll }\end{array}$ & $\begin{array}{c}25(10,1) \\
222(89,9) \\
120(48,6) \\
127(51,4) \\
17(6,9)\end{array}$ & $\begin{array}{c}31(12,4) \\
220(87,6) \\
127(50,6) \\
124(49,4) \\
16(6,4)\end{array}$ & $\begin{aligned} & 17(6,9) \\
& 230(93,1) \\
&- \\
&-- \\
&-\end{aligned}$ & $\begin{array}{c}39(15,5) \\
212(84,5) \\
- \\
- \\
-\end{array}$ & $\begin{array}{c}56(11,2) \\
442(88,8) \\
247(49,6) \\
251(50,4) \\
33(6,6)\end{array}$ \\
\hline FEy basal (\%) - media (DS) & $29,8(5,15)$ & $29,6(5,36)$ & $30,5(5,08)$ & $28,9(5,32)$ & $29,7(5,25)$ \\
\hline \multicolumn{6}{|l|}{ Clave NYHA en el screening - N (\%) } \\
\hline $\begin{array}{l}\text { II } \\
\text { III } \\
\text { IV }\end{array}$ & $\begin{array}{c}175(70,9) \\
72(29,1) \\
0(0,0)\end{array}$ & $\begin{array}{c}178(70,9) \\
72(28,7) \\
1(0,4)\end{array}$ & $\begin{array}{c}191(77,3) \\
56(22,7) \\
0(0,0)\end{array}$ & $\begin{array}{c}162(64,5) \\
88(35,1) \\
1(0,4)\end{array}$ & $\begin{array}{c}353(70,9) \\
144(28,9) \\
1(0,2)\end{array}$ \\
\hline Indice de masa corporal (kg/m²) en el screening - media (DE) & $30,9(5,88)$ & $30,6(6,03)$ & $31,6(6,10)$ & $30,0(7,70)$ & $30,8(5,95)$ \\
\hline Tensión arterial sistólica (mmHg) en la $2^{\circ}$ visita - media (DE) & $130,8(16,64)$ & $130,8(15,98)$ & $132,7(16,91)$ & $129,0(15,49)$ & $130,8(16,30)$ \\
\hline Tensión arterial diastólica (mmHg) en la $2^{\circ}$ visita - media (DE) & $77,2(9,99)$ & $77,6(9,26)$ & $78,0(9,34)$ & $76,8(9,87)$ & $77,4(9,62)$ \\
\hline Filtrado glomerular basal (ml/min1,73 m²) - media (DE) & $69,6(21,63)$ & $70,6(25,16)$ & $71,4(21,85)$ & $68,8(24,90)$ & $70,1(23,45)$ \\
\hline \multicolumn{6}{|l|}{ Filtrado glomerular basal (ml/min1,73 m²) - $\mathrm{n}(\%)$} \\
\hline $\begin{array}{l}<60 \\
\geq 60\end{array}$ & $\begin{array}{c}83(33,6) \\
163(66,0)\end{array}$ & $\begin{array}{c}85(33,9) \\
164(65,3)\end{array}$ & $\begin{array}{c}73(29,6) \\
173(70,0)\end{array}$ & $\begin{array}{c}95(37,8) \\
154(61,4)\end{array}$ & $\begin{array}{l}168(33,7) \\
327(65,7)\end{array}$ \\
\hline
\end{tabular}

NYHA: escala de disnea de la New York Heart Association. IECA: inhibidores de la enzima convertidora de angiotensina. ARA Il: Inhibidores del receptor de angiotensina II. FEy: Fracción de eyección.. Modificado de Senni M, McMurray JJ, Wachter R, McIntyre HF, Reyes A, Majercak I, et al. Initiating sacubitril/valsartan (LCZ696) in heart failure: results of TITRATION, a double-blind, randomized comparison of two uptitration regimens. Eur J Heart Fail 2016;18(9):1193-1202

A

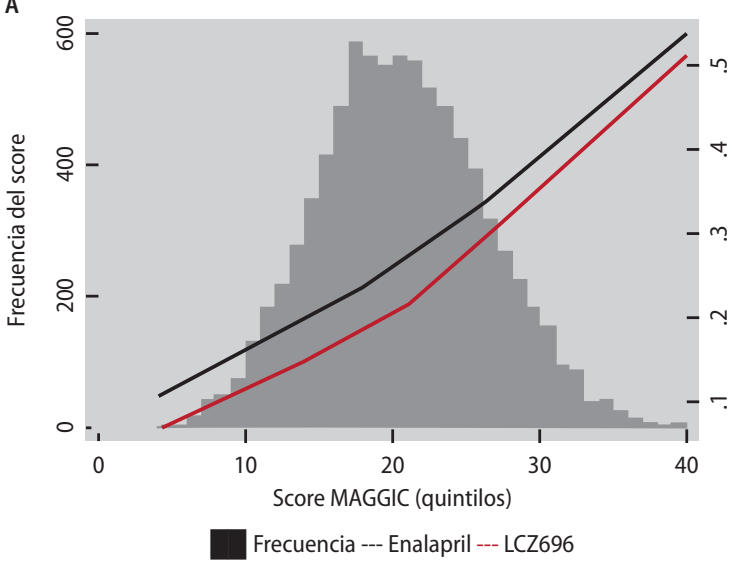

Figura 5. Distribución del riesgo de cada paciente según el score MAGGIC, dividido en quintilos, y su asociación con la posibilidad de alcanzar los puntos finales del PARADIGM-HF, con enalapril o LCZ696. Modificado de Simpson J, Jhund PS, Silva Cardoso J, Martinez F, Mosterd A, Ramires F, et al. Comparing LCZ696 With Enalapril According to Baseline Risk Using the MAG GIC and EMPHASIS-HF Risk Scores: An Analysis of Mortality and Morbidity in PARADIGM-HF. $J$ Am Coll Cardiol 2015;66(19):2059-2071

miento durante dos años, respecto a 4 de 100 pacientes del quintilo 1 (415) (Tabla 4 y Figura 6) ${ }^{49}$.

En 2015 se aprobó el LCZ696 por la FDA para el tratamiento de la insuficiencia cardíaca con fracción de eyección reducida ${ }^{50}$.

Al ser un fármaco nuevo, de reciente incorporación en la práctica clínica, aún permanecen poco dilucidados ciertos problemas de seguridad. Teóricamente, podría incrementar el riesgo de enfermedad de
Alzheimer ${ }^{51}$. A pesar de que aún no se conoce por completo la fisiopatología de esta enfermedad, se sabe que la proteína beta amiloidea participa en ella, y la misma es un sustrato de la neprilisina, con lo cual existe la hipótesis de que este fármaco generaría mayor generación y acumulación de placas amiloideas a nivel cerebral. Dado que el desarrollo de esta enfermedad en general es a largo plazo, desconocemos si este fármaco podría estar relacionado con su desarrollo, además de que el deterioro cognitivo no fue evaluado en el ensayo clínico del fármaco². Actualmente, se está llevando a cabo un nuevo estudio con sacubitril/valsartán en IC con FEy conservada, en el cual se incluye el análisis de la función cognitiva ${ }^{53}$.

\section{INDICACIONES}

El sacubitril/valsartán se recomienda como reemplazo de los IECA para reducir aún más el riesgo de muerte y hospitalizaciones por insuficiencia cardíaca, en pacientes ambulatorios, con fracción de eyección deteriorada, que persisten sintomáticos a pesar de tratamiento óptimo con IECA, betabloqueantes y un antagonista de los mineralocorticoides. Esta indicación es de clase I con nivel de evidencia B2,354.

\section{DISCUSIÓN}

Hemos realizado una revisión de la fisiopatología de la IC, con el sistema neurohormonal del SRAA como regulador y el sistema de péptidos natriuréticos como contrarregulador, permitiendo introducirnos al desarrollo de un nuevo fármaco, el sacubitril/valsartán, que actúa 


\begin{tabular}{|c|c|c|c|c|c|c|c|c|c|c|c|}
\hline \multirow[b]{3}{*}{ Resultado } & & \multicolumn{10}{|c|}{ Categoría de riesgo (puntos) } \\
\hline & & \multicolumn{2}{|c|}{$4-15(n=1762)$} & \multicolumn{2}{|c|}{$1618(n=1,637)$} & \multicolumn{2}{|c|}{$19-21(n=1,675)$} & \multicolumn{2}{|c|}{$22-25(n=1,842)$} & \multicolumn{2}{|c|}{$26-40(n=1459)$} \\
\hline & & $\begin{array}{l}\text { Enalapril } \\
(\mathrm{n}=859)\end{array}$ & $\begin{array}{l}\text { LCZ696 } \\
(n=903)\end{array}$ & $\begin{array}{l}\text { Enalapril } \\
(n=823)\end{array}$ & $\begin{array}{l}\text { LCZ696 } \\
(n=814)\end{array}$ & $\begin{array}{l}\text { Enalapril } \\
(n=865)\end{array}$ & $\begin{array}{l}\text { LCZ696 } \\
(n=810)\end{array}$ & $\begin{array}{l}\text { Enalapril } \\
(n=937)\end{array}$ & $\begin{array}{l}\text { LCZ696 } \\
(n=905)\end{array}$ & $\begin{array}{l}\text { Enalapril } \\
(\mathrm{n}=717)\end{array}$ & $\begin{array}{l}\text { LCZ696 } \\
(n=742)\end{array}$ \\
\hline $\begin{array}{l}\text { Muerte cardiovascular } \\
\text { u hospitalización }\end{array}$ & $\begin{array}{c}n \\
\operatorname{Rate}^{*}(95 \% \mathrm{Cl}) \\
\text { HR }(95 \% \mathrm{Cl})\end{array}$ & $\begin{array}{c}143 \\
7,6(6,4-8,9) \\
0,80(0,63-1,02)\end{array}$ & $\begin{array}{c}123 \\
6,1(5,1-7,3) \\
-\end{array}$ & $\begin{array}{c}203 \\
12,0(10,5-13,8) \\
0,69(0,56-0,86)\end{array}$ & $\begin{array}{c}145 \\
8,3(7,0-9,7) \\
-\end{array}$ & $\begin{array}{c}234 \\
13,6(11,9-15,4) \\
0,75(0,62-0,92)\end{array}$ & $\begin{array}{c}171 \\
10,2(8,8-11,8) \\
-\end{array}$ & $\begin{array}{c}263 \\
14,2(12,6-16,3) \\
0,89(0,74-1,06)\end{array}$ & $\begin{array}{c}230 \\
12,5(11,0-14,3) \\
-\end{array}$ & $\begin{array}{c}273 \\
20,618,3-23,20 \\
0,84(0,71-1,00)\end{array}$ & $\begin{array}{c}243 \\
17,2(15,2-19,5) \\
-\end{array}$ \\
\hline Muerte cardiovascular & $\begin{array}{c}n \\
\operatorname{Rate}^{*}(95 \% \mathrm{Cl}) \\
\text { HR }(95 \% \mathrm{Cl})\end{array}$ & $\begin{array}{c}79 \\
4,0(3,2-5,0) \\
0,90(0,65-1,23)\end{array}$ & $\begin{array}{c}75 \\
3,6(2,9-4,5) \\
-\end{array}$ & $\begin{array}{c}111 \\
6,0(5,0-7,3) \\
0,82(0,62-1,09)\end{array}$ & $\begin{array}{c}91 \\
5,0(4,0-6,1) \\
-\end{array}$ & $\begin{array}{c}146 \\
7,7(6,6-9,1) \\
0,68(0,52-0,88)\end{array}$ & $\begin{array}{c}94 \\
5,3(4,3-6,4) \\
-\end{array}$ & $\begin{array}{c}174 \\
8,7(7,5-10,1) \\
0,84(0,67-1,05)\end{array}$ & $\begin{array}{c}145 \\
7,3(6,2-8,6) \\
-\end{array}$ & $\begin{array}{c}182 \\
12,2(10,5-14,1) \\
0,80(0,65-0,99)\end{array}$ & $\begin{array}{c}153 \\
9,7(8,3-11,4) \\
-\end{array}$ \\
\hline $\begin{array}{l}\text { Hospitalización por } \\
\text { insuficiencia cardíaca }\end{array}$ & $\begin{array}{c}n \\
\operatorname{Rate}^{*}(95 \% \mathrm{Cl}) \\
\text { HR }(95 \% \mathrm{Cl})\end{array}$ & $\begin{array}{c}83 \\
4,4(3,6-5,5) \\
0,74(0,53-1,02)\end{array}$ & $\begin{array}{c}66 \\
3,3(2,6-4,2) \\
-\end{array}$ & $\begin{array}{c}128 \\
7,6(6,4-9,0) \\
0,53(0,40-0,71)\end{array}$ & $\begin{array}{c}70 \\
4,0(3,2-5,1) \\
-\end{array}$ & $\begin{array}{c}134 \\
7,8(6,6-9,2) \\
0,78(0,61-1,02)\end{array}$ & $\begin{array}{c}102 \\
6,1(5,0-7,4) \\
-\end{array}$ & $\begin{array}{c}146 \\
7,9(6,7-9,3) \\
0,97(0,77-1,22)\end{array}$ & $\begin{array}{c}139 \\
7,6(6,4-8,9) \\
-\end{array}$ & $\begin{array}{c}167 \\
12,6(10,8-14,7) \\
0,89(0,72-1,11)\end{array}$ & $\begin{array}{c}158 \\
11,1(9,6-13,1) \\
-\end{array}$ \\
\hline $\begin{array}{l}\text { Todas las causas } \\
\text { demuerte }\end{array}$ & $\begin{array}{c}n \\
\operatorname{Rate}^{*}(95 \% \mathrm{Cl}) \\
\text { HR }(95 \% \mathrm{Cl})\end{array}$ & $\begin{array}{c}105 \\
5,3(4,4-6,4) \\
0,86(0,65-1,13)\end{array}$ & $\begin{array}{c}95 \\
4,5(3,7-5,5) \\
-\end{array}$ & $\begin{array}{c}124 \\
6,7(5,6-8,0) \\
0,84(0,65-1,09)\end{array}$ & $\begin{array}{c}104 \\
5,7(4,7-6,9) \\
-\end{array}$ & $\begin{array}{c}168 \\
8,9(7,7-10,4) \\
0,79(0,63-1,00)\end{array}$ & $\begin{array}{c}126 \\
7,1(5,9-8,4) \\
-\end{array}$ & $\begin{array}{c}207 \\
10,3(9,0-11,8) \\
0,92(0,76-1,12)\end{array}$ & $\begin{array}{c}190 \\
9,5(8,3-11,0) \\
-\end{array}$ & $\begin{array}{c}230 \\
15,4(13,5-17,5) \\
0,80(0,66-0,97)\end{array}$ & $\begin{array}{c}194 \\
12,3(10,7-14,2) \\
-\end{array}$ \\
\hline
\end{tabular}

Mortality and Morbidity in PARADIGM-HF JAm Coll Gardiol 2015:66 (19):2059-2071

sobre este sistema neurohormonal, inhibiendo los receptores de la angiotensina y de la neprilisina ${ }^{44}$.

Sin dudas, la introducción de un nuevo fármaco no está exenta de elogios y críticas. En primer lugar, hay varios aspectos para destacar respecto al diseño del PARADIGM-HF. Un punto muy importante es el número de pacientes que incluyó. Gracias al elevado valor de la muestra para demostrar reducción de muerte cardiovascular que se propuso, y que logró, es que demostró tener un alto poder estadístico. Otro hecho es que se propuso comparar este nuevo fármaco con el enalapril, la piedra angular en el tratamiento de la insuficiencia cardíaca, y no con un placebo, y con la dosis en la que se comprobó que dicho fármaco disminuyó la mortalidad en la IC, en los históricos SOLVD y CONSENSUS. Este hecho le confiere gran validez interna al estudio. Pero al ganar en este punto, perdió en validez externa, debido a que la población estudiada no representó al gran universo de los pacientes con IC con los que nos enfrentamos, que no toleran dichas dosis. Como defensa al PARADIGM-HF, como pudimos observar en el trabajo y en las tablas, la mayoría de los participantes se encontraba en clase funcional (CF) II, y sólo una minoría, en CF IV, que son los pacientes que no toleran la dosis máxima en la práctica clínica, y que al remitirnos a los estudios con enalapril de hace casi 30 años, la población es estadísticamente similar en cuanto a clase funcional (la mayoría se encontraba en CF II) y tolerancia de la dosis máxima de enalapril.

Como críticas al PARADIGM-HF surgen en primer lugar el período de run in, por seleccionar a los pacientes, y de esa manera excluir a todos aquellos que pudieran presentar efectos adversos y a los intolerantes a altas dosis de enalapril. En contraposición a esta crítica, es que el TITRATION, como ya hemos expuesto, realizó un estudio con pacientes tratados con o sin IECA/ARAll, y a su vez, subdivididos en aquellos que toleraban dosis altas o bajas. En el mismo, no se encontraron diferencias estadísticamente significativas entre ambos grupos, ni entre los regímenes de titulación ${ }^{48}$.

Con respecto al CONSENSUS y al SOLVD, debemos aclarar que fueron realizados hace casi tres décadas, cuando el tratamiento de la insuficiencia cardíaca, y los afectados por ella, eran completamente distintos: la mayoría de los pacientes estaban tratados con digoxina y diuréticos, aún no se contaba con betabloqueantes ni con antagonistas de los mineralocorticoides, como contamos actualmente, y que sí recibió la población del PARADIGM-HF. Aun así, la rama tratada con sacubitril/valsartán demostró disminución de la mortalidad frente a la rama tratada con enalapril ${ }^{5-7}$.
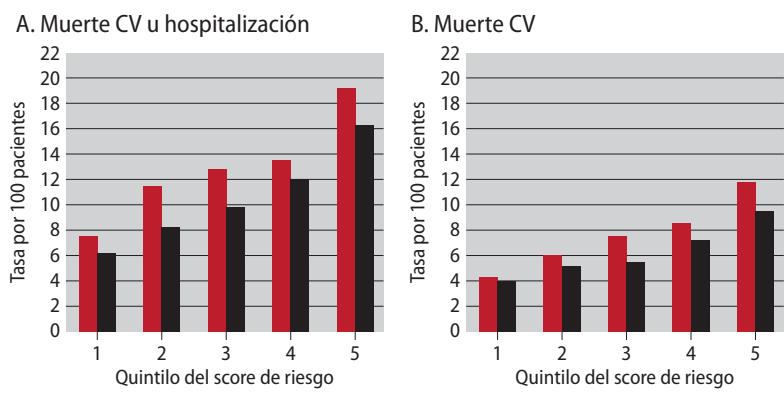

C. Hospitalizaciones por IC

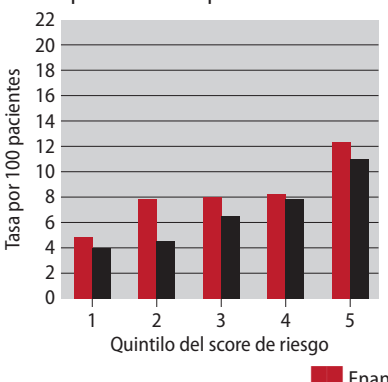

D. Muerte por todas las causas

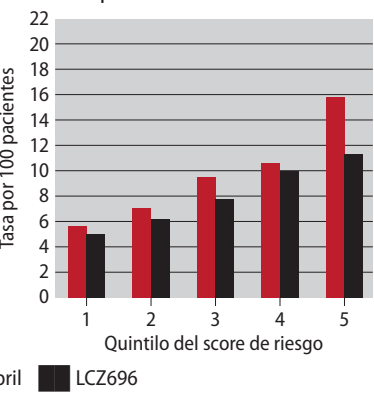

Figura 6. Después de clasificar a los pacientes del estudio PARADIGM-HF en quintiles en base la puntuación de riesgo del score MAGGIC, se determinó la tasa por cada 100 pacientes/año de seguimiento para: (A) el punto final primario compuesto, (B) muerte cardiovascular (CV), (C) hospitalizaciones por insuficiencia cardíaca (IC) y (D) mortalidad por todas las causas. La incidencia de todos los puntos finales aumentó progresivamente a mayor puntaje. El efecto de LCZ696 en comparación con enalapril fue consistentemente superior en reducir dicho riesgo. CV: cardiovascular. IC: insuficiencia cardiaca. Modificado de Simpson J, Jhund PS, Silva Cardoso J, Martinez F, Mosterd A, Ramires F, et al. Comparing LCZ696 With Enalapril According to Baseline Risk Using the MAGGIC and EMPHASIS-HF Risk Scores: An Analysis of Mortality and Morbidity in PARADIGM-HF. J Am Coll Cardiol 2015;66:2065.

Otro de los cuestionamientos que encontramos respecto del PARADIGM-HF es por qué se eligió compararlo con el enalapril, y no, por ejemplo, con el valsartán. Podemos decir que el estudio se propuso compararlo contra un fármaco de indicación clase I con nivel de evidencia A en IC. El valsartán está indicado en las guías como reemplazo del IECA en caso de no ser tolerado. También se discutió si la eficacia a favor del sacubitril/valsartán y en contra del enalapril, fue gracias al valsartán. Para ello, hemos revisado los principales estudios realizados con ARA II. Tanto el ELITE I como el ELITE I| compararon losartán con captopril, encontrándose que en ninguno de los dos casos el ARA II demostró superioridad respecto al IECA, ni en la inciden- 
cia de efectos adversos (ELITE I), ni en disminuir la mortalidad (ELITE II). Sin embargo, en el segundo, por ser un estudio no diseñado para probar no inferioridad, no se pudo afirmar que el losartán no fuera inferior al captopril. En otros ensayos, se decidió comparar si añadir un ARA II a pacientes ya tratados con IECA, disminuiría la mortalidad. Eso aconteció en el Val-HeFT, realizado con valsartán, y en el CHARMAdded, con candesartán, comparando con placebo. En ninguno de los dos se observó una disminución de la mortalidad a favor del agregado del ARA II. Incluso, en el Val-HeFT, se mostró aumento de la mortalidad. En el CHARM-Alternative, que comparó candesartán contra placebo, en los pacientes intolerantes al IECA, se advirtió una reducción de la mortalidad atribuida a dicho fármaco. Aun así, al día de hoy los ARA II no logran formar parte del grupo de los fármacos que disminuyen la mortalidad en IC con FEy disminuida (IECA, betabloqueantes y antagonistas de la aldosterona), y están indicados para los pacientes no toleren los IECA. Por ende, no podemos afirmar en base a los datos de la literatura actual que el beneficio demostrado en el PARADIGM-HF sea meramente gracias a la acción del valsartán.

Un punto que genera controversia en cuanto al fármaco, es por qué se necesita combinar al sacubitril con una segunda droga, y por qué se eligió un ARA II. Lo primero se explica por el hecho de que no alcanza solamente con inhibir la degradación de la neprilisina, sino que se necesita además bloquear el SRAA. Ya hemos enunciado el fracaso del candoxatril. El sacubitril otorgaría un efecto aditivo al aumentar los péptidos natriuréticos, pero no bastaría para atacar al desarreglo neurohormonal presente en la IC, por aumentar la AT II. Respecto al segundo punto, fue coherente haber elegido un ARA II para lograr ese cometido, puesto que ya se había analizado con el omapaprilat la combinación de un inhibidor de la neprilisina con un IECA, en el IMPRESS, en el OVERTURE y en el OCTAVE, lo que resultó en un incremento del angioedema y en la discontinuación del fármaco por la FDA. Esto tiene una explicación farmacológica, ya que al inhibir el SRAA, también se frena la degradación de bradiquininas, moléculas a las cuales se las responsabilizó por dicho aumento en la incidencia del angioedema. El ARA II, al actuar sobre un paso posterior de la cascada de SRAA, no aumenta las bradiquininas. Se podría atribuir a ello que el PARADIGM-HF no reportó mayor número de angioedema, y el éxito de su combinación ${ }^{41-43}$.

Respecto a la seguridad del fármaco, aún quedan algunos puntos por definir. El más conflictivo es el hecho de que aumentaría las posibilidades de desarrollar enfermedad de Alzheimer, dado que la proteína beta amiloidea es sustrato de la neprilisina. Debido a que el PARADIGM-HF fue suspendido prematuramente, no contamos con el tiempo suficiente para pesquisar dicho efecto en esa población, ni el estudio estaba diseñado para ello. Actualmente, se está llevando a cabo el PARAGON-HF, en el cual se está administrando el sacubitril/valsartán en pacientes con IC con fracción de eyección conservada, e incluye la evaluación neurocognitiva en el seguimiento de esta población $n^{51,53}$.

Como puntos de controversia respecto a los efectos adversos, es el mayor número de pacientes con hipotensión sintomática que generó el sacubitril/valsartán en el PARADIGM-HF, a pesar de que ello no produjo la suspensión del fármaco y que la diferencia promedio de tensión arterial fue sólo de 3,2 mmHg menor respecto al enalapril. Frente a este punto, nos volvemos a remitir al estudio TITRATION, el cual no tamizó a los pacientes, e incluyó tanto a los tolerantes a dosis altas como a bajas de IECA o ARA II, o ninguno, sin demostrar diferencias significativas entre ambos. También el mayor riesgo de angioedema, que a pesar de que no fue estadísticamente significativo, quedó latente, porque para realizar el estudio, se tamizó una población capaz de tolerar $20 \mathrm{mg} /$ día de enalapril, y sin historia previa de angioedema. A su vez, la población afro-americana, quienes presentarían mayor riesgo de angioedema, se reclutó en menor medida ${ }^{48}$.

Un punto a considerar en nuestro medio es el costo del sacubitril/ valsartán comparado con el del enalapril. A nivel mundial, sería muy importante contar con otro fármaco capaz de disminuir aún más la mortalidad de la insuficiencia cardíaca que el enalapril, no solo a nive personal, para poder otorgarle mejor calidad y expectativa de vida a cada paciente, sino también a nivel poblacional para reducir los gastos que esta patología genera, tan solo con el número de reinternaciones que produce anualmente, sin contar el costo de los tratamientos invasivos al llegar al estadio avanzado de la misma.

\section{CONCLUSIÓN}

En base a lo analizado, hemos visto que el advenimiento de los nuevos mecanismos de bloqueo neurohormonal con fármacos inhibidores de los receptores de la angiotensina y de la neprilisina, específicamente el sacubitril/valsartán, el primero en su clase, redujeron significativamente la mortalidad respecto a los inhibidores de la conversión de la angiotensina.

Como interrogantes, restan aún los análisis a futuro sobre la utilización de esta nueva droga en la población general, que no es la misma que la seleccionada para el ensayo clínico. Desconocemos aún cómo se comportará en otros tipos de poblaciones, quizás más comprometidas, como ya hemos visto a lo largo del trabajo, que no toleran la medicación clásica y a la dosis probada para reducir la mortalidad en la insuficiencia cardíaca, por lo que creemos que sería importante evaluar la efectividad del fármaco en el mundo real.

\section{BIBLIOGRAFÍA}

1. Mann DL. Tratamiento de los pacientes con insuficiencia cardiaca y fracción de eyección reducida. En Bonow R, Mann D, Zipes D, Libby P. Braunwald. Tratado de Cardiología: texto de medicina cardiovascular. (2015, Décima edición, 512-540). España: Editorial Elsevier.

2. Ponikowski P, Voors AA, Anker SD, Bueno H, Cleland JGF, Coats AJS, et al. ESC Guidelines for the diagnosis and treatment of acute and chronic heart failure. Rev Esp Cardiol 2016;69(12):1167.e1-e85.
3. Sociedad Argentina de Cardiología. Consenso de Insuficiencia Cardíaca Crónica. Rev Arg Cardiol. 2016;84(3):1-50.

4. Gradman AH. Evolving understanding of the rennin-angiotensin-aldosterone system pathophysiology and targets for therapeutic intervention. Am Heart J. 2009;157(6):1-6.

5. Hirvonen T, Pyorala K, Korhonen U, Takunen J, Gundersen T, Aslaksen B, et al. The CONSENSUS Trial Study Group. Effects of enalapril on mortality in severe congestive heart failure. N Engl J Med 1987;316(23):1429-1435. 
6. Nicklas JM, Timmis G, Breneman G, Jafri S, Duvernoy WFC, Davis SW, et al The SOLVD Investigators. Effect of enalapril on survival in patients with reduced left ventricular ejection fraction and congestive heart failure. N Engl J Med 1991:325(2):293-302

7. Nicklas JM, Pitt BP, Timmis G, Breneman G, Jafri SM, Duvernoy WFC, et al. The SOLVD Investigators. Effect of enalapril on mortality and the development of heart failure in asymptomatic patients with reduced left ventricular ejection fraction. N Engl I Med 1992;327(24):685-691.

8. Packer M, Bristow M, Cohn J, Colucci W, Fowler M, Gilbert E, et al. The effect of carvedilol on morbidity and mortality in patients with chronic heart failure. U.S. Carvedilol Heart Failure Study Group. N Engl J Med 1996;334(21):1349-1355.

9. Dargie H, Colucci W, Ford W, Lopez Sendon JL, Remme W, Sharpe N, et al. The CAPRICORN Investigators. Effect of carvedilol on outcome after myocardial infarction in patients with left-ventricular dysfunction: the CAPRICORN randomised trial. Lancet 2001;357(9266):1385-1390.

10. Packer M, Fowler MB, Roecker EB, Coats AJ, Katus HA, Krum H, et al. Effect of carvedilol on the morbidity of patients with severe chronic heart failure: results of the carvedilol prospective randomized cumulative survival (COPERNICUS) study. Circulation 2002:106(17):2194-2199.

11. Brunhuber KW, Hofmann R, Kühn P, Nesser HJ, Slany J, Weihs W, et al. The CIBIS II Investigators and Committees. A randomized trial of beta-blockade in heart failure. The cardiac insufficiency Bisoprolol Study II (CIBIS-II): a randomized trial. Lancet 1999;353(9146):9-13

12. Hjalmarson A, Goldstein S, Fagerberg B, Wedel H, Waagstein F, Kjekshus J, et al. MERIT-HF Study Group. Effect of metoprolol CRXL in chronic heart failure: Metoprolol CR/XL Randomised Intervention Trial in Congestive Heart Failure(MERIT-HF). Lancet 1999;353(9169):2001-2007.

13. Pitt B, Zannad F, Remme WJ, Cody R, Castaigne A, Perez A, et al. The effect of spironolactone on morbidity and mortality in patients with severe heart failure. Randomized Aldactone Evaluation Study Investigators. N Engl J Med 1999;341(10):709-717.

14. Pitt B, RemmeW, Zannad F, Neaton J, Martinez F, Roniker B, et al. Eplerrenone, a selective aldosterone blocker, in patients with left ventricular dysfunction after myocardial infarction. NEngl J Med 2003;348(14):1309-1321.

15. Zannad F, McMurray JJ, Krum H, van Veldhuisen DJ, Swedberg K, Shi H, et al. Eplerrenone in patients with systolic heart failure and mild symptoms. NEngl J Med. 2011;364(1): 11-21.

16. Pitt B, Segal R, Martinez FA, Meurers G, Cowley AJ, Thomas I, et al. Randomised trial of losartan versus captopril in patients over 65 with heart failure (Evaluation of Losartan in the Elderly Study, ELITE). Lancet 1997;349(9054):747-752.

17. Pitt B, Poole-Wilson PA, Segal R, Martinez FA, Dickstein K, Camm A, et al. Effect of Losartan compared with captopril on mortality in patients with symptomatic heart failure: randomized trial - the Losartan Heart Failure Survival Study ELITE II. Lancet 2000; 355(9215):1582-1587.

18. Cohn JN, Tognoni G; Valsartan Heart Failure Trial Investigators. A Randomized Trial of the Angiotensin-Receptor Blocker Valsartan in Chronic Heart Failure. N Engl J Med 2001;345(23):1667-1675.

19. Granger CB, McMurray JJ, YusufS, Held P, Michelson EL, Olofsson B, et al. Effects of candesartan in patients with chronic heart failure and reducer left-ventricular systolic function intolerant to angiotensin-converting-enzyme inhibitors: the CHARM-Alternative trial. Lancet 2003:362(9386):772-776.

20. Hasenfuss G, Mann DG. Fisiopatología de la insuficiencia cardíaca. En Bonow R, Mann D, Zipes D, Libby P. Braunwald. Tratado de Cardiología: texto de medicina cardiovascular. (2015, Décima edición, 454-473). España: Editorial Elsevier.

21. Maron BA, Rocco TP. Farmacoterapia de la insuficiencia cardiaca congestiva. En Brunton L, Chabner B, Knollman B. Goodman \& Gilman. Las bases farmacológicas de laterapéutica. (2012, Doceava Edición, 511-540). México: Editorial Mc Graw Hill.

22. Pitt B. "Escape" of aldosterone production in patients with left ventricular dysfunction treated with an angiotensin converting enzyme inhibitor: implications for therapy. Cardiovasc Drugs Ther. 1995; 9(1):145-149.

23. Maalouf $R$, Bailey $S$. A review on B-type natriuretic peptide monitoring: assays and biosensors. Heart failure reviews 2016;21(5):567-578.

24. Bold AJ, Borenstein HB, Veress AT, Sonnenberg H. A rapid and potent natriuretic response to intravenous injection of atrial myocardial extract in rats. Life sci. 1981; 28(1): 89-94.

25. Kone BC. Molecular biology of natriuretic peptides and nitric oxide synthases. CardiovasC Res 2001;51(3):429-441.

26. Sudoh T, Kangawa K, Minamino N, Matsuo H. A new natriuretic peptide in porcine brain. Nature 1988,332(6159):78-81.

27. Mukoyama M, Nakao K, Hosoda K, Suga S, Saito Y, Ogawa Y, et al. Brain natriuretic peptide as a novel cardiac hormone in humans. Evidence for an exquisite dual natriuretic peptide system, atrial natriuretic peptide and brain natriuretic peptide. J Clin Invest 1991:87(4):1402-1412.

28. Ichiki T, Huntley BK, Heublein DM, Sandberg SM, McKie PM, Martin FL, et al. Corin is present in the normal human heart, kidney, and blood, with pro-B-type natriuretic peptide processing in the circulation. Clin Chem 2011;57(1):40-47.

29. Langenickel T, Dole W. Angiotensin receptor neprylisin inhibition with LCZ696: a novel approach for the treatment of heart failure. Drug Discovery Today Therapeutic Strategies 2014;9(4):131-139.
30. Marcus LS, Hart D, Packer M, Yushak M, Medina N, Danziger RS, et al. Hemodynamic and renal excretory effects of human brain natriuretic peptide infusion in patients with congestive heart failure. A double-blind, placebo-controlled, randomized crossover trial. Circulation 1996:94(12):3184-3189.

31. Hayashi D, Kudoh S, Shiojima I, Zou Y, Harada K, Shimoyama M, et al. Atrial natriuretic peptide inhibits cardiomyocite hypertrophy through mitogen-activated protein kinase phosphatase-1. Biochem Biophys Res Commun 2004;322(1):310-319.

32. Maisel AS, Krishnaswamy P, Nowak RM, McCord J, Hollander JE, Duc P, et al. Rapid measurement of $B$-Type natriuretic peptide in the emergency diagnosis of heart failure. $N$ Engl J Med 2002;347(3):161-167.

33. Januzzi JL Jr, Camargo CA, Anwaruddin S, Baggish AL, Chen AA, Krauser DG, et al. The $\mathrm{N}$-terminal Pro-BNP investigation of dyspnea in the emergency department (PRIDE) study. Am J Cardiol 2005;95(8):948-954.

34. Silver MA, Maisel A, Yancy CW, McCullough PA, Burnett JC Jr, Francis GS, et al. BNP Consensus Panel 2004: A clinical approach for the diagnostic, prognostic, screening, treatment monitoring, and therapeutic roles of natriuretic peptides in cardiovascular diseas es. Congestive Heart Fail 2004; 10(5): 1-30.

35. Januzzi JL, Mann DL. Valoración clínica de la insuficiencia cardíaca En Bonow R, Mann D, Zipes D, Libby P. Braunwald. Tratado de Cardiología: texto de medicina cardiovascular. (2015, Décima edición, 473-484). España: Editorial Elsevier.

36. Wang TJ, Larson MG, Levy D, Benjamin EJ, Leip EP, Wilson PW, et al. Impact of obesity on plasma natriuretic peptide levels. Circulation. 2004, 109(05): 594-600.

37. Miller WL, Phelps MA, Wood CM, Schellenberger U, Van Le A, Perichon R, et al. Comparison of mass spectrometry and clinical assay measurements of circulating fragments of B-type natriuretic peptide in patients with chronic heart failure. Circ Heart Fail 2011;4(3):355-60.

38. Thierer, J. Fisiopatología. En Thierer J. Insuficiencia cardíaca: evidencia, experiencia y opinión (2014, primera edición, 287-295). Buenos Aires: Editorial Intermédica.

39. Elsner D, Müntze A, Kromer EP, Riegger GA. Effectiveness of endopeptidase inhibition (candoxatril) in congestive heart failure. Am J Cardiol 1992;70(4):494-498.

40. Richards AM, Wittert GA, Crozier IG, Espiner EA, Yandle TG, Ikram H , et al. Chronic inhibition of endopeptidase 24.11 in essential hypertension: evidence for enhanced atrial na triuretic peptide and angiotensin II. J Hypertens 1993;11 (4):407-416.

41. Rouleau JL, Pfeffer MA, Stewart DJ, Isaac D, Sestier F, Kerut EK, et al. Comparison of vasopeptidase inhibitor, omapatrilat, and lisinopril on exercise tolerance and morbidity in patients with heart failure: IMPRESS randomized trial. Lancet 2000;356(9230):615-620.

42. Packer M, Califf RM, Konstam MA, Krum H, McMurray JJ, Rouleau JL, et al. Comparison of omapatrilat and enalapril in patients with chronic heart failure: the Omapatrilat Versus Enalapril Randomized Trial of Utility in Reducing Events (OVERTURE). Circulation 2002;106(8):920-926

43. Kostis JB, Packer M, Black HR, Schmieder R, Henry D, Levy E. Omapatrilat and enalapril in patients with hypertension: the Omapatrilat Cardiovascular Treatment vs. Enalapril (OCTAVE) trial. Am J Hypertens 2004;17(2):103-111.

44. Tyler JM, Teerlink JR. The safety of sacubitril-valsartan for the treatment of chronic heart failure. Expert Opin Drug Saf. 2017;16(2):257-263.

45. Gu J, Noe A, Chandra P, Al-Fayoumi S, Liqueros-Saylan M, Sarangapani R, et al. Pharmacokinetics and pharmacodynamics of LCZ696, a novel dual-acting angiotensin receptor-neprilysin inhibitor (ARNi). J Clin Pharmacol. 2010; 50(4):401-414.

46. MCMurray JJ, Packer M, Desai AS, Gong J, Lefkowitz MP, Rizkala AR, et al. Angiotensin-neprilysin inhibition versus enalapril in heart failure. N Engl J Med. 2014; 371(11) 993-1004.

47. Packer M, McMurray JJ, Desai AS, Gong J, Lefkowitz MP, Rizkala AR, et al. Angiotensin receptor neprilysin inhibition compared with enalapril on the risk of clinical progression in surviving patients with heart failure. Circulation 2015;131(1):54-61.

48. Senni M, McMurray JJ, Wachter R, McIntyre HF, Reyes A, Majercak I, et al. Initiating sacubitril/valsartan (LCZ696) in heart failure: results of TITRATION, a double-blind, random ized comparison of two uptitration regimens. Eur J Heart Fail 2016;18(9):1193-1202.

49. Simpson J, Jhund PS, Silva Cardoso J, Martinez F, Mosterd A, Ramires F, et al. Comparing LCZ696 With Enalapril According to Baseline Risk Using the MAGGIC and EMPHASIS-HF Risk Scores: An Analysis of Mortality and Morbidity in PARADIGM-HF. J Am Coll Cardiol 2015;66(19):2059-2071.

50. Fala L. Entresto (SacubitrilNalsartan): First-in-Class Angiotensin Receptor Neprilysin Inhibitor FDA Approved for Patients with Heart Failure. Am Health Drug Benefits 2015;8(6),330-334.

51. Vodovar N, Paquet C, Mebazaa A, Launay JM, Hugon J, Cohen-Solal A. Neprilysin, Cardiovascular, and Alzheimer's diseases: the therapeutic split? Eur Heart J 2015;36(15):902-905.

52. Bayes-Genis A, Lupón J. Neprilisina: indicaciones, expectativas y retos. Rev Esp Cardiol 2016;69(7):647-649.

53. Solomon SD, Rizkala AR, Gong J, Wang W, Anand IS, Ge J, Pfeffer MA et al. Angiotensin receptor neprilysin inhibition in heart failure with preserved ejection fraction: rationale and design of the PARAGON-HF trial. JACC: Heart Failure 2017;5(7):471-482.

54. Yancy C, Jessup M, Bozkurt B, Butler J, Casey D Jr., M.Colvin M, et al. 2016 ACC/AHAVHFSA Focused Update on New Pharmacological Therapy for Heart Failure: An Update of the 2013 ACCF/AHA Guideline for the Management of Heart Failure: A Report of the American College of Cardiology/American Heart Association Task Force on Clinical Practice Guidelines and the Heart Failure Society of America. J Am Coll Cardiol 2016;68(13):1476-1488. 


\title{
PREVALENCIA DEL BLOQUEO INTERAURICULAR AVANZADO EN PACIENTES REVERTIDOS DE FIBRILACIÓN AURICULAR
}

\author{
INTERATRIAL BLOCK PREVALENCE IN PATIENTS WITH REVERTED ATRIAL \\ FIBRILLATION
}

\section{FLORENCIA FORESSI' ${ }^{1}$ VICTORIA HOYLE², FLORENCIA TRAFICANTE ${ }^{3}$, ROMINA DEGANUTTO ${ }^{4}$, M. BELÉN CIGALINI ${ }^{4}$, J. MARTÍN GALIANO5, CARLOS DUMONT ${ }^{4}$, JORGE GARGUICHEVICH ${ }^{4}$}

\section{RESUMEN}

Introducción. El bloqueo interauricular (BIA) representa un sustrato anatomoeléctrico para el desarrollo de arritmias supraventriculares. Su prevalencia en pacientes con fibrilación auricular (FA) no ha sido claramente estudiada. El objetivo de este trabajo es determinar la prevalencia de BIA en pacientes internados por FA y revertidos a ritmo sinusal.

Métodos. Estudio observacional, analítico, prospectivo, unicéntrico. Se incluyeron pacientes internados por fibrilación auricular (FA) y que hubieran presentado en cualquier momento de su evolución reversión a ritmo sinusal. Post reversión inmediata se realizó un electrocardiograma. A todos los pacientes se les realizó un ecocardiograma transtorácico para evaluar el tamaño de la aurícula izquierda (Al).

Resultados. Se incluyeron 48 pacientes, con una edad promedio de 67,7 años y $56,2 \%$ de sexo masculino. Veintiún pacientes $(43,7 \%)$ presentaron historia previa de FA. El 72,9\% de los pacientes fueron revertidos por cardioversión eléctrica, $12,5 \%$ farmacológica y $14,6 \%$ espontánea. El tamaño de la Al por ecocardiografía fue normal en el 6,2\% de los pacientes, levemente dilatada en el $62,5 \%$, moderada en el $27,1 \%$ y severa en el $4,2 \%$. La duración promedio de la onda $\mathrm{P}$ fue de $128,1 \mathrm{~ms}$. La presencia de componente negativo en las 3 derivaciones de la cara inferior solo se observó en el 4,2\% de los pacientes.

Conclusión. En nuestra población, la incidencia de BIA en pacientes revertidos de FA fue baja.

Palabras clave: bloqueo interauricular; fibrilación auricular; arritmias cardíacas.

\section{ABSTRACT}

Introduction. Interatrial block (IAB) represents ananatomo electric substrate for the development of supraventricular arrhythmias. Its prevalence in patients with atrial fibrillation (AF) has not been clearly studied. The objective of this study is to determine the prevalence of IAB in patients hospitalized for AF and reverted to sinus rhythm.

Methods. Observational, analytical, prospective, single-center study. We included patients admitted for atrial fibrillation (AF) and who presented at any time during their evolution a sinus rhythm reversion. After immediate reversal, an electrocardiogram was performed. All patients underwent a transthoracic echocardiogram to evaluate the size of the left atrium (LA).

Results. 48 patients were included, with an average age of 67.7 years. $56.2 \%$ were males. Twenty-one patients (43.7\%) presented a history of AF. $72.9 \%$ of patients were reversed by electrical cardioversion, $12.5 \%$ pharmacological and $14.6 \%$ spontaneous. The size of the LA by echocardiography was normal in $6.2 \%$ of the patients, slightly dilated in $62.5 \%$, moderate in $27.1 \%$ and severe in $4.2 \%$. The average duration of the $P$ wave was $128.1 \mathrm{msec}$. The presence of a negative component in the 3 branches of the inferior side was only observed in $4.2 \%$ of the patients.

Conclusions. In our population, the incidence of IAB in patients with AF was low.

Keywords: interatrial block; atrial fibrillation; cardiac arrhythmias.

REVISTA CONAREC 2018;33(145):176-178 | DOI:10.32407/RCON/2018145/0176-0178

\section{INTRODUCCIÓN}

El hallazgo de ondas $P$ ensanchadas y con muescas es muy frecuente en el curso evolutivo de muchas cardiopatías, pudiéndose explicar en base a un crecimiento auricular izquierdo. Sin embargo, una onda $P \geq 120$ ms no implica exclusivamente el concepto de agrandamiento auricular izquierdo ya que puede tratarse de un bloqueo interauricular (BIA); de hecho, ambas entidades suelen coexistir y los criterios electrocardiográficos superponerse ${ }^{1-3}$. Tanto en nuestra experien-

1. Jefe de residentes de Cardiología.

2. Residente de Cardiología

3. Instructor de residentes de Cardiología.

4. Médico de planta de Cardiología.

5. Ex residente de Cardiología.

Hospital Privado de Rosario. Rosario, Santa Fe, Rep. Argentina

$\triangle$ Correspondencia: Dra. Florencia Foressi. Dorrego 59 Bis 7 mo B. CP 2000. Rosario SantaFe.Argentina.floforessi@gmail.com.

Los autores declaran no poseer conflictos de intereses.

Recibido: 11/10/2017 | Aceptado: 27/08/2018 cia como en la de otros autores, la presencia de "muescas" en la onda $P$ es un dato a considerar, ya que suele acompañar frecuentemente a los BIA 4,5 .

El BIA representa un sustrato anatomoeléctrico para el desarrollo de arritmias supraventriculares, en particular fibrilación auricular (FA), como bien lo describió a fines de la década de los setenta el Dr. Bayés de Luna, hoy conocido como síndrome de Bayés ${ }^{6-9}$.

Los BIA pueden clasificarse en parcial (Figura 1), donde el retraso existiría en la zona del haz de Bachmann (evidenciado por una onda $P \geq 120 \mathrm{~ms}$, con o sin muescas, sin componente negativo final en las derivaciones inferiores), y en avanzado (Figura 2), donde la despolarización de la aurícula izquierda (Al) se produce por la estimulación a partir de la aurícula derecha (por el seno coronario y en menor parte por la fossa ovalis) con una dirección retrógrada caudocraneal, generando una onda $\mathrm{P} \geq 120$ mseg con la presencia de un componente negativo final en las 3 derivaciones inferiores.

Además de los trabajos de Bayés de Luna, diferentes investigadores han demostrado que el BIA avanzado representa un marcador de riesgo de FA o de recurrencia de la misma ${ }^{10-14}$. Su prevalencia en pacientes con FA no ha sido claramente determinada. La mayoría de los estudios incluyen en forma conjunta la presencia de BIA parcial y avanzado. 


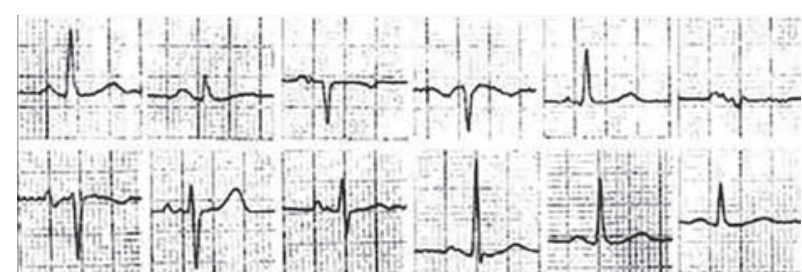

Figura 1. Bloqueo interauricular parcial. BIA: bloqueo interauricular. FA: fibrilación auricular. Modificado de: Cigalini MB, Deganutto R, Galiano JM, Foressi F, Sanziani L, Cardona M, et al. Evaluación de los marcadores electrocardiográicos de riesgo de fibrilación auricular en pacientes sin cardiopatía estructural significativa. Rev Fed Arg Cardiol 2015;44(4):29-33.

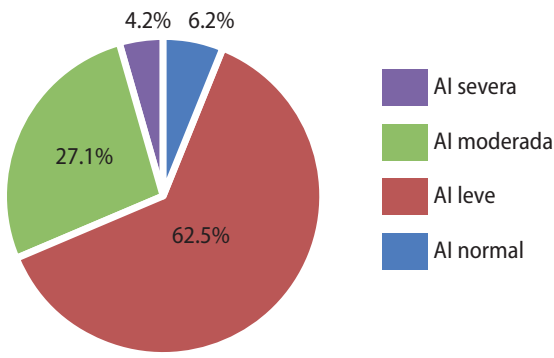

Figura 3. Distribución acorde a tamaño de la aurícula izquierda. Al: aurícula izquierda.

El objetivo de este trabajo es determinar la prevalencia de BIA avanzado en pacientes internados por FA y revertidos a ritmo sinusal, ampliando los registros electrocardiográficos de forma digital, para analizar mejor la morfología de la onda P.

\section{MATERIALES Y MÉTODOS}

Se realizó un estudio observacional, analítico, prospectivo, unicéntrico, desde julio de 2016 hasta febrero de 2017. Se incluyeron pacientes de cualquier edad, sexo y patología, internados por FA en nuestra Unidad Coronaria y que hayan presentado en cualquier momento de su evolución reversión a ritmo sinusal. Inmediatamente posreversión se realizó un electrocardiograma de 12 derivaciones con voltaje habitual, que luego fue ampliado de forma digital. A todos los pacientes se les realizó un ecocardiograma transtorácico para evaluar el tamaño de la Al.

Las variables discretas se expresaron como porcentajes y las continuas, según su distribución, como media y desvío estándar (DE) o mediana y rango intercuartilo.

\section{CONSIDERACIONES ÉTICAS}

El Comité de Docencia e Investigación institucional aprobó el presente trabajo y todos los pacientes han dado su consentimiento por escrito. El trabajo respeta las propuestas de la Declaración de Helsinki.

\section{RESULTADOS}

Se incluyeron 48 pacientes, con una edad promedio de 67,7 años (3489) el 56,2\% de sexo masculino. Veintiún pacientes $(43,7 \%)$ presentaron historia previa de FA.

La patología predominante fue la hipertensión arterial (58,3\%) (Tabla 1). El tamaño de la Al por ecocardiografía fue normal en 3 pacientes $(6,2 \%)$, dilatada de manera leve en 30 (62,5\%), moderada en 13

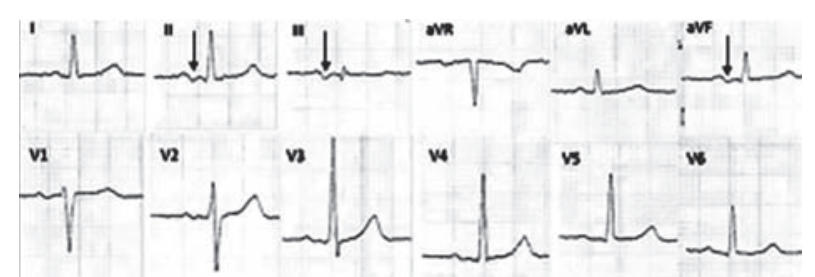

Figura 2. Bloqueo interauricular avanzado. BIA: bloqueo interauricular. FA: fibrilación auricular. Modificado de: Cigalini MB, Deganutto R, Galiano JM, Foressi F, Sanziani L, Cardona M, et al. Evaluación de los marcadores electrocardiográficos de riesgo de fibrilación auricular en pacientes sin cardiopatía estructural significativa. Rev Fed Arg Cardiol 2015;44(4):29-33.

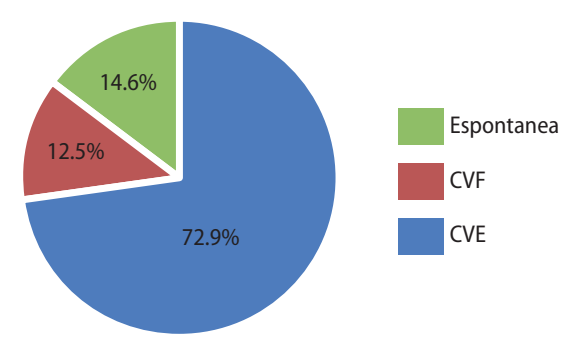

Figura 4. Distribución acorde a tipo de reversión de fibrilación auricular. FA: fibrilación auricular. CVE: cardioversión eléctrica. CVF: cardioversión farmacológica

Tabla 1. Características basales $(n=48)$.

\begin{tabular}{|c|c|}
\hline Edad media (años) & 67,7 \\
\hline Sexo masculino - n (\%) & $27(56,2 \%)$ \\
\hline Historia previa de FA - n (\%) & $21(43,7 \%)$ \\
\hline Al normal - n (\%) & $3(6,2 \%)$ \\
\hline Agrandamiento Al leve - n (\%) & $30(62.5 \%)$ \\
\hline Agrandamiento Al moderado - n (\%) & $13(27,1 \%)$ \\
\hline Agrandamiento Al severo - $\mathrm{n}(\%)$ & $2(4,2 \%)$ \\
\hline HTA - n (\%) & $28(58,3 \%)$ \\
\hline Cardiopatía isquémica - n (\%) & $9(18,7 \%)$ \\
\hline Valvulopatía - n (\%) & $7(14,5 \%)$ \\
\hline AIT - n (\%) & $2(4,2 \%)$ \\
\hline Enfermedad vascular periférica - n (\%) & $3(6,2 \%)$ \\
\hline Sin cardiopatía estructural - n (\%) & $12(25 \%)$ \\
\hline
\end{tabular}

FA: fibrilación auricular. Al: aurícula izquierda. HTA: hipertensión arterial. AlT: accidente isquémico transitorio.

$(27,1 \%)$ y severa en $2(4,2 \%)$ (Figura 3). Treinta y cinco pacientes $(72,9 \%)$ fueron revertidos por cardioversión eléctrica, 6 (12,5\%) farmacológica y 7 (14,6\%) lo hicieron de forma espontánea (Figura 4). La duración promedio de la onda P fue de 128,1 ms (120-200), 39 de las cuales $(81,25 \%)$ presentaron muescas. La presencia de componente negativo en las 3 derivaciones de la cara inferior solo se observó en 2 pacientes (4,2\%), 1 de ellos con historia previa de FA. En 6 pacientes (12,5\%) se registró en dos derivaciones (predominando D III y aVF), 2 de ellos con antecedentes de FA. En 10 pacientes (20,8\%) se visualizó en una sola derivación (D III en el 90\% de los casos).

\section{DISCUSIÓN}

En nuestra población de pacientes recientemente revertidos de FA, la prevalencia de BIA avanzado fue baja (4,2\%).

Hemos encontrado un solo trabajo similar efectuado en 61 pacientes re- 
vertidos farmacológicamente de FA. En él la prevalencia del BIA avanzado fue del $18 \%$ con una recurrencia de FA en estos pacientes del $90 \%$ al año ${ }^{11}$. EI BIA existe como entidad anatomoeléctrica y debe ser considerado como un verdadero bloqueo, con diferentes grados, al igual que los otros bloqueos del sistema de conducción. Se encuentra fuertemente asociado con arritmias supraventriculares y es probablemente un predictor de accidente cerebrovascular cardioembólico ${ }^{15-18}$. Un simple electrocardiograma permite la identificación inmediata de la patente de BIA avanzado.

La limitante principal de nuestro estudio ha sido el bajo de número de pacientes. Es probable que estudios de mayores dimensiones, que

\section{BIBLIOGRAFÍA}

1. Tsao CW, Josephson ME, Hauser TH, O'Halloran TD, Agarwal A, Manning WJ, et al. Accuracy of electrocardiographic criteria for atrial enlargement: validation with cardiovascular magnetic resonance. J Cardiovasc Magn Reson 2008;10(1):7.

2. Spodick DH, Ariyarajah V. Interatrial block: the pandemic remains poorly perceived. Pacing Clin Electrophisiol 2009:32(5):667-72.

3. Galiano J, Deganutto R, Cigalini M, Foressi F, Hoyle V, Dumont D, et al. Precisión de los criterios electrocardiográficos para el diagnóstico de agrandamiento auricular izquierdo. ¿Agrandamiento auricular izquierdo o trastorno de conducción auricular? (Octubre de 2015). Poster presentado en XXXIV Congreso Nacional de Cardiología.

4. Ariyarajah V, Apiyasawat $S$, Puri P, Spodick DH. Specific electrocardiographic markers of P-wave morphology in interatrial block. J Electrocardiol 2006;39(4):380-4.

5. Cigalini MB, Deganutto $R$, Galiano JM, Foressi F, Sanziani L, Cardona $M$, et al. Evaluación de los marcadores electrocardiográficos de riesgo de fibrilación auricular en pacientes sin cardiopatía estructural significativa. Rev Fed Arg Cardiol 2015:44(4):29-33.

6. Bayés de Luna A. Bloqueo a nivel auricular. Rev Esp Cardiol 1979;32(1):5-10

7. Bayés de Luna A, Fort de Ribot R, Trilla E, Julia J, García J, Sadurni J, et al. Electrocardiographic and vector cardiographic study of interatrial conduction disturbances with left atrial retrograde activation. J Electrocardiol 1985; 18(1):1-13.

8. Bayés de Luna A, Platonov P, Cosio FG, Cygankiewicz I, Pastore C, Baranowski R, et al. Interatrial blocks. A separate entity from left atrial enlargement: a consensus report. J Electrocardiol 2012;45(5):445-51.

9. Conde D, Baranchuk A. Bloqueo interauricular como sustrato anatómico-eléctrico de arritmias supraventriculares: sindrome de Bayés. Arch Cardiol Mex 2014;84(1):32-40 incluyan además pacientes con mayor patología, puedan demostrar otra prevalencia.

\section{CONCLUSIÓN}

En nuestra población, la incidencia de BIA avanzado en pacientes revertidos de FA fue baja. A pesar de esto, su pronto reconocimiento ayudaría a un monitoreo cardíaco más intensivo en busca de FA y a la iniciación más temprana de anticoagulación y/o tratamiento antiarrítmico, ayudándonos de esa manera a prevenir accidentes cerebrovasculares y sus devastadoras consecuencias.

10. Caldwell JC, Koppikar S, Barake W, Redfearn DP, Michael K, Simpson C, et al. Advanced interatrial block is associated with atrial fibrillation recurrence after successful pulmonary vein isolation for paroxysmal atrial fibrillation. J Electrocardiol 2013;46(1):e1.

11. Enríquez A, Conde D, Hopman W, Mondragon I, Chiale PA, De Luna AB, et al. Advanced interatrial block is associated with recurrence of atrial fibrillation post pharmacological cardioversion. Cardiovasc Ther 2014;32(2):52-6.

12. Enríquez A Conde D, Femenía F De Luna AB, Ribeiro A, Muratore C et al Relation of interatrial block to new-onset atrial fibrillation in patients with Chagas cardiomyopathy and implantable cardioverter defibrillators. Am J Cardiol 2014:113(10):1740-3

13. Enríquez A, Sarrias A, Villuendas R, Ali FS, Conde D, Hopman WM, et al. New-onset atrial fibrillation after cavotricuspid isthmus ablation: identification of advanced interatrial block is key. Europace 2015;17(8):1289-93.

14. Tekkesin Al, Çinier G, Cakilli Y, Hayıroğlu MI, Alper AT. Interatrial block predicts atri al high rate episodes detected by cardiac implantable electronic devices. J Electrocardiol 2017:50(2):234-7.

15. Ariyarajah V, Apiyasawat S, Najjar H, Mercado K, Puri P, Spodick DH. Frequency of interatrial block in patients with sinus rhythm hospitalized for stroke and comparison to those without interatrial block. Am J Cardiol 2007:99(1):49-52.

16. Ariyarajah V, Puri P, Apiyasawat S, Spodick DH. Interatrial block: A novel risk factor for embolic stroke? Ann Noninvasive Electrocardiol 2007;12(1):15-20.

17. Martinez-Selles M, Baranchuk A, Elosua R, Bayes de Luna A, O'neal WT, Kamel H, et al. Advanced interatrial block and ischemic stroke: The Atherosclerosis Risk In Communities Study. Neurology 2016;87(23):2499.

18. Martinez-Selles M, Escobar LA, Baranchuk A. Interatrial block and the risk of ischemic stroke. J Atheroscler Thromb 2017;24(2):185-6. 


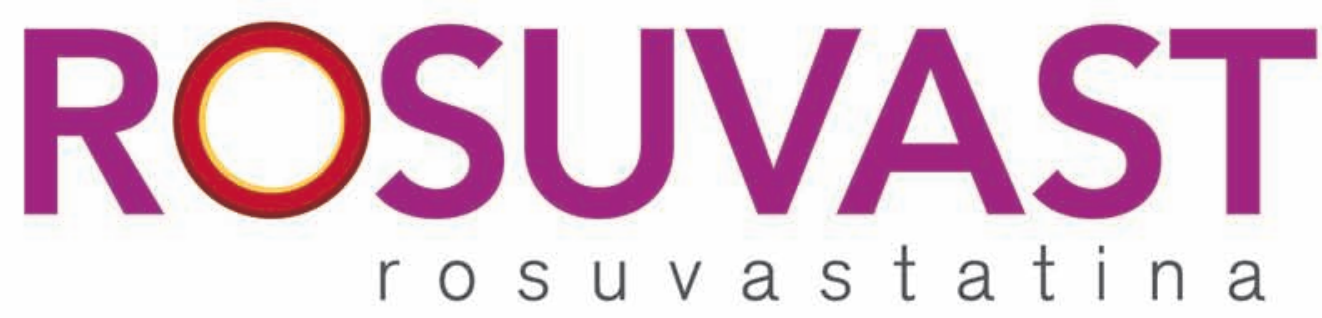

\section{Una categoría superior en estatinas, con máxima efectividad.}

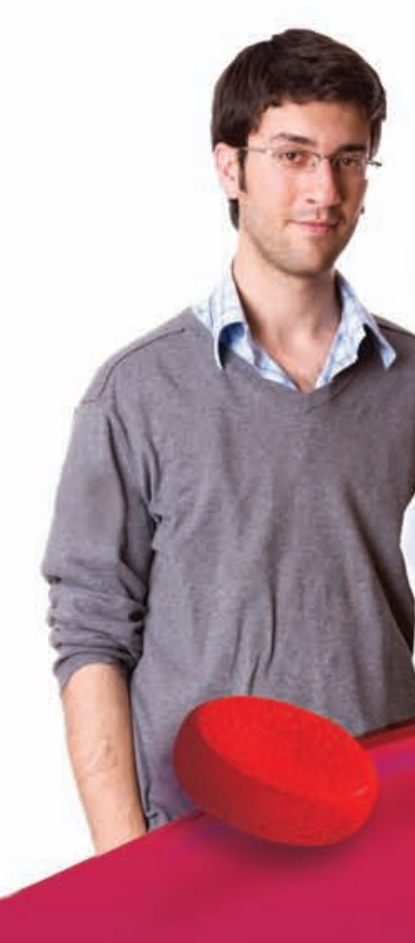

Rosuvast 10 mg: comprimidos x 14, 28 y 56.

Rosuvast 5/20/40 mg: comprimidos $\times 28$.
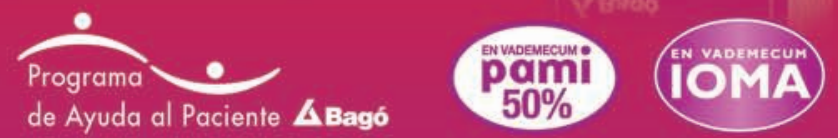

Composición: Cada comprimido recubierto contiene: Rosuvastatina $5,10,20$ ò $40 \mathrm{mg}$. Acción Terapéutica: Inhibidor de la HMG-CoA reductasa. Indicaciones: Hiperlipidemia y Dislipidemia Mixta. Hipertrigliceridemia. Disbetalipoproteinemia primaria (Hiperlipoproteinemia Tipo III). Hipercolesterolemia Familiar Homocigota. Enlentecimiento de la Progresión de la Aterosclerosis. Prevención de eventos cardiovasculares. Posologia: 5 a $40 \mathrm{mg}$ una vez por dia por vía oral, con o sin alimentos; $40 \mathrm{mg}$, solo si no se alcanza el objetivo de colesterol-LDL con $20 \mathrm{mg}$. Dosis inicial habitual: $10 \mathrm{mg} / \mathrm{dia}$. Marcada hiperlipidemia y objetivos terapéuticos agresivos, dosis inicial: $20 \mathrm{mg}$. Los niveles lipidicos deben analizarse dentro de las 2 a 4 semanas y la dosis debe ajustarse. Hipercolesterolemia familiar homocigota: dosis inicial $20 \mathrm{mg} /$ dia. Pacientes asiáticos: dosis inicial $5 \mathrm{mg} / \mathrm{dia}$. Con ciclosporina: limitar dosis a $5 \mathrm{mg}$ /dia. Con lopinavir y ritonavir: limitar dosis a $10 \mathrm{mg} / \mathrm{dia}$. Con niacina o fenofibrato: reducir la dosis. Con /dia. Con lopinavir y ritonavir: limitar dosis a $10 \mathrm{mg} /$ dia. Con niacina o fenofibrato: reducir la dosis. Con
gemflbrozil: $10 \mathrm{mg} /$ dia. Insuficiencia renal severa (no en hemodialisis); inicial: $5 \mathrm{mg}$; no exceder $10 \mathrm{mg} / \mathrm{dia}$. Contraindicaciones: Hipersensibilidad a cualquier componente; enfermedad hepática activa o elevaciones persistentes inexplicables de transaminasas séricas; embarazo y lactancia. Advertencias y Precauciones: Se recomiendan pruebas de función hepática antes y a las 12 semanas del inicio 0 al aumentar la dosis y semestralmente. Casos de rabdomiolisis con insuficiencia renal aguda debido a mioglobinuria, que aumentan con la dosis más alta. Precaución en pacientes con factores predisponentes para miopatia (deterioro renal, edad avanzada, hipotiroidismo tratado inadecuadamente). Discontinuar si se observan niveles elevados de creatina quinasa, o si se diagnostica o se sospecha una miopatia o si se presenta

una condición aguda (por ejemplo, sepsis, hipotensiòn, deshidratación, cirugia mayor, trauma, trastornos metabólicos, endocrinos o electroliticos severos, convulsiones no controladas). Advertir al paciente que informe de inmediato dolor, sensibilidad o debilidad muscular inexplicable, malestar o fiebre, Precaución con anticoagulantes cumarinicos, ketoconazol, espironolactona, y cimetidina. Considerar reducción de dosis en caso de proteinuria y/o hematuria persistentes inexplicables. Interacciones: Antiácido combinado de hidróxido de magnesio y aluminio: ingerir al menos 2 horas después de Rosuvast. Reacciones adversas: Anormalidades de las enzimas hepáticas, rabdomiólisis con mioglobinuria y falla renal aguda y miopatía (incluyendo miositis). Condujeron a la discontinuaciỏn: náusea, mialgia, dolor abdominal. Informadas con mayor frecuencia $(\geq 2 \%)$ : cefalea, mialgia, dolor abdominal, astenia, nàuseas. Post-comercializaciön: artralgia, hepatitis, ictericia y pérdida de la memoria. Presentaciones: Rosuvast 10: Envases conteniendo 14,28 y 56 comprimidos recubiertos. Rosuvast 20: Envase conteniendo 28 comprimidos recubiertos. Rosuvast 5 y 40 : Envases conteniendo 28 comprimidos recubiertos

Especialidad Medicinal autorizada por el Ministerio de Salud. Certificado N 51.203

Información completa para prescribir: consultar el prospecto (www.bago.com.ar) a comunicarse con Laboratorios Bagó S.A. - Información de Productos Departamento Médico: (011) 4344-2216 infoproducto@bago.com.ar 


\title{
MÉTODOS ECOCARDIOGRÁFICOS PARA EVALUAR LA AURÍCULA DERECHA UTILIZANDO LOS VALORES DE CORTE PUBLICADOS POR SOCIEDADES INTERNACIONALES
}

\author{
ECHOCARDIOGRAPHIC METHODS TO EVALUATE THE RIGHT ATRIUM \\ USING THE VALUES PUBLISHED BY INTERNATIONAL SOCIETIES
}

\author{
MARÍA DEL PILAR ACOSTA ${ }^{1}$, MARCELO STORINO ${ }^{2}$, GUILLERMO GODOY ${ }^{2}$, VANESA MARASA ${ }^{2}$, VÍCTOR ARREGUI ${ }^{3}$, JUAN ERRIEST ${ }^{4}$, JORGE \\ CAMILLETTII ${ }^{5}$, ALEJANDRO VILCHEZ ${ }^{3}$, DIEGO MARTÍNEZ DEMARÍA ${ }^{3}$, MARÍA LAURA PLASTINO ${ }^{6}$
}

\section{RESUMEN}

Introducción. El tamaño de la aurícula derecha (AD) medido por ecocardiografía ha mostrado ser un marcador de riesgo cardiovascular en diferentes condiciones cardíacas. La cuantificación del tamaño de la AD se realiza más comúnmente en la vista apical de 4 cámaras, donde se realiza planimetría para estima el área. Hasta el momento, no se conocen estudios que correlacionen el área de la AD (Área AD) con los nuevos valores de corte propuestos para el volumen de la AD. Las guías de la Sociedad Americana de Ecocardiografía (ASE)/Sociedad Europea de Cardiología (ESC) establecen que el parámetro recomendado para evaluar el tamaño de la $\mathrm{AD}$ es el volumen $\mathrm{AD}(\mathrm{Vol} \mathrm{AD})$ calculado a través del método área-longitud o de sumatoria de discos en un solo plano apical de 4 cámaras. Objetivos. Correlacionar el volumen de la $\mathrm{AD}(\mathrm{Vol} \mathrm{AD})$ con el área de la $\mathrm{AD}$ según los parámetros de las recomendaciones ASE/ESC.

Materiales y métodos. Estudio observacional y descriptivo, retrospectivo, donde se analizaron 109 pacientes que concurrieron al laboratorio de Ecocardiografía del Hospital Italiano de La Plata para control cardiovascular entre los meses de septiembre y octubre del año 2015; la edad media fue de 56,41 \pm 17 años, 53,21\% de sexo masculino.

Resultados. Del total de participantes, 24 (22,01\%) fueron clasificados con AD anormal por Área AD y $15(13,76 \%)$ con $A D$ anormal por Vol $A D(p<0,02)$. De los 85 pacientes que tuvieron AD normal según Área AD, el 2,75\% (3 pacientes) tu vieron $\mathrm{V} v \mathrm{O}$ AD anormal; contrariamente, de los 24 que tuvieron $A D$ anormal por área, 12 tuvieron también AD anormal por Vvol AD (concordancia moderada, kappa 0,53). El análisis estadístico según género evidenció una concordancia mejor para el sexo femenino (kappa 0,73 vs. 0,43). La variabilidad interobservado para evaluar las dimensiones de la AD según Área AD fue de $2,4 \pm 0,2 \mathrm{~mm}$ y según Volvolumen AD de $4 \pm 0,36 \mathrm{ml} / \mathrm{m} 2$; valores que concuerdan con reportes previos. Se observó una correlación positiva lineal moderada entre el Área AD y el Vol AD $(r=0,799)$

Conclusión. Los valores de corte para tamaño AD según el área y el volumen han demostrado una buena concordancia, mejor aún para el sexo femenino. Es importante seguir las recomendaciones de las guías de la ASE/ESC, evaluar a los pacientes según los valores de corte recomendados y definir dilatación AD por Vol AD y Área AD.

Palabras clave: aurícula derecha, ecocardiografía.

\section{ABSTRACT}

Introduction. The size of the right atrium (RA) measured by echocardiography has been shown to be a marker of cardiovascular risk in different heart diseases. The quantification of the size of the RA is most commonly performed in the apical view of 4 chambers, where planimetry is performed to estimate the area. So far, there are no known studies that correlate the area of RA with the new proposed cut-off values for RA volume. The guidelines of the American Society of Echocardiography (ASE) / European Society of Cardiology (ESC) establish that the recommended parameter to evaluate the size of the RA is the RA volume calculated through the area-length method or the sum of discs in a single apical plane of 4 chambers.

Objective. To correlate the volume of the RA (RA vol) with the area of the RA according to the parameters of the ASE / ESC recommendations.

Materials and Methods. Observational and descriptive, retrospective study; 109 patients were analyzed who attended the Echocardiography laboratory for cardiovascular monitoring between the months of September and October of 2015; the average age was $56.41 \pm 17$ years, $53.21 \%$ were males.

Results. Of the total of participants, 24 (22.01\%) were classified with abnormal RA by RA area and $15(13.76 \%)$ with abnormal RA by RA Vol $(p<0.02)$. Of the 85 patients who had normal RA according to RA Area, 2.75\% (3 patients) had abnormal RA Vol. Conversely, of the 24 who had abnormal RA by area, 12 also had abnormal RA by RA Vol (moderate agreement, kappa 0.53). The statistical analysis ac cording to gender showed a better agreement for the female sex (kappa 0.73 vs 0.43). Interobserver variability to evaluate the dimensions of the RA according to RA Area was $2.4 \pm 0.2 \mathrm{~mm}$ and according to RA volume of $4 \pm 0.36 \mathrm{ml} / \mathrm{m} 2$; values that agree with previous reports. A moderate linear positive correlation was observed between RA Area and RA Vol (r 0.799).

Conclusion. The cut-off values for RA size according to area and volume have shown a good agreement, even better for the female sex. It is important to foIlow the recommendations of the ASE / ESC guidelines, evaluate patients according to the recommended cut-off values and define RA dilatation by RA Vol and RA area.

Keywords: right atrium, echocardiography

REVISTA CONAREC 2018;33(145):180-182 | DOI:10.32407/RCON/2018145/0180-0182

\footnotetext{
1. Jefa de Residentes de Cardiología.

2. Médico staff de la Unidad de Eco Doppler Cardiovascular.

3. Médico staff del Área de Cardiología.

4. Jefe de Medicina Nuclear.

5. Jefe del Área de Cardiología.

6. Jefa de la Unidad de Eco Doppler Cardiovascular.
}

Cátedra de Posgrado en Cardiología, Facultad de Ciencias Médicas, Universidad Nacional de La Plata. Hospital Italiano de La Plata. La Plata, provincia de Buenos Aires, Rep. Argentina.

$\triangle$ Correspondencia: Dra. María del Pilar Acosta. Calle $9 n^{\circ} 1124$ 2B, CP 1900, La Plata. Buenos Aires, Rep. Argentina. madelpilar_acosta@hotmail.com

Los autores declaran no poseer conflictos de intereses.

Recibido: 10/10/2017 | Aceptado: 01/06/2018

\section{INTRODUCCIÓN}

La aurícula derecha (AD) contribuye con el llenado ventricular derecho, inicialmente como reservorio del retorno venoso sistémico, luego como conducto pasivo en la diástole temprana y finalmente como conducto activo en la diástole tardía durante la contracción auricular'. El tamaño de la AD medido por ecocardiografía ha demostrado ser un marcador de riesgo cardiovascular en diferentes condiciones cardíacas, presenta remodelado reverso luego de la ablación por fibrilación auricular y pareciera ser dependiente del genero². El Área AD es predictor de mortalidad o trasplante en pacientes con hipertensión pulmonar primaria ${ }^{3,4}$. Utilizando el ecocardiograma, la AD se puede 


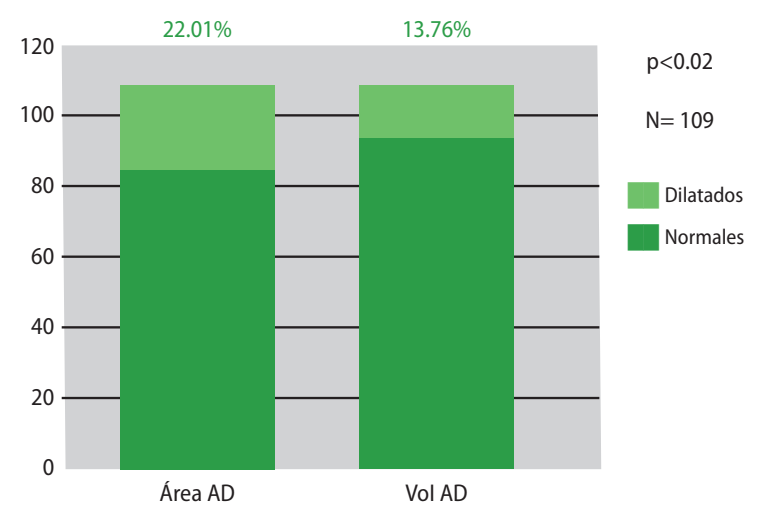

Figura 1. Distribución de pacientes con aurícula derecha dilatada según el método de evaluación ecocardiográfico utilizado. AD: aurícula derecha. Vol: volumen

apreciar desde diferentes vistas; la cuantificación del tamaño de la AD se realiza más comúnmente en la vista apical de 4 cámaras. Desde esta ventana se realiza planimetría para estimar el área (límite superior normal $\left.18 \mathrm{~cm}^{2}\right)^{5-7}$.

Los volúmenes de la AD son más sólidos y precisos para la determinación del tamaño de la AD en comparación con las dimensiones lineales. Se ha propuesto para la determinación del Vol AD una vista única de área longitud y/o técnica de sumatoria de discos ${ }^{6,8}$.

Hasta el momento no se conocen estudios que correlacionen el Área $\mathrm{AD}$ con los nuevos valores de corte propuestos para el Vol AD.

\section{OBJETIVO}

El propósito de este estudio es correlacionar el volumen de la AD con el área de la $A D$, según los parámetros de las recomendaciones de la Sociedad Americana de Ecocardiografía (ASE) y la Sociedad Europea de Cardiología (ESC).

\section{MATERIALES Y MÉTODOS}

En el presente estudio observacional y descriptivo, retrospectivo, se analizaron 109 pacientes que concurrieron al laboratorio de Ecocardiografía del Hospital Italiano de La Plata para control cardiovascular entre los meses de Septiembre y Octubre del año 2015. El trabajo fue previamente evaluado y aceptado por el comité de bioética del Hospital Italiano de La Plata.

\section{POBLACIÓN Y DATOS ECOCARDIOGRÁFICOS}

A los participantes se les realizó eco-Doppler cardíaco convencional transtorácico utilizando un ecocardiógrafo General Electric Vivid S5.

Todas las mediciones se realizaron de acuerdo con las recomendaciones actuales de la ASE y ESC.

Se incluyeron mediciones de diámetro ántero-posterior de aurícula izquierda (diám APAl), área de la aurícula izquierda (Área Al) y volumen auricular izquierdo indexado a la superficie corporal (VolAli). El Vol AD fue evaluado a través del método de área longitud y/o técnica de sumatoria de discos desde una vista única en 4 cámaras. La medida se obtuvo al final de la sístole, en el frame que precede la apertura de la válvula tricúspide. Se trazó la planimetría de la AD y

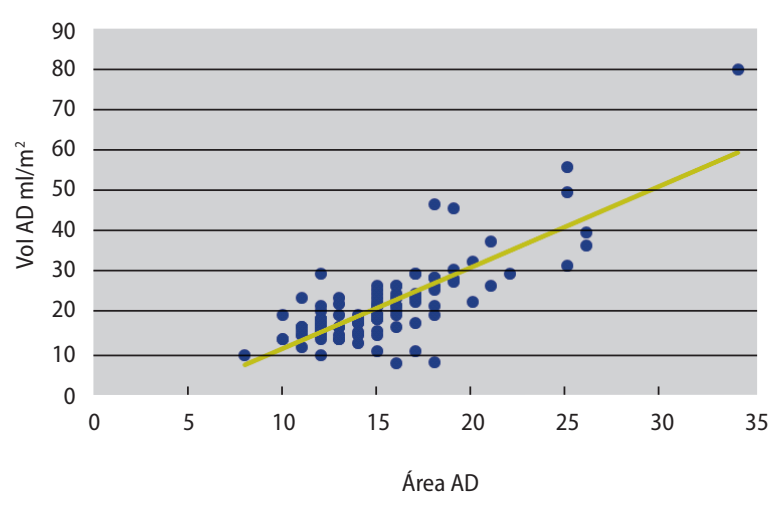

Figura 2. Correlación entre el área y el volumen de la aurícula derecha. AD: aurícula derecha. Vol: volumen.

el volumen fue indexado a la superficie corporal. El Área AD fue medida en vista apical de 4 cámaras y en fin de sístole, en el cuadro justo antes de la apertura de la válvula tricúspide, mediante el trazado de la interfaz sangre tejido de la AD, excluyendo el área debajo del anillo de la válvula tricúspide.

Los diámetros del ventrículo izquierdo (VI) fueron medidos con modo $\mathrm{M}$ en eje corto paraesternal izquierdo, guiado por 2D. La función sistólica del VI fue evaluada con la fracción de eyección (FEy) a través del método de Simpson. Se obtuvo el índice de masa VI (IMVI) según las recomendaciones de la ASE.

Cada valor registrado representa el promedio de tres latidos consecutivos. Todas las medidas fueron realizadas online y grabadas en una base de datos.

Para evaluar la variabilidad interobservador, dos operadores independientes, midieron el área y el volumen de la AD en 10 pacientes seleccionados, sin conocer los resultados obtenidos por el otro observador.

\section{TAMAÑO AD}

Las guías ASE/ESC establecen que el parámetro recomendado para evaluar el tamaño de la AD es el Vol AD calculado a través del método área-longitud o de sumatoria de discos en un solo plano apical de 4 cámaras. El rango normal del volumen de la AD por Eco $2 \mathrm{D}$ es de $25 \pm 7 \mathrm{ml} / \mathrm{m}^{2}$ en hombres y $21 \pm 6 \mathrm{ml} / \mathrm{m}^{2}$ en mujeres ${ }^{9}$.

\section{DATOS CLÍNICOS}

Al momento del examen se registraron edad, altura, peso, ritmo cardíaco y comorbilidades.

\section{ANÁLISIS ESTADÍSTICO}

Los resultados fueron expresados como porcentajes o medias con desvío estándar (DE). Para evaluar la fuerza de relación entre el área y el volumen de la AD, y calcular la asociación entre estas variables, se utilizó el coeficiente de correlación de Pearson (r). El test de concordancia de kappa se utilizó para calcular la fuerza de acuerdo entre ambos métodos.

La variabilidad interobservador se expresó como la media y DE de la diferencia absoluta entre las medidas realizadas por dos investigadores. La significación estadística de referencia fue $p<0,05$. El análisis fue realizado utilizando Microsoft Excel. 


\section{RESULTADOS}

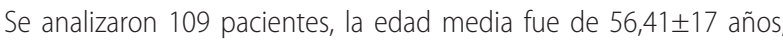
$53,21 \%$ de sexo masculino.

\section{ECO DOPPLER CARDÍACO Y CORRELACIÓN ENTRE ÁREA AD Y VOL AD}

Al utilizar los valores de corte publicados para agrandamiento de la AD, 24 pacientes (22,01\%) fueron clasificados con AD anormal por Área AD y $15(13,76 \%)$ con $A D$ anormal por Vol $A D(p<0,02)$ (Figura 1).

De los 109 pacientes analizados, se observó una correlación positiva lineal moderada entre el Área AD y el Vol AD $(r=0,799)$ (Figura 2). De los 85 pacientes que tuvieron AD normal según Área AD, el 2,75\% (3 pacientes) tuvo Vol AD anormal, contrariamente, de los 24 que tuvieron $A D$ anormal por área, 12 tuvieron también $A D$ anormal por Vo AD (concordancia moderada, kappa 0,53).

El análisis estadístico según género evidenció que la concordancia fue mejor para el sexo femenino en relación con el masculino (kappa 0,73 vs. 0,43)

\section{VARIABILIDAD INTEROBSERVADOR}

La variabilidad interobservador para evaluar las dimensiones de la $A D$

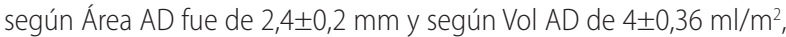
valores que concuerdan con reportes previos.

\section{DISCUSIÓN}

La evaluación del tamaño auricular derecho medida a través del Vol AD y Área AD, aplicando los valores de corte publicados, permiten estratificar el riesgo en un significativo número de pacientes.

Como la AD no se agranda en forma simétrica, la evaluación unidimensional, sería poco sensible para detectar los cambios en el tamaño de la AD. Nuestros resultados, confirman hallazgos previos y demuestran que en esta población se pone de manifiesto que al utilizar los valores de corte para identificar pacientes con dilatación auricular derecha deberían considerarse las dimensiones obtenidas a través del Vol $A D$ y Área $A D^{8}$.

En relación con otros estudios, el presente trabajo demostró también que el tamaño AD depende del genero ${ }^{10,11}$.

\section{CONCLUSIÓN}

Los valores de corte para el tamaño AD según el área y el volumen han demostrado una buena concordancia, mejor aún para el sexo femenino. Es importante seguir las recomendaciones de las guías de la ASE/ESC, evaluar a los pacientes según los valores de corte recomendados y definir dilatación $A D$ por Vol $A D$ y Área AD.

\section{BIBLIOGRAFÍA}

1. Gaynor SL, Maniar HS, Prasad SM, Steendijk P, Moon MR. Reservoir and conduit function of right atrium: impact on right ventricular filling and cardiac output. Am J Physiol Heart Circ Physiol 2005;288(5):H2140-5.

2. Pathak RK, Middeldorp ME, Lau DH, Mehta AB, Mahajan R, et al. Aggressive risk factor reduction study for atrial fibrillation and implications for the outcome of ablation: the ARREST-AF cohort study. I Am Coll Cardiol 2014;64(21):2222-31.

3. Galiè N, Humbert M, Vachiery JL, Gibbs S, Lang I, Torbicki A, et al. 2015 ESC/ERS Guidelines for the diagnosis and treatment of pulmonary hypertension: The Joint Task Force for the Diagnosis and Treatment of Pulmonary Hypertension of the European Society of Cardiology (ESC) and the European Respiratory Society (ERS). Endorsed by: Association for European Paediatric and Congenital Cardiology (AEPC), International Society for Heart and Lung Transplantation (ISHLT). Eur Heart J 2016:37(1):67-119.

4. Lescano AJ, Gomes Sánchez MA. Hipertensión pulmonar. lera Ed. Buenos Aires: Librería AKADIA Editorial, 2017.

5. Rudski LG, Lai WW, Afilalo J, Hua L, Handschumacher MD, Chandrasekaran K, et al. Guidelines for the echocardiographic assessment of the right heart in adults: a report from the American Society of Echocardiography endorsed by the European Association of Echocardiography, a registered branch of the European Society of Cardiology, and the Canadian Society of Echocardiography. J Am Soc Echocardiogr 2010;23(7):685-713.
6. Kou S, Caballero L, Dulgheru R, Voilliot D, De Sousa C, Kacharava G, et al. Echocardiographic reference ranges for normal cardiac chamber size: results from the NORRE study. Eur Heart J Cardiovasc Imaging 2014;15(6):680-90

7. Quraini D, Pandian NG, Patel AR. Three-dimensional echocardiographic analysis of right atrial volume in normal and abnormal hearts: comparison of biplane and multiplane methods. Echocardiography 2012;29(5):608-13.

8. D'Oronzio U, Senn O, Biaggi P, Gruner C, Jenni R, Tanner FC, et al. Right heart assessment by echocardiography: gender and body size matters. J Am Soc Echocardiogr 2012;25(12):1251-8

9. Lang RM, Badano LP, Mor-Avi V, Afilalo J, Armstrong A, Ernande L, et al. Recomendaciones para la Cuantificación de las Cavidades Cardíacas por Ecocardiografía en Adultos: Actualización de la Sociedad Americana de Ecocardiografía y de la Asoci ación Europea de Imagen Cardiovascular. J Am Soc Echocardiogr 2015:28(1):1-39.

10. Lang RM, Bierig M, Devereux RB, FlachskampfFA, Foster E, Pellikka PA, et al. Recommendations for chamber quantification: a report from the American Society of Echocardiography's Guidelines and Standards Committee and the Chamber Quantification Writing Group, developed in conjunction with the European Association of Echocardiography, a branch of the European Society of Cardiology. J Am Soc Echocardiogr 2005; 18(12): 1440-63.

11. Peluso D, Badano LP, Muraru D, Dal Bianco L, Cucchini U, Kocabay G, et al. Righ atrial size and function assessed with three-dimensional and speckle-tracking echocardiography in 200 healthy volunteers. Eur Heart J Cardiovasc Imaging 2013:14(11):1106-14 

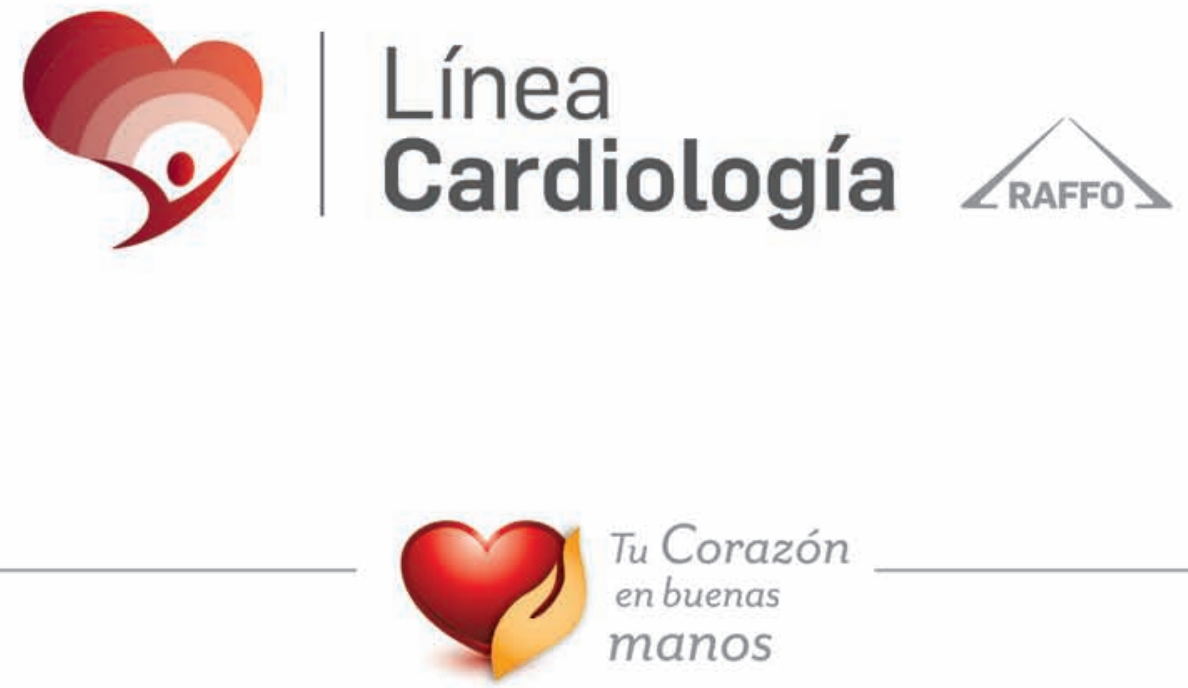

Tu Corazón

en buenas

manos

Nabila

NŌSTER

AMLODIPINA \VALSARTAN

A Alpertan'

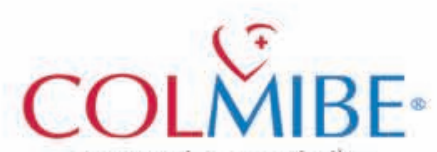

atorvastatina / ezetimibe

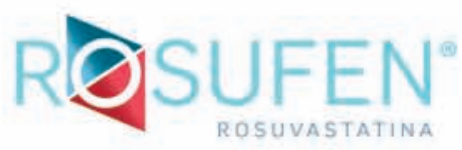

1. LIPIFEN

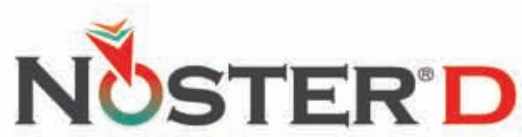

AMLODIPINA / VALSARTAN / HCTZ

\section{चैAlpertan'D}

$\$ \frac{\text { Nabratín }}{\text { clopidosel }}$

(9) ZOLPLAT 


\title{
ISQUEMIA CEREBRAL SILENTE PERIOPERATORIA EN PACIENTES CON FIBRILACIÓN AURICULAR
}

\author{
PERIOPERATIVE SILENT CEREBRAL ISCHEMIA IN PATIENTS WITH ATRIAL \\ FIBRILLATION
}

\author{
ALEJANDRO E. CONTRERAS ${ }^{1}$, FEDERICO ROCA ${ }^{2}$, JOSE I. REVIGLIONO ${ }^{3}$, FLORENCIA BECERRA ${ }^{4}$, TERESITA CORNAVACA ${ }^{4}$, RICARDO A. \\ ALBERTINI ${ }^{3}$, ALDO H. TABARES ${ }^{5}$
}

\section{RESUMEN}

Introducción. Frecuentemente en la práctica clínica se plantea la necesidad de revertir la anticoagulación con antagonistas de la vitamina K en pacientes con fibrilación auricular (FA) previo a la realización de procedimientos invasivos. Trabajos científicos recientemente publicados sugieren que es segura la suspensión del tratamiento anticoagulante sin necesidad de terapia sustitutiva con heparina. Objetivos. Determinar si los pacientes con FA decon bajo riesgo tromboembólico presentaron eventos cerebrales isquémicos silentes durante intervenciones invasivas luego de la suspensión de la anticoagulación.

Métodos. Estudio observacional, prospectivo, que se realizó mediante el seguimiento clínico de pacientes internados para procedimiento invasivos desde el año 2010 a la actualidad en el Hospital Privado Universitario de Córdoba. Resultados. Fueron evaluados 7 pacientes con FA de bajo riesgo tromboembólico, a quienes se los estudió mediante resonancia nuclear magnética cerebra pre- y posquirúrgicas (en secuencias de difusión, T2 y FLAIR). La totalidad de la muestra tenía FA, encontrándose bajo tratamiento anticoagulante con antagonistas de la vitamina $\mathrm{K}$, y tenía una mediana de $\mathrm{CHA}_{2} \mathrm{DS}_{2}$-VASC de 2 puntos (0-2 puntos, riesgo tromboembólico bajo). El día de la intervención quirúrgica el grupo de estudio presentó un RIN promedio de $1,36(1,02-1,86)$ y necesitaron para alcanzar el rango terapéutico de anticoagulación 4,86 días (4-5 días). Ninguno recibió heparinas en dosis anticoagulantes y un solo paciente recibió profilaxis. No se evidenciaron eventos neurológicos clínicamente evidentes, sin embargo en un paciente $(14,2 \%)$ se observó una imagen isquémica cerebral en el posoperatorio, sin repercusión clínica.

Conclusión. A pesar del pequeño número casos, nuestra experiencia genera la hipótesis de que algunos pacientes con FA con bajo riesgo de tromboembolismo perioperatorio podrían tener isquemia silente sin terapia anticoagulante. Un estudio futuro con mayores dimensiones teniendo en cuenta el momento de realización de las imágenes y el seguimiento a largo plazo podría dilucidar la frecuencia de la isquemia silente y sus consecuencias

Palabras clave: isquemia encefálica; anticoagulantes; tromboembolia; cirugía.

\section{ABSTRACT}

Introduction. Frequently in clinical practice the need to reverse anticoagulation with vitamin $\mathrm{K}$ antagonists in patients with atrial fibrillation (AF) prior to performing invasive procedures is considered. Recently published scientific papers su ggest that the suspension of anticoagulant therapy is safe without the need for heparin replacement therapy.

Objective. To determine whether patients with AF with low thromboembolic risk presented silent cerebral ischemic events during invasive interventions after the suspension of anticoagulation.

Methods. An observational, prospective study was carried out through the clinical follow-up of inpatients for invasive procedures from 2010 to the present at the Private University Hospital of Córdoba.

Results. Seven patients with AF of low thromboembolic risk were evaluated, who were assessed by cerebral magnetic resonance imaging before and after surgery (in diffusion, T2 and FLAIR sequences). The whole sample had AF and were anticoagulated with vitamin $\mathrm{K}$ antagonists and had a 2-point $\mathrm{CHA}_{2} \mathrm{DS}_{2}-\mathrm{VASC}$ median (0-2 points, low thromboembolic risk). On the day of the surgical intervention, the study group presented an average INR of 1.36 (1.02-1.86) and needed 4.86 days (4-5 days) to reach the therapeutic anticoagulation range. None received heparins in anticoagulant doses and only one patient received prophylaxis. No clinically evident neurological events were evident, how ever one patient (14.2\%) showed a cerebral ischemic image in the postoperative period, without clinical repercussions.

Conclusion. Despite the small number of cases, our experience generates the hypothesis that some patients with AF with a low risk of perioperative thromboembolism could have silent ischemia without anticoagulant therapy. A future study with larger dimensions taking into account the moment of performance of the images and long-term follow-up, could elucidate the frequency of silent ischemia and its consequences.

Keywords: ischemia; anticoagulants; thromboembolism; surgery.

REVISTA CONAREC 2018;33(145):184-186 | DOI:10.32407/RCON/2018145/0184-0186

\footnotetext{
1. Médico de Planta, Servicio de Cardiología.

2. Médico de Planta, Servicio de Radiología.

3. Médico de Planta, Servicio de Medicina Interna.

4. Médico Residente, Servicio de Medicina Interna.

5. Jefe de Servicio de Medicina Vascular.

Hospital Privado Universitario de Córdoba. Instituto Universitario de Ciencias Biomédicas de Córdoba. Córdoba,. Argentina.
}

$\triangle$ Correspondencia: Dr. Alejandro Contreras. Naciones Unidas 346, Córdoba, Rep. Argentina.aletreras@hotmail.com.

Los autores declaran no poseer conflictos de intereses.

Recibido: 10/11/2017 | Aceptado: 01/06/2018

\section{INTRODUCCIÓN}

En los pacientes con fibrilación auricular (FA) de bajo a moderado riesgo embolígeno en tratamiento con anticoagulantes orales (ACO) que deben ser sometidos a procedimientos invasivos, la estrategia de suspensión del anticoagulante 5 días previos al procedimiento, comparada con el tratamiento que incluye el cabalgamiento con heparinas periprocedimiento, ha demostrado tener resultados similares en cuanto a eventos tromboembólicos. Por lo cual, actualmente, se sugiere la suspensión del ACO previamente 1 .

Luego de cirugías valvulares o de ablación de FA por radiofrecuencia, la evaluación mediante resonancia magnética cerebral ha demostrado la presencia de isquemia cerebral silente posprocedimiento ${ }^{2,3}$. El objetivo del presente trabajo es determinar si los pacientes con FA de riesgo tromboembólico bajo, en quienes se recomienda la sus- 
Tabla 1. Características de la población

\begin{tabular}{|c|c|c|c|c|c|c|c|c|}
\hline & Edad (años) & Género & CHA2DS2-VASC & Cirugía & RIN previo & RM Preop. (días) & RM Postop. (días) & Isquemia silente \\
\hline 1 & 70 & Mujer & 1 & Cataratas & $1,86^{*}$ & 5 & 0 & Sí \\
\hline 2 & 50 & Varón & 0 & Artroscopia de mano & 1,15 & 6 & 10 & No \\
\hline 3 & 70 & Varón & 1 & Implantes dentarios & 1,09 & 7 & 29 & No \\
\hline 4 & 81 & Mujer & 2 & Cataratas & 1,48 & 9 & 27 & No \\
\hline 5 & 86 & Mujer & 2 & Artroscopia de mano & $1,73^{* *}$ & 1 & 56 & No \\
\hline 6 & 81 & Mujer & 2 & Reemplazo total de cadera & 1,02 & 36 & 2 & No \\
\hline 7 & 82 & Mujer & 2 & Polipectomía vesical & 1,17 & 27 & 33 & No \\
\hline
\end{tabular}

Administración de vitamina K preoperatoria vía oral: * $2 \mathrm{mg} ;{ }^{* *} 3 \mathrm{mg}$.

RIN: razón internacional normatizada. RM: resonancia magnética. Preop: preoperatorio. Postop: posoperatorio

pensión del ACO sin realizar terapia puente (bridging) con heparina, presentan eventos cerebrales isquémicos silentes al someterse a procedimientos invasivos.

\section{MATERIAL Y MÉTODOS}

Estudio observacional, prospectivo, que se realizó mediante el seguimiento clínico de pacientes internados para procedimiento invasivos desde el año 2010 a la actualidad en el Hospital Privado Universitario de Córdoba. Inicialmente se analizó cada participante mediante un protocolo confeccionado en esta institución ${ }^{4}$, el cual avala que pacientes con FA de bajo riesgo tromboembólico $\left(\mathrm{CHA}_{2} \mathrm{DS}_{2}\right.$-VASc menor o igual a 2) suspendan la medicación anticoagulante 4 a 5 días previos al procedimiento, sin realizar terapia con heparinas. Luego fueron evaluados mediante resonancia magnética (RM) de cerebro, utilizando secuencias de cortes axiales en T2, FLAIR y difusión, sagitales en T1 y coronales en T2, pre- y posoperatorias. Las imágenes fueron analizadas y comparadas por un especialista en neurorradiología. Se utilizó un resonador de 1,5 tesla. Todos los participantes firmaron un consentimiento informado.

Las variables categóricas se expresan en porcentaje y las variables continuas en promedio y desvío estándar. Para su análisis se usó el paquete estadístico InfoStat/P (Universidad Nacional de Córdoba, 2014).

\section{RESULTADOS}

Fueron evaluados 126 pacientes intervenidos en 159 procedimientos, de los cuales 82 (52\%) no recibieron terapia "puente" con enoxaparina. Se realizaron imágenes de RM cerebral en 18 casos antes del procedimiento invasivo. Posteriormente, al excluirse los pacientes que realizaron "puente" con enoxaparina y aquellos a los que no se les realizó control con RM en el posoperatorio, el tamaño de la muestra fue de 7 pacientes con RM pre- y posoperatoria, a quienes se les suspendió el ACO y no fueron tratados con enoxaparina.

El grupo en estudio estaba formado por 5 mujeres (71\%) y 2 hombres (29\%), con edad promedio de 74,2 años (50-86 años). La totalidad de la muestra tenía FA, encontrándose anticoagulados con antagonistas de la vitamina $\mathrm{K}$, con una mediana de $\mathrm{CHA}_{2} \mathrm{DS}_{2}$-VASC de 2 puntos (0-2 puntos, riesgo tromboembólico bajo). El día de la intervención quirúrgica el grupo de estudio presentó un RIN promedio de 1,36 $\left(1,02^{-1} 1,86\right)$ y necesitaron para alcanzar el rango terapéutico de anticoagulación 4,86 días

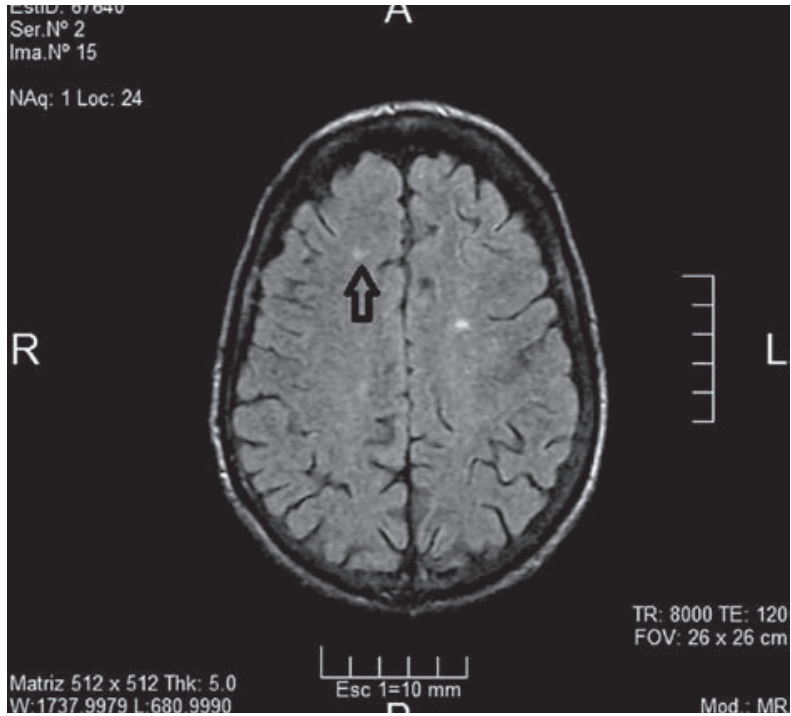

Figura 1. Resonancia magnética (FLAIR) realizada en tiempo posquirúrgico evidenciando imagen embólica subcortical frontal derecha.

(4-5 días). Ninguno recibió heparinas en dosis anticoagulantes y un solo paciente recibió profilaxis. No se evidenciaron eventos neurológicos clínicamente evidentes, sin embargo un paciente presentó una lesión isquémica silente nueva (14,2\% del total). Dicha imagen isquémica fue observada en el paciente 1 (Tabla 1), cuya RM preoperatoria se había realizado 5 días previos a la cirugía y posprocedimiento el mismo día de la cirugía. Se observó una nueva imagen puntiforme, hiperintensa en T2 y FLAIR, subcortical frontal anterior derecha, no observada en la RM preoperatoria (Figura 1)

\section{DISCUSIÓN}

El principal hallazgo de nuestro trabajo fue encontrar un caso de isquemia cerebral silente en pacientes con FA no valvular de bajo riesgo tromboembólico. Las microembolias son más frecuentes que los eventos con manifestaciones clínicas y las imágenes de difusión demuestran una incidencia de entre 10 y 40\% periprocedimiento de distintas intervenciones ${ }^{3}$. Es controvertido el significado de dicho hallazgo ya que no presentaron correlato clínico y esto se corresponde con isquemia silente sin consecuencias en otros escenarios perioperatorios ${ }^{2,5}$, sin embargo otros autores han demostrado que dichos eventos diagnostica- 
dos por RM se correlacionan con desarrollo de deterioro cognitivo y demencia en el seguimiento ${ }^{6}$, o incluso podrían ser predictores de eventos clínicos cerebrovasculares futuros?

Park et al. en un estudio de pacientes sometidos a intervenciones carotídeas $^{8}$, demostraron que la mayoría de las lesiones embólicas son de pequeño tamaño (menos de $5 \mathrm{~mm}$ de diámetro). Y el tamaño y la extensión de la lesión así como la modalidad de imagen utilizada para el diagnóstico de isquemia silente tienen suma importancia, ya que solo la secuencia de difusión en RM permite detectar lesiones isquémicas recientes, ocurridas incluso dentro de las primeras horas, permitiendo caracterizar el edema citotóxico que generan al restringir la difusión del agua en el espacio extracelular. Las lesiones preceden en varias horas a su visualización en secuencias habituales como T2 y FLAIR, y aún más para la tomografía computarizada. Sin embargo, en estudios experimentales con animales, las imágenes FLAIR demostraron correlacionarse con infartos confirmados histopatológicamente. En cambio, es incierto si las lesiones positivas en difusión, posteriormente con el tiempo, son positivas en FLAIR. Por último, existen diferencias en cuanto a la sensibilidad de la resonancia, al comparar imágenes con resonadores de 1,5 vs. 3.0 tesla9.
Nuestra experiencia tiene limitaciones, principalmente referidas al número de pacientes y al momento de realizar la RM previa y posterior a la cirugía. Hay una gran variabilidad en los tiempos en los que fueron hechas y es de notar que el único caso en que la RM posterior fue positiva se realizó el mismo día de la cirugía y fue positivo en imágenes T2 y FLAIR, por lo que probablemente el evento isquémico ocurrió antes del procedimiento. Se podrían haber perdido isquemias silentes si se hubiesen realizado las imágenes en las primeras horas o días luego de la cirugía.

\section{CONCLUSIÓN}

A pesar del pequeño número casos, nuestra experiencia genera la hipótesis de que algunos pacientes con FA de bajo riesgo de tromboembolismo perioperatorio podrían tener isquemia silente sin terapia anticoagulante. Un estudio futuro con mayores dimensiones teniendo en cuenta el momento de realización de las imágenes y el seguimiento a largo plazo, podría dilucidar la frecuencia de la isquemia silente y sus consecuencias.

\section{BIBLIOGRAFÍA}

1. Douketis JD, Spyropoulos AC, Kaatz S, Becker RC, Caprini JA, Dunn AS et al. Perioperative bridging anticoagulation in patients with atrial fibrillation. $N$ Engl J Med 2015;373(9):823-33

2. Jeon SB, Lee JW, Kim SJ, Chung CH, Kwon SU, Choi CG et al. New cerebral lesion on T2-weighted gradient-echo imaging after cardiac valve surgery. Cerebrovasc Dis 2010;30(2):194-9.

3. Gaita F, Caponi D, Pianelli M, Scaglione M, Toso E, Cesarani F et al. Radiofrequency catheter ablation of atrial fibrillation: A cause of silent thromboembolism? Magnetic resonance imaging assessment of cerebral thromboembolism in patients undergoing ablation of atrial fibrillation. Circulation 2010;122(17):1667-73.

4. Revigliono Jl, Cornavaca T, Becerra F, Albertini R, Contreras AE, Tabares A. Control perioperatorio de la anticoagulación con antagonistas de la vitamina K en cirugía electiva. Medicina (B Aires) 2014:74(5):385-90

5. Lickfett L, Hackenbroch M, Lewalter T, Selbach S, Schwab JO, Yang A et al. Cerebral diffusion-weighted magnetic resonance imaging: A tool to monitor the thrombogenicity of left atrial catheter ablation. I Cardiovasc Electrophysiol 2006; 17(1):1-7
6. Vermeer SE, Prins ND, den Heijer T, Hofman A, Koudstaal PJ, Breteler MMB. Silent brain infarcts and the risk of dementia and cognitive decline. N Engl J Med 2003;348(13):1215-22.

7. Kang DW, Lattimore SU, Latour LL, Warach S. Silent ischemic lesion recurrence on magnetic resonance imaging predicts subsequent clinical vascular events. Arch Neurol 2006;63(12):1730-3.

8. Park Kl, Chung PW, Kim YB, Moon HS, Suh BC, Yoon WT. Post-interventional microembolism: Cortical border zone is a preferential site for ischemia. Cerebrovasc Dis 2011;32(3):269-75.

9. Deneke T, Jais P, Scaglione M, Schmitt R, Di Biase L, Christopoulos G et al. Silent cerebral events/lesions related to atrial fibrillation ablation: A clinical review. J Cardiovasc Electrophysiol 2015;26(4):455-63. 


\section{PAXOND}

LOSARTÁN I HIDROCLOROTIAZIDA

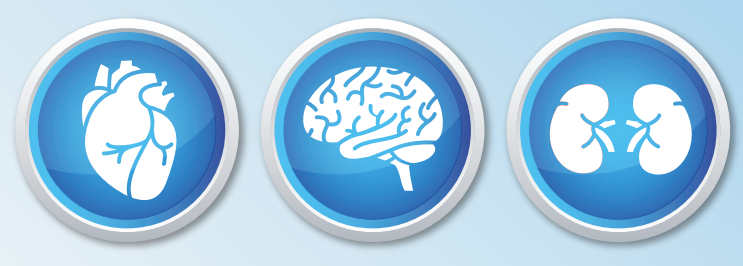

\section{Eficacia antihipertensiva con protección de órgano blanco ${ }^{1-4}$}

\section{PAMI 80\% IOMA}

Paxon` 50 - 100: envases por 30 y 60 comprimidos recubiertos ranurados conteniendo losartán

Paxon $\mathrm{XR}^{\Theta}$ : envase por 30 comprimidos de liberación controlada conteniendo losartán.

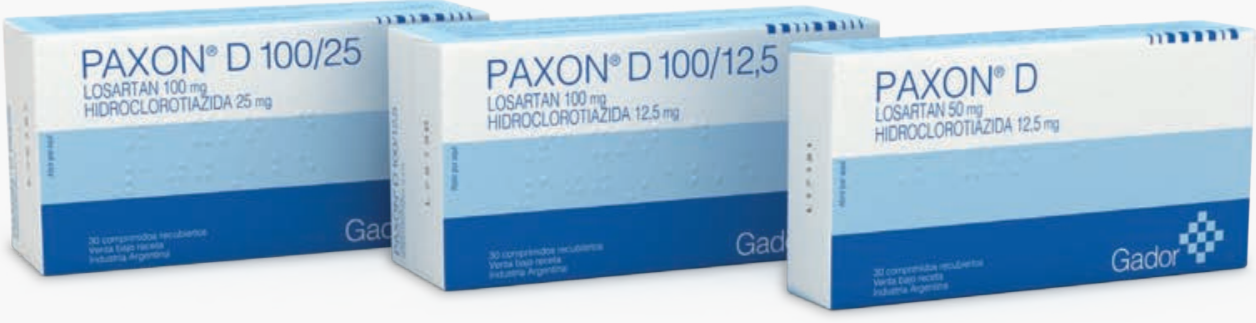

PAMI 60\%

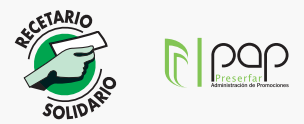

Paxon $D^{\circledR}$ : envases por 30 y 60 comprimidos recubiertos ranurados conteniendo losartán e hidroclorotiazida.

Paxon $D^{\oplus} 100 / 12,5-100 / 25$ : envases por 30 comprimidos recubiertos ranurados conteniendo losartán e hidroclorotiazida.

Referencias: 1. Little WC y col; Effect of losartan and hydrochlorothiazide on exercise tolerance in exertional hypertension and left ventricular diastolic dysfunction; Am J Cardiol 2006 Aug 1;98(3):383-5. 2. Moen MD, Wagstaff AJ; Losartan: a review of its use in stroke risk reduction in patients with hypertension and left ventricular hypertrophy; Drugs 2005;65(18):2657-74. 3. Brenner BM y col; RENAAL Study Investigators. Effects of losartan on renal and cardiovascular outcomes in patients with type 2 diabetes and nephropathy; N Engl J Med 2001 Sep 20;345(12):861-9. 4. Elliott WJ, Meyer PM; Incident diabetes in clinical trials of antihypertensive drugs: a network meta-analysis: Lancet 2007 Jan 20;369(9557):201-7.

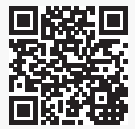

Para más información sobre PAXON ${ }^{\circledR}, \mathrm{PAXON}^{\otimes} \mathrm{XR}$ y $\mathrm{PAXON}{ }^{\circledR} \mathrm{D}$ visite www.gador.com.ar

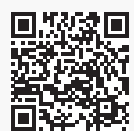

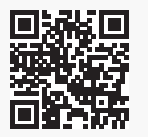

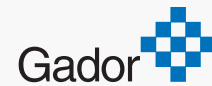

$\overline{\text { Al Cuidado de la Vida }}$ 


\title{
ABLACIÓN EXITOSA DE VÍA ANÓMALA EN PACIENTE CON ANOMALÍA DE EBSTEIN
}

\author{
SUCCESSFUL ABLATION OF ANOMALY PATHWAY IN PATIENT \\ WITH EBSTEIN ANOMALY
}

\section{MARÍA F. FIRPO' ${ }^{1}$, MARÍA FERNANDA GODOY' ${ }^{1}$ DANIELA FERNANDA CHILABERT'1, JUAN M. DOMÍNGUEZ², CAMILA ANTONIETTA ${ }^{3}$, MARCELO LANZOTTI' ${ }^{4}$, SILVANO DIANGELO ${ }^{5}$}

\section{RESUMEN}

La anomalía de Ebstein (AE) consiste en el desplazamiento congénito de las valvas septal y posterior de la tricúspide hacia el ventrículo derecho. Gracias a esto, existe dilatación auricular por "atrialización" ventricular, insuficiencia tricuspídea y falla ventricular derecha. Un 30\% se asocia con arritmias supraventriculares y síndrome de Wolff-Parkinson-White (WPW). Se presenta el caso de un paciente con ablación exitosa de vía anómala con coexistencia de AE y síndrome de WPW.

Palabras clave: anomalía de Ebstein. síndrome de Wolf-Parkinson-White.

\begin{abstract}
Ebstein Anomaly (EA) consists of the congenital displacement of the septal and posterior leaflets of the tricuspid valve towards the right ventricle. Thanks to this, there is atrial dilation due to ventricular "atrialization", tricuspid valve regurgitation and right ventricular failure. $30 \%$ is associated with supraventricular arrhythmias and Wolff-Parkinson-White syndrome (WPW). We present the case of a patient with successful ablation of abnormal pathway with coexistence of EA and WPW syndrome.
\end{abstract}

Keywords: Ebstein anomaly, Wolff-Parkinson-White syndrome.

REVISTA CONAREC 2018;33(145):188-190 | DOI:10.32407/RCON/2018145/0188-0190

\section{INTRODUCCIÓN}

La anomalía de Ebstein (AE) engloba un amplio espectro de anomalías caracterizado por diferentes grados de desplazamiento y adherencia de la valva septal y posterior de la tricúspide hacia la cavidad del ventrículo derecho, con desplazamiento y dilatación del anillo. Parte del ventrículo se introduce en la aurícula derecha, fenómeno conocido como "atrialización", con afectación de su función. Existe crecimiento de la aurícula derecha y habitualmente se asocia con comunicación interauricular (CIA), favoreciendo el shunt de derecha a izquierda. Las alteraciones anatómicas y hemodinámicas descritas condicionan el desarrollo de insuficiencia tricuspídea, arritmias supraventriculares y falla ventricular derecha'.

La AE tiene una incidencia de 1 cada 200.000 nacidos vivos y representa el 0,3 al 0,6\% de los pacientes con cardiopatías congénitas. Se asocia hasta en un 20-30\% con vías anómalas y síndrome de WolfParkinson-White (WPW)2.

Presentamos un caso clínico de un paciente con la coexistencia de AE y síndrome de WPW al que se le realizó estudio electrofisiológico con ablación exitosa de la vía anómala.

\footnotetext{
1. Residente de Cardiología.

2. Jefe de Residentes de Cardiología.

3. Médica de planta. Servicio de Electrofisiología y Arritmias.

4. Jefe de Servicio de Electrofisiología y Arritmias.

Instituto Cardiovascular de Rosario
}

$\triangle$ Correspondencia:Dra. María Florencia Firpo. mariaflorenciafirpo@gmail.com

\section{CASO CLÍNICO}

Paciente de sexo masculino de 38 años, con antecedentes familiares de cardiopatía isquémica (padre con infarto agudo de miocardio a los 47 años), con diagnóstico de AE a los 6 años y con el antecedente de ablación fallida de vía anómala hace 7 años en otra institución. Bajo tratamiento con flecainida 100 mg cada 12 horas. Presentó en los últimos 8 años episodios de palpitaciones paroxísticas, requiriendo internación por tal motivo en múltiples oportunidades, en una de las cuales se constató taquiarritmia regular con complejo QRS ancho con morfología de bloqueo completo de rama derecha, sin descompensación hemodinámica (Figura 1).

Fue evaluado en forma ambulatoria mediante electrocardiograma que evidencia signos de preexcitación ventricular (Figura 2), prueba ergométrica graduada, con desaparición del patrón de preexcitación durante el máximo esfuerzo, y ecocardiograma Doppler, que informó cavidades derechas severamente dilatadas e implantación baja de la valva septal de la válvula tricúspide compatible con AE.

Se decidió continuar la evaluación mediante estudio electrofisiológi$\mathrm{Co}$, en el cual se indujeron dos taquiarritmias: una taquicardia por reentrada auriculoventricular (TRAV) ortodrómica con conducción aberrante y una TRAV antidrómica (Figuras 3A y B). En base a dichos hallazgos se realizó ablación de vía anómala posteroseptal derecha, sin complicaciones (Figura 4)

Actualmente el paciente se encuentra asintomático, sin medicación antiarrítmica luego de dos años de seguimiento.

\section{DISCUSIÓN}

La expresión clínica de la AE es muy variable y depende fundamentalmente del grado de malformación anatómica del apara- 


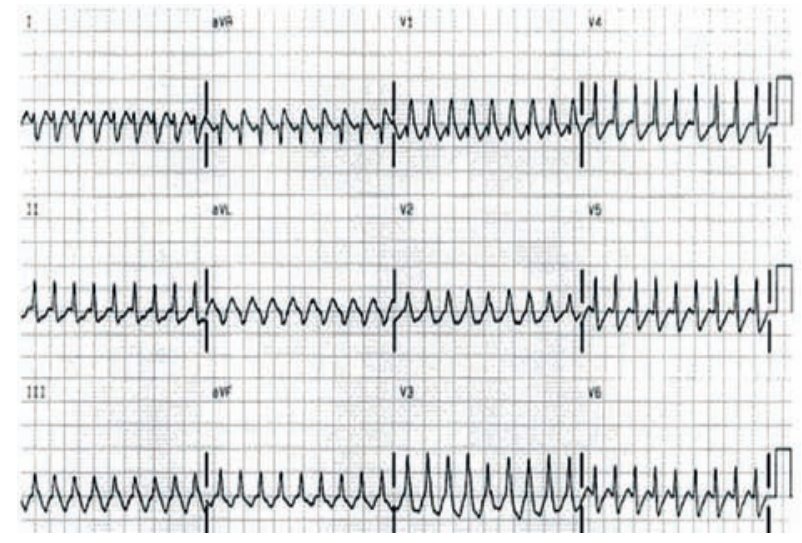

Figura 1. Taquiarritmia regular con complejo QRS ancho con morfología de bloqueo completo de rama derecha.

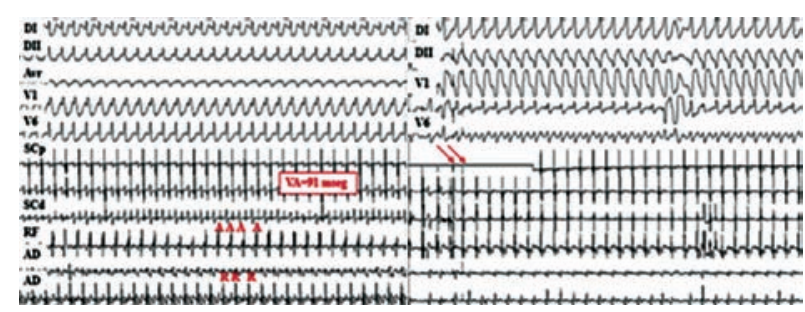

Figura 3. A) Taquicardia por reentrada auriculoventricular (AV) ortodrómica con conducción aberrante. B) Taquicardia por reentrada AV antidrómica con registros intracavitarios.

to valvular tricuspídeo, de la presencia de disfunción ventricular derecha y de la existencia de un cortocircuito derecha-izquierda'. Los síntomas como cianosis e insuficiencia cardíaca (IC) grave pueden aparecer a edades muy tempranas de la vida y con frecuencia mejoran al disminuir las resistencias vasculares pulmonares. En niños mayores de 10 años y en la edad adulta, la presencia de arritmias sintomáticas constituye la forma de presentación más frecuente ${ }^{3}$. Sin embargo, no es infrecuente que se manifieste con cianosis progresiva, disminución de la tolerancia al ejercicio, fatiga e IC derecha. En presencia de comunicación interauricular pueden sufrir embolias paradójicas, abscesos cerebrales y tienen mayor riesgo de muerte súbita.

Los pacientes con preexcitación presentan más frecuentemente fibrilación auricular (FA) y aleteo auricular (AA) que la población general ${ }^{4}$. Esto se debe, en parte, a la presencia de un período refractario auricular corto y una mayor vulnerabilidad auricular que favorece el desarrollo de arritmias supraventriculares. En caso de FA o AA, la presencia de una vía accesoria con conducción anterógrada puede desencadenar fibrilación ventricular y muerte súbita.

La ablación por radiofrecuencia en pacientes con cardiopatías congénitas es un desafío terapéutico debido a las alteraciones anatómicas descritas y a la frecuente asociación con múltiples vías anómalas. No obstante, es el tratamiento de elección en la actualidad para el manejo del síndrome de preexcitación ventricular, siendo un método seguro y efectivo en esta población de pacientes ${ }^{5}$. En varias muestras ob-

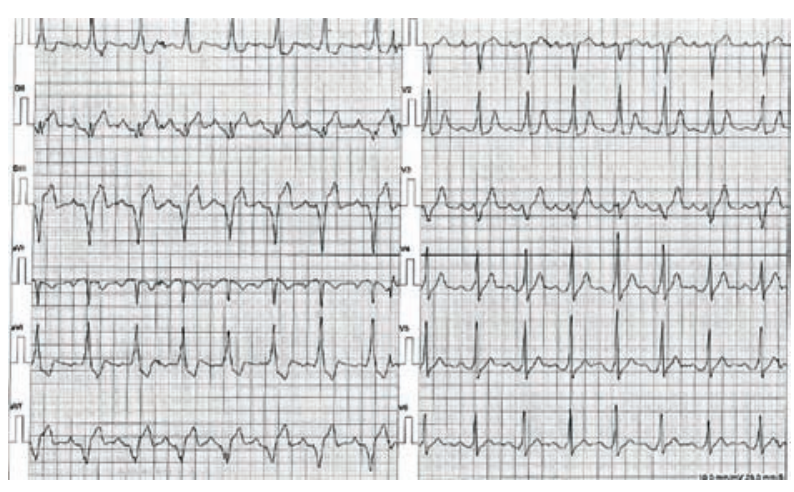

Figura 2. Electrocardiograma de ingreso. Ritmo sinusal con segmento PR corto y onda delta (flecha).

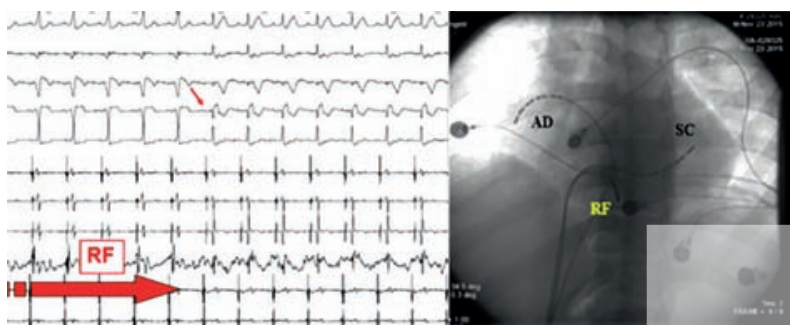

Figura 4. Electrocardiograma de superficie y registros endocavitarios donde se constata bloqueo de conducción por vía anómala durante aplicación de radiofrecuencia en el 60 latido (flecha). Fluoroscopia con el catéter de ablación posicionado en la región posteroseptal en el sitio de ablación exitosa. AD: aurícula derecha. SC: seno coronario. RF: catéter de radiofrecuencia.

servacionales de pacientes con WPW y AE se visualizó que la localización más frecuente de la vía anómala es la región posterior o posteroseptal (56\%), tal como lo encontrado en nuestro paciente 6 . La ablación por radiofrecuencia tiene una tasa de éxito del 90-95\%, siendo algo menor para las vías accesorias de localización septal

En un estudio descriptivo realizado por el Servicio de Electrofisiología y Arritmias de nuestra institución, con 178 pacientes (de febrero del 2003 a julio del 2016), con el objetivo de analizar la eficacia y seguridad de ablación por radiofrecuencia para el tratamiento de las arritmias en pacientes con vías anómalas, se demostró una elevada tasa de éxito inmediato $(92,13 \%)$ y un bajo porcentaje de complicaciones, de los cuales el $99 \%$ fueron menores.

\section{CONCLUSIÓN}

La AE es una malformación congénita infrecuente, asociada en un gran número de casos a síndromes de preexcitación. La incidencia de arritmias supraventriculares como FA es frecuente por la dilatación de cavidades derechas, y en pacientes con preexcitación puede significar alto riesgo de fibrilación ventricular. La ablación por radiofrecuencia tiene buenos resultados y es segura, por lo que representa el tratamiento de elección en síndrome de WPW, en especial en pacientes con anomalías congénitas. 


\section{BIBLIOGRAFÍA}

1. Attenhofer Jost C, Connolly HM, Dearani JA, Edwards WD, Danielson GK. Ebstein's Anomaly. Congenital Heart Disease for the Adult Cardiologist. Circulation 2007;115(2):277-285.

2. Iturralde Torres P. La anomalía de Ebstein asociada al sindrome de Wolff-Parkinson-White. Arch Cardiol Mex 2007;77(2):37-39.

3. Martínez-Losas P, Freitas-Ferraz A, Vivas D, Viana-Tejedor A. Sindrome de Wolff-Parkinson White como presentación de anomalia de Ebstein. Semergen 2015;41(6):52-54.

4. Iturralde P, Nava S, Sálica G, Medeiros A, Márquez MF, Colin L, et al. Electrocardiograph ic Characteristics of Patients with Ebstein's Anomaly Before and After Ablation of an ACcessory Atrioventricular Pathway. J Cardiovasc Electrophysiol 2006;17(12):1332-1336.
5. Kinoshita O, Agatsuma T, Hanaoka T, Tomita T, Tsutsui H, Yazaki Y, et al. Radiofrequency catheter ablation of accessory pathway in a patient with Ebstein's anomaly and atrial septal defect. A case report. Angiology 2005;56(2):221-223.

6. Betancourt Reyes G, Betancourt Betancourt G, González Pérez A. Síndrome de Wolff Parkinson White: reporte de un caso. Revista Cubana de Medicina Intensiva y Emergencias 2017;16(2):48-56.

7. Bartolomé F, Sánchez Fernández-Bernal C, Torres Feced F. Ablación con catéter de vías accesorias en pacientes con cardiopatías congénitas. Rev Esp Cardiol 1999;52(11):1028-1031 


\title{
DENERVACIÓN SIMPÁTICA COMO TRATAMIENTO ALTERNATIVO EN ADOLESCENTE CONTAQUICARDIA VENTRICULAR CATECOLAMINÉRGICA POLIMÓRFICA
}

\author{
SYMPATHETIC DENERVATION AS AN ALTERNATIVE TREATMENT \\ IN ADOLESCENTS WITH CATECHOLAMINERGIC POLYMORPHIC \\ VENTRICULARTACHYCARDIA
}

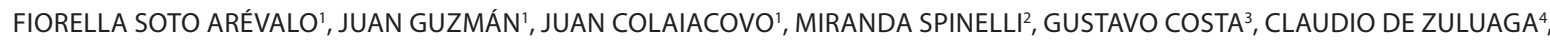 \\ GUSTAVO ROMERA ${ }^{5}$
}

\section{RESUMEN}

La taquicardia ventricular catecolaminérgica polimórfica es una entidad caracterizada por el desarrollo de taquiarritmias potencialmente fatales en circunstancias que incrementan el tono simpático debido a una alteración en los canales iónicos del músculo cardíaco. Los betabloqueantes constituyen el tratamiento de elección. En pacientes con arritmia refractaria o cuando existen contraindicaciones formales para el uso de fármacos, está indicado el implante de cardiodesfibrilador implantable con riesgo de múltiples descargas. Se ha propuesto como nueva herramienta la denervación simpática cardíaca izquierda.

Palabras clave: denervación, simpatectomía, taquicardia ventricular.

\section{ABSTRACT}

Polymorphic catecholaminergic ventricular tachycardia is an entity characterized by the development of potentially fatal tachyarrhythmias in circumstances that increase sympathetic tone due to an alteration in the ion channels of the cardiac muscle. Beta-blockers are the treatment of choice. In patients with refractory arrhythmia or when there are formal contraindications for the use of drugs, implantation of an implantable cardioverter-defibrillator is indicated, with the subsequent risk of multiple discharges. Left sympathetic cardiac denervation has been proposed as a new tool.

Keywords: denervation, sympathectomy, ventricular tachycardia.

REVISTA CONAREC 2018;33(145):191-193 | DOI:10.32407/RCON/2018145/0191-0193

\section{INTRODUCCIÓN}

La denervación simpática cardíaca izquierda (DCSI) es una intervención antifibrilatoria que previene en gran medida la liberación de noradrenalina en el corazón', reduciendo potencialmente arritmias mortales mediadas adrenérgicamente. Es un tratamiento eficaz para pacientes refractarios a betabloqueantes y bloqueantes cálcicos, en los que actualmente se cree que el único tratamiento adicional disponible es el cardiodesfibrilador implantable (CDI) ${ }^{2}$. Sin embargo, la calidad de vida de estos pacientes disminuye dado que incluso el ejercicio modesto inicia taquicardias ventriculares rápidas que desencadenan terapias del CDI. Por lo tanto, representa una importante alternativa de tratamiento.

\footnotetext{
1. Residente de Cardiología.

2. Jefe de Residentes de Cardiología.

3. Médico de planta de Servicio de Electrofisiología.

4. Jefe de Servicio de Electrofisiología.

5. Médico de planta de Unidad Coronaria.

Hospital Nacional "Profesor Alejandro Posadas", Buenos Aires, Rep. Argentina

$\triangle$ Correspondencia: Dra. Fiorella Soto Arévalo. Hospital Nac. Prof. A. Posadas. Pte. Illia s/n y Marconi, CP 1684 El Palomar, Morón, Provincia de Buenos Aires, Argentina. fiore1988@hotmail.com
}

Los autores declaran no poseer conflictos de intereses.

Recibido: 15/11/2017| Aceptado: 30/03/2018

\section{CASO CLÍNICO}

Paciente de 16 años, de sexo masculino, sin antecedentes clínicos de relevancia, que a los 6 años en contexto de estudio por pérdida del sensorio (síndrome convulsivo versus síncope) se evidenciaron episodios de taquicardia ventricular (TV) durante el esfuerzo en estudio ergométrico y en los momentos de actividad en el Holter (Figura 1). Con estos elementos se diagnosticó taquicardia ventricular catecolaminérgica polimórfica (TVCP) e inició tratamiento con betabloqueantes y bloqueantes cálcicos (atenolol/ verapamilo).

Luego a los 8 años, por presentar en Holter control TV no sostenida a pesar del tratamiento con cronotrópicos negativos se decidió el implante de un CDI. Un año después cursó internación por múltiples descargas apropiadas del CDI por taquicardia ventricular durante la actividad física los días previos, por lo que se rotó esquema antiarrítmico a metoprolol y amiodarona.

Ingresó a la unidad coronaria por tormenta eléctrica sin descompensación hemodinámica por lo que se aumentó dosis de los fármacos antiarrítmicos utilizados más infusión de lidocaína (Figura 2). En esta instancia se decidió en conjunto con servicio de Electrofisiología realizar estelectomía y simpatectomía bilateral, presentando como complicación a las 24 hs shock séptico asociado a encefalopatía con posterior resolución del cuadro con antibióticos. Se decidió otorgar alta hospitalaria con indicación de tratamiento con amiodarona y metoprolol. 


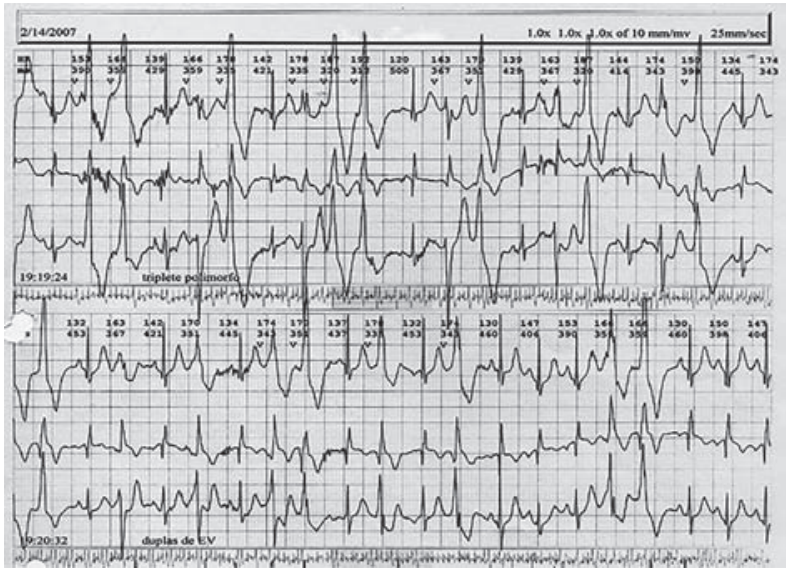

Figura 1. Holter en el que se objetiva taquicardia ventricular.

En la evolución se observó una disminución de la carga arrítmica, sin presentar nuevos eventos (Figura 3).

\section{DISCUSIÓN}

La TVCP es una canalopatía iónica cardíaca caracterizada por arritmias ventriculares desencadenadas por esfuerzo físico o estrés emocional ${ }^{3,4}$. El síncope suele ser una de sus primeras manifestaciones clínicas, presentando ECG y ecocardiograma normal, por lo que usualmente se atribuye de forma errónea a trastornos neurológicos; se establecen así retrasos en el diagnóstico de hasta 2 años desde el primer síntoma ${ }^{5}$. En el registro PACES se estimó que tres de cada cuatro niños presentan síntomas que amenazan la vida ${ }^{6}$, con un retraso diagnóstico de más de 1 año en el 38\% de estos casos. La muerte súbita se reporta como presentación inicial hasta en un 30\% de los casos?

La TVCP está originada por mutaciones en genes implicados en la homeostasis del calcio de las células cardíacas. Se identifican dos genes causales: el gen del receptor de ryanodina $(R Y R 2)^{8,9}$, con un patrón de herencia autosómico dominante, y el gen cardíaco de la calsecuestrina (CASQ2) ${ }^{10,11}$ con un patrón de herencia autosómico recesivo.

Las arritmias ventriculares en la TVCP típicamente presentan un eje de QRS alterno con rotación de $180^{\circ}$ sobre una base de latido a latido, la llamada taquicardia ventricular bidireccional. El inicio de esta actividad ectópica durante la prueba de esfuerzo se observa sistemáticamente a las frecuencias cardíacas 110-120 lpm. La complejidad y la frecuencia de las arritmias empeoran progresivamente a medida que aumenta la carga de trabajo y, si el ejercicio no se interrumpe rápidamente, la TV bidireccional puede degenerar en TV polimórfica y fibrilación ventricular.

Desde que se reconoció la naturaleza adrenérgica de estos eventos, los betabloqueantes han sido el estándar de atención. El estudio de Hayashi et al. ${ }^{12}$ evidenció que los pacientes que tomaban betabloqueantes tuvieron menos eventos que los pacientes sin tratamiento, demostrando además una eficacia superior de betabloqueantes no selectivos sobre selectivos. El nadolol se mostró superior al resto de betabloqueantes en la prevención de arritmias durante la terapia. Los autores señalan que la falta de cumplimiento de la medicación es una importante causa de recurrencia de eventos arrítmicos.

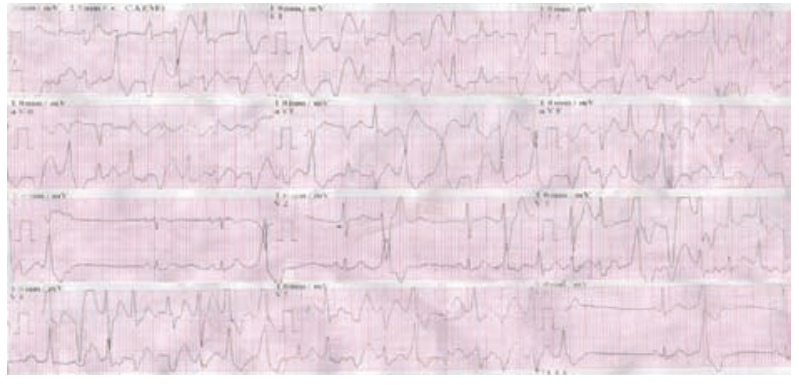

Figura 2. Electrocardiograma que evidencia taquicardia ventricular catecolaminérgica polimórfica.

En 2011, se informó el efecto antiarrítmico de la flecainida en pacientes con TVCP que ya usan betabloqueantes. La terapia dual reduce la arritmia y los eventos, especialmente después de la falla de la monoterapia betabloqueante ${ }^{13}$. En el Registro TVCP de PACES, 51 pacientes $(23 \%)$ recibieron regímenes combinados de flecainida-betabloqueante. Ninguno de los adherentes a las dosis óptimas de ambos fármacos experimentó un síncope o un paro cardiaco ${ }^{6}$.

Se plantea la implantación de un CDI como medida para prevenir la muerte súbita en pacientes con TVCP refractaria a betabloqueantes y en los sobrevivientes de paro cardíaco ${ }^{14}$. Sin embargo, los choques de CDI, al causar dolor y miedo, aumentan la liberación de catecolaminas y pueden provocar tormentas eléctricas con la posibilidad de causar la muerte (o contribuir a esta) en lugar de proporcionar una solución. Por lo mencionado, es necesario realizar una programación cuidadosa del CDI, ya que la efectividad de los shocks apropiados depende del mecanismo de arritmia, usualmente efectivo solo cuando el ritmo tratado es fibrilación ventricular ${ }^{15}$.

Se ha descrito el bloqueo simpático permanente mediante la DCSI como una nueva modalidad en el tratamiento de TVCP. La explicación al procedimiento es que la denervación simpática cardíaca izquierda interrumpe la principal fuente de norepinefrina liberada en el corazón, aumentando el umbral de fibrilación ventricular y la refractariedad ventricular. Dado que la denervación simpática cardíaca izquierda es una denervación preganglionar, no hay reinervación ${ }^{16}$.

El trabajo de De Ferrari et al. ${ }^{15}$ proporciona evidencia de que DCSI desempeña un papel importante en el tratamiento de la TVCP, reduciendo la probabilidad de eventos potencialmente mortales, lo que inevitablemente mejora la calidad de vida de estos pacientes jóvenes y sus familias. Los resultados principales de este estudio pertenecen a los 38 pacientes que tuvieron evento cardíaco mayor (paro cardiaCo, descargas del CDI, síncope arrítmico) a pesar del tratamiento médico óptimo con $\beta$-bloqueantes o flecainida tolerados al máximo, logrando reducir significativamente los eventos cardiacos mayores (de 100\% a 32\%). Veintinueve pacientes tenían CDI, de los cuales un 76\% presentó descargas apropiadas del CDI reduciéndose a 34\%, así como también las tormentas eléctricas disminuyeron de un 38\% a un 14\%. Hoy en día las indicaciones aceptadas internacionalmente de DCSI incluyen: pacientes que continúan presentando eventos cardiacos pese a un tratamiento betabloqueante óptimo; pacientes portadores de CDI con descargas apropiadas repetidas; intolerancia a los efectos secundarios de los betabloqueantes; y pacientes jóvenes de alto riesgo a los cuales presumiblemente la medicación no les va a proteger completamente o como "puente" a la implantación de un CDI ${ }^{17}$. 


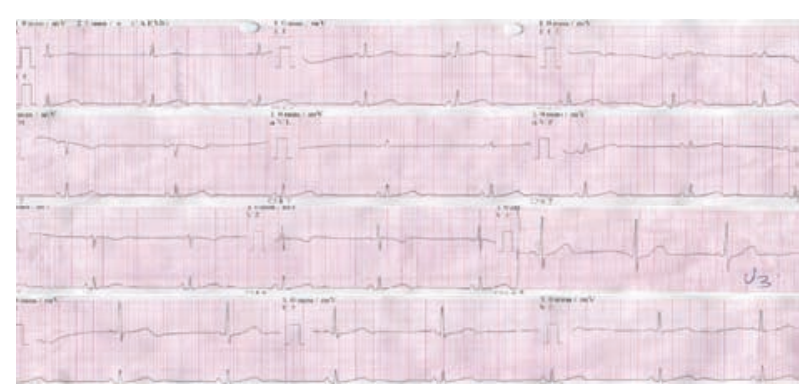

Figura 3. Electrocardiograma en reposo sin presencia de arritmia ventricular.

El primer reporte de cirugía toracoscópica videoasistida para DCSI para pacientes con síndrome de QT largo fue publicada en el año 2003. Este procedimiento se asocia con un menor perfil de riesgo que la toracotomía abierta, reduciéndose además la tasa de complicaciones, con menor estadía hospitalaria. Usualmente se realiza en una hora $^{18}$.

Los efectos secundarios incluyen hiperhidrosis compensatoria, rubor facial de tipo arlequín, síndrome de Horner. Sin embargo, la satisfacción de los pacientes supera los efectos adversos: el 91\% de los pacientes recomienda el procedimiento a otros pacientes afectados ${ }^{19}$.

\section{CONCLUSIÓN}

En la TVCP, cuando los betabloqueantes han fracasado y el CDI causa múltiples descargas inefectivas, la denervación cardíaca simpática puede ser una terapia adicional útil como nueva estrategia terapéutica.

\section{BIBLIOGRAFÍA}

1. Palanca V, Quesada A, Trigo A, Jiménez J. Arrhythmic storm induced by AICD discharge in a patient with catecholaminergic polymorphic ventricular tachycardia. Rev Esp Cardiol 2006;59(10):1079-80.

2. Rosso R, Kalman JM, Rogowski O, Diamant S, Birger A, Biner S, et al. Calcium channel blockers and beta-blockers versus beta-blockers alone for preventing exercise-induced arrhythmias in catecholaminergic polymorphic ventricular tachycardia. Heart Rhythm 2007;4(9):1149-54.

3. Leenhardt A, Lucet V, Denjoy I, Grau F, Ngoc D, Coumel P. Catecholaminergic polymorphic ventricular tachycardia in children: a 7-year follow-up of 21 patients. Circulation 1995;91(5):1512-19.

4. Liu N, Ruan Y, Priori S. Catecholaminergic polymorphic ventricular tachycardia. Prog Cardiovasc Dis 2008;51(1):23-30.

5. Priori SG, Napolitano C, Memmi M, Colombi B, Drago F, Gasparini M, et al. Clinical and molecular characterization of patients with catecholaminergic polymorphic ventricular tachycardia. Circulation 2002;106(1):69-74.

6. Roston T, Vinocur J, Maginot K, Mohhamed S, Salerno J, Potts JE, et al. Catecholaminergic polymorphic ventricular tachycardia in children: analysis of therapeutic strategies and outcomes from an international multicenter registry. Circ Arrhythm Electrophysiol 2015;8(3):633-42.

7. Kozlovski J, Ingles J, Connell V, Hunt L, McGaughran J, Semsarian C, et al. Delay to diagnosis amongst patients with catecholaminergic polymorphic ventricular tachycardia. Int J Cardiol 2014;176(3):1402-4

8. Priori SG, Napolitano C, Tiso N, Memmi M, Vignati G, Bloise R, et al. Mutations in the cardiac ryanodine receptor gene (hRyR2) underlie catecholaminergic polymorphic ventricular tachycardia. Circulation 2001;103(2):196-200.

9. Laitinen PJ, Brown KM, Piippo K, Swan H, Devaney JM, Brahmbhatt B, et al. Mutations of the cardiac ryanodine receptor (RyR2) gene in familial polymorphic ventricular tachycardia. Circulation 2001;103(4):485-90

10. Lahat H, Eldar M, Levy-Nissenbaum E, Bahan T, Friedman E, Khoury A, et al. Autosomal recessive catecholamine- or exercise-induced polymorphic ventricular tachycardia: clinical features and assignment of the disease gene to chromosome 1p13-21. Circulation 2001;103(23):2822-7.

11. Postma AV, Denjoy I, Hoorntje TM, Lupglazoff JM, Da Costa A, Sebillon P, et al. Absence of calsequestrin 2 causes severe forms of catecholaminergic polymorphic ventricular tachycardia. Circ Res 2002;91(8):e21-e26

12. Hayashi M, Denjoy I, Extramiana F, Maltret A, Buisson NR, Lupoglazoff JM, et al. Incidence and risk factors of arrhythmic events in catecholaminergic polymorphic ventricular tachycardia. Circulation 2009;119(18):2426-34.

13. Van der Werf C, Kannankeril P, Sacher F, Krahn AD, Viskin S, Leenhardt A, et al. Flecainide therapy reduces exercise-induced ventricular arrhythmias in patients with catecholaminergic polymorphic ventricular tachycardia. J Am Coll Cardiol 2011;57(22):2244-54.

14. Moray A, Kirk EP, Grant P, Camphausen C. Prophylactic left thoracic sympathectomy to prevent electrical storms in CPVT patients needing ICD placement. Heart Lung Circ 2011;20(11):731-3.

15. De Ferrari GM, Dusi V, Spazzolini C et al Clinical management of catecholaminergic polymorphic ventricular tachycardia: the role of left cardiac sympathetic denervation. Circulation 2015;131(25):2185-93.

16. Wilde AAM, Bhuiyan ZA, Crotti L, Facchini M, De Ferrari GM, Paul T, et al. Left Cardiac Sympathetic Denervation for Catecholaminergic Polymorphic Ventricular Tachycardia. N Engl J Med 2008;358(19):2024-9.

17. Tarrado X, Sarquella-Brugada G, Saura L, Manzanares A, Julia V, Ribo JM. Denervación cardiaca simpática izquierda en las arritmias ventriculares congénitas: experiencia inicial. Cir Pediatr 2014;27(2):98-101

18. Wang LJ, Wang J. Video-assisted thoracoscopic sympathectomy for congenital long QT syndromes. Pacing Clin Electrophysiol 2003;26(4):870-3.

19. Waddell-Smith KE, Ertresvaag KN, Li J, Chaudhuri K, Crawford JR, Hamill KJ, et al. Physical and Psychological Consequences of Left Cardiac Sympathetic Denervation in Long-QT Syndrome and Catecholaminergic Polymorphic Ventricular Tachycardia. Circ Arrhythm Electrophysiol 2015;8(5):1151-8. 


\title{
TROMBO EN LA AORTA APARENTEMENTE SANA, EL PODER DE LA ANTICOAGULACIÓN
}

\author{
THROMBUS IN APPARENTLY HEALTHY AORTA; THE POWER \\ OF ANTICOAGULATION
}

YU SHAN LIN', DIANA GUTIÉRREZ', EZEQUIEL LERECH', LUCIANO OCAMPOS², JULIETA SORICETTI³, DANIEL ORQUERA

\section{RESUMEN}

Los trombos móviles en la aorta sana en ausencia de enfermedad constituyen una entidad poco frecuente, cuya sospecha clínica suele aparecer luego de eventos embólicos. La ecocardiografía cardíaca transesofágica constituye una herramienta de gran utilidad para el diagnóstico. La forma más frecuente de presentación es la embolización arterial a predominio del miembro superior izquierdo. A continuación, se presenta un caso de una paciente con trombo móvil en la aorta ascendente sintomática por impotencia funcional y frialdad en el miembro superior izquierdo al esfuerzo y ausencia del pulso, la cual requirió anticoagulación con posterior resolución.

Palabras clave: trombosis, aórtica torácica, anticoagulantes.

\section{ABSTRACT}

Mobile thrombi in the healthy aorta in the absence of disease constitute a rare entity, whose clinical suspicion usually appears after embolic events. Transesophageal cardiac echocardiography is a very useful tool for diagnosis. The most frequent form of presentation is arterial embolization with predominance of the left upper limb. Wepresent a case of a patient with a mobile thrombus in the as cending symptomatic aorta due to functional impotence and coldness in the left upper limb due to stress and absence of the pulse that required anticoagulation, and was subsequently solved.

Keywords: thrombosis, thoracic aorta, anticoagulant.

REVISTA CONAREC 2018;33(145):194-196| DOI:10.32407/RCON/2018145/0194-0196

\section{INTRODUCCIÓN}

El diagnóstico de trombos móviles en la aorta sana, ausente de enfermedad ateroesclerótica y aneurismática, es poco frecuente, de etiología compleja que usualmente suele sospecharse luego de eventos embólicos con una estrategia de tratamiento aún desconocida ${ }^{1,2}$ Los métodos no invasivos de imágenes permiten identificar el foco

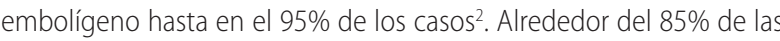
embolias arteriales tienen origen cardíaco, siendo la ecocardiografía transesofágica (ETE) de gran utilidad porque permite un examen exhaustivo tanto del corazón como de la aorta torácica' (Figura 1). La mayoría de los trombos proceden de la aorta abdominal y asientan en aneurismas o lesiones arterioescleróticas, aunque también se ha encontrado en zonas aparentemente sanas ${ }^{3,4}$.

La presentación clínica más frecuente es la embolígena, siendo la más habitual en las extremidades con cierto predominio por el miembro superior izquierdo $(\mathrm{MSI})^{5}$. Sin embargo, puede afectar cualquier parte del organismo.

1. Residente de Cardiología.

2. Jefe de residentes de Cardiología

3. Médico de planta de Cardiología.

Servicio de Cardiología, Hospital General de Agudos Carlos G. Durand. Ciudad Autónoma de Buenos Aires, Rep. Argentina.

$\triangle$ Correspondencia:Dr.Lin Yu Shan.Río de Janeiro 595, CABA. linyushan25@gmail.com

Los autores declaran no poseer conflictos de intereses.

Recibido: 01/11/2017 | Aceptado: 05/06/2018

\section{CASO CLÍNICO}

Paciente de sexo femenino, de 47 años, sin factores de riesgo cardiovasculares y sin antecedentes clínicos, oriunda de la zona rura de Santiago del Estero, consultó ambulatoriamente al Servicio de Cardiología para la realización de riesgo quirúrgico para una histerectomía por hipermenorrea secundaria a miomas. Al interrogatorio refirió presentar desde hace 3 meses parestesias y paresia moderada asociada a impotencia funcional y frialdad en MSI al esfuerzo. En

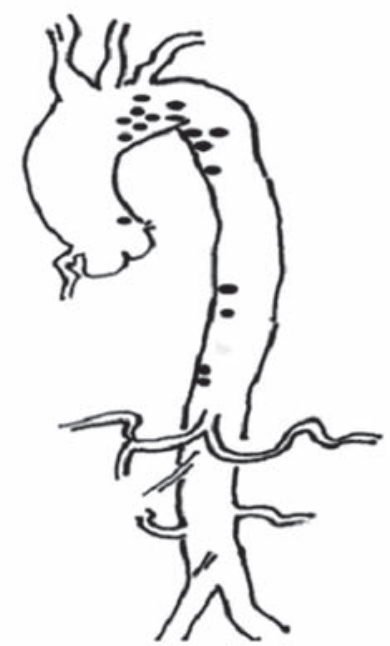

Figura 1. Sitios de localización más frecuentes de trombos en la aorta. Modificado de Pagn S, Trivedi J, Ganzel BL, Williams M, Kapoor N, Ross C et al. Thoracic aortic mobile thrombus: is there a role for early surgical intervention?. Ann Thorac Surg 2011;91(6):1875-81. 


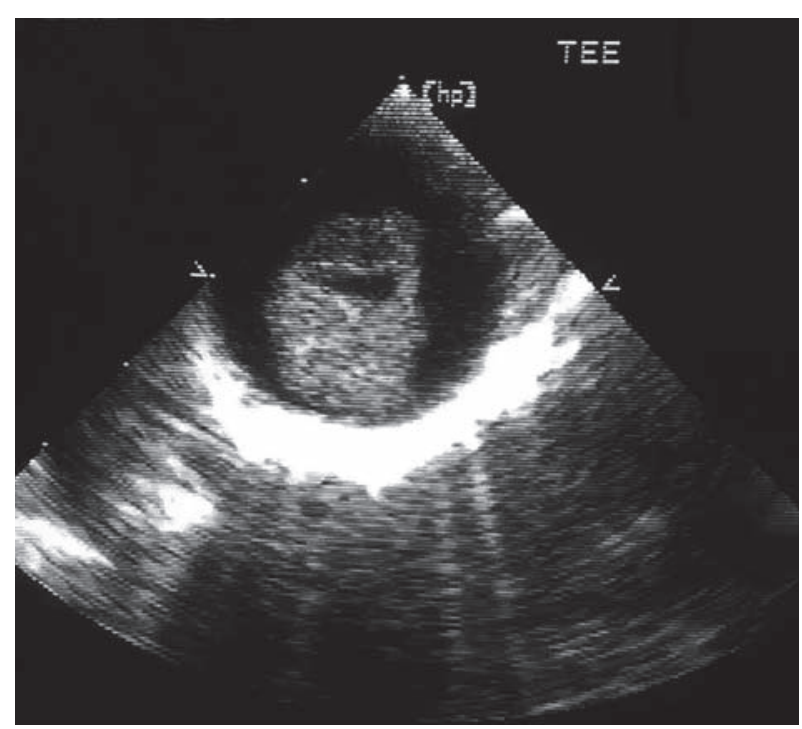

Figura 2. Ecocardiografía transesofágica al ingreso. Flecha roja: masa móvil de gran tamaño en aorta descendente.

cuanto a la medicación, únicamente se encontraba en tratamiento con anticonceptivos hormonales orales. Al examen físico, se constató ausencia de pulso en MSI con disminución del relleno capilar y de la temperatura por lo que se decidió evaluación mediante eco-Doppler arterial de miembro superior izquierdo que evidencia oclusión de las arterias axilar, humeral, radial y cubital. Ante dichos hallazgos, se realizó un análisis de enfermedades trombofílicas, que resultó negativo, y un ETE (Figura 2) y angiotomografía (Figura 3), los cuales informaron una aorta descendente no dilatada sin evidencia de disección, con extensa masa móvil de $21 \times 10 \times 12$ mm y anclaje distal más oclusión de arteria subclavia izquierda desde ostium hasta tercio medio de la arteria humeral izquierda. Por las imágenes de los estudios complementarios, se planteó el diagnóstico diferencial entre trombo y angiosarcoma, por lo que se la evaluó mediante una tomografía con emisión de positrones que no evidenció aumento de la captación en la aorta torácica (Figura 4). Con la sospecha de diagnóstica de trombo se suspendió la cirugía ginecológica, se inhibió farmacológicamente el ciclo menstrual y se inició anticoagulación hasta definir conducta. Durante la internación evolucionó con dolor en miembro inferior derecho con disminución de los pulsos en el mismo, por lo que se realizó eco-Doppler arterial de miembro inferior derecho que evidenció oclusión de la arteria poplítea derecha.

Encontrándose en tratamiento anticoagulante, se realizó nuevo ETE a las 3 semanas que no evidenció trombo. Posteriormente se le realizó una histerectomía laparoscópica, evolucionando favorablemente en el posoperatorio. Fue externada a los 10 días con anticoagulación oral.

\section{DISCUSIÓN}

La fisiopatología de los trombos aórticos no está claramente definida y su diagnóstico es usualmente a partir de una embolización periférica. Son más frecuentes en pacientes de edad avanzada o con múltiples factores de riesgo cardiovasculares y arteriosclerosis aórtica severa ${ }^{1,6,7}$. En los casos de masas móviles en una aorta previamente sana pueden ser resultado de una enfermedad de hipercoagulabilidad primaria causada por déficit

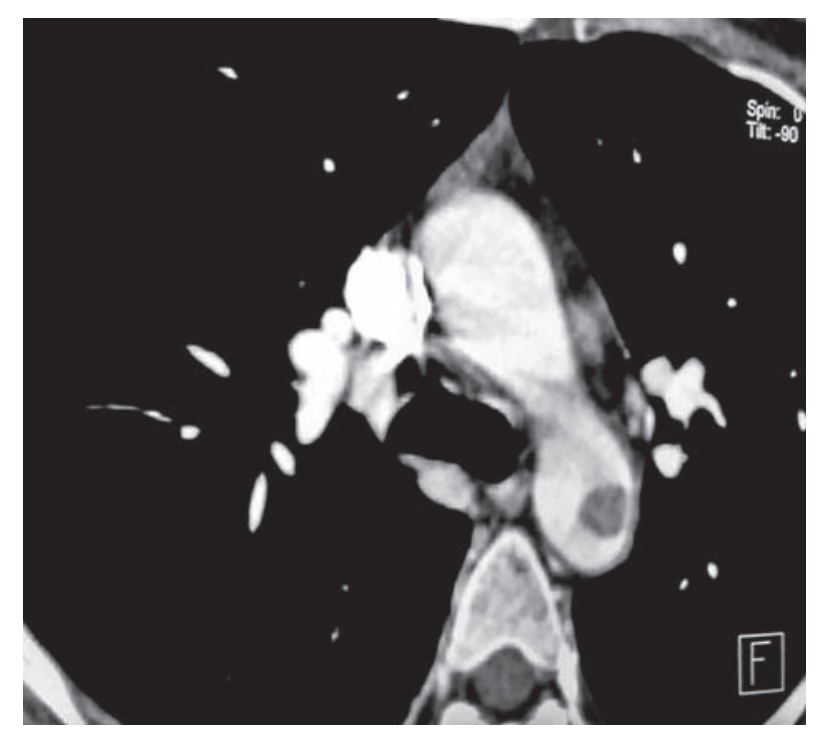

Figura 3. Angiotomografía. Flecha roja: masa en aorta descendente.
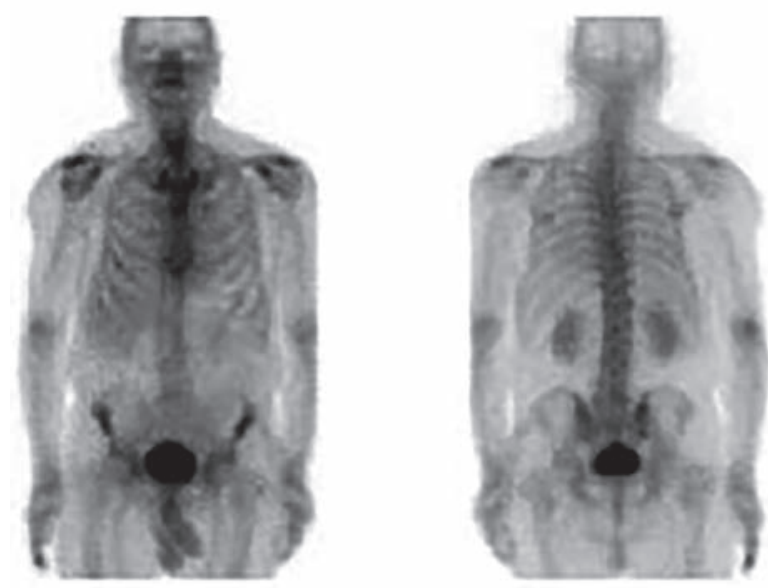

Figura 4. Tomografía con emisión de positrones sin evidencia de aumento de captación en la zona de la aorta

de uno o más componentes del sistema de anticoagulación, o un desorden agudo secundario a lupus, terapia con estrógenos, reacciones inmunológicas hacia la heparina, entre otros. El antecedente familiar de alteraciones trombofilicas sugiere un desorden del sistema de coagulación $n^{5,6}$

Es necesario realizar el diagnóstico diferencial con otras masas aórticas, como es el caso de los tumores. El diagnóstico definitivo requiere del estudio histológico e inmunohistoquímico, sin embargo la resonancia magnética es la prueba por imágenes más útil para este diagnóstico diferencial, y la tomografía con emisión de positrones ${ }^{8}$. También es importante contemplar la posible disección aórtica por las implicaciones terapéuticas.

Para el diagnóstico de esta patología es fundamental la realización de un ETE dado tiene una elevada exactitud diagnóstica y permite valorar el tamaño, la morfología y el punto de anclaje del trombo, así como las características de la pared aórtica ${ }^{1,6}$. También es importante la angiotomografía para la ubicación exacta en casos quirúrgicos ${ }^{4}$. 
La piedra angular del tratamiento de esta patología es la anticoagulación. Un período de aproximadamente dos semanas es recomendado para realizar un nuevo ETE o angiotomografía para evaluar el éxito terapéutico de la anticoagulación $n^{5,6}$.

Si el paciente tiene un riesgo quirúrgico aceptable con trombo de alta movilidad y falta de disminución del tamaño a pesar del tratamiento anticoagulante o repite nuevos episodios embólicos, se sugiere la conducta quirúrgica temprana a menos que el trombo tenga menos de $1 \mathrm{~cm}$ de tamaño ${ }^{5}$. Se recomienda anticoagulación oral por un año más aspirina después de la trombectomía. En caso de que el paciente presente historia familiar de trombosis, se recomienda anticoagulación oral de por vida ${ }^{5}$.

\section{BIBLIOGRAFÍA}

1. Dee W, Geibel A, Kasper W, Konstantinides S, Just H. Mobile thrombi in atherosclerotic lesions of the thoracic aorta: the diagnostic impact of transesophageal echocardiography. Am Heart J 1993;126(3):707-10.

2. Reber PU, Patel AG, Stauffer E, Müller MF, Do DD, Kniemeyer HW. Mural aortic thrombi: An important cause of peripheral embolization. I Vasc Surg 1999;30(6):1084-9.

3. Laraudogoitia E, Evangelista A, García del Castillo H, Lekuona I, Palomar S, González-Alujas T, et al. Trombo en aorta torácica como causa de embolismo periférico diagnosticado por ecocardiografía transesofágica. Rev Esp Cardiol 1997;50(1):62-4.

4. Hahn TL, Dalsing MC, Sawchuk AP, Cikrit DF, Lalka SG. Primary aortic mural thrombus: presentation and treatment. Ann Vasc Surg 1999;13(1):52-9.

\section{CONCLUSIÓN}

En pacientes con embolia arterial, además de descartar focos de embolia habituales es conveniente investigar la aorta torácica (ETE y/o angiotomografía), incluso en sujetos sin factores de riesgo cardiovasculares clásicos. Ante la duda diagnóstica entre angiosarcoma y trombo se recomienda continuar evaluación mediante tomografía con emisión de positrones o una resonancia magnética para descartar proceso maligno que obligue a un abordaje quirúrgico inmediato. La anticoagulación oral sigue siendo la estrategia recomendada ante la presencia de trombos.

5. Choukroun EM, Labrousse LM, Madonna FP, Deville C. Mobile thrombus of the thoracic aorta: diagnosis and treatment in 9 cases. Ann Vasc Surg 2002;16(6):714 22.

6. Laperche T, Laurian C, Roudaut R, Steg PG. Mobile thromboses of the aortic arch without aortic debris. A transesophageal echocardiographic finding associated with unexplained arterial embolism. The Filiale Echocardiographie de la Société Française de Cardiologie. Circulation 1997;96(1):288-94.

7. Patra P, Pillet JC, Chaillou P, Duveau D. Traitement chirurgical des lesions emboligenes de la crosse de l'aorte. In: Ed. Pharmapost, Paris, 1997 pp 11-31.

8. Thalheimer A, Fein M, Geissinger E, Franke S. Intimal angiosarcoma of the aorta: report of a case and review of the literature. J Vasc Surg 2004;40(3):548-53. 


\title{
REGLAMENTO DE PUBLICACIONES DE LA REVISTA DEL CONSEJO ARGENTINO DE RESIDENTES DE CARDIOLOGÍA
}

\author{
RULES OF PUBLICATIONS OF CONAREC JOURNAL
}

La Revista del Consejo Argentino de Residentes de Cardiología (CONAREC) publica artículos sobre temas relacionados con la Cardiología en su más amplio sentido. La Revista CONAREC es una publicación bimestral de marzo a diciembre (cinco números anuales) con objetivos asentados en la divulgación de material científico y educativo sobre la especialidad

La publicación es de tipo impresa y electrónica (www.revistaconarec.com.ar), ambas de acceso gratuito. La distribución se realiza a nivel nacional y está dirigida a residentes y concurrentes de Cardiología, así como a cardiólogos clínicos e intervencionistas, técnicos en Cardiología, centros asistenciales, asociaciones científicas, bibliotecas y facultades de Medicina.

Los principios editoriales de la revista se basan en las recomendaciones para manuscritos enviados a revistas Biomédicas (Recommendations for the Conduct, Reporting, Editing, and Publication of Scholarly Work in Medical Journals) redactadas por el Comité Internacional de Editores de Revistas Médicas (Internacional Comittee of Medical Journal Editors - ICMJE) en su más reciente actualización, disponible en www.icmje.org.

\section{ORIGINALIDAD DEL MATERIAL}

Los artículos enviados deben ser originales e inéditos. No serán aceptados trabajos que se encuentren publicados o en evaluación en otras revistas científicas tanto en el mismo como en distinto idioma.

Artículos duplicados. Se consideran artículos duplicados aquellos que contienen material que ya ha sido publicado en su totalidad o en gran parte, o se encuentra incluido en o estrechamente vinculado a otro trabajo que ha sido enviado o aceptado para su publicación en otra revista. Estos artículos no serán aceptados para su publicación.

Publicaciones secundarias. La publicación secundaria de material publicado en otras revistas puede ser justificable y beneficiosa, especialmente cuando se intenta transmitis información relevante a la mayor audiencia posible (ej: guías de práctica clínica, registros con datos nacionales sobre patologías prevalentes en materia de salud pública). Los artículos se considerarán para publicación secundaria siempre y cuando se ajusten a las recomendaciones ICMJE y los editores de ambas revistas lo aprueben. Además debe ser debidamente aclarado en el texto que ya ha sido publicado en todo o en parte y deber citarse adecuadamente la publicación original.

\section{ÉTICA}

Los trabajos clínicos experimentales que sean enviados para su evaluación deben elaborarse respetando las recomendaciones internacionales sobre investigación clínica desarrolladas en la Declaración de Helsinki de la Asociación Médica Mundial revisada recientemente (www.wma.net/es/policy) y deben haber sido aprobados por un Comité de Ética institucional o regional responsable en experimentación humana. En el caso de utilización de animales de laboratorio, deberá ajustarse a las normas de la Sociedad Americana de Fisiología. Los autores de los artículos aceptan la responsabilidad definida por el Comité Internacional de Editores de Revistas Médicas (www.icmje.org).

\section{PROTECCIÓN DE LA PRIVACIDAD DE LOS PACIENTES}

No pueden publicarse descripciones, fotografías u otros detalles que contribuyan a identificar al paciente, a menos que esta información sea indispensable para la exposición del material; en ese caso, el paciente o el padre o tutor de los menores de edad expresarán su consentimiento por escrito, el cual deberá adjuntarse.

\section{REGISTRO DE ENSAYOS CLÍNICOS}

La Revista CONAREC apoya las políticas para registro de ensayos clínicos de la Organización Mundial de Salud (OMS) y del ICMJE, reconociendo la importancia de esas iniciativas para el registro y divulgación internacional de información sobre estudios clínicos, en acceso abierto. En consecuencia, solamente se aceptarán para publicación los artículos de investigaciones clínicas que hayan recibido un número de identificación en uno de los Registros de Ensayos Clínicos validados por los criterios establecidos por la OMS e ICMJE. El número de identificación se deberá consignar al final del resumen.

\section{SECCIONES}

\section{Artículos originales}

Son trabajos científicos o educativos de investigación básica o clínica original. Debe seguir la estructura "IMRD", es decir, debe tener Introducción, Material y métodos, Resultados y Discusión (véanse las normas de publicación ICMJE). Además son necesarias una Conclusión y Referencias bibliográficas. Cuando la situación lo amerite, se pueden agregar Agradecimientos y un Apéndice adjunto.

Condiciones: texto general hasta 5.000 palabras, resumen hasta 500 palabras, 3-6 palabras clave, tablas más figuras hasta 8, referencias hasta 40, autores hasta 10.

\section{Revisión anual}

La Revisión Anual consiste en un tema relevante de la especialidad que será desarrollado durante todo el año en cada volumen. Será escrita por profesionales destacados, Miembros Honorarios o del Comité Asesor del CONAREC a pedido del Comité de Redacción. Condiciones: texto general hasta 5.000 palabras, resumen hasta 500 palabras, 3-6 palabras clave, tablas más figuras hasta 8, referencias hasta 40, autores hasta 3.

\section{Revisión por expertos}

Son artículos sobre temas relevantes de la especialidad solicitados por el Comité de Redacción a autores de reconocida trayectoria (nacionales o extranjeros). Excepcionalmente podrán ser considerados para publicación artículos no solicitados por el Comité siempre y cuando se ajusten al presente reglamento.

Condiciones: texto general hasta 5.000 palabras, resumen hasta 500 palabras, 3-6 palabras clave, tablas más figuras hasta 8, referencias hasta 40, autores hasta 3.

Médicos de Guardia

Son artículos sobre el manejo racional y protocolizado de diferentes circunstancias que se presentan en la práctica diaria. Son revisados y consensuados previamente con especialistas en el tema, que culminan con un diagrama de flujo sobre el manejo diagnóstico-terapéutico de la patología.

Condiciones: texto general hasta 3.000 palabras, resumen hasta 150 palabras, tablas más figuras hasta 6, referencias hasta 20, autores hasta 8.

\section{Caso clínico}

Es la descripción de un caso clínico de características inusuales, que incluye su abordaje diagnóstico y terapéutico, y su resolución final. Debe acompañarse de una introducción, una discusión bibliográfica y las conclusiones pertinentes.

Condiciones: texto general hasta 2.000 palabras, resumen hasta 350 palabras, tablas más figuras hasta 5 , referencias hasta 20, autores hasta 10.

\section{Imágenes en Cardiología}

Son imágenes, no necesariamente excepcionales, pero sí ilustrativas, que deben ir acompañadas de una leyenda explicativa, un resumen del caso clínico y una breve reseña bibliográfica. Condiciones: texto general hasta 1.200 palabras, resumen hasta 350 palabras, figuras hasta 8 , referencias hasta 10 , autores hasta 10 .

\section{Editoriales}

Son comentarios y/o análisis de un artículo publicado en el número de la revista en el que aparece y es solicitado por el Comité de Redacción a un autor experto en el tema. Asimismo, pueden solicitarse comentarios sobre temas no relacionados con un artículo en particular.

Condiciones: texto general hasta 1.200 palabras, referencias hasta 10.

\section{Monografía seleccionada}

Son monografías seleccionadas y/o premiadas por el Comité Científico de la última Jornada Interresidentes de Cardiología, adaptadas para la publicación en la revista (ver normas de publicación ICMJE).

Condiciones: texto general hasta 10.000 palabras, resumen hasta 500 palabras, 3-6 palabras clave, tablas más figuras hasta 10 y referencias hasta 100.

\section{Selección de artículos relevantes, guías y consensos publicados}

La selección del material estará a cargo de miembros del Comité de Redacción teniendo en cuenta las principales revistas nacionales e internacionales.

Condiciones: se confeccionará una lista en la que conste el título del artículo seleccionado y la correspondiente cita de la revista en la que fue publicado según las normas generales de publicación de CONAREC

\section{Agenda CONAREC}

Se publicarán las actividades más importantes correspondientes al bimestre de la edición. 


\section{RECEPCIÓN, EVALUACIÓN Y PUBLICACIÓN DE ARTÍCULOS}

El envío del artículo (texto, tablas y figuras) debe realizarse por correo electrónico a conarecrevista@gmail.com consignando en el asunto la sección a la que corresponda.

Cada manuscrito recibido será examinado por el Comité de Redacción con la su pervisión del Comité Asesor y de ser adecuado a las normas de publicación será evaluado por dos árbitros externos especializados en el tema en forma doble ciego: el material será enviado a estos últimos sin consignar el nombre de los autores ni el centro al que pertenecen. Si los revisores consideran necesaria la realización de modificaciones, se enviarán las sugerencias al autor responsable preservando la identidad del revisor. El autor recibirá una respuesta preliminar dentro de los 3 meses de remitido el manuscrito correctamente, debiendo realizar los cambios sugeridos a la brevedad y reenviar el material para su nueva evaluación. Finalmente, se notificará al autor responsable sobre la aceptación o el rechazo del manuscrito.

El Comité de Redacción se reserva el derecho de introducir, con el consentimiento de los autores, todos los cambios editoriales exigidos por las normas gramaticales y las necesidades de edición de la revista.

Aprobada la publicación del trabajo, CONAREC retiene los derechos de autor para su reproducción total o parcial.

\section{PREPARACIÓN DEL MANUSCRITO}

El artículo debe estar escrito en castellano, en un procesador de texto Word (Microsoft ${ }^{\oplus}$ ) o similar (con formato compatible) y guardado con extensión * doc 0 *.docx. El tamaño de la página debe ser A4 o carta, con doble espacio interlineado, márgenes de 25 mm con texto justificado y con tamaño de letra de 12 puntos tipo Times New Roman. Las páginas se numerarán en forma consecutiva comenzando con la portada.

Cada artículo debe ser presentado con una primera página que debe contener: a) título del artículo en mayúscula con negrita; b) apellido y nombres completos de los autores; c) institución en que se desempeñan; d) cargos que ocupan; e) título abreviado para cabeza de página; f) título en inglés; g) número total de palabras del artículo, sin las referencias bibliográficas; h) número de palabras del resumen; i nombre y dirección completa, código postal y dirección de correo electrónico del autor con quien se deba mantener correspondencia; j) declaración de la existencia o no de conflictos de intereses.

Para consignar los nombres de los autores, se debe colocar el apellido seguido por el nombre de pila y la inicial del segundo si lo tuviere, separado por punto y coma del siguiente (por ejemplo: Herrera Paz Juan J; Thierer Jorge). Continuado con punto seguido el lugar donde se realizó el trabajo. Debajo se debe colocar el lugar donde desempeña su tarea laboral y cargo que ocupa cada uno de los autores señalado con notas al pie, usando números consecutivos. Quienes figuren como autores deben habe participado en la investigación o en la elaboración del manuscrito y hacerse públicamente responsables de su contenido, adaptándose a las normas para la autoría expuestas por la IMCJE.

La segunda página debe incluir a) resumen en español; b) palabras clave en español; c) resumen en inglés americano (abstract); d) palabras clave en inglés (keywords); e) número de identificación en el registro de Ensayos Clínicos cuando corresponda. Las palabras clave deben ser términos incluidos en la lista del Index Medicus (Medical Subject Headings - MeSH) y Descriptores en Ciencias de la Salud (DeCS). Para la selección de estos se recomienda visitar los siguientes enlaces: http://www.nlm.nih.gov/ mesh/2014/mesh_browser/MBrowser y http://decs.bvs.br

Luego, en la tercera página, se debe desarrollar el contenido del manuscrito de acuerdo con las especificaciones de cada tipo de artículo, iniciando una nueva página para cada sección. Cada sección de la estructura "IMDR" debe ir con negrita mayúscula, mientras que las siguientes subsecciones dentro de la estructura IMDR deben ir con negrita tipo título separadas de las secciones por espacio simple.

\section{Unidades de medida}

Como unidades de medida se utilizarán las del sistema métrico decimal, usando comas para los decimales. Todas las mediciones clínicas, hematológicas y químicas deben ex presarse en unidades del sistema métrico y/o Ul, aclarando, cuando sea necesario, los rangos de referencia del laboratorio que realizó las determinaciones.

\section{Abreviaturas}

Solo se utilizarán las abreviaturas comunes, evitándose su uso en el título y en el resumen. La primera vez que se empleen irán precedidas por el término completo, excepto que se trate de unidades de medida estándar.

\section{Tablas y Figuras}

Las tablas y figuras deben presentarse en hojas individuales y se enumerarán consecutivamente con números arábigos (1, 2, etc.) según el orden que fueron citadas en el texto, con un título breve para cada una de ellas. Deben ser rotuladas con la palabra Tabla o Figura en negrita continuada por el número correspondiente de figura o tabla. Todas las abreviaturas de la tabla no estandarizadas deben explicarse. Las notas aclaratorias deben ir al pie de la tabla utilizando los siguientes símbolos en esta secuencia: * $\dagger, \ddagger, \S, \eta_{1}^{* *}$, ,

Las figuras deben estar en formato TIFF, PSD o JPEG a 300 dpi en formato final. Deben ser numeradas correlativamente con una leyenda explicativa en hoja aparte. El tamaño usual de las fotografías debe ser de 127×173 mm. Los títulos y las explicaciones detalladas se colocan en el texto de las leyendas y no en la ilustración misma.

\section{Referencias bibliográficas}

Las referencias bibliográficas solo se limitarán a citar a aquellos artículos originales directamente relacionados con el trabajo, evitándose mencionar artículos de revisión sobre el tema expuesto. Se enumerarán las referencias de manera consecutiva con números arábigos entre paréntesis. Se incluirán todos los autores cuando sean seis o menos; si fueran más de seis, el sexto será seguido de la expresión "et al". Los títulos de las revistas serán abreviados según el estilo empleado en el Index Medicus. Ejemplos según tipo de publicación a citar:

1. Registro de Procedimientos Diagnósticos y Terapéuticos efectuados durante e período 2006-2007. Colegio Argentino de Cardioangiólogos Intervencionistas (CACI). Disponible en http://www.caci.org.ar/addons/3/158.pdf. Consultado el 01/01/2009. (Para páginas web)

2. Ambrosy AP, Vaduganathan M, Huffman MD, Khan S, Kwasny MJ, Fought AJ, et al. Clinical course and predictive value of liver function tests in patients hospitalized for worsening heart failure with reduced ejection fraction: an analysis of the EVEREST trial. Eur J Heart Fail. 2012;14(3):302-11. (Para revistas en inglés).

3. Guardiani F, Mana M, Vázquez R. Trombosis simultánea en el infarto agudo de miocardio. Pancoronaritis. Rev Conarec. 2008;30(96):290-92. (Para revistas en español).

4. Braverman A, Thompson R, Sanchez L. Enfermedades de la aorta. En: Bonow R, Mann D, Zipes D, Libby P. Braunwald, Tratado de Cardiología: texto de medicina cardiovascular (2013, Novena edición, 1324-1354). España: Editorial Elsevier. (Libro).

\section{APÉNDICE - ESTRUCTURA"IMRD"}

Introducción. Establece el propósito del artículo y realiza el resumen de los fundamentos lógicos para la observación del estudio. Da únicamente las referencias estrictamente pertinentes. Se presentan los objetivos del trabajo, y se resumen las bases para el estudio o la observación. No debe incluir resultados o conclusiones del trabajo.

Materiales y métodos. Incluye una descripción de: a) La selección de los sujetos estudiados y sus características. b) Los métodos, aparatos y procedimientos; en estudios clínicos se informarán detalles del protocolo (población estudiada, intervenciones efec tuadas, bases estadísticas). c) Guías o normas éticas seguidas. d) Descripción de los métodos estadísticos utilizados. Describe claramente la selección de los sujetos destinados a la observación y la experimentación (pacientes o animales de laboratorio, incluido grupo de control). Debe identificar edad, sexo y otras características relevantes de la población, los métodos, aparatos (proporcionar el nombre, dirección de la empresa que lo produce) y procedimientos con suficientes detalles que permitan a otros investigadores la reproducción de los resultados. Deben mencionarse las drogas y las sustancias químicas, incluidos nombre químico, dosis y vías de administración.

Dentro de esta sección deberá aclararse, si correspondiera, el análisis estadístico realizado, así como el programa utilizado para ello, y el nivel de significancia preestablecido. Los trabajos clínicos aleatorizados (randomizados) deberán presentar información sobre los elementos más importantes del estudio, que contengan el protocolo y la hoja de flujo de la inclusión de los pacientes, y además deberán seguir los lineamientos de CONSORT (consúltese el artículo en la página web de instrucciones de la revista).

Los autores que presentan revisiones deberán incluir una sección en la que se describan los métodos utilizados para la ubicación, la selección y la síntesis de datos; estos métodos deberán figurar abreviados en el resumen.

Resultados. Los resultados deben presentarse con una secuencia lógica en el texto, las tablas y las ilustraciones. No se deben repetir en el texto todos los datos de las tablas las ilustraciones, debiendo destacar solo las observaciones importantes. Las tablas y las figuras deben utilizarse en el número estrictamente necesario para explicar el materia y para valorar su respaldo. Se recomienda emplear gráficos como alternativa para las tablas con numerosas entradas.

Discusión. Resalta los aspectos nuevos e importantes del estudio, las conclusiones de ellos derivadas, y su relación con los objetivos que figuran en la Introducción. No se debe repetir información que ya figure en otras secciones del trabajo. Evitar declaraciones de prioridad y referencias a trabajos aún no completados. Incluir los hallazgos, sus implicaciones y limitaciones, incluso lo que implicaría una futura investigación. Relacionar las observaciones con las de otros estudios importantes.

Las conclusiones deben estar relacionadas con los objetivos del estudio. Se deben evitar informes no calificados y conclusiones que no estén completamente respaldados por los datos. Los autores deben evitar dar informaciones sobre costos-beneficios económicos a menos que el artículo incluya datos económicos y su análisis. Plantear otras hipótesis cuando esté justificado, pero rotuladas claramente como tales. Las recomendaciones pueden incluirse cuando resulten apropiadas.

Agradecimientos. Precediendo a la bibliografía; si cabe se citarán: reconocimiento por apoyo técnico, aportes financieros, contribuciones que no lleguen a justificar autoría. En estos casos los autores serán responsables de contar con el consentimiento escrito de las personas nombradas.

Apéndice. En esta sección, de carácter opcional, deberá incluirse todo aquel materia no contemplado en los apartados previos, y que resulte necesario o facilite la comprensión del manuscrito remitido. Ejemplo de esto son los formularios empleados para llevar adelante una encuesta, ilustraciones de una maquinaria empleada para una determinada tarea, o similar. 